\title{
Knowing Women
}

\section{Same-Sex Intimacy, Gender, and Identity in Postcolonial Ghana}

Serena Owusua Dankwa

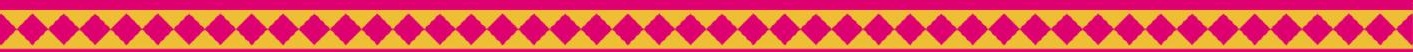

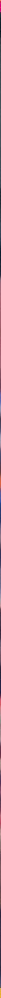

A F R IC A N I DEN T I T I ES

$$
\text { Past and Present }
$$




\section{Knowing Women}

Knowing Women is a study of same-sex desire in West Africa, which explores the lives and friendships of working-class women in southern Ghana who are intimately involved with each other. Based on in-depth research of the life histories of women in the region, Serena Owusua Dankwa highlights the vibrancy of everyday same-sex intimacies that have not been captured in a globally pervasive language of sexual identity. Paying close attention to the women's practices of self-reference, Dankwa refers to them as "knowing women" in a way that both distinguishes them from and relates them to categories such as lesbian or supi, a Ghanaian term for female friend. In doing so, this study is not only a significant contribution to the field of global queer studies in which both women and Africa have been underrepresented, but a starting point to further theorize the relation between gender, kinship, and sexuality that is key to queer, feminist, and postcolonial theories. This title is also available as Open Access on Cambridge Core.

SERENA OwUSUA DANKWA is an Associate Researcher in the Institute of Social Anthropology and the Interdisciplinary Center for Gender Studies at the University of Bern. She previously held the Sarah Pettit Fellowship at Yale University and worked as a journalist with Swiss Radio and Television. Today, she advocates for the rights and dignity of migrant women and queers of color in Switzerland. She is a co-founder of the Black feminist network Bla*Sh and a co-editor of the book Racial Profiling: Struktureller Rassismus und antirassistischer Widerstand (2019). 


\title{
AFRICAN IDENTITIES: PAST AND PRESENT
}

\author{
GENERAL EDITORS
}

Toyin Falola, The University of Texas at Austin Carina Ray, Brandeis University

\begin{abstract}
African Identities: Past and Present offers scholars a unique publishing platform for exploring the multivalent processes through which collective identities have come into being. Books in this series probe the work that African identities have been made to do, the varied investments that historical and contemporary actors have made in them, and the epistemological dilemmas and intellectually fraught politics of writing about such contingent categories of being. The focus on African identities makes clear the series' commitment to publishing histories of the complex and ongoing processes of identity formation through which Africans have taken on shared senses of being. This series calls upon its authors to unpack the flexible, fluid, contingent, and interactive nature of collective African identities, while also exploring how historical actors have alternatively sought to delimit, expand, or otherwise challenge the boundaries of such identities.
\end{abstract}




\section{Knowing Women}

Same-Sex Intimacy, Gender, and Identity in Postcolonial Ghana

SERENA OW U S A D AN KW A

Universität Bern, Switzerland 


\section{CAMBRIDGE \\ UNIVERSITY PRESS}

University Printing House, Cambridge CB2 8BS, United Kingdom

One Liberty Plaza, 20th Floor, New York, NY 10006, USA

477 Williamstown Road, Port Melbourne, VIC 3207, Australia

314-321, 3rd Floor, Plot 3, Splendor Forum, Jasola District Centre, New Delhi - 110025, India

79 Anson Road, \#06-04/06, Singapore 079906

Cambridge University Press is part of the University of Cambridge.

It furthers the University's mission by disseminating knowledge in the pursuit of education, learning, and research at the highest international levels of excellence.

www.cambridge.org

Information on this title: www.cambridge.org/9781108495905

DOI: $10.1017 / 9781108863575$

(C) Serena Owusua Dankwa 2021

Published with the support of the Swiss National Science Foundation

This work is in copyright. It is subject to statutory exceptions

and to the provisions of relevant licensing agreements;

with the exception of the Creative Commons version the link for which is provided below, no reproduction of any part of this work may take place without the written permission of Cambridge University Press.

An online version of this work is published at doi.org/10.1017/9781108863575 under a Creative Commons Open Access license CC-BY-NC-ND 4.0 which permits re-use, distribution and reproduction in any medium for non-commercial purposes providing appropriate credit to the original work is given. You may not distribute derivative works without permission. To view a copy of this license, visit https://creativecommons.org/licenses/ by-nc-nd/4.0

All versions of this work may contain content reproduced under license from third parties.

Permission to reproduce this third-party content must be obtained from these third-parties directly.

When citing this work, please include a reference to the DOI 10.1017/9781108863575

First published 2021

A catalogue record for this publication is available from the British Library.

Library of Congress Cataloging-in-Publication Data

Names: Dankwa, Serena Owusua, 1975- author.

Title: Knowing women : same-sex intimacy, gender, and identity in postcolonial Ghana /

Serena Owusua Dankwa, Universität Bern, Switzerland.

Description: 1 Edition. I New York : Cambridge University Press, 2021. I Series: African

identities: past and present I Includes bibliographical references and index.

Identifiers: LCCN 2020025740 (print) I LCCN 2020025741 (ebook) I ISBN 9781108495905

(hardback) I ISBN 9781108811026 (paperback) I ISBN 9781108863575 (ebook)

Subjects: LCSH: Lesbianism - Ghana - History. I Lesbians - Ghana - Social life and customs. I

Interpersonal relations - Ghana. I Gender identity - Ghana.

Classification: LCC HQ75.6.G4 D36 2021 (print) I LCC HQ75.6.G4 (ebook) I DDC 306.76/

6309667-dc23

LC record available at https://lccn.loc.gov/2020025740

LC ebook record available at https://lccn.loc.gov/2020025741

ISBN 978-1-108-49590-5 Hardback

Cambridge University Press has no responsibility for the persistence or accuracy of URLs for external or third-party internet websites referred to in this publication and does not guarantee that any content on such websites is, or will remain, accurate or appropriate. 
For Ajokor, may you rest in peace and power

For all Black wom n, who love against the grain 


\section{Contents}

List of Figures

page viii

Acknowledgments

Prologue: Arrival Stories

Introduction: Freeing Our Imaginations

1 Tacit Erotic Intimacies and the Culture of Indirection

2 Supi, Secrecy, and the Gift of Knowing

3 "The One Who First Says 'I Love you'”: Dbaa Barima, Gender, and Erotic Subjectivity

4 Sugar Motherhood and the Collectivization of Love

5 “Doing Everything Together": Siblinghood, Lovership, Incest, Family

Conclusion: A Fabric that Never Goes Out of Fashion 


\section{Figures}

1 Janet Aidoo's living quarters during rainy season in Accra (2007)

2 An Under-20 semi-professional women's football team gathering before a friendly game (2008)

3 Two women's teams being cheered at by young men from the neighborhood (2007)

4 Older friends and neighbors selling fish in Korkoi Okudzeto's vicinity at Suakrom market (2008)

5 Hamda Ibrahima at a credit association meeting of her young Muslim women's group (2007) 


\section{Acknowledgments}

As with any project that has taken almost two decades to complete and spans three different continents, there are many moments that inspired this book and the doctoral research that it is based on. The process was as unpredictable and surprising as events in my own life during these years, and it has been enriched by many different people. In order to prevent the list of names from becoming exceedingly long, I will focus on thanking those who accompanied me throughout the journey or encouraged and supported me at crucial moments on the way to publishing this book.

First and foremost my heartfelt gratitude goes to those women who shared their knowledge with me in Ghana, but whose names can only be rendered as pseudonyms: Ameley Norkor, Janet Aidoo, Adwoa Boateng, Hamda Ibrahima, Adi Cortey, Lydia Sackey, Dina Yiborku, Ma'Abena Oppong, Teley Kwao, Becky McCarthy, Stone Addai, Okaile Allotey, Stella Odamten, and the thirty more women who allowed me to record their life histories. Their names represent all the "knowing women," whose lives and love stories remain untold and whose work and knowledge does not come to public recognition due to the ambiguities attached to the disclosure of same-sex desire. Their generosity and their willingness to engage with my many questions and to articulate their insights, without knowing what form it would eventually take in my rendering, enabled me to write this book. My thanks also go to those women who interacted with me but refused to be interviewed. Resisting my desire to document their life narratives and thus resisting being incorporated into a body of intellectual knowledge reminded me of the limitations of scientific knowledge production and of that which can be known at large. Most of all, I extend my heartfelt thanks to my research associate Josephine Enyonam Agbenozan. Without her skills, courage, and commitment, and her tolerance of my social and cultural missteps, this research would have been only a shadow of what it eventually became. 
There are several mentors in different parts of the world who encouraged, inspired, and supported the anthropological doctorate from which this book developed. Special thanks to my "Doktorvater" Heinzpeter Znoj at the University of Bern, who made it possible for me to enter a doctoral program at a Swiss university despite my unconventional educational background and my lateral entry into academia. He believed in this project and encouraged me to travel in order to seek and find relevant specialists and mentors among different disciplines. The guidance, warmth, and generosity shown by my co-supervisor, Rudolf Gaudio, in sharing his own findings and experiences in "the field," also substantially supported me in completing my thesis and turning it into a book at a time when my participation in academic conversations was limited by my work for an NGO and my responsibilities as a single mother. I am also grateful for the intellectual and moral support provided at different stages by Jafari Allen, Jean Allman, Akosua Adomako Ampofo, Signe Arnfred, Christa Binswanger, Gracia Clark, Akosua Darkwah, Michelle Gilbert, Jack Halberstam, Anne Hugon, Takyiwaa Manuh, Stephan F. Miescher, Charmaine Pereira, Steven Pierce, Graeme Reid, Brigitte Schnegg, Rachel Spronk, Sjaak van der Geest, Doris WastlWalter, and Gloria Wekker.

Decisive academic support in embarking on and sustaining this research project was provided by the Institute for Social Anthropology, my home base at the University of Bern and the Network Gender Studies Switzerland. I am particularly grateful to the board members and my fellow doctoral students of the Gender Graduate School Bern/Fribourg "Scripts and Prescripts" (2005-2009) and to the members of our small collective data interpretation group at the Interdisciplinary Center for Gender Studies. Throughout and beyond the completion of my doctoral thesis, the Interdisciplinary Center for Gender Studies provided me with practical and intellectual support. My gratitude also extends to my temporary Ghanaian home base at the Centre for Gender Studies and Advocacy and the Institute of African Studies at the University of Ghana, Legon.

This project would not have been possible without a doctoral grant from the Swiss National Science Foundation (SNSF) between 2006 and 2009 and a grant by the Commission for Research Partnerships Developing Countries (KFPE), which enabled me to collaborate with colleagues in Ghana. In 2010, I was offered the "Sarah Pettit 
Fellowship" by the Women's, Gender and Sexuality Studies program at Yale University under the direction of George Chauncey. This fellowship came at a moment when financial support and affiliation to a stimulating academic environment was much needed. It provided new directions for my research, in particular through Yale's Black Feminist reading group. An additional write-up grant by the SNSF allowed me to spend valuable time as a visiting scholar at Yale's Department of Anthropology under Mike McGovern and at the Institute for Research on Women, Gender and Sexuality at Columbia University under Saidiya Hartman in 2011/12. I am also grateful for the SNSF's support in making this book an open access publication.

Finally, I am indebted to the generosity of my peers, friends, or (metaphorical) siblings, who encouraged and sustained me emotionally, materially, and intellectually through challenging conversations; reading, formatting, or editing drafts; cooking meals; hosting me in Ghana or the USA; taking care of my daughter Ayeley; and otherwise encouraging me to complete this project. I would particularly like to thank Akua Gyamerah, Andrea Hungerbühler, Andrea Notroff, Anna Lena Weissheimer, Annemarie Woodmann, Bill Fischer, Dominique Grisard, Ellie Gore, Emily “Aunty“ Asiedu, George P. Meiu, Henriette Gunkel, Jack U. Tocco, John Cooper, Jovita dos Santos Pinto, Kofi Takyi Asante, Lane R. Clark, Lindsey Green-Simms, Martin Kaiser, Maryke Rumo, Michelle Cottier, Nadine Dankwa-N’Toum'Essia, Nicole Burgermeister, Rahel El-Maawi, Sandro Isler, Simon Dankwa, Tara Thierry, Tina Büchler, Yakubu Ismaila, Yv E. Nay, Zethu Matebeni, as well as $\mathrm{Bla} * \mathrm{Sh}$, the feminist network of women of African descent in Germanspeaking Switzerland.

A final and special thank you, however, must go to four individuals: to Simone Marti, whose passion, tenderness, and perseverance has nurtured me beyond words; to Patricia Purtschert, without whom I would have not ventured into doctoral research and whose critical sisterhood has been a support to me throughout; to my father Edward Kwame Akurang Dankwa who replied to the many uncomfortable questions I have asked over the years and who always gave his unconditional support; and to my mother Edith Dankwa-Hauri who - while teasing me that there were already enough books in the world - co-mothered my daughter and gave me all the space I needed to make this book happen. 


\section{Prologue: Arrival Stories}

I went to buy a bag of onions from her. After chatting for two or three minutes, she smiled at me. With a mischievous twinkle in her eyes she shook my hand and told me she liked me a lot. Two minutes later she said it again with more emphasis. I laughed and tried to change topics by asking her about her children. She mentioned a seven-year-old daughter and added that she was not married, before asking back: "And you, do you have a child?" - "No.” - "Why not?" - "Because, I'm not married, I don't have a husband" - "I really like you, why are you not married?" - "I don't like that." - "Then I will marry you." I laughed, asking back: "And who would be the husband?" - "You," came the answer. ${ }^{1}$

The onion-seller's name was Patricia Opoku. She was pointed out to me from afar by a friend who ran a store in the market. Rumor had it that children who peeked into Patricia Opoku's room one afternoon saw her having sex with another woman. They were nicknamed ctwe ne ctwe (vagina and vagina). Perhaps, Patricia had heard about my research interest and assumed that I would not meet her proposal with disgust or irritation. But even if she was not aware of my inquiry, our conversation was safe: firstly, because the trope of marriage has as many socio-economic as it has romantic or sexual overtones in a Ghanaian working-class context; and secondly, because in the event that I became offended she could always revoke her statements by claiming she was joking, with an innocent "but how can woman and woman possibly get married?"

I was nowhere near to marriage, neither to a man nor a woman, when I embarked on my research on women who love women in postcolonial Ghana. Given my interest in their love lives, the women's questions as to what I was looking for myself, if not for love, were understandable, as was the other commonly asked question regarding my heritage. To Akan Twi-speakers I often replied I was "obsfa, dadecfa," half-stone,

1 Fieldnote based on a conversation with Patricia Opoku, April 19, 2008. 
half-iron, an Akan metaphor for being of dual-cultural heritage. ${ }^{2} \mathrm{My}$ knowledge of this old-fashioned metaphor did not go unnoticed. Whether it was smiled at or appreciated, it gave some credence to both my Ghanaian heritage and my "mixed-race" status as an "outsider within" (Abu-Lughod 1991). Drawing on the feminist insight that knowledge is always situated (Haraway 1991), our personal arrival stories and the point where we begin to develop our thoughts and research practices are inextricably linked.

I first arrived in Ghana as the baby of a Swiss mother and a Ghanaian father, who was the first to study in his family. The scholarship that brought him to Europe just after Ghana's independence required that he return to "serve his country," which he did with much fervor. However, by the time I was seven, Ghana's economic and political situation had deteriorated in such a way that my parents used their remaining funds to return to Switzerland. My connection to Ghana began to take shape through Sunday afternoons spent in the living rooms of other SwissGhanaian families in small-town Switzerland. Eating Ampesi and Kontomire stew, listening to old-time highlife tunes and to the grownups talking politics, I picked up on the bitter nostalgia among educated Africans who were frustrated with postcolonial African governments and struggling to cope with the effects of institutional racism in Europe (El-Tayeb 2015; Wa Baile et al. 2019).

As is often the case with bi-national families, the bonds between the small family in German-speaking Switzerland and the extended family in southern Ghana were framed by mutual obligations and interrupted long-distance calls. The Ghana we visited whenever we could afford to was different to the Ghana that emerged from the narratives of white Swiss friends who ventured out to discover West Africa on their own terms: as travelers, exchange students, or researchers working on the Basel Mission. I envied them for developing a rapport with Ghana that seemed to be free from complicated personal ties. Back in Switzerland, they were credited for having discovered another world. Meanwhile, I studied western classical music and was met with disappointment when European connoisseurs of Africa realized I was neither an "expert in foreign affairs" nor an "african

2 This metaphor was imparted to me as a child. I treasured it, as a mixture of stone and metal is stronger than the stereotypical portrayal of "mixed-race" subjects as impure, torn, fragile, or disloyal. There is an old Ghanaian fabric that goes by that name. 
princess" ${ }^{3}$ - nor was I interested in heteronormative understandings of princesshood. Rather, the experience of being seen as "the Other" (Hall 2004) was the starting point for conducting research myself. This location shaped my search for those Others whose very existence seemed to lie beyond the imagination of many: African women who love women in Africa.

\section{Desiring Same-Sex Intimacies}

When I started my research, there existed no self-declared lesbian group in Ghana that might have offered itself as an obvious place to start. I thus sought to find women whose female friendships included erotic intimacies. The epistemological challenge was to identify women who were intimately involved with each other without assuming either the primacy of their sexual liaison over other aspects of their friendships or a fixed boundary between sexual and non-sexual intimacy. This would have privileged and reified "sexuality," the very category I had set out to question. While the manner in which I went about my research owed much to post-structuralist theories that have destabilized categories of identity, my approach arose from simple necessity. Given the absence of a language about "lesbianism," and given the fact that in public discourse same-sex desire was considered taboo, it was not feasible to state upfront that I was looking for women who had sexual relationships with each other. When I did state the matter directly, I encountered a range of self-proclaimed experts on sin and sex who expressed a voyeuristic interest in the sexual aspects of "what lesbians do." These "experts" - including hotel owners, journalists, or pastors - carried out their own covert "research" in order to produce sensationalizing sermons or media accounts featuring same-sex affairs. They were quick to declare their own heterosexuality - and invited me to do as they did. From such encounters I learned much about the mechanisms through which lesbianism is imagined - secret cults, prostitution, and promiscuity - but little about the day-to-day practices of women who love women.

Initially, I tried to follow-up on public rumors about the double sexlives of female members of Ghana's "jet-set" (such as university-

3 This conundrum, faced by many Afropean women, is captured in the poem “african princess” by Nigerian-German writer Olumide Popoola (1999, 53). 
trained professionals or frequent-flying wives among Ghana's political and business elite). Doors were continually closed in my face, however, and I eventually gave up. In the two instances where I did manage to speak to elderly elite women who were said to have had female lovers, I did not dare broach the issue of same-sex intimacy: it would have been indecorous to do so, as I was so much their junior. Similarly, economically powerful but less educated market women only lingered at the horizon of my search, namely in the accounts of unmarried young sports women who were committed to protecting the privacy of their older lovers or "sugar mothers," and who sensed that absolute discretion might be the key to the viability of their own same-sex desires in the future. As a result, I found myself in a position where I had to contend with what is perhaps a corollary of ethnographic work on sexual intimacies: that it is easier to carry out participant observation and find respondents among those who have less "prestige" to lose and whose lives are shaped by material precariousness.

Inspired by a rich body of literature that retrieves African women's voices by reading against the grain of missionary and court records (White 2000; Hodgson and McCurdy 2001), I began my research by studying boarding-school reports at the Basel Mission Archive ${ }^{4}$ and scanning through customary court cases at the National Archives of Ghana, in which women accused each other over seemingly minor issues. While colonial records have been useful sources to historians exploring male same-sex transgression, female desires are much less visible. Boarding-school and mission reports do, however, hint at the significance of girlfriendships and adult women's intimate desires alongside marriage and motherhood. Some of the more far-fetched matters brought up in customary court cases reminded me of the explanations often given to outsiders when fights ensue between jealous female (ex-)lovers in the marketplace. To outsiders, unaware of the amorous passions of the fighting women, the catalysts for these explosive disputes seem petty. Often, it is the degree of intensity on display that alerts

4 My interest in the Basel Mission Archive was kindled by the fact that the activities of the Basel Mission Society represent one of the most important historical links between Switzerland and Ghana. Though Switzerland did not possess formal colonies, cultural historians have interpreted the legacy of the Basel Mission as part of Switzerland's "colonialism without colonies" and its stake in the ongoing production of racialized colonial knowledge (Purtschert, Lüthi and Falk 2012, 43). 
insiders and leads them to speculate about the erotic passion at stake in the conflict between the fighting women.

The more I became convinced that female same-sex passions were prevalent in Ghana, and the more trust I built up among the women I interacted with, the more I heard them bring up the term supi - the polyvalent term for an intimate same-sex friend or lover that became an important starting point for my research. I followed up on a mention of this term one early evening, while waiting for my youngest respondent, eighteen-year-old Khadija Coleman, who lives among a host of elderly female relatives in Accra Central.

Khadija's aunties illegally tap electricity and run a hidden "drinking spot" that attracts women who work at the nearby night market; women who like to smoke and drink cheap local liquor, and are considered "rough" or "indecent" by normative Ghanaian standards. One of the regulars, a tall tomato seller dressed in red funeral clothes, kept teasing and joking with us. As she finally whooshed out of the compound, agitated and squiffy, another woman mumbled after her: "this one oh: supi." Unsure if I had heard right, I inquired: "What is supi?" - "You said you don't know supi?" she asked in disbelief. "I can show you, I can teach you. I can take you to this room and show you," she said, pointing to the poky chamber where Khadija's mother was taking a nap. One of Khadija's aunties intervened, "She doesn't like what you are telling her." I laughed, shook my head, and lied that I had "someone" back home already, which made her continue: "So I can just talk to you and advise you [about it]." ${ }^{\prime 6}$

It was safe to casually follow up on the term supi in the tipsy atmosphere among Khadija's "aunties." A few weeks later in the same compound, however, I found myself hitting a wall as I took to interviewing the eldest woman among them, Khadija's ninety-year-old great grandmother. I was genuinely interested in the life history of the frail, elderly lady with the big glasses who sat in the open door of her room all day, quietly following the lively conversations and dealings going on in her narrow compound. From previous visits I knew that she was aware of both the sex work and the same-sex passions flourishing inside and around their drinking spot compound. Thus, after she had told her life story, I tried to find a way into the topic of same-sex love,

5 Drinking spot, sometimes abbreviated to spot, designates a local liquor store and street bar.

6 Fieldnote based on conversations in Khadija Coleman's compound at Accra, December 1, 2007. 
by picking up on one of her favorite subjects: her deceased son, whom she, like everyone else, considered a kodjo besia, a feminine man. ${ }^{7}$

He worked as a hairdresser in Nigeria and apparently he had a child there. But Nana Mansa did not seem to believe it herself. Instead she fondly remembers the midwives' self-fulfilling joke at his birth: For half an hour they made her believe she had given birth to a girl.

I could not resist asking the suggestive question as to whether there were "women like her son, women who liked women." Her face froze and she firmly shut down any further conversation: "If you want to enter that subject, you will not find an answer." 8

Among my primary respondents, it was established by the time they allowed me to record their life history that I studied cultures of same-sex intimacy. But with elderly women I did not feel entitled to touch on this directly. Nevertheless, spurred by the desire to elicit some kind of information on the topic, I attempted to cajole Nana Mansa into talking about it and thus hastened the closure of our conversation. This raises a set of ethical questions. Since I could not establish my project and search participants by advertising through official channels, the process of locating respondents was bound up with long conversations in which I would convey my own queerness. The only way to appropriately broach my research subject therefore was through indirection. My approach was thus informed by the indirect ways in which sexuality in Ghana has been dealt with historically, by the current anti-gay discourse, and not least by the strategies of my key respondents, who would often deter me from making plain my research interest.

Participant observation, the much-debated method at the heart of anthropology, is especially necessary when exploring practices that are considered non-normative or taboo. This holds true not only for the study of same-sex intimacy, but for any practices that fall outside normative ideals and require explorative research. Anthropologists of West Africa have pleaded for radical forms of participating, which acknowledge that there is no observation without participation, and which seek "social closeness" and "emotional involvement" (Spittler 2001; Van der Geest 1998). But what does radical participation mean with regard to exploring erotic friendship and same-sex intimacy? Where are the boundaries

7 "Kodjo besia" is a term used for a boy or a man who has traits or interests that are associated with women (such as cooking). See also Chapter 1.

8 Fieldnote based on a conversation with Nana Mansa at Accra, January 7, 2008. 
between social and emotional closeness, feelings of affection, and sexual attraction? How far should and can emotional involvement go? And beyond this particular subject, how much spontaneous lying and evasion about one's own intimate life is permissible in the field, when we expect or hope that our informants will be truthful?

Inspired by the paradigms of "feminist anthropology," questions about the power dynamics and "the relationship between the writer (and readers) and the people being written about" (Abu-Lughod $1993,5)$ are at the heart of this inquiry. I am particularly drawn to Lila Abu-Lughod's critique of Clifford and Marcus's approach to "writing culture" (Abu-Lughod 1991; Clifford and Marcus 1986). As a feminist of mixed Palestinian and US-American parentage or, as she says, a "halfie," Abu-Lughod is wary of the ways in which participant observation risks flattening out internal cultural differences. Even if (as in Clifford and Marcus's approach) culture is written with an emphasis on the poetic, and even if the subjectivity of the author is exposed, "writing culture" engages in a professionalized generalization about Others. Abu-Lughod advocates writing "ethnographies of the particular," by finding "ways of writing about lives so as to constitute them as less other" (1991, 149). This approach resonates with my own "halfie" position as the daughter of a Swiss working-class nurse and a Ghanaian medical doctor, straddling "split loyalties" and the inherent dilemma of observing while participating. The experience of being "othered" in both African and European contexts had made me wary of the grand identitarian schemes of feminist or lesbian solidarities that assume a joint identity or engage participatory research methods that may lead to the downplaying of differences (Ahmed 2000). An ethnography of the particular that seeks to document lived experiences through the process of generating life hi/stories has the potential to (re)articulate differences, without othering them.

Being "particular" necessitates a close look at the epistemological and methodological premises upon which data is collected and transformed into analysis (Weiss 2011). Often, the daunting task of unearthing stigmatized or hidden sexual cultures seems to obviate a critical analysis of the process of data collection and interpretation. Therefore, research on same-sex desiring subjects has been particularly susceptible to treating "data as 'raw' data, with no attention to the ways data are used, derived, or produced" (Weiss 2011, 650). By spelling out my methodological tools and analytical practices, I seek to write against the veiling of 
the process of knowledge production and, perhaps, to decolonize or at least interrupt the hegemonic ways in which "queer" Others have been called into being in juxtaposition to "modern" homosexuals. In this book, one attempt at making more transparent the process of generating data is reflected in the different typefaces used when quoting my respondents. Since they usually code-switched, all the words that were originally uttered in Twi or Ga and have been translated are put in italics, while terms that were originally uttered in Ghanaian English remain non-italicized. Though it may irritate the flow of reading, this unevenness is a reminder of the processes of translation that are inherent to knowledge production and scientific research.

\section{The Ethics and Erotics of Being Indirect}

Locating same-sex desiring working-class women in Ghana required the "unlearning" of my pre-conceived notions of sexuality as a social identity and the developing of an indirect language of allusion. To begin with, the process of locating respondents was difficult and lengthy. It took shape through a series of (constitutive) misunderstandings that taught me to be discreet and indirect, as this early interaction, recorded in my fieldnotes, reveals:

Yesterday we took Janet and her brother to an upscale bar that was rumored to cater to gay audiences - a place Janet did not know. While Josephine [my research associate] engaged her brother in a conversation, I paired up with Janet and told her I was interested in the lives of women who had a very close female friend. Janet's English was rusty, and so was my Twi, but her flirtatious response to my clumsy explanations indicated that she understood that I was interested in women whose same-sex friendships included erotic intimacies - and so did her unconcealed scanning of the female couple that arrived at the bar only just before we left. As we walked out, she swiftly took Josephine aside and spoke to her in a low voice, to Josephine's great amusement. As she later told me, Janet claimed she had perfectly understood what I was after, but that I had been beating around the bush rather than fully expressing my sexual interest. Whereas I felt I had asked her to talk to me about female same-sex bonds and networks, she believed I was interested in practicing sexual intimacy with her. Three weeks later, prior to interviewing her, she told me that she too "studied" and "interviewed" the girls she had an interested in, before proposing to them. ${ }^{9}$

9 Fieldnote based on conversations with Janet Aidoo at Accra, January 30, 2006. 
As this episode shows, the potential for misunderstanding in ethnographic observation has surprising and paradoxical implications. Janet Aidoo, whom I had met years before through my long-standing friend Josephine Enyonam Agbenozan, was not used to being asked to speak about same-sex intimacy and certainly not to someone she had barely met. Unimpressed by my being a doctoral research student, she made her own sense of my desire for knowledge. Hence, any attempt at explaining my interest in intimate same-sex cultures could easily be interpreted as a subdued way of indicating sexual interest, inasmuch as the desire, on the one hand, to speak about intimacy and, on the other, to speak intimately cannot be detached from each other (Cameron and Kulick, 2003). One might also argue that Janet chose to sexualize my intentions as a way of articulating her own interest in say, having a well-to-do "half-caste" girlfriend, somewhat "exotic," yet accessible - or in setting the romantic foundations for a lasting overseas connection. While I never expected that I would have much control over how my intentions in the field were interpreted, this encounter alerted me to the fact that researcher and researched do "study" each other on an intimate level and thereby create erotically charged situations.

These ambiguities speak not only to the complexities of researching sexualities or any other topic that is shrouded in secrecy, but to the broader question of the place of the erotic in the field. The posthumous publication of Bronislaw Malinowski's personal Diary (1967), in which he detailed how he "lusted" after missionary and Trobriand women, begs for a thorough examination of the question: What does it mean for ethnographic research if is not possible without moments of affection and/or desire? What if the person you are about to interview asks you to rub some lotion on her back? What does it mean if the urge arises to embrace and comfort a respondent who is heartbroken? Whether or not one decides to yield to such impulses, they shape our research in significant ways (Newton 1993; Kulick and Willson 1995; Lewin and Leap 1996). Kulick in particular argued that desire can be epistemologically productive, since erotic relationships, whether or not consummated sexually, represent "one especially poignant means through which anthropologists become aware of themselves as positioned, partial, knowing selves" (1995, 18). This must, however, include a critical awareness of the "racist and colonialist conditions which make possible the unidirectional discourse about the sexuality of the people we study" (Kulick 1995, 4). 
Making clear my research interest without reproducing preconceived notions of sexual identity or misleading respondents as to the fact that I would write about the topic of intimacy and about whatever our interactions and conversations included, was a challenge. Besides, I had to learn how to deal with the queerness - hence the "deviance" attributed to my project - and the rejections and ambiguities it implied. Once women realized that I was aware of the erotic dimension of their friendships, they either distanced themselves or began to sound out romantic prospects, which they did more or less aggressively. Feeling vulnerable and exposed, my dismissal of blatant sexual advances was born out of personal fears and a fraught respect for cross-cultural intimacies, rather than out of clear-cut moral or strategic considerations. Once attuned to the indirect ways in which the women themselves jokingly foreclosed or deflected unwanted attention, while keeping male and female suitors in their favor, I became more confident in flirtatiously negotiating "the erotics of fieldwork" (Newton 1993, 5).

Whether this mutual observation - this feeling out of each other's motives - is pleasurable or frightening, the desire for knowledge reflects the fieldworker's dependence on their respondents. This dependence, however, is overwritten when reversed in writing by ethnographers who appear as the "knowing strangers" (Ahmed 2000) who authorize their own interpretation of the Other's desires, thereby veiling their own, ethnographic desire. Cultural critic Sara Ahmed has taken the question of "who knows" and who translates strangers and strangeness into a field of knowledge, as the starting point from which to scrutinize the ways in which (white Australian) feminist ethnographers have presented their native "informants" as friends and co-authors. By simply framing them as co-authors we conceal "that the ones who are known have not authorized the forms of writing and knowledge produced by ethnographers, but have been authorized by it" (Ahmed 2000, 55). Ahmed demonstrates that the fraught solidarities in the field hinge on our troubled desire to hear (and speak for) the subaltern, while the condition of the subaltern is constituted by the impossibility of being heard on her own terms (Spivak 1988).

When I asked Josephine Enyonam Agbenozan to translate ${ }^{10}$ and assist me in this project, we were already close and had spent time

10 With a few exceptions my respondents' mother tongue was either Ga or Twi two quite different languages. Although I labored to learn Twi years before 
together both in Ghana and Switzerland. As reflected in the above situation with Janet, Josephine was more than an assistant. She became my research associate, whose desire to know critically shaped the emerging data. We usually met up in the afternoons to visit women, and afterwards, often until late into the night, to write down informal conversations, reflect upon our respective interactions, compare notes, and evaluate where and how they diverged from one another. In Suakrom, my second research site, Josephine stayed with me on the weekends. We would take turns cleaning, cooking, fetching water, and carrying it up to the room I rented on the top floor of a two-storey family house. When doing interviews together, our different cultural sensitivities and ways of expressing ourselves made for a multidirectional social situation that allowed for complex and indirect interactions. In this triangular interview situation, it was not necessarily our questions, but rather our closeness and contestations that inspired respondents to strike up conversations about the meanings of samesex friendship and intimacy.

\section{Telling Life Hi/stories}

Pursuing my interest in retrieving women's voices by documenting their day-to-day lives, I adopted a methodological tool of open narrative interviews that followed a biographical approach (Dausien 1994) and the concept of life hi/story ${ }^{11}$ (Rosenthal 1993; Rosenthal and Fischer-Rosenthal 1997). This was configured by a consideration of Ghanaian narrative traditions (Clark 2010). While sociologists highlight the usefulness of "biographical self-representations" in EuroAmerican societies, in which the individual is constantly called into doing "biographical work" (Rosenthal and Fischer-Rosenthal 1997, 412), Africanists emphasize the usefulness of the life history genre, especially in the Akan context with its elaborate orality and narrative traditions (Clark 2010; Miescher 2005). As Gracia Clark explains,

embarking on academic research, I have not reached a level of proficiency that would allow me to participate confidently in deeper conversations.

11 The slash in life hi/story accounts for the distinction sociological biography researcher Rosenthal makes between experienced and narrated life history, "erlebte und erzählte Lebengeschichte" (1993). It points to the inherent subjectivity of an auto-biographical narration and calls for a thorough analysis of the multi-dimensional process by which it is constructed. 
Akan people are trained to give coherent and indirect narrative accounts from childhood:

Every time children go on an errand or adults pay a visit, they are asked on arrival to present their okwansu, the story of their trip. This story should not be interrupted. It starts with the circumstances that led up to their making the journey and ends with the arrival. Relatives and neighbors judge a child's maturity and intelligence by the coherence of the okwansu. The story also sets the stage for any subsequent request by describing the circumstances which created the need for it. Ideally it is voiced explicitly, so that they can be ready with a response or alternative solution (2010, 9-10).

Following Akan guest protocols, before being formally welcomed arriving visitors are seated, given water, and then asked to explain their motivation and intention of the visit. Thus my "grand tour" opening question to their life hi/story was preceded by my own "arrival story" that described how I had met and became interested in my respondent's life history. I also repeated what they already knew, that I was writing a book about women in Ghana and their "friendships" with each other consciously using the term friendship which is ambiguous in itself and open to interpretation.

Though it was appropriate and helpful to frame my research interest in historical terms, the life history approach was not always conducive to grasping the erotic dimension of women's lives. Many women did not consider their intimate lives to be relevant or to be something that can be directly voiced as part of one's history. Often they elaborated on their amorous same-sex relationships in more detail only in our followup conversations. However, re-telling the past and crafting a personal biography was significant to initiating reflections about their intimacies and connecting my external, conceptual questions to their lived experience. Unlike conversations happening in between market stalls, within the hearing of neighboring traders, the recording situation required a quiet, intimate space. Finding a calm interview spot within the women's personal environment was often challenging; noise was a major issue. Especially when the electricity was on: It was not always feasible to switch off rattling fans, TV or radio programs, which were sometimes put on precisely to ensure privacy. Whenever possible, the first interview would take place inside or just outside their room. This meant having to keep other compound members supportive. In some cases, some privacy could be brought about by bringing along 
foodstuffs and asking the interviewee's relatives to prepare food for all of us, while we could retreat to a quiet corner of the compound. If such a corner could not be carved out, interviewees suggested a friend's room or a drinking spot in the area. Toward the end of my fieldwork in Suakrom, I conducted interviews up in my room, out of reach of the members of the compound with whom I lived.

The recording was rounded off by going for a stroll, eating together, and my buying cell phone credits to ensure that they could get back to me if they were unsettled by the repercussions of sharing their story and their concerns. Making monetary reimbursement in an appropriate, casual way, especially after in-depth, stirring conversations, took some practice. I did not usually inform respondents in advance that I would compensate them. Although cash gifts are commonly handed to interviewees by investigative print journalists, ${ }^{12}$ this was not necessarily expected, depending on the interviewee's social positioning and on our rapport. A few women, with whom I was only loosely connected, did not want to give further weight to the information provided by engaging in a immediate monetary "transaction." Most women, however, told me I should offer whatever I wanted to give "from my heart" or they expressed their hope that I would help out in an emergency. Such situations always arose sooner or later: a child or grandmother in need of urgent medical care, or a funeral that begged for contributions funerals being one of the biggest investments in southern Ghanaian life. While it was instructive to be immersed in women's constant negotiations around mutual material assistance, I often saw myself negotiating unspoken hopes and expectations that did not match my budget. Aware of the reputed stinginess of Europeans who enjoyed the hospitality of local Ghanaians, I indeed needed to figure out what I wanted to give "from my heart" and what was appropriate, considering my position as a prospective professional scholar. One way of thanking respondents on a more collective level was to host small parties at a local drinking spot. These occasions made for a welcome change, especially as many women were curious to meet the others

12 In a chapter on "Corruption, Investigation and Extraversion" Jennifer Hasty (2005) elaborates on the nuanced accounts of prestation by journalists who lack access to official sources of information. While some are keen to distinguish such gifts from the unethical practice of bribery, others pragmatically consider it an exchange of information for money (Hasty 2005, 135-36). 
I had made contact with. In Accra, where respondents from different boroughs would attend, such events at least temporarily generated community.

\section{Locating the "Field"}

The core anthropological data of this project consists of fieldnotes and fifty-nine audio-taped interviews generated during a total of seventeen months of multi-sited ethnographic fieldwork in southern Ghana: An initial stay in February/March 2006; two main research periods of seven months each in 2007/08; and a concluding stay in January 2012. During the first research period I was based primarily in Accra; during the second phase I lived in the medium-sized town that I am referring to as Suakrom, composed of the Twi words "to learn" and "town." Sadly, the unpredictability of present and future sentiments against those who may be read as sexual deviants warrants this pre-cautionary measure.

While starting to interact with women like Janet and other workingclass women who did not portray their same-sex intimacies in lesbian terms, I was equally interested in the emerging activist communities that did identify with notions of lesbianism. Thus, I became involved with the activities of a community-based sexual rights initiative in an impoverished neighborhood of Accra. To prevent local hostilities, this initiative that grew into an NGO presented itself as a human rights office, while also doing HIV/AIDS prevention work and tapping into global funds for sexual minorities.

The collaboration with this NGO proved tricky, since my agenda to make contacts and preliminary inquiries was confronted with the agenda of its leader, who urged me to fundraise and build up the NGO's practically non-existent lesbian wing. The leader bemoaned the attitude and the lack of dedication of the women he had put in charge of forming a lesbian group. He appealed to me to raise their consciousness by "educating" them about "who they are" - conveying, thereby, that the fullest and most liberating expression of loving a woman as a woman was to develop a sexual identity. Although his appeal was not compatible with my open-ended, inductive approach, I followed his invitation to organize an afternoon party to gather women who had once shown interest in being part of a women's group. This party provided a fruitful entry point. Stella Odamten, 
a former group facilitator of the NGO, introduced me to a range of women who engaged in intimate same-sex friendships in her neighborhood. Stella also declared that the only route to gain access to and win the trust of "lesbians," was to pretend to be "one of them." While my own queerness obviated pretense, I refrained from explicitly "outing" myself in favor of following the women's examples of being indirect. Many women were either unfamiliar or uncomfortable with terms like "queer," "lesbian," and "bisexual" or simply did not provide the space for a "coming out" narrative. Given that the script to "come out" and assume a sexual identity was not desired by the majority of my respondents, I sought indirect ways of conveying that I was aware of the sexual intimacies that could connect two "very close" female friends; an awareness that was invariably attributed to my own (stated or presumed) same-sex experience.

Coincidentally, I discovered that I could make discreet statements by way of showing photographs. Alongside pictures of my parents and siblings, I had photographs of mostly female or gender-bending friends, including a picture of myself arm in arm with a former female lover. While some women ignored our romantic glance, possibly reading it as a sign of Westerners' reputed extravagances, others seemed to detect the "special" quality of our intimacy: They flirtatiously inquired about my age and whether I was married or had a child. Rather than preempting more intrusive questions by either reducing my age to twenty-nine (as many childless women do) or blankly telling them that due to my economic privilege, I could afford to approach my mid-thirties without husband or children, I volunteered information about how my life diverged from a heteronormative script. Even though increasing numbers of educated Ghanaian woman do not conform to the script of being married by the age of thirty either, the fact that I freely admitted to it, sparked suspicions about my queerness.

In search of a second urban field site, Suakrom drew my attention because of its considerable difference from the megacity of Accra in terms of its size and ethnic composition. The majority of my respondents in Accra belonged to the Ga-Dangme ethno-linguistic group indigenous to the southeast of Ghana. The Ga-Dangme constitute about 7.4 percent of the overall population. Suakrom, in contrast, is dominated by the Akan, Ghana's largest ethno-linguistic group that hails from south-central and western Ghana. The Akan make up 
47.5 percent of Ghana's 24 million inhabitants (Nyarko 2010, 34). The reputed beauty, wit, and post-independence sophistication of Suakrom's townswomen and the rumors in Ghana about the town's relaxed sexual morals made Suakrom a compelling environment in which to examine shifting representations of gender and sexuality. The town's statistically high HIV rate and foreign sponsored AIDS prevention program targeting MSM (Men who have Sex with Men) and working with peer educators added to Suakrom's appeal as a site for conversations about sexuality. Moreover, in 2006, during the media scandal around a supposedly "banned homoconference," that was to take place in Accra, homosexuality was consistently attributed to "other" ethnic and political groups. Suakrom, as a multi-ethnic, commercial town and former transit hub, could provide ample grounds for the articulation of rumors and suspicions - and, hence, inroads for conversation about sexual Others.

There were two additional local incentives to do research in Suakrom: its vibrant marketplace and a state-sponsored semiprofessional women's football team. Dominated by autonomous female traders, the marketplace historically constitutes an important site for the forging of women's trading associations and personal alliances, as shown in Gracia Clark's work on Akan traders in Central Market Kumasi, one of West Africa's largest markets (1994). The female football arena is, furthermore, considered a bonding space for self-assertive young women, many of them with masculine gender presentations. As I had found in my interactions with similar teams in Accra, the football pitch was a playground for female masculinities and a space in which same-sex bonds were tacitly tolerated. Young, unmarried, and from outside of town, most of Suakrom's female footballers lacked local kin ties and had little social and cultural capital. They lived under precarious economic conditions and found financially supportive "sugar mummies" in the marketplace.

The question of who provides financially emerged not only in my respondents' relationships or in flirtatious negotiations such as the one with Patricia Opoku, captured in the Prologue's vignette. Questions over material differences cut across the process of doing research and my own friendships and research relations. Both in Accra and Suakrom most of the women who were ready to engage with me and Josephine, my research associate, were subjected to precarious material circumstances, 
while I was considered a well off "half-caste" or "Burger."13 Negotiations over the status and scope of our connections formed a crucial part of the process of spinning a web of research relations. My relationship with Josephine was equally shaped by the economic, geopolitical, and educational disparities with which we had to contend. At the same time, the tensions between myself, Josephine, and our respondents enabled spaces of social closeness that allowed us to share intimate life histories - spaces that alerted me to the politics of transnational friendship and (dis)connection, and the kind of solidarity that could perhaps span such irreducible differences.

13 This term became popular in the 1980s as a way of referring to the large numbers of Ghanaians who migrated to Germany, supposedly Hamburg, and displayed their newly acquired (possibly bourgeois) wealth during their home visits to Ghana. 


\section{Introduction: Freeing Our Imaginations}

It is a peaceful evening. We are sucking oranges; six or seven footballers, spread out on the steps near the taxi rank. Opposite the street a fluctuating little crowd is catching a Nollywood flick on a small television screen, mounted at the back of a DVD-selling kiosk. In our midst: Edna, as clingy as always, snuggling up to Aisha. All of a sudden, their bantering tilts into a loud argument. My bewilderment prompts one of the senior team members to give me a roundup of Edna and Aisha's story. Edna wanted to separate from her girlfriend Naa, who also happened be her "team mother" (that is, a senior team member who was "taking care" of Edna). Naa felt that Edna was turning away from her. Not long before leaving the team to join the police force, Naa decided to "test" Edna by asking Aisha to propose to Edna and see whether she would accept. Rather illogically to me, the idea was that if Edna accepted Aisha's proposal, it would mean that she had started involving herself with other women already and had therefore distanced herself from Naa. The "test" became serious when Aisha and Edna fell in love and Aisha didn't know how to tell her friend Naa. ${ }^{1}$

I never knew what to make of the scheming and exchanging among female friends and same-sex lovers that led to jealousies, rivalries, often to broken hearts, and always to endless trails of gossip. Was Naa "testing" Edna, her lover, or Aisha, her friend? Or, given that Naa was about to leave the team, was she wittingly "passing on" her lover to her friend? The young women themselves felt that "gossiping" and lack of privacy was the source of their own and all of "Africa's" problems. "Abroad" they imagined, things were different because people do not interfere and meddle in each other's lives as much. I responded to such claims by stating that in lesbian circles in metropolitan Europe, gossip and "dyke" dramas were as prevalent as they were in Accra or Suakrom. Admittedly though, the dramas I witnessed seemed to be particularly intense if they occurred among women who

1 Fieldnote based on a conversation with Aba Adama, December 7, 2007. 
depended on each other to make ends meet, whereas the stereotypical white middle-class lesbian is financially independent and makes her own good money.

Indeed, the female same-sex relationships I came across in southern Ghana were never "private." The networks of female footballers thrived not so much on stable couples, but on friendships such as the one between Naa and Aisha who probed each other's loyalties. Such friends engaged in practices that impelled them to fight and revive or abandon their friendships, again facilitated by other friends, such as the footballer who imparted to me the story about $\mathrm{Naa}$ and Aisha. It was not only "team mothers" and "team daughters" who had a say in making or breaking the love relationships of their best friends; the involvement of supposedly mediating friends or cousins was integral to the informal networks I encountered. In many queer settings around the world, friends play a key role in connecting potential lovers. But the informal networks of same-sex desiring women are perhaps even more crucial in places where match-making has not been outsourced to online dating platforms and to bars and clubs as thoroughly as in metropolitan Europe. Further, working-class women in Ghana rely on close friends not only to match them with a lover, but also for providing material and spatial assistance, for instance by offering room for them to sleep together, by making housing and job arrangements, by feeding and raising each other's children, or by taking care of each other's aging parents.

This book is, in essence, about these friendships. It focuses on the everyday lives and intimate discursive practices of women who love women in postcolonial Ghana. It explores the agency of female friends who emphasize that they have been "doing everything together": bathing together, washing together, cooking together, sleeping together, and eating from the same bowl. Such same-sex intimacies exist alongside and beyond sexual rights politics. They invoke a spectrum of sensual and sexual intimacies that defy the analytical boundaries drawn between kinship, friendship, and sexuality. This ethnography pushes us to perceive the vibrancy of everyday same-sex intimacies that have not been captured in the language of sexual identity. It does so by retelling stories that can only be heard if we allow ourselves to imagine more than what frames our own being. As Binyavanga Wainaina conjured in his six-part video documentary on YouTube: "we must free our imaginations" in order to "make new exciting things" and 
create our own stories on the African continent (2014). In particular, Wainaina speaks out against the uninspired moral politics that frame current debates against homosexuality on the continent; he prompts middle-class Africans not to allow their "life of imagination" and innovation to be stifled by a neocolonial mentality of submissiveness and officialdom. This ethnography aims at freeing our imagination to the transformative energies and the creativity inherent to queer, as in unruly, same-sex cultures in Africa and elsewhere.

One of the main obstacles to hearing the voices of women who love women in Africa seems to be the concept of homosexuality. Certainly, the idea that same-sex desires can provides us with an inherent (homo) sexual identity offers an antidote to a homophobic discourse that considers same-sex desire evil, sick, or both, but never the basis for a valid identity. On the other, however, it firmly links the question of what we $d o$ (sexually) to the question of who we are. This correlation between sexual practice and social identity is not universally given, but emerged out of sexology studies in late nineteenth-century Europe (Foucault 1980). Even if our desires and intimate practices do impact on how we relate and position ourselves in the world, they do not necessarily translate into a constitutive self-identity. And what do we mean by identity in any case? Depending on context and academic discipline, identity invokes "a collective self-understanding," it provides "the ground for social and political action," it points "to something allegedly deep, basic, abiding and foundational" or highlights the "fluctuating and fragmented nature of the contemporary self," to name just a few ways in which identity is put to scholarly use (Brubacker 2004, 33-35). With regard to homosexuality, identity is further complicated by its association with metropolitan lesbian and gay lifestyles, (rainbow) colors, and consumer tastes (Weeks 1977; D’Emilio 1983). ${ }^{2}$ While the umbrella term "sexual identities" has served as a starting point to politicize gender diversity and same-sex desires on the African continent, its attending transnational $\mathrm{LGBT}^{3}$ politics, privilege the

2 From a historical perspective, Marxist scholars (Weeks, 1977; D’Emilio 1983) have traced the emergence of gay and lesbian (sub)cultures from the period of industrialization in Europe's colonial metropoles to their solidification under consumerist capitalism in the late twentieth century.

3 The acronym LGBT (lesbian, gay, bisexual and trans*) is constantly being extended to include further gendered and sexual self-identities. Though I am aware that the extension LGBTIQ has gained currency among North Atlantic organizations, I deploy the acronym LGBT when referring to a global 
project of making sexuality visible over other forms of agency and identification. As such, I avoid notions of sexual identities in order to impede the conflation of various ways of experiencing desire and intimacy with one monolithically imagined sexual self-identity that can be put into plural and translated into any cultural context. Instead I revert to a broader notion of erotic subjectivity when referring to specific selfrelations and erotic understandings of self. Intimacy, however, is used as a more relational term when contextualizing closeness and encounters with those to whom we bond and relate to in significant ways.

$*$

"To intimate is to communicate with the sparest of signs and gestures," queer theorist Lauren Berlant writes, while "intimacy also involves an aspiration for a narrative about something shared" $(1998,281)$. In the North Atlantic world, this narrative of something to be shared is set within a realm of desire, choice, and domesticity, to the point where intimacy is associated primarily with love and sexuality and with independent and supposedly egalitarian, "modern" relationships (Giddens 1993). Though the female friendships I chose to focus on are indeed sexually intimate and engender erotic subjectivities, they span a range of shared, intimate practices that cannot be understood adequately through concepts of sexuality. The context of postcolonial precariousness in Ghana requires that many things are shared that would be considered intimate or private in middle-class Europe. Inevitably, practices of sharing shoes, beds, or mobile phones and the exigencies of everyday survival bring into close proximity the lives of people who are neither married nor partnered. The close bonds emerging between neighbors, friends, or family members are instigated through economically and emotionally significant practices such as sharing food or bath water. I understand intimacy through the emotional rifts, the passions, and the fragilities engendering same-sex relationships that are inspired by both material and affective needs and desires.

My understanding of the "erotic" as a powerful human resource is inspired by the black lesbian feminist Audre Lorde. In her essay on the "Uses of the Erotic" (Lorde 1984) Lorde considered friendship and sexual connection vital tools in women's assertion of their own

institutionalized framework and LGBTI when referring to African activist contexts where the extension of the I (for intersexual) has always been preferred (cf. Epprecht 2008, 24). 
humanity, in surviving gendered and racialized violence, and dealing with the exclusions and subjugations imposed by the forces of global capitalism. Thus, as formulated by ethnographers working on the black Caribbean, Lorde's understanding of "the power of the erotic" $(1984,58)$ and her reading of the erotic through the sensual goes far beyond associations of "sex and sexuality" (Allen 2011, 96). As Jafari Allen writes, for Lorde, the erotic is not only about our sensual and sexual energy, but a transcendent and transforming force, "the deep subjective," which she recognizes as "a lens through which we scrutinize all aspects of our existence" (Allen 2011, 96, citing Lorde 1984). Knowledge of the joy we can experience compels us "not to settle for the convenient, the shoddy, the conventionally expected, nor the merely safe" (Lorde 1984, 57). This capacity for and awareness of joy is vivid in the narratives I encountered in Ghana and emerges as a powerful site of knowledge production. To me, Lorde's sensitivity to the humanizing power of the erotic has been best captured in Allah Made Us, Rudolf Gaudio's study of male same-sex intimacies in Northern Nigeria (2009) and in Gloria Wekker's ethnography on The Politics of Passion (2006) among women who love women in Surinam.

This book also is set in the legacy of feminist works that explore the resilience and creativity of urban working-class women in Ghana - in particular the landmark studies Sharing the Same Bowl (Robertson 1984), Onions Are My Husband (Clark 1994) and I Will Not Eat Stone (Allman and Tashjian 2000), which made crucial contributions to understanding female agency in southern Ghana. They explored the shifts in gender relations, the real and imagined blessings of Akan matriliny and the legendary autonomy and flexibility of female traders throughout southern Ghana, in responding to rapidly changing and ever more aggressive global economies. My own concern with the livelihoods of working-class women seeks to extend the analytical scope of female agency in Ghana by including the affective and erotic dimension of their everyday lives. My inquiry thus responds to the African feminist call for research on sexuality that is sensitive not only to gender and power (McFadden 2003; Pereira 2003; Tamale 2011) but also, as Sylvia Tamale insists, to "pleasure, eroticism and desire," as a means to overcome "the tired polemics of violence, disease, and reproduction" clinging to the study of sexual bodies in Africa (2011, 23-31). It also responds to the call for theoretically engaged 
ethnographies of female same-sex relations, pronounced since the advent of queer anthropology (Blackwood 1986; Weston 1993; Boellstorff 2007). The lacunae in inquiries on specifically female samesex relationships speaks to the epistemological challenge of investigating sexual intimacies in general and to the double methodological challenge of exploring female and same-sex desires in Africa. Bridging these gaps requires a transdisciplinary approach that draws on anthropological, historical, and philosophical materials and engages queer, feminist, and postcolonial epistemologies.

The "postcolonial" in the book's title refers not so much to the chronological time period since Ghana's independence, but to an analytical perspective, which is mindful of the colonial legacy persistent in our scientific disciplines and systems of knowledge. As Nikita Dhawan and María do Mar Castro Varela outline, postcolonial theory needs to be understood as an "anti-disciplinary" project that seeks to excavate and destabilize the links between particular scientific discourses and (neo) colonial, disciplined ways of knowing. In so doing, this project sheds light on the material relations that work to fix " 'the Others' in the position of 'the Others"' $(2009,9)$. A postcolonial feminist approach in particular seeks to unravel the entangled, historical makings of gender in the global South and North and to dethrone the racial and gendered categories that have framed European imperialism as an inevitable global process and women of color as modernity's constitutive Others. This approach is equally mindful of different positionalities among formerly colonized subjects and distinguishes between metropolitan Others (such as migrant scholars of color) and the subaltern who cannot make herself heard as the Other. Gayatri Spivak describes the subaltern as a person who is removed "from all lines of social mobility" and lacks the structures that would make her agency recognizable $(2012,430)$. In response to the popularity and what she considers the "metropolitan romanticization" of subalternity among feminist activists and scholars in the North, Spivak clarifies that "no one can say 'I am a subaltern"” for, "subalternity is a position without identity" (Spivak 2012, 431). While cautioning postcolonial feminists not to wipe out the voices of the subaltern, by speaking for them, Spivak does not release us from doing "the ambivalent work of representation" (Heinemann 2019, 46) and thinking from a place of subalternity.

In this book the daunting work of writing subaltern intimacies is tackled against the backdrop of racialized, colonial representations of 
African sexual bodies and encouraged by its African womanist, feminist, and queer critiques.

\section{“Queer” Intimacies in Millennium Africa}

Wary, perhaps, of revisiting sexist and racist stereotypes about African women's bodies, African feminists and gender activists have been slow at taking up research on sexuality and on female desires in particular (Arnfred 2004). Since the turn of the millennium, however, a major shift has happened, as exemplified by edited collections focusing on "African sexualities" (Tamale 2011; Bennett and Pereira 2013; Ekine and Abbas 2013) in response to the call for research on "subaltern sexualities" pioneered by the South Africanbased feminist journals Agenda (Gqola 2005; Potgieter 2006) and Feminist Africa (Mama, Pereira and Manuh 2005; Salo and Gqola 2006). Ugandan legal scholar Sylvia Tamale was the first African feminist to contextualize and explicitly write against the rapidly expanding anti-gay climate that has accompanied and spurred this shift (2003). Recently, African activists have begun to document and compile the life stories of "queer Africans" in different parts of the continent (Mwachiro 2014; Azuah 2016) and two outstanding films made in Nairobi (Chuchu 2014; Kahiu 2018) speak of urban Kenya as the hub of African LGBTI activism outside South Africa. Moreover, artistic analyses of non-normative genders and sexualities (Muholi 2010; Matebeni 2014), fictional accounts (Martin and Xaba 2013), and Afropolitan online-magazines such as Q-zine ${ }^{4}$ are bringing "queer perspectives" from African metropoles to broader audiences. These activist initiatives are using the term queer, which appears to be more open and less fraught with Euro-American connotations than the term lesbian. As a strategic term, capturing a variety of non-conforming genders and same-sex practices, queer has started cutting across activist endeavors in Africa and its diasporas.

This book addresses three major gaps persisting in the scholarship on "homosexuality" in Sub-Saharan Africa. First, most scholarly publications concerned with homosexuality in the global South have focused on men. This correlates with a larger privileging of male sexual bodies and desires and the long-standing denial of sexually meaningful female

4 https://issuu.com/q-zine, accessed July 3, 2017. 
intimacies in colonial and postcolonial sources (Blackwood and Wieringa 1999). This legacy was continued in the academic field of lesbian/gay anthropology in the 1980s, when gay anthropologists remained silent about the putative insignificance of female same-sex intimacies and only found what was recognizable to their gaze. As Blackwood put it, male scholars talked to male informants about male sexual activities and neglected the sources on female same-sex relations or assumed that the limited data did not allow for analysis $(1986,5)$. Moreover, female homosexuality was held to be less regulated, "less developed, less common and less visible than male homosexuality" (Blackwood and Wieringa 1999, 44). This raises a more general question regarding which spaces are considered public and by whom and which ones are overlooked or considered invisible. In many places the presumed invisibility of female same-sex bonds is the result of the private/public split and a paradigm that has linked homosexuality to "spaces that are coded as masculine and public within the sources themselves" (Sinnott 2009, 226).

Second, there are few empirical studies that explore the experiences, as opposed to the textual and discursive representations of contemporary Africans, who engage in same-sex relationships. Scholars analyzing historical texts and media representations of homosexuality and the political homophobia of African nationalists (Hayes 2000; Epprecht 2004; Hoad 2007) have been credited for heralding the sub-field of Queer African Studies (Macharia 2009). Increasingly, African philosophers and political scientists are broaching the subject by bringing colonial "sodomy laws" and postcolonial homophobic rhetorics to bear onto broader political analyses. Prominently Achille Mbembe theorized Africa's “silent sexual revolution" and its adjacent politics of "phallic power" (2010). While the literature on homophobic debates and their religious and political ramifications (Chitando and van Klinken 2016; Currier 2019) is rapidly expanding, studies of the everyday practices of same-sex desiring Africans remain scarce (Awondo, Geschiere and Reid 2012, 161). Ethnographies that focus on Africans who engage in same-sex intimacies without claiming a specific sexual identity are even more rare.

Third, ever since Defiant Desire (Gevisser and Cameron 1994) the first edited collection on Gay and Lesbian lives in South Africawas published, research on same-sex intimacies in Africa tended to 
focus on Southern Africa. ${ }^{5}$ This corresponds with extensive colonial documentation of sexuality in Southern Africa, stimulated by white settler colonists and the attendant presence of imperial anthropologists (colonists were less present in British West Africa with its system of indirect rule). South Africa's contemporary position as Africa's economic powerhouse and more importantly decades of liberation struggle inspired a focus on human rights, including sexual rights. ${ }^{6}$ Today, South Africa's role as Africa's only nation-state that fully embraces and protects homosexuality in its constitution and one of the first countries worldwide that granted full marital rights to same-sex couples facilitates research on gender and sexuality. Conversely, South Africa's high rates of gender-based violence and so-called corrective rapes of (masculine presenting) lesbians, which have been considered a backlash to South Africa's liberal constitution, called for academic and activist projects working on female-bodied same-sex intimacies in the Southern Africa region (Morgan and Wieringa 2005; Lorway 2008; Gunkel 2010; Matebeni 2012).

Embarking on this research project in 2006, there were no published empirical texts on same-sex intimacy in Ghana. I was thus excited to gather the few existing essays and dissertations by Ghanaian students (Yahaya 2003; Tetteh 2004) and North Atlantic exchange students (Rehnstrom 2001; Harrington 2005; Kim 2005) at the sociology department of the University of Ghana, Legon. Most importantly, Tetteh's focus on working-class women in Accra attuned me to the fact that notions of friendship, rather than sexuality provide important leads into adult women's same-sex intimacies. Tetteh noted that "ordinary ladies' friendship associations" such as mutual-help organizations offer ideal cover for same-sex lovers "to share fellowship and companionship," alongside their lives as wives and mothers $(2004,18)$. Cultural analyses of the derogatory depictions of "lesbians" in Nigerian and Ghanaian

5 Prior to this collection, South African historians came across the same-sex "marriages" of male workers in South African gold mines. These "mine marriages" were interpreted primarily as practical, situational arrangements (Harries 1990; Moodie and Ndatshe 1994).

6 This progressive legal situation is due not least to prominent black and white figures in the liberation struggle who openly identified as gay. Most famously the anti-apartheid, gay rights, and AIDS activist Simon Nkoli was said to have influenced the African National Congress and Nelson Mandela's constitution. 
cinema contribute to the study of the representation of female samesex desire in West Africa (Green-Simms and Azuah 2012; GreenSimms 2012). Above all, empirical inquiries into the strategies of pockets of gay-identifying activists in Accra (O'Mara 2007), on coastal communities of same-sex desiring men known as "Saso people" (Banks 2011; Otu 2018), and on cross-dressing university students (Geoffrion 2012) in Cape Coast attest to the increasing visibility of male gender-bending and same-sex practices and the lack of substantive work on female same-sex intimacies.

Analyses of the politicization of homosexuality in Cameroon (Gueboguo 2006; Awondo 2010; Nyeck 2013), in Ghana (Tettey 2010), and in the Gambia (Nyanzi 2013), and anthropological work on male same-sex cultures in the urban centers of francophone West Africa (Teunis 1996; Nguyen 2010; Broqua 2009) revealed how the emergence of gay activism has been framed by HIV/AIDS initiatives and how male intimacies have been associated with sex work and transactional sex. In Nigeria, pioneering anthropological work has been done on male same-sex intimacies (Gaudio 1998/2009; Pierce 2007) and recently, the gap on women's same-sex desires has been tackled in an anthology that documents the first-hand narratives of "Nigeria's queer women" (Mohammed, Nagarajan and Aliyu 2018). Besides these documentations, feminist fiction writers are freeing our imaginations with regard to non-normative genders and female desires in Nigeria and its diaspora (Okparanta 2013/2015; Etaghene 2015; Popoola 2017). ${ }^{7}$ Not least, the work of the Coalition of African Lesbians (CAL) and the "lesbian-led" Queer African Youth Networking Centre (QAYN) document and attest to the different experiences of male and female African activists within male-dominated LGBTI initiatives (Kouassiaman and Armisen 2012, 6). Still, the difficulty of integrating the study of same-sex intimacies into African feminist spaces and larger debates in African gender studies prevails. This omission necessitates a closer look at the colonial ghost haunting representations of female sexual bodies in Africa.

7 In 2006, the inclusion of the short story "Jambula Tree" by the Ugandan author Monica Arac de Nyeko in African Love Stories (Aidoo 2006) attested to the power of fictional writing on and the recognition of female same-sex desires and its relevance by feminists across the continent. 


\section{Colonial Ghosts and Keyholes: (De)sexualizing African Bodies}

The production of knowledge about, and the regulation of, sexual, racialized bodies was at the heart of Europe's civilizing mission (Stoler 1995; McClintock 1997; Lugones 2007). Depictions of rampant primordial African men and women in need of containment and enlightenment, and the childlike, noble savage who is free of sexual "degenerations" and in need of protection from corrupting influences from the East, indicate a veritable obsession with the sexual (Hoad 2007; Epprecht 2008; Gandhi 2006). These sexualized and racialized figures justified not only the imposition and continuation of colonial power; these Others provided the background for the construction of white, "modern" masculinities and femininities (McClintock 1995; Purtschert 2006; Gunkel 2010).

The study of "primitive" sexual behaviors, such as male "sodomy" and other non-procreative sexual practices tagged as "unnatural carnal knowledge," was an integral part of British imperialism (Hoad 2007, $3-7)$. It was informed by the voyeuristic travelogues of European explorers and sustained by fears of insurrection (Arondekar 2009). One of the most widely acknowledged writers and travelers vested in observing, translating, and documenting sexual practices was the British officer Richard Burton. Burton (1885) devised a "sotadic zone," in which the flourishing of "homosexual" practices was facilitated by climatic conditions. Burton's "Orient" constituted the center of his pseudo-geographical latitudes of "sotadism," whereas northern Europe and Sub-Saharan Africa were the only two regions on the globe he considered mostly "uncontaminated" (Karsch-Haack 1911). On the one hand, Burton's defensive rhetoric testifies to "his wishful thinking of the 'East' as a world free from the theological and moral repressions of western Christendom" and is important "in rendering the Orient into a homosexual utopia for Europe's sexual refugees"; on the other, it fueled "the energies of a moralizing chorus intent on accumulating (homo)sexual evidence for the savagery of Europe's subject races" (Gandhi 2006, 52-53).

This spy-like gaze, coupled with nostalgia about "uncontaminated," non-western sexualities, is reproduced in the writings of early twentieth-century anthropologists who waded through the small print of colonial and precolonial travelogues and missionary 
reports (Karsch-Haack 1911; Westermarck 1908) in order to map out homosexual practices across the globe. While the bulk of these documents focus on men, the German entomologist and armchair anthropologist Ferdinand Karsch-Haack was attentive to what he considered "lesbian love" in Africa. Steeped in the racist sexologist paradigms of the early twentieth century (and in particular of his colleague Magnus Hirschfeld), Karsch-Haack's weighty compendium Das gleichgeschlechtliche Leben der Naturvölker (1911) features an entire chapter on tribadism (female genital rubbing). Karsch-Haack compiled and re-interpreted the vivid descriptions of explorers who examined "macroclitorides" and "hypertrophic" labia minoras. Interested in the nature-culture question, these (pre-) colonial adventurers inquired into whether "monstrous" labias and clitorides were "racial peculiarities" 8 or resulted from "tribadism" and other "excessive" cultural practices (such as the elongation of the labia or the use of dildos in initiation rites). Karsch-Haack was critical of the heteronormative, masculine voices of the travelogues and mission reports he relied on.

Writing against notions of the unfeeling "mannish woman" as a "degenerated creature," Karsch-Haack's compendium can easily be considered an expression of his personal interest in rehabilitating "homosexuality." Nevertheless, such accounts also reiterate what Tamale labels the "voyeuristic, ethnopornographic obsession with what [European scholars] perceived as exotic (read perverse) African sexual cultures" (2011, 19). Tamale suggests that "ethnopornographic" depictions of African women as unfeminine, hyperfertile, insatiable, backward, or barbaric reflect the imperial anxieties of their authors. But they reflect more than that. The racialized images of African women's bodies and practices constituted the "periphery" of metropolitan sexual regimes, which, in turn, served to normalize constructions of white bourgeois femininity (cf. Purtschert 2019). This "ethnopornographic" gaze has been reproduced in policy-oriented social science and media reports on reproductive health and fertility control in Africa, and not least in the discourses on sexual health and the HIV/AIDS crisis (see Caldwell et al. 1989). The AIDS paradigm has contributed to a profound re-medicalization of African bodies since the mid-1980s (Tamale 2011, 15) and to a revival of colonial

8 The author's translation of “Rasseneigentümlichkeiten” (Karsch-Haack 1911). 
constructions of black sexuality as promiscuous and inherently Other (Spronk 2006, 10).

The colonial ghosts haunting representations of female desires prominently surface in the conflicting interpretations of African "women marriages." Discussions over the motives for and the meanings of these institutionalized marriages between two females evince a divide between (straight) African feminists and (white) queer feminists, which leaves little room for queer African perspectives. "Women marriages" have been reported in about forty, mostly patrilineal African societies, and explained on the grounds of hereditary considerations or reproductive exigencies (Tietmeyer 1985). For the Nuer for instance, Edward Evans-Pritchard mentioned how a barren, wealthy woman could become a "woman-husband" and marry one or several wives "in exactly the same way as a man marries a woman" (1951,108-9). In these marriages, often forged by female diviners, the "woman husband" paid bride-wealth and chose a genitor for her wife, whose offspring would belong to her (the "husband's"), lineage.

Interestingly, accounts written prior to the advent of gay and lesbian studies in the 1970s were more likely to imagine or allude to the possibility of eroticism within these marriages (Wieringa 2005). Melville Herskovits, for instance, formulates that "it is not to be doubted that occasionally homosexual women [in Dahomey] who have inherited wealth [...] utilize the relationship in which they stand to the women whom they 'marry' to satisfy themselves" (1937, 338). Decades later, Herskovits' assumption was dismissed by feminist anthropologists, whose concern was with the gender regimes, the lineage, and the class structures framing female marriages. In fact, they left unexplored possible erotic aspects of some women's marriages (Krige 1974; Smith Oboler 1980). Without considering intimate connection as additional or primary incentive for a woman to marry a woman, they were quick to assume the non-sexual nature of these bonds and invested in rendering female spouses "heterosexual." ${ }^{10}$ More recent

9 Theses marriages have variously been referred to as "woman-marriage," "woman-to-woman marriage," or "gynaegamie." For the purposes of this discussion, I refer to the phenomenon as "women marriages" (cf. Wieringa 2005, 299).

10 Similarly, ethnographer Judith Gay who did account for the erotic dimension of bonding friendships between girls in Lesotho (1986) assumed that adult women who pursue sexual interests have either opposite- or same-sex relations, and not both, thereby imposing the Euro-American "homo/hetero binarism." 
research highlights the aspects of mutual care and emotional intimacy that were mentioned by elderly Gikuyu women involved in such marriages (Njambi and O'Brien 2000). Second-Wave feminists, however, perhaps wary of imposing what was perceived as an utterly modern configuration of (non-procreative) sexuality and/or aware of the colonizing keyhole gaze (the legacy of gathering information by peeping into bedrooms), tagged concerns with kinship and reproduction rather than intimate companionship as the sole purpose of marriage in Africa.

Audre Lorde was the first feminist to take up Herskovits' allusion to homosexuality. In an essay that tackles the racism and heterosexism shaping competition among black women in the USA, Lorde mentions women marriages. "Some marriages of this kind are arranged to provide heirs for women of means who wish to remain 'free,' and some are lesbian relationships" (2007, 34). She frames women's autonomous economic and erotic alliances in West Africa as part of a lost diasporic past in which women of African descent "enjoyed each other in a sisterhood of work and play and power" (Lorde 2007, 50). Lorde's note provoked a strong reaction from Nigerian anthropologist If Amadiume, an expert on Igbo women marriages. In the foreword to Male Daughters, Female Husbands (1987), Amadiume attacks "western" feminists for usurping the meanings of an African institution $(1987,7)$ and angrily rejects the possibility of sexual intimacy in women marriages. Indeed, she deems Lorde's analogy, "shocking and offensive" (Amadiume 1987). Ironically, Amadiume's attack is directed toward a queer feminist of African descent, who herself grappled with the primacy of white feminist interpretations of "lesbianism." Was Amadiume really unable to imagine the possibility of emotionally and sexually meaningful intimacies between female spouses? While her anger is understandable in the face of the ongoing commodification and cultural appropriation of African bodies and practices, Amadiume's refusal to imagine more reflects her seemingly uncritical adherence to a binary framework of homo- versus heterosexuality.

Today, lesbian feminist scholars are careful not to hasten the sexual labeling of female husbands and their wives. Still, the statement that "most African women in same-sex relations live their lives" in "silence" and "marginalization" (Morgan and Wieringa 2005, 19) has its pitfalls. The multi-authored life story project Tommy Boys, Lesbian Men and Ancestral Wives (2005) seeks to break this "silence" by giving evidence to the historicity of "female homosexuality" in 
Southern Africa. Contesting the absence of explicit historical references to female homosexual practices, the editors deplore that previous researchers did not "give very detailed descriptions of what the girls actually did when they were in bed" (Morgan and Wieringa 2005, 297). While such statements rightly point at the failure of androcentric researchers to recognize the possibility of fulfilling sexual intimacies between women (Blackwood 1986; Carrier and Murray 1998), the question of what exactly happened in bed echoes legacies of peeping into "native" bedrooms. The risk of reducing intimate lives to sexual categories looms large in the quest to uncover and inscribe homosexuality into Africa's history. The keyhole gaze and other colonial technologies that characterized the search for homosexual evidence resonate with the scholarly and activist desires to validate same-sex practices through history.

I have focused on debates about women marriages in some detail, as they illustrate both the problem of the colonial gaze, when drawing on Other cultures in order to make arguments about sexual categories and their attendant Euro-American studies and disciplines, and the heterosexist ghosts haunting African feminists bound to write against the ongoing colonial appropriations of black women's bodies. Bearing this in mind, the next section considers some of the few existing anthropological references to same-sex friendships and desires in colonial Ghana. It begins by looking at anecdotal references to Akan women's "extra-large beds" and outlines the need for intersectional and queer-feminist analyses. I then turn to the historical practice of "friendship marriage" in southern Ghana and the conceptual potential of friendship as opposed to and alongside sexuality.

\section{Extra-Large Beds and the Subalternity of Female Desires}

(L)esbian affairs were virtually universal among unmarried Akan women of the Gold Coast (now Ghana), sometimes continuing after marriage. Whenever possible, the women purchased extralarge [sic] beds to accommodate group sex sessions involving perhaps half-a-dozen women.

(Greenberg 1988, 66)

This quote, taken from the US sociologist David Greenberg's (1998) work, exemplifies some of the anecdotal references, sweeping generalizations, and unaddressed methodological problems that inhere in the 
literature on sexual behavior in Africa (Pinechon 2000; Arnfred 2004; Tamale 2011). Not unlike the sexologists of the early twentieth century, social scientists such as Greenberg (1988) (see also Murray 2000) waded through colonial notes and footnotes in order to produce comparative maps of homosexuality, without critically assessing their source materials (cf. Dynes 1992). Greenberg's assertions about the universality of "lesbian" practices among the Akan derive from his personal conversations with Eva Meyerowitz, who carried out fieldwork in the 1940s. While Greenberg's claim has been considered empirically weak (Murray 2000, 359), it also evokes assumptions about racialized difference and about Africans' purported sexual "Otherness." Before considering his, albeit interesting interpretation of African women's same-sex "friendships," I will briefly contextualize the comparative mappings of gay anthropologists at the time.

A crucial starting point to the cross-cultural study of homosexuality was Foucault's distinction between sexual practice and sexual identity. In his History of Sexuality, Foucault sketched out that sexuality is not a natural given but rather a historical construct implicated in hegemonic forms of power $(1980,103)$. He argued that sexuality as an intrinsic trait and "homosexuals" and "heterosexuals" as essentially distinct types of persons were generated as European medical doctors and psychiatrists promoted the idea that sexual acts were indicative of an individual's biological or psychic truth. The religious and scientific obsession with sex was part of a gradual shift from a "deployment of alliance," a system focusing on the regulation of marriage and kinship ties, to the "deployment of sexuality" in which the knowledge about one's own body and its sensations took center stage (1980, 108). Equipped with technologies of the self, bodies became subjects by internalizing and reproducing the sexual categories on offer, and by fashioning sexual self-identities. ${ }^{11}$

Greenberg's work can be understood as part of a wider search for cross-historical and cross-cultural "evidence" that was inspired by the gay liberation movement of the 1970s and the subsequent emergence of gay/lesbian anthropology. Invested in establishing homosexuality as

11 Ann Laura Stoler discussed Foucault's underlying Eurocentrism and lack of theorizing on the racialized figures constituted outside of metropolitan sexual regimes $(2002,320)$. Her critique is informative in looking at how the intimacy of the colonial encounter (i.e., within sexual relationships between colonizing men and colonized women) impacted metropolitan notions of race and sexuality as well. 
a cultural formation, this anthropological subfield illustrated that same-sex desires could not be considered psychological aberrations but formed the basis for relational models tied to a society's age, gender, and kinship structures. A typology of age-defined, genderdefined and egalitarian forms of "institutionalized homosexualities" was developed and correlated with different types of societies in grand "ethnocartographic" mappings (Weston 1993; Drucker 1996). A "gender-defined" type of homosexuality, in which "certain people took on social roles and characteristics of a different gender" was ascribed to Sub-Saharan Africa and an "egalitarian" model of homosexuality clustered in Euro-American societies (Drucker 1996, 76-77). While I am highly critical of such cartographies, their focus on relational constellations drew my attention to the language of kinship and friendship deployed by same-sex desiring women in Ghana, as well as the context-specific connections (and disconnections) between language, practice, and subjectivity.

Returning to the abovementioned intimacies between Akan women, Greenberg held that "egalitarian," homoerotic friendships developed mostly among children and adolescents, but also considered the sexual bonds between African women to be egalitarian (1988, 66-71). Murray (2000), another "ethnocartographer," however, disclaimed Greenberg's assertions about African women's "egalitarian” intimacies and distinguished them from "modern egalitarian" lesbian relationships. Certainly, same-sex relationships between Africans who seemed to be equals posed a conceptual challenge to the notion of progression from "pre-capitalist" age-defined and (slightly more "complex") gender-defined homosexualities toward an ideal-typical modern egalitarian homosexuality (cf. Murray 1998, 274). Aside from the boundary-drawing reductionism of such mappings, notions of female egalitarianism have a feminist, but nevertheless problematic, dimension. Greenberg suggested that "lesbian relationships are not repressed in kinship-structured societies, and do not entail gender transformation; they tend more often to be egalitarian, possibly because women are not socialized to compete for status with other women, or to dominate" $(1988,73)$. Arguably, the feminist-inspired idea that women's intimacies are less competitive than men's is informed by a Euro-American context, in which women, as wives, have been framed as social subordinates. Yet, such heteropatriarchal ideas about the sameness of female same-sex friends are not unique to the global North. 
Rudolf Gaudio discussed similar perceptions in northern Nigeria among 'yan daudu. This Hausa term pertains to men "who are said to talk and act 'like women"” and to enact "passive" sexual roles with normatively gendered men $(2009,3)$. The close friendship between two "yan daudu is understood as "girlfriendship" (Ikawance). It denotes the affectionate and platonic bonds between girls, and it is also used by adult women. When 'yan daudu refer to a close male friend as their "girlfriend," this is reflective not only of the feminine self-understandings of "yan daudu, but of normative ideas about female friendship. While such "girlfriendships" may in practice include sexual intimacies, these feminine intimacies are generally glossed as non-hierarchical and non-sexual. ${ }^{12}$ Thus (same-gender) intimacies between two feminine men are belittled or disparagingly equated with "lesbianism" (Gaudio 2009, 73). As Gaudio concludes, through "this patriarchal equation of sex and power, sex between equals is cast as something 'feminine' and is therefore seen as mere play, less real and less consequential than sex between people of different social status" $(1998,128)$. While the disregard of relationships that lack a binary power division is reflective of norms that associate sexuality with asymmetry, dominance, and inequality (Pierce 2007), the real and the imagined sameness and subordination of feminine subjects and the assumption that "girlfriendships" are per se playful and egalitarian are constitutive of the discursive gap of certain (female) same-sex intimacies.

This gap is at its widest when imperialist and local patriarchal structures reinforce each other in rendering invisible the agency of the seemingly powerless. Such subtle patriarchal entanglements have been theorized by postcolonial feminists and most pointedly by Gayatri Spivak who characterized the colonial debate around the practice of widow burning a case of white men, seeking to save "brown women from brown men" (1988). In the colonial narrative these widows were framed as passive victims who needed to be rescued from native men. Indian elite on the other hand emphasized widows' heroic choice of voluntarily following their husbands into death. In either case the women's own voices remain

12 The fact that intimacy between friends who occupy the same gender role ought to be framed as non-sexual points to the threat that same-gender homoeroticism poses to the established order of men's (seemingly) non-erotic patriarchal bonding (Sedgwick 1990). 
inaudible. ${ }^{13}$ Such silences and erasures persist in notions of (African) women's harmonious girlfriendships or their inconsequential sexual liberties in extra-large beds.

The theoretical and empirical lacuna on female same-sex cultures in Africa owes much to the complexities of these women's intersectional subject positions. As Kimberlé Crenshaw's concept of intersectionality $(1989 ; 2015)$ reveals, it is the most privileged among the marginalized whose realities are considered in research and social policies: black men are framed as the targets of racism, white women as targets of sexism, and white gay men as targets homophobia. The multi-faceted subjectivities and concerns of those affected by multiple oppressions and exclusions, such as women who are black, queer, and working-class, fall through the (analytical) cracks or are considered to be too "particular" to make for overarching claims or analyses. These discursive erasures are even more pronounced regarding my respondents in Ghana, who do not necessarily identify as black, queer, or workingclass or not in the way in which these categories have been understood in North Atlantic settings. Accordingly, their knowledge and realities have been barely captured in either queer or postcolonial studies.

\section{Queer-Feminism and the Oceanic Fluidities of Same-Sex Intimacy}

This book is inspired, in part, by an epistemological question that has been posed most searchingly by queer-feminist theorists: to what extent is sexuality, as an analytical category, the appropriate lens through which to conceptualize female same-sex desires and intimacies in postcolonial Ghana?

At the outset, queer theory has been understood as a range of critical perspectives on heteronormativity, "those structures, institutions, relations and actions that promote and produce heterosexuality as natural, self-evident, desirable, privileged and necessary" (Cameron and Kulick 2003, 149). The difference between lesbian/gay studies and queer studies is comparable to the difference between women's studies and gender studies: while gender studies shifted attention from female

13 As Rahul Rao argues, imperialist "rescue narratives" are still at work "in the contemporary eagerness of white gays to save brown gays from brown homophobes" (2010, 182). 
bodies and identities to a focus on the construction and the relations between all genders, queer studies shifted attention from the practices and concerns of (queer) groups and individuals to the scrutiny of the processes that render these practices non-normative in the first place (Boellstorff 2007). Given that not all strands of queer theorizing are invested in a feminist critique of gender hierarchies, the phrase queerfeminism highlights the ongoing need to engage with gender and power relations, while looking at sexual and other categories of difference (Nay 2017). Though the term queer is increasingly used as a convenient shortcut for LGBT identities and the ever-expanding extensions of this acronym $^{14}$ or as a label that seeks to remain elastic, I am interested in queer as a theoretical approach established by lesbian feminist thinkers, who unsettled the complacency of lesbian/gay studies (Halperin 2003,340 ) and in practices of queering that allow for the uprooting of entrenched notions of (sexual) politics and activist agency.

In the 1990s queer "was a term that challenged the normalizing mechanisms of state power to name its sexual subjects: male or female, married or single, heterosexual or homosexual, natural or perverse" (Eng, Halberstam, and Muñoz 2005, 1). Extending from a critical focus on sexual and gendered normativities, queer theory became a powerful tool to interrogate the social processes and logics of power that produce and recognize but also normalize and sustain identity and "its multiple social antagonisms, including race, gender, class, nationality, and religion" (Eng, Halberstam, and Muñoz 2005). This broad critique led to a destabilization of the metropolitan emphasis on "coming out," hence on the liberating effects of sexual (self-)disclosure and public recognition with its tendency to flatten out or displace a range of unbridled and troubling, but potentially productive "queer" feelings (Love 2007). At the same time, the analytical opposition between sexual identity and practice began to blur through geographical and anthropological scholars of "queer globalization," who looked at the ways in which concepts of (gay) sexuality travel and work to reconfigure specific same-sex cultures through their transnational circulation (Altman 1997; 2001; Jackson 2000; Binnie 2004).

14 Besides LGBTI, the acronym that attuned toward the inclusion of intersexual identities, the initials $\mathrm{Q}$ for queer or questioning, or A for asexual or allied have been added and in some contexts rounded up by a Plus (LGBTIQA+). 
An important critique of the narrative of sexual modernity and the unequal power relations shaping processes of queer globalization has been made by postcolonial cultural theorists (Massad 2002; Puar 2007). Joseph Massad (2007) in particular is concerned with the role of what he polemically calls the "Gay International": gay tourists, activists, and anthropologists who are spreading an Orientalist discourse of sexuality. He argues that the attention given to sexual acts and to the homosexual/heterosexual binarism supersedes specific, precolonial epistemes of same-sex desire. The activism of transnational LGBT organizations thus prompts local populations to interpret previously unmapped intimacies as sexual and as deviant in the first place. Whereas postcolonial critiques focus on textual representations rather than the lived experiences of queer subjects in the postcolony, queer studies have focused on processes of comingout and on the metaphorical "closet" (the secret bars and bedrooms in which queers have been hiding) in metropolitan settings in the global North. This focus, as in Eve Sedgwick's seminal Epistemology of the Closet (1990), is barely compatible with the contexts of my respondents in Ghana, to whom private closets and bedrooms are not a given. As Omise'eke Natasha Tinsley puts it, "too many northern studies of same-sex sexuality [...] stay out of springs or swamps and close to bedrooms" $(2010,25)$. Conversely, Tinsley makes the materiality of the ocean waters the point of departure in "Black Atlantic, Queer Atlantic" (2008), invoking the unruly (queer) bonds forged in the sex-segregated holds of slave ships:

You see, the black Atlantic has always been the queer Atlantic. What Paul Gilroy never told us is how queer relationships were forged on merchant and pirate ships, where Europeans and Africans slept with fellow - and I mean same-sex - sailors. And, more powerfully and silently, how queer relationships emerged in the holds of slave ships that crossed between West Africa and the Caribbean archipelago. (Tinsley 2008, 191-92)

Tinsley's "queer imaginings of the Middle Passage" are inspired by the etymology of the Creole term mati, the word Afro-Surinamese women use for a female friend or lover: "figuratively mi mati is 'my girl,' but literally it means mate as in shipmate - she who survived the Middle Passage with me" (Tinsley 2008, 192). Closets have little bearing on the lives of working-class women in Ghana either: many of the women who became my respondents shared bedrooms, clothing, and other 
"private" items tucked away in large "Ghana-must-go" bags and boxes - ready to make a move, or hoping to travel across the ocean one day.

\section{Cultures of Relatedness and the Revolutionary Potential of Friendship}

The lacuna on female same-sex relations in West Africa is not only a result of male-dominated or one-dimensional identity politics, but a discursive emphasis on sexuality as a domain seemingly separate from friendship.

While precolonial homosocial spaces in southern Ghana allowed for the strengthening of friendships between men and between women, ${ }^{15}$ the little-known institution of "friendship marriage" was designed to formalize adult same-sex friendships. Agonwsle agyale or "friendship marriage" has been documented for the Nzema, a small Akan subgroup on Ghana's west coast (Signorini 1971). Italo Signorini described how same-sex friends could officialize and strengthen their connection, while simultaneously being married to an opposite-sex partner. However, he refrained from answering his implicit question as to whether these friendships included sexual intimacies. According to later ethnographers of the Nzema, "friendship marriage" had become obsolete by the mid-1980s, yet agonwoleycle kpalc or "good' friendship" - another type of lifelong ritualized bond, that usually united two persons of the same sex - was still found (Grotanelli 1988). Distinctions between ritualized friendships and marriage raise the epistemological question of classification as to whether such formalized same-sex bonds should be listed as friendship or as marriage, and whether marriage is always indicated by the use of the terms husband and wife. Grotanelli concluded that friendship bonds were usually formed between two men, and "more rarely between two women, in which preliminaries partly similar to those of real marriage are performed, partners cohabit for short periods, exchange presents, and share the same bed or mat" (1988, 210). Although today's gift exchanges between girlfriends in Ghana are not ritualized through a script that formally involves the couple's families, Grotanelli's

15 "Youngmen's" associations and girls' puberty and initiation rites (Sarpong 1991; Steegstra 2004) in particular speak to the significance of homosociality in both patri- and matrilineal precolonial Ghanaian contexts. 
description resonates with the relationships I observed: Age gaps are highlighted and performed through the exchange of money, gifts and services, and spatial intimacies; the sharing of rooms and mats is significant marker for passionate bonds involving erotic intimacies.

To my knowledge "friendship marriage" has been found only among the Nzema. However, despite its marginality in the Akan historiography, it speaks to my own inquiry: the fact that women in different parts of West Africa could officially take on a husband's role highlights the primacy of social networks and kinship ties and the non-static conceptualization of gender (Amadiume 1987; Oyéwùmí 1997; Nzegwu 2005). This transferability of gender roles applies to southern Ghana, where a person's gendered status is not necessarily determined by a person's sex (Akyeampong and Obeng 1995). Historically, social status depended on a person's social age, which thrives on a range of qualities such as physical age, charisma, lineage affiliation, reproductive capacities, entrepreneurial success, and religious authority - the sexual body being but one aspect of personhood. The linguistic absence of gender in personal pronouns in southern Ghanaian languages suggests a grammar of gender that differs from the linguistic binaries of most European languages. In the Akan language - Ghana's lingua franca - this absence is accompanied by a vocabulary used to designate feminine males and masculine females, explored in Chapter 3. The notion that gender is situational and denotes a relational position that configures the scope of Ghanaian personhood today is therefore a critical strand of my analysis. This is useful, for instance, in conceptualizing how powerful, post-menopausal women take on male-connoted elder roles, while adolescent girls have the liberty to perform certain youthful masculinities, for instance in the female football arena.

Generally, Ghanaian attitudes toward gendered and sexual desires have been relaxed (Appiah 2008, 20), underpinned by the high value placed on fertility and reproduction. As reflected in the annual reports of the Basel Mission's first girls' boarding schools, pre-marital pregnancies were only problematic for the duration of a girl's pregnancy. Female missionaries observed that a "fallen girl" resumed respect by successfully giving birth and becoming a mother (Sill 2007; Dankwa 2009). Alongside this pro-natalist culture, sexual activity has been regarded as an integral part of life, and the lack of sexual satisfaction in marriage a reason for divorce. As I witnessed in several informal conversations, sexual relationships are considered vital for both men's 
and women's physical and mental health; adults who do not engage sexually are regarded with suspicion. During puberty, masturbation has been tacitly expected and approved of as a route toward approaching sexual maturity, especially among girls (Bleek 1976, 51, quoting McHardy 1968). In the same vein, children's "mock marriages" and "love games" used to be encouraged and were only restricted by taboos regarding pre-nubile pregnancies (Sarpong 1991). These ideas about sexual activity being healthy were challenged (but not replaced) by somatophobic moral norms introduced by pietistic missionaries from Scotland, Basel, and Bremen and underpinned by the Victorian British laws imposed on the Gold Coast in the colonial period.

Certainly, scholarly interest in practices of same-sex "friendship marriage" echoes lesbian and gay efforts to formalize same-sex relationships through the institution of marriage. In the global North, marriage has become a powerful means to recognize and solidify same-sex intimacies as more than just "friendships." The fact that my respondents of different backgrounds often referred to their lovers as siblings, mothers, or daughters alerted me to consider kinship theories. Recent studies of kinship have moved away from their structural-functionalist foundations to look at the social impact of technologies of assisted reproduction and practices of adoption (Strathern 1992; Franklin and McKinnon 2001), and forms of gay and lesbian kinship (Weston 1991; Moore 2011). These studies aim at dissolving the artificial boundaries not only between biological and social kinship, but also between reproductive and non-reproductive sexual relations and affiliations. They shift focus from an examination of "homosexual institutions" in relation to society, to an examination of how categories of kinship are produced through non-procreative relational ties and networks. So far, however, the study of queer kinship has tended to focus on the global North. By being attentive to the personal meanings women attach to their same-sex intimacies in Ghana, this book rethinks the study of kinship in two critical ways: it deals with queer notions of family-making that call into question the naturalness of the nuclear, heteronormative family, and combines this with an understanding of kinship as an active mode of relating that considers the everyday practices and "processes by which certain kinds of relationships are endowed with emotional power" (Carsten 2004, 161). In Cultures of Relatedness (2000) Janet Carsten introduces "relatedness," as an umbrella to compare a variety of ways of being related that challenge rigid, functionalist understandings of kinship in the South. 
The epistemological challenge of conceptualizing erotic intimacies, without assuming the centrality of sexual acts, has been broached by queer postcolonial scholars who took their cues from Foucault (1989). In a brief interview he demystifies "the revolutionary potential of homosexual sex" and advocates for "friendship as a way of life" (Gandhi 2006, 42). Foucault holds that ultimately homosexuality "disturbs people" and defies the dominant social order not as a way of having sex but as a way of inventing friendship and reimagining sociality $(1989,310)$. He considers same-sex friendship a mode of life that "can yield intense relations not resembling those that are institutionalized" and "run counter to the ideology of the sexual liberation movements" (Foucault 1989, 310-11). Several queer scholars engage this notion of friendship by emphasizing the subversive potential of non-normative, nonformalized bonds in forging alternative methods of alliance (Eng et al. 2005; Allen 2011) and undermining the (sexual) binaries that informed colonial epistemologies (Gandhi 2006). In Affective Communities Gandhi investigates the intersections of different traditions of resistance that short-circuit "the tedious generativity of power under modernity," that is "the power of power to reproduce" itself (Gandhi 2006, 41). Focusing on the intimate and the provisional within resistance - on elusive, homo(a)sexual friendships across differences and "inchoate" coalitions - rather than on the effectively organized revolutionary movements, Gandhi holds that anti-imperialism resides in its provisionality and in making "an unexpected 'gesture' of friendship toward all those on the other side of the fence" (Gandhi 2006, 189).

Against this background, friendship emerges as a useful entry for conceptualizing female intimacies that may span a variety of elusive attachments, for instance, when lesbian-feminist historians unearthed the passionate, effusive letters written by female "friends" in nineteenth-century Britain and North America. These letters, exchanged between well-to-do boarding school girls, wives, and widows (SmithRosenberg 1975; Faderman 1981; Vicinus 1984), but also between African-American working-class women (Hansen 1995), reveal the prevalence and intensity of "special" female friendships, but were mostly beyond the reach of sexual evidence. ${ }^{16}$ Interpreting these

16 However, in "No Kisses Is Like Youres," Karen Hansen examines the letters of two nineteenth-century African-American women that do include explicit references to eroticism (1995). 
infatuations as loving, "romantic friendships," Faderman has been critiqued for assuming the feminine and asexual nature of these bonds and thus covering up the possibility of female sexual aggression and masculinity (Halberstam 1998, 55-65). Although one might concede that female friendships have been romanticized, this focus opened up new perspectives on female intimacies that have been beyond the ostensibly sexual. For, as Biddy Martin holds, queer theory must attend not only to sensationalized, (gender) transgressive practices and sexual subcultures, but to the unspectacular, quiet fascinations and attachments "that do not necessarily reproduce, reflect, or line up neatly with political ideologies or oppositional movements" $(1996,14)$.

Utopian ideas of friendship and of coalition-building "across the fence" do not tell us how to do empirical research. Yet in refusing prescribed categories of difference, they point to the political potential of "inchoate" affiliations, of alternative ways of knowing, and, perhaps, of "freeing our imaginations." I therefore mobilize friendship as a conceptual tool to grasp the intense affective and corporal same-sex intimacies that do not speak their name but may nevertheless yield a basis for "a way of life" in Ghana or elsewhere.

\section{The Book}

The question of how to refer to the women whose life narratives I am studying is a challenging issue throughout this book. I avoid nouns such as supi or lesbian. Supi could be considered a specifically Ghanaian or even West African term. Nonetheless, it is important to resist using it generically. The transformation of supi into an overarching category would divest it of the shifting and contingent ways it has been used by the women I spoke to. Fixed and appropriated by academics, emic terms may turn meaningless for the people who coined them in the first place. Often I am referring to my primary respondents as "women who desire women," indicating that same-sex desire must not always imply a lived love relationship. This phrase reflects the fact that most of these women preferred to use verb constructions over nouns to describe themselves. Increasingly, however, I settled for "same-sex desiring women." The noun persisting in this phrase has been rejected not only by queer feminists who exposed "woman" as a heteropatriarchal construction (Butler 1990), but also by some African feminists who consider "woman" (as a category) an essentializing "western" invention 
(Oyéwùmí 1997). Given that my primary respondents, even those who transgressed gender boundaries, conceived of themselves as being of the "same sex" as their female lovers, and positioned themselves as women, I cannot do away with this noun. As Tinsley (2010) pointed out, for black working-class women in America, the claim to womanhood has been a powerful one in the face of colonial violence and chattel slavery that denied them a gender identity. In Ghana, where the legacy of the transatlantic slave trade in contemporary affairs is a less immediate one (despite the sizable numbers of freed Africans who returned to the shores of West Africa in the nineteenth century), womanhood is considered an achieved status. Claims to womanhood amount to a way of asserting humanness in the face of multiple post- and neocolonial subjugations. Therefore, the noun "woman" and its cognates are retained in the discourse that follows.

Chapter 1, "Tacit Erotic Intimacies and the Culture of Indirection," demonstrates how the neoliberal political and religious landscape has called sexuality into discourse. This is done by focusing on a key debate on homosexuality in Ghana, the debate over an "international homoconference" that was supposedly planned by Ghanaian gay activists and subsequently banned by the government. The global media coverage accounted neither for the fierce national media rivalries that conjured up the public outcry against said "homoconference" nor for the "pro-gay" voices that made themselves heard in the ensuing "homoconference" controversy. The chapter further looks at the role and activities of Ghana's first gay activist. In so doing, it lays out the basis for understanding how the women I interacted with resisted, resignified, or performed the international language of LGBT activism and human rights. Their reluctance to name and out themselves, a practice deemed essential to empowering homosexual subjects transnationally, and their subsequent "voicelessness" call for a close investigation of the language spoken within the informal networks of female friends and lovers.

Chapter 2, "Supi, Secrecy, and the Gift of Knowing," explores the genealogy of the polyvalent term supi. It distinguishes between the shifting public representations of supi and what I consider supi as a practice and an intimate same-sex discourse. Focusing on the recollections of two adult Akan women in particular, I examine the exchange of gifts and erotic intimacies, and the homosocial spaces and hierarchies by which supi practices are informed. In the narratives 
of these women, supi is framed as a learning experience and an introduction to the ways in which same-sex desire can be negotiated and celebrated in disguise. Invoked as a form of knowledge about how to conceive of female same-sex passion, while at the same time veiling it, supi amounts to a learning process. Despite the tacit and elusive character of the knowledge at stake, it is constitutive of the bonding networks of those respondents whom I consider "knowing women."

Chapter 3, "The One Who First Says 'I Love You': Dbaa Barima, Gender, and Erotic Subjectivity," focuses on the gendered language through which my respondents framed their same-sex relationships. It centers on a close reading of the life history and the everyday practices of Janet Aidoo. This young auto sprayer views herself as "the man" visà-vis her female lovers and claims to be the one who proposes love and initiates sex. In contrast to western notions of gender expression, her masculinity is not threatened by her quest to find a husband and have a child and thereby assert herself as an adult woman of her matrilineage. Rather it is her precarious economic reality that curtails her masculine ideals of being able to entertain and provide for a female lover. The "styles" and strategies Janet and two slightly older respondents deployed to make up for this deficiency require a careful look at the situationality of gender in West Africa, and at the Akan figure of the sbaa barima, or "manly woman." Often such claims to being "the king" or "the man" hinged on the question of who was older or erotically more experienced within a specific relationship. Thus intertwined with age and seniority, gender emerges as an inherently relational category.

Chapter 4, "Sugar Motherhood and the Collectivization of Love," examines motherhood as a metaphor for intimate relationships forged across considerable differences in social and economic status. It takes up from the mother-daughter terminology deployed by senior and junior female football players who consider each other "team mothers" and "team daughters" or praise themselves for having an established market woman as their "sugar mama." This requires a closer look at the world of female football, at the figure of the market woman, and at the materiality of love in Ghana. The chapter also touches on dynamics of exploitation and inequality within relationships that include an older "giver" and a younger "receiver" and examines how "team mothers" and "team daughters" may exchange not only material gifts, but also their girlfriends. Through practices such us providing 
each other with potential lovers, friendships are probed and "tested." These practices limit the togetherness of twosomes, while containing and binding them into a circular logic of female sociality. This paves the way for a focus on the reciprocities of everyday love and for an extended understanding of same-sex passion as a socializing process.

Chapter 5, “'Doing Everything Together': Siblinghood, Lovership, Incest, Family" attends to the ways in which intimate ties between women of the same age group are often framed in sibling terms. Drawing on the idealized closeness and harmony afforded to uterine sisters in Akan culture, a lover may be invoked as a sister in order to front a non-sexual connection. In an insider discourse, however, claims to being siblings "of the same blood" index forms of enduring attachment that have gone through passionate sexual and non-sexual stages. While some women emphasize romance and the "sharing of the body," everyday practices such as bathing, washing, and eating together over extended periods of time emerge as the crucial markers of sibling intimacies. Conversely, this chapter explores the incest considerations of those women who fell in love with a genealogical cousin - who is indeed considered a sibling according to Ghanaian kinship principles. Female same-sex lovers in Ghana who raise children together and name them after each other, who take care of each other's elders, and build joint networks that include husbands and genealogical kin, do not claim queer family status. Neither queer kinship theorists who tend to focus on the global North nor Africanist anthropologists dealing with "lineages" and "domestic groups" have considered these "arrangements" to be family. The chapter therefore contends that the practices of female lovers who appeal to each other as "siblings" are usefully examined from a (queer) family perspective. 


\section{Tacit Erotic Intimacies and the Culture of Indirection}

"Lesbians in Ghana?" The assumption that I was looking for "lesbians" in a place where "lesbianism" must be invisible, if it exists at all, loomed large when I described my research to friends and colleagues in Switzerland - even though I never claimed I was actually looking for "lesbians," but rather for women who love women and whose same-sex friendships included erotic intimacies. My conviction that such intimacies existed everywhere, with or without claims to a particular sexual orientation, was met with well-meant ethnocentric or heterosexist assertions about African women's pragmatic sexual lives, which are devoid of romantic, let alone same-sex, love. With the growing media attention on the homophobic statements of various African leaders, however, the existence of Ghanaian "lesbians" seemed more plausible and my colleagues' concerns shifted toward "the situation" these women must be facing in "homophobic Africa." My own interest in the regular lives and discursive practices of women who love women, whether or not they identify as lesbian, was thus challenged and inspired, in part, by the presumption that homosexuality was inherently "modern" and EuroAmerican, and that homophobia was backward and African.

This set of issues became even more poignant when aggressive anti-gay statements gained momentum in Ghana the year I embarked on fieldwork. In September 2006, a government minister announced the ban of a reputed "homoconference." The rumors surrounding this statement developed a life of their own. Though the "homoconference" turned out to be a media hoax and had never been planned, it gripped the public imagination and fueled a heated media and political debate. Controversial questions concerning "lesbianism" and "homosexualism"

Parts of this chapter were first published in Dankwa, Serena O. (2020). The Imagined Homoconference: 'Activistism' and the Politics of Indirection. In Rachel Spronk and Thomas Hendriks eds., Readings in Sexualities from Africa.

Bloomington: Indiana University Press, pp. 177-185 
or "gayism" have reverberated through Ghana's media landscape ever since. Arriving a few months after the controversy had cooled down, a welcome signboard in the airport's immigration section declared that "pedophiles and other sexual deviants" are not welcome in Ghana and that such "aberrant behavior" would be harshly punished. Compelled to "prove" the very existence of women who love women in Ghana, this new preoccupation with "sexual deviants" further complicated my quest to refute the one-dimensional portrayal of Africa as invariably homophobic.

This chapter traces some of the key discursive shifts that have taken place around homosexuality in Ghana and, in particular, that have marked a move away from a tacit historical acceptance of certain intimacies. Based on a discussion of the 2006 "homoconference" controversy, it begins by exploring how anti-gay ${ }^{2}$ rhetorics proliferate at the conjuncture of national and international church and media discourses. This is contextualized in relation to understandings of supi practices, historical speech norms and southern Ghanaian tenets of discretion and indirection in sexual matters. I then go on to explore the role of charismatic Christianity, the media, and the law in shaping and disciplining discourses of dissident sexuality in the country. Finally, using personal accounts of activists themselves, the chapter touches on the impacts of global gay rights discourses on local gender relations and the "silence" of same-sex desiring women at the early stages of Ghana's gay movement. My argument is that global LGBT initiatives have prioritized male homosexuality and activism in a way that renders illegible tacit forms of “queer" resistance, including Ghanaian women's culture of indirection.

Throughout the chapter, I draw out the connections and disconnections between public discourses on homosexuality and gay rights and

1 In 2006, the neologisms "gayism" and "homosexualism" revealed that sexual practice is not considered the basis for a (legitimate) social identity. Today, these terms are less common but used more explicitly in derogatory ways. Further, the ongoing distinction between homosexuality and lesbianism in public debates in Ghana, indicates that female same-sex intimacies are not simply subsumed under male ones. For the use of "gayism" in the Ghanaian press, see Emmanuel Akli, "Ghana: Anglicans flay gay bishops." The Chronicle, published online at http:// allafrica.com/stories/200707170593.html, July 17, 2007, accessed July 12, 2014; for the use of "homosexualism," see The Statesman, "Why should Kufuor peep into our bedrooms," Sept 7, 2006, republished on www.ghanaweb.com/G hanaHomePage/features/artikel.php?ID=110178, accessed February 6, 2014.

2 Avoiding the Euro-American psychological connotations of (homo)phobia, I tend to refer to the specific forces attacking Africans who are tagged as "lesbians" or "gays" as anti-gay forces. 
tacit ways of articulating, interpreting, and enacting same-sex passion. By contextualizing female same-sex intimacies in relation to historical notions of silence, gender relations, and speech norms in southern Ghanaian, this chapter responds to the call by queer African activists to interrupt the "single story of "African homophobia"" 3 (Ndashe 2013; Sika and Okech 2019), that is, a one-dimensional, ahistorical, and reductive account that ignores the shifting ways in which same-sex intimacies are configured, articulated, and understood in different African contexts.

\section{The Imagined "Homoconference"}

"Government would like to make it absolutely clear that it shall not permit the proposed conference of International Gays and Lesbians to take place anywhere in Ghana," Ghana News Agency announced on August 31, 2006. Apparently the then Minister of Information, Kwamena Bartels, signed a statement asserting that "Ghanaians were a unique people whose culture, morality and heritage totally abhorred homosexual and lesbian practices and any other form of unnatural sexual acts." 4 The ban was uttered a few days after Prince Kweku MacDonald appeared on Joy FM's "Super Morning Show." The popular radio talk show featured a panel discussion on HIV/AIDS education. Prince Kweku MacDonald, director of an initiative promoting sexual health and human rights education, was invited to speak about an HIV research survey he was working on with a group of peer educators. These young men gathered data about Men who have Sex with Men (MSM), provided safer sex information, and distributed condoms. Indicating plans to host a conference - "It is coming in September, we have received funding" (O'Mara 2007, 35) - and revealing himself as the "president" of the hitherto unknown Gay and Lesbian Association of Ghana (GALAG), Prince's on-air statements sparked adamant rumors about an impending homoconference.

3 See also: Keguro Macharia, "Homophobia in Africa is not a single story." The Guardian, opinion piece, May 26, 2010, published online at www.theguardian.com /commentisfree/2010/may/26/homophobia-africa-not-single-story, accessed February 22, 2018.

4 Ghana News Agency, "Govt bans International Homo Conference," September 1, 2006, republished on www.ghanaweb.com/GhanaHomePage/Ne wsArchive/artikel.php?ID=109849, accessed July 3, 2014. 
For weeks Prince MacDonald's name ${ }^{5}$ haunted newspapers and airwaves and came to stand for the perceived moral decay of Ghana's youth, its growing appetite for consumerist, cosmopolitan lifestyles, and its susceptibility to sexual immoralities. While Bartels was the highest ranked politician to make a public statement, local authorities and charismatic church leaders seized the opportunity to condemn homosexuality together with other sinful practices associated with sex tourism and the West's corrupting influence: commercial sex, cyber-sex, pornography, and pedophilia. Within a few days, the gay community over which Prince claimed his presidency had come to epitomize all sexual and social ills. Invoking culture, religion, or both, "homosexuals" were demonized and condemned. In the ensuing controversy, male same-sex intimacies came to be firmly associated with "gayism" and gay rights activism. The preoccupation with men reflects a shift toward the patriarchal Euro-American focus on male sexuality and a concern with public health agendas and with HIV/AIDS in particular. Nevertheless, for many of my female respondents, the controversy was a crucial reference point in conveying Ghanaian norms of respectability and in exemplifying why both male and female same-sex intimacies should remain "a silent trade" (Dankwa 2009) and not be discussed in the public arena.

$*$

Soon after the "homoconference" news broke, speculations arose that it had been contrived by the media. A columnist held that the oppositional NDC, the National Democratic Congress and its charismatic founding father and former president, Jerry J. Rawlings, who had himself in fact repeatedly been suspected of having male lovers, must be the driving force behind the conference. ${ }^{6}$ Some online postings

5 Prince MacDonald is the pseudonym of an activist whom I first met a few months prior to the "homoconference" controversy. He goes by different names. In its various spellings MacDonald is the name popularized through the media. In order to provide an index of the distance between the media portrayal of his activist persona and my own analysis on the basis of not only textual representations but of personal conversations; however, I will refer to him by his first pseudo-name, Prince.

6 John Arthur, “Thank You, Mr President," September 20, 2006, republished on www.ghanaweb.com/GhanaHomePage/features/artikel.php?ID=110818, accessed February 6, 2014. Whether or not there is any substance to these rumors, they match politically motivated portrayals of Rawlings as a corrupted "half-caste" (with a Scottish father) rather than a "full-blooded Ghanaian" 
opined that the NPP, the then ruling New Patriotic Party, had a vested interest in a media scandal, for it allowed them to deflect from more pressing media debates, such as corruption and cocaine dealings within government ranks; by banning a "homoconference" the NPP could reclaim their authority and popularity, some suspected. ${ }^{7}$ Besides comments discrediting Ghana's main oppositional parties - the NDC with its strong rural basis; the NPP, which is often accused of Akan elitism; and the CPP, the much smaller Nkrumahist Convention People's Party - others were critical of Ghana's endemic factionalism, pointing out that politicians on all sides were simply trying to score points. Instrumentalized by a range of social and political actors, the public imagination of a grand "homoconference" that needed to be condemned and overthrown, prompts a range of questions.

While the "banned homoconference" had its immediate oppressive effects, it marked the beginning of a noisy public debate. It became the catalyst for an ongoing outcry against the sexualization of the public sphere and the perceived threat of immoral practices attributed to the West. This explicit, sexualized discourse emerging through the global flows of a liberalized "mediascape" (Appadurai 1990) clashed with Ghanaian speech cultures with their tenets of politeness, indirection, and discretion. Thus, before sketching out the role that Ghana's press and political culture played in the public construction of a threatening "gay community," historical speech norms and ethnic stereotypes as well as the rise of charismatic Christianity in Ghana and the nomenclature of LGBT rights need to be considered.

\section{Verbal Discretion and Indirection}

"Silence" has been the chief metaphor through which postcolonial African sexuality has been broached by scholars and policymakers. Yet the claim that Africans shroud everything sexual in silence and secrecy is as reductionist as the stereotype of African hypersexuality. In her anthology Re-thinking Sexualities in Africa (2004), Signe Arnfred questions the conceptual usefulness of a "culture of silence" that is said

(Hasty 2005, 143) or as an immature "smallboy" who lacks the wisdom of a respectable African statesman (Hasty 2005, 13).

7 For example, the title of an online comment read "Because of the NPP cocain[sic] issue," reacting to the column "The conference that never was!" (also see footnote 12). 
to mark African societies. Instead she advocates for an identification of "different types of silences" (2004a, 73). As opposed to an oppressive silence, Arnfred argues that in Africa a culture of discretion has prevented discursive rather than sexual acts. It is this same discretion that impedes the public display of affection between opposite-sex partners and the explicit intergenerational talk about one's own or other people's sexual lives - especially if that life happens beyond marriage and reproduction - foreclosing the claims to sexuality as lifestyle and identity.

Southern Ghanaian culture of discretion and indirection concerning sexual matters is strongly associated with the Akan and the Twi language. The designation "Akan" refers to around twenty ethnolinguistic subgroups that occupy a large part of southern Ghana and speak mutually intelligible dialects. ${ }^{8}$ Despite internal rivalries, Ghanaian scholars hold that divergences in cultural practice among these subgroups are subtle and that "the uniformity of their cultural norms [is] beyond doubt" (Yankah 1995, 5). Among these norms are the linguistic practices that aim to contain dissent and the imperative of verbal indirection. Akan linguists refer to indirection as the practice of not directly addressing sensitive issues in order to ward off "face-threatening" interactions (Obeng 1994; Yankah 1995). Proverb, metaphor, euphemism, meandering, circumlocution, and other communicational strategies are used to save face and to verbalize "unspeakable utterances" (Obeng 1994, 60). Thus, "such delicate things as death, certain kinds of diseases, menstruation, as well as acts related to the sexual organs are not usually talked about directly" (Obeng 1994, 56). This is exemplified by the frequent use of apologetic and figurative expressions. ${ }^{9}$

In Speaking for the Chief (1995), Kwesi Yankah argues that Akan speakers recognize the social and performative power of the spoken word. This awareness that language shapes the world it is describing, informs verbal taboos and a preference for metaphoric speech (Yankah 1995, 51). Yankah traces the culture of indirect speech to oratory

8 Besides the official language of English, most Ghanaians understand a Twi dialect, the main written versions being Asante Twi, Akuapem Twi, and Fante. Baule is another acclaimed version of Akan that is spoken in eastern Ivory Coast.

9 Thus, directness is considered blunt and impolite, and personal questions are prefixed with a precautionary "please, excuse." The emphasis on verbal discretion as a form of fearful politeness is not unique to the Akan. It is comparable to the notion of kunya, meaning shame or modesty, described for the Hausa context of northern Nigeria for instance (Pierce 2007, 551). 
traditions at Akan courts, where chiefs and royals do not address their interlocutors directly but have an eloquent spokesperson, the Dkyeame, to skillfully address delicate and ambivalent matters. As royal orator the Jkyeame mediates potentially harmful words directed at the chief and uses proverbs to poetically embellish the chief's public speech acts. Similar figures are found among the Ga-Dangme, the Ewe, and other language groups in West Africa (Yankah 1995, 16).

My Ga-speaking respondents in Accra tended to invoke sex more explicitly than Twi speakers. They used direct verbs for "having sex," which were translated into English as "fucking" or "sexing." In Accra, tenuous stereotypes circulate about the sexual looseness of the Ga and the Fante, the second largest Akan group with its own formal literary dialect. Thus, regarding sexuality it seems that the norms of verbal indirection and their attending taboos are associated with the Asante, Ghana's dominant Akan subgroup, and with its royal court in particular. The perception that both the Ga and the Fante lack discretion and verbal indirection and are prone to exuberant, "shameless" behavior, such as cross-dressing and "homosexuality," has been attributed to their exposure to European merchants on the coast since the fifteenth century. This does not, however, allow for conclusions about a higher prevalence or acceptance of same-sex intimacies. If the $\mathrm{Ga}$ and the Fante are indeed sexually more outspoken than the Twi-speaking Akan, this may suggest that the moral requirement to conceal sexual desires are reduced among the less centralized (sub)groups of southern Ghana. Social historians have argued that the Asante kingdom in particular was obsessed with vertically controlling all forms of power, speech, and social formations (Akyeampong 1997; McCaskie 1981). It begs the question of whether the coastal groups south and east of the former Asante state are faced with less normative pressure to keep face and veil sociocultural transgressions than the Asante.

Generally, the fact that Akan norms elegantly contain ambiguities by not naming them, unsettles popular claims that "homosexuality" used to be absolutely "taboo" and "unspeakable." Arguably, homosexuality as a concept did not exist in precolonial Ghana. We cannot, however, assume that same-sex desires were never publicly discussed. In a sweeping comment on the "homoconference," philosopher Kwame Anthony Appiah countered Minister Bartels' claim that homosexuality "violently offends the culture, morality and heritage of the entire people of Ghana" $(2008,19)$. He reasoned that it is the obsession 
with everything sexual among "contemporary religious sects (Christian and Muslim) who are busy evangelizing in Africa" (Appiah 2008, 20-21) that has led to anxieties about same-sex intimacies. Appiah refers to the wave of charismatic Christianity emanating from the USA that began to sweep across the globe in the 1980s. This neo-Pentecostal type of Christianity has firmly taken root in Anglophone West Africa and has reconfigured Ghana's religious and sexual landscape.

\section{Charismatic Sexualization}

Ghana records the highest percentage of Christian inhabitants in West Africa (Kirschke and Kirschke-Schwartz 2013, 73), and its current religious climate is part of West Africa's third charismatic wave of Christian Pentecostalism (Asamoah-Gyadu 2005). This wave has affected the country's entire public life. While only 28.3 percent of Ghana's inhabitants identify as Pentecostal or charismatic Christians, ${ }^{10}$ a broad spectrum of charismatic thought impacts the practices of older mission churches as well as the activities of Islamic groups. Due to its close involvement in the media and entertainment sectors, charismatic thought also shapes Ghanaian culture, including its sexual culture.

Ghana's religious transformations are intertwined with broader economic and political developments (Gifford 2004; Shipley 2009). Identified with decolonization, pan-Africanism, and industrialization, Kwame Nkrumah, Africa's first independent president, has been celebrated as an icon of black pride. In Ghana he is referred to as osagyefo, the "redeemer." Nkrumah's overthrow in 1966 heralded years of political upheaval and public frustration over state corruption that led to the seizure of power by the angry young Flight Lieutenant Jerry J. Rawlings in 1981. At the onset of his military rule Rawlings was celebrated as "Junior Jesus" (Shipley 2009, 525). Rawlings passionately urged "Ghanaians to eschew foreign commodities and presented collective moral discipline as a solution to neocolonial economics" (Shipley 2009, 527). This included a series of military attacks on market women who were blamed for hoarding and using food shortages to make personal gains, thus hindering national development (see Chapter 4). By 1983, droughts, loss of cocoa crops, fuel shortages,

10 www.indexmundi.com/ghana/demographics_profile.html, accessed October 31, 2018. 
and the forced repatriation of one million Ghanaians from Nigeria led to the country's economic collapse. While nominally still espousing visions of African socialism, Rawlings' military regime instituted a Structural Adjustment Program. In line with the conditions stipulated by the World Bank and the International Monetary Fund, this program opened up Ghanaian markets to foreign capital and privatized state enterprises (Shipley 2009, 523-26). As Jesse Shipley argues, charismatic pastors and prophets offered the spiritual language to rationalize and justify the ensuing marketization.

The charismatic movement has been led by "men of God" who largely communicate in English and in a directive style that clashes with Akan notions of indirection. Styled as businessmen and entertainers, they emphasize prosperity, internationalism, transformation, and deliverance and their wealth is regarded as an indicator of their spiritual legitimacy. With its constant glorification of success, this new Christianity shifted attitudes toward individual wealth. By promoting individual success as a blessing from God the charismatic movement undermined "traditional culture" that prevented individuals from prospering much more conspicuously than their fellows, for instance, through witchcraft accusations, in order to keep communities united (Gifford 2004, 185). Moreover, the importance placed on monogamous marriage that promises middle-class respectability and upward mobility attracts young women; and while top leadership roles are difficult to attain, women play significant roles as ushers or evangelists (Gifford 2004).

The proliferation of private radio stations in the mid-1990s was crucial to the spread of charismatic Christianity in Ghana. Selfacclaimed prophets successfully increased their following by broadcasting sermons and healing people over the radio - the popularity of call-ins owing much to the fact that charismatic Christians who have been delivered from sickness or other "blockages" are obliged to testify in order to keep their healing (Gifford 2004, 34). Today, charismatics invest considerable resources into their TV presence. North American imports are televised in the name of local churches and Ghanaian and popular Nigerian pastors bring in videoed sermons. These televised services are as prominent as European football, "telenovelas" (South American soap operas) or the latest Nollywood films, and amount to a form of popular entertainment.

At least since the liberalization of the media, charismatic thought has dominated public opinion and contributed to the creation of 
a "sexualized public sphere": churches actually created "sexuality as a subject of public discourse, if only in its negation" (Bochow 2008, 424). In her ethnographic work on courtship, Astrid Bochow explored how Ghanaian youth are caught between global images about the normalcy of premarital sex and the churches' imperative to abstain. Indeed, public discussions chastise the supposedly rampant and unrestrained behavior of insatiable adolescents and booklets, such as "seXsense: The 'Sixth Sense' Missing from Today's Sex 'Miseducation'” (Perbi and Perbi 2007), advise upwardly mobile youth on how to contain their erotic thoughts and desires. Such admonishments reverberate in the stances of underemployed young men, for whom a costly marriage is out of reach. A jobless secondary school graduate, for instance, who made a virtue of his virginity by styling himself as an aspiring pastor kept interrogating me over my research. He claimed to be doing research himself into sexual transgressions in order to chastise sinful behavior, while embroiling others, often young women, in discussions about abstinence. Such practices echo Foucault's "repressive hypothesis," which considers the narratives generated in confessional boxes as more than just by-products of Victorian Europe. Rather, Foucault argues, concerns with sexual sin or pathology voiced in confession boxes or on psychiatric couches were constitutive of the obsession with and "the production of the truth about sex" $(1980,71)$. In Ghana, the rumors about the sexual scams of prophets (and married women who seek pastoral help over fertility problems and end up being impregnated by the pastor himself) and the public obsession with distinguishing between real and fake "men of God" (Shipley 2009, $457)$ alerted me to the productivity of talking sex and sin.

The various charismatic church formations have invoked same-sex desire in different ways. At one end of the spectrum are the jet-setting charismatics who preach positive thinking and emphasize selfconfidence and self-management as the key to spiritual progress and financial prosperity. Their take on sexuality centers on the establishment of nuclear family lives and pushes the heteronormative family ideal against both a "non-western" pro-natalist tradition and the "modern"-day technological "means of trying to bring children into the world" (Kisseado 2002, 13). Same-sex practices are construed as a stumbling block to the small family ideal that promises upward mobility to Ghana's aspiring middle classes. At the other end of the spectrum are the prophetic Pentecostal churches which specialize in 
delivering believers from diabolic forces. As Birgit Meyer explored (1999), the Pentecostal split from mission churches in the 1960s thrived on the quest to integrate local deities and witchcraft as real forces. In search of reasons for why believers do not receive their deserved prosperity, prophetic leaders detect water and snake spirits, reverse ancestral curses, and remove "blockages" that are frequently caused by family members (Gifford 2004, 105). Such demonic spirits are often sexualized and imagined as being transferred through sexual contact. ${ }^{11} \mathrm{Mami}$ Wata is one spirit that has been specifically associated with same-sex desire. Found in ocean myths throughout West and Central Africa (Drewal 2008), this mermaid spirit-figure is believed to "marry" and possess its male and female followers.

Some churches offer deliverance sessions to cast out Mami Wata and other spirits that may instill their followers with same-sex desires. Such collective healing sessions have been described as highly ambivalent or even productive in giving their participants a sense of not being "the only one" and fostering a discourse of same-sex desire (Rehnstrom 2001). The ambivalent role of pastoral care in same-sex intimacies dawned on me when Ameley Norkor told me about the "witch in the wig." Ameley, a petty trader in her late thirties, lived in a densely populated neighborhood, sharing one room with her husband, two children, and her girlfriend at the time. One day, her increasingly jealous girlfriend took Ameley to a pastor in the mountains who was supposed to solve the problems their relationship faced. Having spoken to them separately, the pastor conveyed to Ameley that a spell resided inside the hair extensions that her girlfriend had bought for her. The pastor asserted that once Ameley removed the artificial hair (which she did), her girlfriend would "confess" that she was bewitching Ameley's conjugal life - and sure enough the girlfriend did confess. Moreover, recurring rumors about priests inviting women to have sex with each other on their premises indicate the power historically associated with female sexuality (cf. Akyeampong 1997). Finally, an elderly woman in Accra vividly remembered a wedding between two market women performed by a Christian pastor. Others confirmed having heard or read about such a wedding in the early 1990s. Such instances indicate

11 Being a "point of least resistance," orgasms are said to lend themselves not only to the transmission of sexual diseases, but to the transfer of satanic spirits (Gifford 2004, 100) that need to be contained and combatted. 
that the charismatic wave has invoked same-sex desire not only in its negation. Nevertheless, I was surprised when a young journalist told me about a "lesbian" friend of hers who was taken to a female pastor by her father. Instead of the expected cure however, the pastor told her "we are all doing it, but you are doing it too openly."

Church activities are central to the everyday lives of a majority of Ghanaians, including the women I interviewed. Some were ambiguously attracted by the charismatic gospel and its emphasis on modern marriage and nuclear family lives. Others found the model of monogamous conjugality to be unfeasible and at odds with their own multi-layered erotic and economic lives. Generally, the clash between same-sex passions and heteronormative family structures produced contradictions that could only be contained by living a double life. There existed, however, noteworthy differences between those women who adhered to charismatic denominations and those who attended older mission churches. The worry about the negative impact of desiring the same sex seemed most bothering to those who were eager to be "uplifted" - not least socio-economically - through their allegiance to a charismatic prophet. Often, they seemed to worry less about celestial consequences than about the this-worldly repercussions of being branded as "lesbian," and, above all, the gossip damaging their reputation and livelihood. It seems that the Presbyterians and the Catholic churches have been more indirect in condemning same-sex practices and have conveyed that samesex desire is a vice no more sinful than other vices. Women who chose to belong to these long-standing denominations therefore tended to place "lesbianism" among other wrongs, such as alcoholism or adultery, and relativized sermons about the evils of same-sex desire by offering that the pastor's message is for "those who want to hear it." Stories about "fake," imperfect, and erring ministers who justified or strategically confessed their sexual wrongs, were readily taken up as a source of consolation or relieving laughter.

\section{Media, Gossip, and Public Space}

They "found people who will be talking on the radio as [if] they're organizing a conference," 12 Prince vented his scorn for Ghanaian journalists: they were "hungry" for sensational news and made up

12 Interview with Prince MacDonald at Accra, June 23, 2007. 
eyewitnesses to boost newspapers sales. Prince's comments about the Ghanaian lack of "journalistic ethical code" (IGLHRC 2006) call for a closer look at the "daily drama of national news" and the circulation of public commentary (Hasty 2005, 2).

While radio programs are always within earshot, newspapers remain the most visible sign of Ghana's vibrant news culture ever since they galvanized popular support for Ghana's independence in 1957. Just as the media was liberated from the colonial forces, however, Nkrumah nationalized the media and outlawed the private press as he consolidated his authority in a one-party political system. Reflecting the domination of a political class that mobilized market women and school-leavers, the state media worked toward unifying a range of ethnic and regional identities, political factions, and economic interests "through a superordinating narrative of national integration and development" (Hasty 2005, 11). Two decades later, Rawlings heavily relied on the media to bolster his charisma and legitimate his heavyhanded regime, while harassing the private press to near extinction. In line with the larger wave of democratization that swept across the continent, the newspaper licensing law was lifted only in 1991, the year before Rawlings held and won presidential elections. Reemerging after decades of abuse and repression, the private press instantly positioned itself as an angry oppositional source of discourse. Relying on sales and readership, however, underpaid journalists could not do without rumors and anonymous tips, and they came to be located at the interface of official and unofficial news. Prince's alleged conference announcement was hosted by Accra's first private radio station just before its ban was announced by the state-owned news agency under President John Kufuor, Rawlings' successor. By giving a platform to the "homoconference" rumors, journalists captured and heightened the anxieties over globalization and changing moralities in Ghanaian society.

I got a sense of the economy of such rumors in the town that emerged as site of a second smaller "homoconference." In this town, a restaurant owner indicated to one of his regulars who happened to be a journalist that "gay men" were congregating in the hall at the back of his premises. This happened the very day rumors started flying about Accra's international "homoconference." Not without pride, Mr. Badu, the restaurant owner, who has a vested interest in things sexual (for instance, he was planning to start a "transient hotel" with 
rooms to rent for the hour), conveyed to me that the years he had spent in Switzerland taught him to read men who are feminine, fashionable, and flirtatious, as homosexuals. Positioning himself as a worldly man, he told me that he admonished his customer not to publicize the matter. The customer, however, worked for a tabloid radio station that thrives on circulating controversial stories. Soon enough Mr. Badu's town was mentioned as the alleged second "homoconference" site. As I found out, Prince had indeed rented the hall at the back of Mr. Badu's restaurant to hold a meeting with a group of local peer educators, and, as Mr. Badu suggests, they tried to fake straightness by inviting "lady friends" as well. ${ }^{13}$

Implicated in a culture where journalism is recognized as an essentially political practice (Hasty 2005, 122), the fact that Joy FM hosted a "homosexual" was interpreted, not least, as a sign of journalistic complicity in making a supposedly un-Ghanaian practice worthy of national attention. As one of the few academic publications on the "homoconference" summarized: the "difficulty was in ensuring that the opponents of homosexuals did not see the media outlet as having a pro-homosexual viewpoint" (Essien and Aderinto 2009, 130).

\section{Gay and Anti-Gay Globalization}

In Ghana, as one of Africa's most stable democracies and fastest growing economies, the introduction of sex into public discourse has taken place in an increasingly neoliberal context where choice, entrepreneurialism, and individual consumer tastes are being valorized while the actual chances for prosperity have been reduced for the majority of Ghanaians (Shipley 2009, 524). This context is reflected in a growing weariness of AIDS and of the "NGOization" (Tsikata 2009) that contributed to the imagination of a "homoconference."

Scholars of queer globalization have pointed out that AIDS has played a crucial role in the process of tying male same-sex practices to international gay institutions, capital, and identities (Altman 2001). AIDS has become "a vehicle generating the global flow of developmental capital to previously marginal associations and challenging the

13 According to the representative of the regional HIV/AIDS program, this is a standard practice among the MSM peer workers, who try to suggest to the "general population" that they have girlfriends. Interview with M. A., June 1, 2007. 
moralising state" (Cohen 2005, 300). At this historical conjuncture of neoliberalism and AIDS, foreign investments in community-based organizations seemed to encourage the formation of Ghanaian sexual rights initiatives at a moment when Ghana's semi-public gay scene seemed to consist of a few late night bars in the heart of Accra. Frequented not least by MSM peer workers who had gone through British sponsored human rights trainings, by flamboyant black and white tourists, businessmen, and international aid professionals, this small bar scene is suggestive of an emerging cosmopolitan gay sphere, while also reflecting the uneven effects of a gendered and racialized (gay) globalization.

Steven Pierce tentatively suggested that the expansion of male samesex subcultures in Nigeria coincided with the oil boom (Pierce 2008). Similarly, reports on an anti-gay march in May 2010 in Ghana's oilrich Takoradi-Sekondi metropolitan area suggest a link between economic growth, moral anxieties about sexual behavior, and the growing visibility of urban same-sex cultures. Ever since the discovery of offshore oil reserves in 2007, the coastal twin-city has been tagged as the hub of moral decadence and venereal diseases. Undergirded by the vitriolic comments of a regional minister who called for "the arrest of all homosexuals," 14 Takoradi-Sekondi has seen protests of youth associations that fashion themselves as part of an "antigay and anti-lesbians [sic] movement." 15

As social historians have argued, sexual identities and politics flourished under particular socio-economic conditions that allowed for the creation of individual lifestyles and homosexual politics (Weeks 1977). This link between "capitalism and gay identity" (D'Emilio 1983; Drucker 1996) speaks to the ways in which the African debates are shaping through the antagonism between pro- and anti-gay movements (cf. Broqua 2012). However, the fact that many young Ghanaians are looking to metropolitan consumer styles while living under precarious economic circumstances suggests that it is not necessarily economic growth that encourages the emergence of gay and anti-gay identifications. Even in Niger - one of the poorest countries in the world - the

14 Star Observer, "World news: Ghana orders the arrest of all homosexuals," January 24, 2014, republished on www.ghanaweb.com/GhanaHomePage/Ne wsArchive/artikel.php?ID=110183, accessed July 21, 2011.

15 CitiFM online, "Thousands attend first Anti-Gay protests in Ghana," June 4, 2010, republished on www.ghanaweb.com/GhanaHomePage/NewsArchive/ar tikel.php?ID=183484, accessed February 6, 2014. 
global accessibility of gay-themed news and television series played a central role in the constitution of self-identified gay groups (Tocco 2008). Claims to new social identities that are amplified through their (anti-gay) opposition are tied up with regional and global media practices and audiences.

If the proliferation of radio call-in shows engaged non-literate audiences, electronic media extended the mediascape to diasporic Ghanaians. Ghanaweb, the most popular online news portal in Ghana and its diaspora, has been at the forefront in archiving and disseminating news and opinion pieces, including vitriolic anti-gay columns. In her analysis of Ghanaweb's coverage of news stories pertaining to homosexuality, Akua Gyamerah (2015) shows that the media functions not only as a site for mobilization against homosexuality and a stage for the attacks between competing political parties, but also as a key platform for a range of public discussions about "homosexuality." The three main themes emerging from these debates between 2011 and 2014 are "culture and tradition," "religious values and morals," and "anti-imperialism and sovereignty." The latter refers to the notion that economically and geopolitically powerful governments and organizations in the global North are "culturally imposing their beliefs and values regarding same-sex sexualities and sexual rights on African nations and that resistance to such acts are about sovereignty and anti-imperialism." Culture and tradition is deployed to condemn "homosexuals" but also to reject homophobic statements, for instance, when "pro-gay" columnists and professionals voice that "we [Ghanaians] don't use violence to solve a problem" (Gyamerah 2015). Certainly, the anonymity of cyberspace invites angry and violent comments that clash with historical Akan standards of verbal artistry, subtleness, and indirection.

A year after the "homoconference" debate, the mention of homosexuality on the radio shows that I overheard in battered taxis and trotros (minibuses) did not seem to invoke strong feelings in people one way or the other. Whether they were tired from work or of the topic, the commentary was benign or even humorous compared to the aggressive online postings. It seemed to be part of a culture in which all mishaps and transgressions fall prey to more or less benign mockery. At least in densely populated, impoverished compounds, neighbors are ridiculed in turn, and mockery amounts to an outlet that balances unspoken 
agreements by which everyone ought to ensure each other's survival. This culture of mockery, which does not usually tilt into physical violence, is missing from the abusive online voices that shout their threats anonymously and in English.

\section{Nature, Nurture, and the Law}

Several times during my research in southern Ghana, I heard cases of female same-sex lovers being taken to the police station. In one case I had the chance to talk to the police officer in charge a week after the incident. The case involved two young women: a stocky football player and her feminine lover, whose mother resided in Germany. Upon the mother's annual visit in Suakrom, she was enraged to find out that her daughter had rented and furnished a room for her "friend," the footballer. Eventually, however, it was not the mother, but the daughter's ex-girlfriend that got the police to arrest the two lovers. At the police station they were given a warning letter and a small release fine that another friend, a market trader, agreed to pay for them. Josephine, my research associate, suspected that the mother must have made sure her daughter did not receive a police record which would hamper a future visa application. Apparently, all the policeman kept saying during the interrogation, was, "why are you doing this to yourselves?" (aden na mo ha mo hõ?). ${ }^{16}$ Finally, he made the two women swear an oath that they would refrain from "seeing" (hu) and "playing" (di agoro) with each other. Yet, as the football player told me later, there was no Bible to swear on, which is why she considered the oath invalid.

The retelling of this incident took place one early evening just outside Suakrom market. As the market closed several female traders who knew the couple joined us and I asked them what exactly police officers accused them of in such cases. This prompted another football player to tell me that police officers would sometimes stop them on the street to tell them to stop playing their game, and that they were never brave enough to ask the officers what game they were referring to. She bragged that she herself would never agree to stop anything, unless she was told what game they were referring to.

16 All quotes in this paragraph are from a fieldnote written on January 20, 2008, at Suakrom. 
These instances reveal how verbal indirection works in different registers and in several directions. Policemen remain inexplicit when admonishing football-playing young women who openly flirt with each other. In turn, although it might seem obvious that a gendered or erotic "play" of sorts is taking place, the women can pretend not to understand and not to feel interpellated by what has not been explicitly articulated.

As I approached the policeman a week later, he was unwilling to remember the case of the footballer and her well-to-do lover (thus adding weight to the suspicion that the lover's mother might have bribed him). Indeed, the policeman showed little interest in female same-sex cases in general. He brushed my questions aside by arguing that there was no physical evidence when sexual acts occurred between two women, besides, they would always deny having had sex anyway. Instead, he took to talking about sex-related cases that do leave physical traces - such as domestic violence or defilement leading to teenage pregnancies. He also discussed, as already mentioned, the occult sexual crimes, in which men lose their genitals. Apparently, in one case a man came to the police station and showed the policeman that his genitals had disappeared (cf. Sackey 2006).

To date, there have only been a few scattered cases of "consenting adults" prosecuted based on the sodomy clause in Ghana's Criminal Code (1960) that reads:

(1) Whoever has unnatural carnal knowledge - (a) of any person of the age of sixteen years or over without his consent shall be guilty of a first degree felony and shall be liable on conviction to imprisonment for a term of not less than five years and not more than twenty-five years; or twenty-five years; or (b) of any person of sixteen years or over with his consent is guilty of a misdemeanour; or (c) of any animal is guilty of a misdemeanour. (2) Unnatural carnal knowledge is sexual intercourse with a person in an unnatural manner or with an animal. ${ }^{17}$

Inherited from British Common Law, variations of this wording are still found in the Penal Codes throughout the former British colonies interpreted as outlawing non-procreative "sodomitical" acts, the law is primarily associated with sexual acts involving a penis (Ottosson

17 Criminal Code of Ghana (1960), as amended to 2003, Act 29, Section 104.

Government of Ghana: Accra. 
2007). As the Ghanaian press has noted, the law is silent on female homosexuality. ${ }^{18}$ Unlike other former British colonies (most notably Uganda and Nigeria), there have not been no legal attempts to update or expand this law toward an inclusion of female same-sex acts.

Part (b) of the law treats consensual sexual acts as a misdemeanor punishable with up to three years of imprisonment. It is this part that is singled out by international human rights organizations (Søgaard 2013, 43). Despite the law's embedded limitations (how can an "unnatural" intimate act be proven if it involved consenting adults?), its existence has its symbolic effects. First, people have been prosecuted based on retrospective claims that an act was non-consensual as detailed in part (a) of the law. While Ghana's sodomy law is judicially merely symbolic (Søgaard 2013, 44), it acts as a deterrent and sanctions stigmatization and violent outbursts against gender non-conforming men and women whose sexuality is considered "deviant." ${ }^{19}$ Moreover, reports pertaining to the Greater Accra region show that not only men but also women who are seen as homosexuals easily fall victim to blackmailing and assaults by ex-lovers, landlords, family members, or police officers who seek to extort money, rape them, or refuse to investigate their cases (Kouassiaman and Armisen 2012).

Whenever my respondents mentioned situations in which they were taken to the police office because of a female lover, it had been by jealous friends, employers, or a lovers' family members who turned them in as a way to intimidate them. Although the cases were mostly settled peacefully (and in some cases the accused women were even able to pull personal strings within the police to reverse the accusation), these instances clearly signaled to the women that they ought to be highly discreet about their same-sex desires.

In 2010, the phrase "unnatural carnal knowledge" received some attention in a talk show on Ghana's CitiFM. The Accra-based radio station allowed law lecturer Ernest Kofi Abotsi to reflect on the flaws of the sodomy law's antiquated wording. "The word natural or

18 Daily Graphic, “Gays can be prosecuted," June 7, 2011, republished on www .ghanaweb.com/GhanaHomePage/NewsArchive/artikel.php?ID=210533, accessed February 6, 2014.

19 See also "No Choice but to Deny Who I Am" Violence and Discrimination against LGBT People in Ghana, www.hrw.org/report/2018/01/08/no-choicedeny-who-i-am/violence-and-discrimination-against-lgbt-people-ghana, accessed March 7, 2018. 
unnatural, it's a very difficult concept [...] What is natural is based on individual preference." ${ }^{20}$ Abotsi's musings about the interpretability of nature are in tune with a speech culture that values debates and disagreements about (proverbial) meanings, and treasures word plays with an openness to new interpretations (cf. Shipley 2013, 135). On air, Abotsi explains why he considers the sodomy clause "a legislative error":

Given the diverse and cosmopolitan nature of our society today, individuals' sexual orientation is something that is difficult to standardize [...] the understanding of what constitutes an unnatural sexual relationship is dependent on a person's own personal experiences, the person's own concept of what is good and bad and morality among others. So from a purely critical and academic point, I think it is difficult for me to be saying that our law prohibits homosexuality. ${ }^{21}$

Besides Abotsi, the human-rights lawyer and former minister of gender, children, and social protection Nana Oye Lithur strongly argued that homosexuality in Ghana is legal. In 2010 these lawyers belonged to a minority of intellectuals who publicly asserted themselves against the increasingly homophobic climate. In a public lecture, sociologist Akosua Adomako Ampofo declared that Ghana has "become a very intolerant nation" $(2011,8)$. She scrutinized the hypocrisy of many churches, she called upon humanist Christian values, and implored Ghanaians to be compassionate. More commonly, the sodomy clause has been discredited on the grounds that it is incompatible with the Ghanaian claim to be the regional hub of democracy that allows for the freedom of expression and, the fact that it is in tension with the constitutionally enshrined protection on the right to privacy. ${ }^{22}$

Public debates about the sodomy law were dominated not only by questions over the meaning of "unnatural carnal knowledge." At stake was the naturalness of homosexuality more generally; that is, the

20 CitiFM, "Ghana's laws do not prohibit homosexuality - Law lecturer.” Radio broadcast, interview with Ernest Kofi Abotsi, May 14, 2010, accessed September 9, 2019. www.ghanaweb.com/GhanaHomePage/NewsArchive/arti kel.php?ID=182046, accessed February 6, 2014

21 CitiFM, "Ghana's laws do not prohibit homosexuality - Law lecturer." Radio broadcast, interview with Ernest Kofi Abotsi, May 14, 2010, accessed September 9, 2019.

22 Stephen Atta Owusu, "Homosexuality in Ghana: An increasing growth in numbers," January 6, 2011, republished on www.ghanaweb.com/GhanaHom ePage/features/artikel.php?ID=200705, accessed January 14, 2014. 
question of whether one is homosexual by "nature" or by "nurture." Entrenched in the "nurture" argument - which states that one is not born but becomes a homosexual through the wrong kind of upbringing is the idea that homosexuality is a behavior that can be unlearnt. This conviction is espoused in columns by self-identified "ex-gay" Christians who write about their "recovery," fraught with "many relapses," and their arrival at a place where "things are pretty stable." 23

Relatedly, nature keeps being invoked in pseudo-scientific ways by well-traveled respectable citizens, such as the restaurant owner Mr. Badu. In an interview he told me that "these [homosexual] people should be helped rather than condemned, they should be allowed to meet. Not everybody is fortunate. Some are born with too much male hormone in their bodies." ${ }^{24}$ In opposition to widespread representations of the "passive" feminine men being the homosexual deviant, Mr. Badu seems to pathologize the testosterone-driven, hypermasculine partner, whose sexual encounters with men (and women) are not necessarily considered deviant. ${ }^{25}$ Similarly, Mahmood, a returnee from Europe who now spent a lot of time trading money inside Suakrom market and observing the market women, suggested that some individuals, including women, were simply more into having sex than others and were thus ready to seek it from different genders. Such arguments suggest that homosexuality in contemporary Ghana is not necessarily associated with deviance from expected gender roles, as queer historians have revealed for early twentieth-century Europe and North America (cf. Chauncey 1994), but with notions of a strong male or female sexual appetite.

Rather than attributing the above attitudes to some kind of sexual drive or "nature," Appiah points out the carnal-friendly Ghanaian take on sexual activity in general. During his childhood in Kumasi, Appiah overheard conversations in which sex was considered to be pleasurable in the first place, while the gender of a sexual partner seemed to be of secondary importance. In 2010, in an interview about his own

23 Sena Afari, "Homosexuality in Ghana: The great 'coming out,"” September 8, 2006, republished on www.ghanaweb.com/GhanaHomePage/features/artikel .php? ID=110253, accessed February 7, 2014.

24 Interview with Kwaku Badu at Suakrom, March 28, 2008.

25 Comparatively, in small-town South Africa, the fact that "big men" have male sexual partners has been regarded as an effect of their excessive masculinity, rather than a sign of their deviance (Reid 2007). 
experience of "coming out" in a British-Ghanaian Christian family, he held that not long ago, homosexuality was not something Ghanaians were preoccupied with at all. Appiah's casual optimism is based on his impression that "Ghanaians like sex too much to think that in the end it [homosexuality] is a bad thing." ${ }^{26}$ At the same time, however, current anti-gay debates heavily draw on and fuel moral anxieties over the sexualization of the public sphere and recently, charismatic initiatives such as the National Coalition for Proper Human Sexual Rights and Family Values aim at further criminalizing homosexuality. ${ }^{27}$

\section{Noisy Men and Silent Women?}

So far female voices have been marginal both to debates on the cultural imperialism of international LGBT organizations (Massad 2002, 361) and to my own discussion of what could be considered anti-gayism in Ghana. This omission results not only from a focus on published texts, but also warrants a look at the gender contestations at the heart of queer activist projects that seek to unify a range of male and female erotic subjectivities. I am less interested in the personal tensions that contributed to the difficulty of consolidating a gay and lesbian movement in Ghana at the time of my research, than in the ways in which women seemed to resist their incorporation into a joint activist voice and identity.

The story of Ghana's LGBTI activism began when Prince joined forces with his friend Stella Odamten. According to Stella, he asked her to accompany him to a youth and human rights training program sponsored by the British Council. Aimed "to empower young people to protect themselves from HIV and advocate for their gender and human rights," the series of workshops was held outside Accra, away from inquisitive friends and family. To unemployed young people who lacked the means to pursue any formal professional training, these foreign-sponsored educational training sessions amounted to more

26 Max Miller, "What was your experience like coming out of the closet in an evangelical family in Ghana?”, online interview with Kwame Anthony Appiah, recorded September 13, 2010, http://bigthink.com/videos/ghanaians-like-sextoo-much-to-be-homophobic, accessed February 13, 2017.

27 Mohammed Awal, "We'll campaign against any party who supports homosexuality - Group,” April 18, 2018 https://starrfmonline.com/2018/04/ well-campaign-against-any-party-who-supports-homosexuality-group, accessed November 2, 2018. 
than an interesting diversion. Listening to Stella's descriptions of the feedback rounds, role-play exercises, and other group bonding exercises through which they were encouraged to express and jot down their fears and desires on post-its and flipcharts, I was reminded of the "technologies of the self" (Foucault 1998) that the medical anthropologist Vinh-Kim Nguyen critically describes in The Republic of Therapy (2010). Nguyen observed the participatory workshops and "talking shops" attended by HIV/AIDS volunteer workers in neighboring Francophone West African countries (2010, 40). These training sessions incited participants to strive toward self-knowledge and selfimprovement and taught them how to structure confessional group conversations themselves. Additionally, the program Stella and Prince attended in Ghana provided them with opportunities to bond with each other and to put their transnational communication skills to the test. By engaging in these programs, they also established social relations with foreign experts - contacts that proved crucial for future mentoring and funding opportunities.

Stella was eager to apply the confessional technologies acquired in these training sessions to the WSW (Women Who Have Sex With Women) group Prince asked her to build up. With the help of her same-sex loving female cousin, Stella who had never had a female lover herself started to assemble the women of her neighborhood in Accra who she knew or suspected of being lovers. She began with icebreaker games, she informed the participants about human and sexual rights, and she encouraged them to talk and to develop a sense of a shared (lesbian) identity. Keeping these women's sustained interest and establishing a female group proved to be a harder challenge than Prince's task of recruiting young men and organizing their street activities as sexual health educators; HIV/AIDS gave the men a raison-d'être, some cash, and an identity as "peer workers." Meanwhile Prince managed to rent a tiny office space between shanty homes, beauty parlors, and makeshift auto body shops. Its premises a purple painted reefer container covered with corrugated iron sheets - was shared with a corner shop selling condensed milk, candy, cans, and biscuits; the wide gutter separating the container from the road was bridged by wooden planks. This space became the hub of the lively gatherings of the MSM peer workers. Stella on the other hand could only motivate WSW to join the monthly gatherings by offering them T'n'T (an allowance for "time and 
transportation"). She could not offer the prospects of a structured assignment as peer educators promoting safer sex.

Soon, Stella felt alienated and pushed out of the NGO that became the basis of GALAG, the Gay and Lesbian Association of Ghana. The two young women Prince hired to replace Stella faced similar difficulties in building GALAG's women's wing. Unlike Stella, both these secondary school graduates had been long involved with female lovers themselves and were interested in availing themselves of a lesbian activist identity. However, none of them was successful in mobilizing global sexual categories and consolidating a lesbian group. In the three or four women's gatherings organized at the office during my research period, women in their early twenties only attended if they were single and looking for potential lovers and if they had nothing better going on that afternoon. A few women in their thirties usually came late. Some only came for the soft drinks afterward, and older women were virtually absent and avoided being affiliated with Prince altogether, even prior to the bad publicity he received through the "homoconference" debate. Prince, however, believed that the female activists he tried to work with were not committed enough to make the project work. He felt that they liked going out with him and the peer workers, but that they expected him to pay for the drinks. While he complained about their passive and consumerist attitude, the two "lesbian" activists complained about Prince's secretiveness and suspected that he had more money at his hands than he would admit. Having signed his successful grant proposal for a "lesbian" source of funding, they felt he was not evenly sharing the funds that were meant to benefit specifically the women.

While GALAG's young women seemed to lack initiative and looked to Prince as their patron, it was even more difficult to involve older same-sex desiring women.

They don't even talk about it. They think so far as we [...] do what we want to do, and it's private (.) there is not need of any association, there is no need of any open coming out, there is not need to fight for acceptance, the- that is what the women will [say:] "so why are you making all this noise you rather expose us, we just want to be there quietly and enjoying what we do." 28

Interview with Prince MacDonald at Accra, June 23, 2007. 
These quiet woman lovers, many of them mothers and wives, expressed no interest in organizing themselves under the banner of sexual orientation. "They don't have the names for them[selves] and they don't have the- or they don't make all the noise we do- make these days about it. [S.D.: So how do you make the noise?] Yes, the noise, the noise means that, at least in every society there should be someone who will talk, and that's why we think we need to talk and we need to tell people we are there." Prince was aware that public claims to having "a sexuality" were a novel and "noisy" mode of seeking public recognition. The "we" he summoned refers to junior men who provided information about safer sex as sexual health activists and who dared to make themselves heard in radio shows and on online platforms. In terms of class and gender affiliations, these peer workers had little to lose as Prince put it. As children they were considered to be "kodjo besia," ${ }^{29}$ feminine boys, and as underemployed adults they struggle to produce a nuclear family home and could not easily project normative adult manhood. Normatively gendered same-sex desiring men, on the other hand, avoid the "noise" and the risk of losing their privacy. Besides, some of these masculine-presenting men are comfortable patrons and do not conceive of their sexual activities with subordinate (feminine) men, as same-sex acts altogether (cf. Reid 2007; Gaudio 2009, 132).

\section{Naming, Labeling, and (Dis)Identifying}

Prince's concern with names and naming points to the importance that labeling of same-sex practices has gained for activists, throughout the postcolony. On the one hand, compelled to counter homophobic narratives and argue for the historicity and the cultural authenticity of same-sex practices (Rao 2010), it can be crucial to be able to reveal indigenous words and in-group terms - such as the Akan term "saso"30

29 Though the term is not necessarily negative, it can be used to insult men who are considered to be too emotional or "soft" (cf. Geoffrion 2012, 11). Literally, "besia" is the Fante word for woman and Kodjo (Kodwo, or Kwadwo, in its different transliterations) is the day name given to every Monday-born boy. Although it is a Fante term it is chiefly employed among the Ga who used to be said to be particularly accepting of gender variant behavior.

30 According to William Banks, "mi saso" is translated as "my mate" or "my colleague" (2011, 265). Kwame E. Otu refers to Sassoi (plural) as "selfidentified, effeminate men," who see themselves as co-equals (Otu 2018). 
or "sasso" used among communities of male same-sex lovers (Banks 2011; Otu 2018). On the other hand, the success of "Third World" LGBT initiatives relies on the ability to fabricate coherent cultural translations and to be legible as "gay" by international LGBT organizations (Rao 2010,194). Thus, a cosmopolitan gay and lesbian lexicon is indispensable for attracting potential donors. Prince sweepingly attributed women's reticence to speak out and name themselves to the "double stigma" of being female and homosexual, that is, to the "more marginalized" position of lesbians in general. While this assessment echoes a global human and women's rights discourse, it does not reflect on the fact that women's marginalization from public discourse is reproduced by the HIV-inflected gender asymmetries that have shaped queer African associations. However, the unwillingness of many women to embrace the label lesbian or to coin specific Ghanaian names to politicize their intimacies cannot be reduced to universalizing notions of lesbian invisibility and women's oppression.

Most of the women I interviewed refused to categorize themselves based on their sexual intimacies and "disidentified" (Muñoz 1999) with both globally circulating and local terms labeling same-sex desires. Ameley Norkor, for instance, a wife and mother in her thirties in Accra, took issue with the act of attaching any fixed name to what she sometimes referred to as the "friendship thing." I asked Ameley about the origins of the term supi - a term often used to denote girls' same-sex practices - that I had also heard used among adult woman lovers in Accra. Ameley replied that she does not know "where the word came from." Instead she asserted that as a child, when she started "doing it, it didn't have a name, but now it has gotten a name [...] to the extent that when" a female friend visits you on a regular basis, "they'll ask her questions [...] because I'm now notorious for this, and immediately they see me with someone, then it means that! They have painted me black." ${ }^{31}$ Rather than challenging the public attitudes that condemn women who (seem to) pursue their same-sex desire, Ameley pragmatically held its naming, and the negativity that goes along with terms such as supi, responsible for the practice's bad reputation. Although she did distinguish between sexual and non-sexual female intimacies, she considered every woman a potential lover and deemed

31 All quotes within this paragraph are taken from an interview with Ameley Norkor at Accra, April 4, 2007. 
it unnecessary to produce nominal distinctions between different types of female intimacies.

Similarly, Okaile Allotey, a vocal woman in her mid-twenties, rejected homosexual and sexualizing labels. She was part of "Giving Lesbians a Voice," the group Stella enthusiastically formed, while working with Prince. At the first gathering, a dance party that attracted a significant number of festively dressed women, Okaile gave the welcome address and renamed the group "Giving Women a Voice." Stella's report on that gathering states that "we believe using the normal term women here will help other lesbians who are shy of us and are not comfortable hearing the name mentioned, to also join and be part of our program." ${ }^{32}$ Discussing the possibility of reforming the group with my support, Okaile kept correcting Stella whenever she referred to the group as lesbian. "I don't hate the word but it's common, it's too cheap," ${ }^{33}$ Okaile told me. The term supi carries similar connotations. "Everybody knows what supi means, everybody knows what is lesbian, but when I say 'girls in the wood' you will crack your mind a little, 'girls in the wood, what is the meaning of it?' You crack your mind a little before you will catch up. Do you [get] what I want to say? So I prefer that." Okaile took pleasure in coining her own phrases such as "girls in the wood." For, in the remoteness of the deep woods, with no man around, she argued, "anything can happen. You can't stay in a room when you are four or five girls for a year without anything. You will be feeling something so you (claps her hands) join things together." Yet, neither the imperative to be indirect nor her allusions to same-sex desire as situational ${ }^{34}$ stopped Okaile from employing the term lesbian on occasion to talk about herself and her street-wise female mates.

As the political scientist Nivedita Menon reminds us, terms such as lesbian or bisexual circulate in different ways and take on ever new meanings in India and other contexts where English is not the dominant language $(2007,15)$. Stella, for instance, referred to the masculine styled

32 Report on the group meeting in Accra on August 20, 2005, by Stella Odamten.

33 All quotes within this paragraph are taken from an interview with Okaile Allotey at Accra, May 25, 2007.

34 The notion of "situational homosexuality" has been critiqued on the grounds that it aims to set apart same-sex practices in single-sex spaces such as prisons, sailing boats, psychiatric wards, or boarding houses, from seemingly more authentic forms of "true" homosexuality, neglecting that all forms of sexuality are situated and given meaning by a specific context (Kunzel 2002, 253-54). 
women of her group as "lesbians," and to the more feminine ones as "bisexuals," regardless of their actual sexual lives, thus making gender rather than sexuality the reference point. Similarly, Okaile did not call all women who opted for a female lover "lesbians." Indeed, in her usage "lesbian" emerged as a shorthand only for those women who were particularly committed to initiating and actively pursuing same-sex relationships against all odds. When it came to forming a group, however, she deemed all terms associated with sexual practice too "obvious." One of the expressions that circulated among Okaile's friends for a few months was "the-value-is-the-same." This slogan was introduced by the Ghanaian government in July 2007 to convey to the public how the currency change worked: 10,000 old cedis were replaced by one new GHC (Ghana Cedi), the value remaining the same. Among Okaile's friends "the-value-is-the-same" became an in-group salute that indexed a doubly understood sameness: the equivalence of same- and opposite-sex passion, and perhaps their "sameness" and solidarity as what I consider, knowing women - that is, women knowing how to value and pursue intimate same-sex desires. Rather than investing in fixing or politicizing a term, Okaile revels in the polysemy of the provisional names she generates. At the women's party we eventually held in Stella's family compound, Okaile announced that we were starting a "ladies social club." Although she did not use the term "lesbian," it seemed to be understood among the guests that the group would serve as a socializing platform for "knowing women" whose aim was to connect with potential female lovers. Despite her interest in organizing group activities that would empower same-sex desiring women socially and economically, it did not occur to Okaile to organize around a particular term or to collaborate with male sexual rights activists.

Stella, on the other hand, who had never had a female lover, proudly identified as a lesbian rights activist and women's group facilitator and readily embraced a cosmopolitan LGBT lexicon. Her failed fundraising efforts for the "ladies social club," however, made me realize to what extent the international field of LGBT activism calls for the performance of a lesbian self. In fact, I encouraged Stella to write a funding proposal to the representatives of a Swiss lesbian organization whom she had briefly met while working with Prince. I advised her to prioritize her concern with the human rights of women in her locale who live an effectively "bisexual" life, without, however, pretending to be a lesbian herself. Her carefully composed one-page proposal letter 
was rejected on the basis that Stella's formulations seemed to be "intentionally vague" and that the organization could only support clear-cut "lesbian projects." ${ }^{35}$ Had I advised Stella to strategically present herself as a lesbian, her proposal might have been successful. It seems that internationally the performance of a homosexual identity is more coherent and even more legible than the realities of those who would qualify as lesbians based on their sexual practices but have not learned to narrate their desires in terms of having a "sexual identity."

One of the benefits of working with Prince was the access Stella gained to Euro-American gay volunteers and lesbian travelers and to the lesbian cultural materials (brochures, books, DVDs) they brought. One such overseas foreigner was Latasha Ray, a retired AfricanCanadian who had based herself in Accra for a few years. She supported Stella's efforts of building up a lesbian women's group by hosting two or three meetings at her own apartment in an upscale neighborhood of Accra. As Stella's reports show, these "programs" were "exciting, educational and full of discussions"; social and confessional games were played, and Latasha distributed copies of black lesbian-feminist magazines and spoke about topics such as HIV and lesbian feminism. ${ }^{36}$ To what extent these parties succeeded in raising lesbian consciousness or a sense of being part of a transnational lesbian community is difficult to evaluate. Latasha herself confided to me that she felt her efforts made little impact. A few weeks before returning to Canada, she bitterly complained about Ghana's lack of "real lesbians." Based on her own romantic involvement with two young women, she concluded that Ghanaian women did not mind getting married. And although they practiced same-sex love with much fervor, they lacked a sense of lesbian awareness.

Stella did not give up easily on her vision of teaching women about their rights and pursuing her own professional identity as a group facilitator. In one of her reports she noted that Latasha shared her international experience in the field of "Women Activistism [sic]" with the "sisters" present at the meeting. ${ }^{37}$ Surely, Stella meant activism. Notwithstanding, the emphasis her misspelling puts on the figure

35 Personal email communication between the author and Cordelia Oppliger, December 12, 2007.

36 Report on the women's group meeting of October 8, 2005, by Stella Odamten.

37 Report on the women's group meeting of September 11, 2005, by Stella Odamten. 
of the activist reflects Stella's aspirations to acquire an activist identity. Her formulation attests to an understanding of activism as a selfperpetuating activity that teases out knowledge through "technologies of the self." Whatever the activist-ing is supposed to achieve in the world at large and among queer collectivities and the state, it provides its bearer - the group-facilitating activist herself - with the basis for a self-identity. Stella's unintentional slip of the tongue seems to sum up the "noise" of charismatic preaching, radio interviews, online comments, legal debates, and gay activist struggles within which the process of defining female same-sex love (if indeed that is a destiny) is incomplete.

\section{Conclusion: Tacitness Meets “Activistism”}

A decade after Ghana's democratization and media liberalization, the "homoconference" became the epitome of the "noise" attributed to the intersecting voices of sensational journalists and sexual rights activists. Indeed, it marked the starting point of an ongoing debate that speaks to anxieties about rapid economic, political, and social changes. Triggered by the exposé of a self-identified gay man, the media controversy hinted at the public concerns over a growing number of vocal young men who speak the language of human rights and are feared for challenging existing power relations. What made the "homoconference" debate particularly poignant to my respondents was that it brought terms like "gay" and "lesbian" into circulation. Furthermore, the homo/hetero binarism (and hence the notion that homosexual and heterosexual persons constitute two essentially different types of persons) gained currency. The scarcity of female voices within these media debates indicates that a textual focus on "homosexuality" and on state sanctioned forms of "homophobia" amplifies the male voices of journalists, online commentators, politicians, and activists who are able to make themselves heard. The "noise" they produce drowns out the indirect language and the tacit politics of working-class women who desire women but whose passions are bound to remain elusive.

The question of visibility and the tensions between male and female African LGBTI activists indicated in this chapter, hint not only a reproduction of gendered asymmetries, but are tied in with global funding streams. Analyzing the underrepresentation of women's queer organizations in Nairobi, Kaitlin Dearham suggests that men's greater 
willingness to "come out" speaks of women's economic marginalization, their care obligations as young mothers, and to the donor imperatives of focusing on HIV/AIDS (Dearham 2013, 189). As Varyanne Sika and Awino Okech further argue, the funding necessary for movement building rarely allows for "intersectional programming" and donor focus on "single issues" leads to competition between groups $(2019,29)$. Certainly, when sexual health is at stake, the outcomes of supporting same-sex desiring men appear to be more straightforward, whereas women's sexuality seems to be complicated by gender issues. This, of course, reflects the patriarchal perceptions of women's issues as particular and less generic than those of men.

Ghana's charismatic culture with its threats of spiritual fakeness (Shipley 2009) and its desire to uncover the hidden have marshaled the sexualization of the public sphere. While the recent processes of calling (homo)sexuality into discourse echoe Foucault's repressive thesis, it has to be remembered that sodomy laws and homosexual theories had long traveled through missionary and colonial interventions. The question is why and how they have become such an imposing force during the last two decades. A comparative analysis of the discourses on homosexuality in Cameroon, Senegal, Uganda, and South Africa shows markedly different trajectories in the ways in which anti-gay rhetorics are unfolding in different postcolonial African countries (Awondo, Geschiere and Reid 2012; Ndashe 2013). The differences hinge on regional political economies, on diverging sexual histories of the former colonial powers (unlike Britain, France did not impose sodomy laws for instance), the specific ways in which the figure of the "homosexual" is invoked as culturally foreign, or the role of Christian and Muslim religious authorities in construing and denouncing "gayism." These dynamics and the positive national legal and policy trends currently unfolding tend to be obscured by the "single story of "African homophobia"” (Ndashe 2013).

One factor contributing to the reservations of Ghanaian workingclass women against the "noise" is their general reluctance to commit to set identities, sexual or otherwise. Many of the women I interacted with went by different personal names, had several mobile phone numbers (without necessarily owning their own phone), pursued various informal jobs, and had different lovers in different locations. The idea of adhering to one fixed social or political identity did not occur to their postcolonial subject positions (cf. Mbembe 2001). It seemed to be 
unaffordable and undesirable. In light of the culture of verbal indirection where overt sexual talk is considered blunt, even the younger women who used the term lesbian for themselves were reluctant to side with gay men and engage in visible lesbian rights activism. Their tacitness and tendency to shy away from or disidentify with overt sexual politics, however, did not stop these women from being fascinated with lesbian sex gadgets and cultural materials, nor from the lifestyles and identities transported by overseas volunteers, tourists, and activists, or by researchers like myself.

To Stella Odamten, "activistism" and her identification as (an albeit straight) lesbian activist held the temporary hope of making a living by doing what she felt she was best at: teaching human rights, facilitating groups of women, and imparting to them lesbian "technologies of the self" (Foucault 1998). These technologies profess to detangle and channel unpredictable desires into clear-cut identities. Given Ghanaian cultural norms of discretion and indirection, the quest to become visible (and marketable) on a global gay map is complicated for both male and female activists. By rejecting the project of classifying themselves in sexual terms, however, the women I encountered have been even less legible as "queer" subjects to LGBT funding bodies than men. Their same-sex passions, which are not nearly as silent as they seem to be, are the subject of the following chapters. 


\section{Supi, Secrecy, and the Gift of Knowing}

It is common in schools for a female or girl to call another girl her "girl friend," "dear," "girl lover" or "supi." This type of girl friend is different from the normal friendship between girls. They behave like a man and a woman. They fondle each other till they experience a special sensation. Those two friends have strong emotional attachment. They write love letters to each other and exchange gifts. They can cry when one is parting as if they are husband and wife. It is common for two girls to fight over a girl friend, a girl lover or supi in schools. Junior girls are usually taken as supi by senior girls.

(Adjabeng 1996, 41)

The advice booklet that first spelled out the term supi to me lay among a pile of school-books in an upper middle-class home in Accra. It belonged to a young boarding-school girl. Teenage Sex and Love, by well-known Christian writer and educator Joshua Adjabeng, advises young women about the dangers of life and school life in particular. While deterring readers from drugs, premarital sex, and abortion, a paragraph titled "Lesbians or "Supi" warns against a certain "type" of friendship that is "common" but not "normal." Though Adjabeng compares this type of intimacy to that of "a man and a woman," he is only explicit about the sexual dimension when admonishing the younger girl who, "is happy because the senior protects her. She also thinks her senior loves her so much. She realizes the devil's trick when she has become emotionally and sexually attached to the partner." Apart from the reference to the "devil's trick," Adjabeng's statement corresponds with the remarks of my own respondents, who emphasized the significance of exchanging gifts and letters as the key feature of having a supi during girlhood. Unlike Adjabeng and other Christian authors, my respondents did not necessarily equate supi with lesbianism, but rather with the close bonds between young girls, whether or not their intimacies included sexual practices. 
When exploring the shifting meanings and valences of supi in Ghana, it is crucial to distinguish between the term supi as it is discussed in public debates and supi as an intimate discourse. While in public debates supi is strongly associated with boarding school and college girls, an understanding of supi as a bonding practice between girls and women is by no means limited to secondary schools. To avoid conflating the public register and the intimate lived realities of my respondents - and indeed overusing the term supi, given that some of my respondents were unfamiliar with or disliked the term - I will deploy the phrase girlfriendship (Gaudio 2009) to refer specifically to erotic female friendships in youthful single-sex contexts. In this way, this chapter documents the gap between supi as a public discourse and supi as an intimate practice of knowing by outlining the shifting media representations of supi and by examining the affective and subjective meanings generated within girlfriendships themselves.

As this chapter suggests, supi, understood as a practice of discovering and entrenching same-sex desire through the exchange of gifts, has been integral to female bonding in a variety of colonial, postcolonial, and possibly precolonial homosocial institutions in Ghana. In the first part of the chapter, I trace public representations of supi through the accounts of four elderly women who attended the first Ghanaian girls' schools in the 1930s. Their recollections evoke the ways in which boarding-school crushes and intimacies were framed in mother-child terms in Victorian England (Vicinus 1984), in North America (SmithRosenberg 1975), and in black South Africa (Blacking 1978), respectively. Through an analysis of selected newspaper articles, video-films, market pamphlets, and religious publications in Ghana, I then assess the ways in which supi has been increasingly associated with lesbianism. Finally, the discourse about the "un-Africanness" of same-sex desire warrants a more detailed examination of the term's genealogy and its possible historical link to Ghana's Asafo companies.

In the second part of the chapter, I explore supi as an intimate discourse emerging from the life narratives of Adwoa Boateng and Ma'Abena Oppong in Suakrom. Both women formed their first girlfriendships during secondary school and both underscored that the bathhouse and other hideouts served as important spaces to express and evaluate same-sex attraction. Their emphasis on secrecy, on learning how to decipher the amorous promises of gift exchange, and on being taught how to "feel" for a supi, speaks to the intensity, the joys, 
and the anxieties of first-time (same-sex) love at school and elsewhere. On the one hand, the expectation of exchanging gifts was at the heart of their girlfriendships, which calls for a critical engagement with theories of the gift. On the other hand, a manifest language of being "ushered" into desiring a female friend and "learning" how to go about erotic passion prompts the question about the extent to which first-time supi love amount to a kind of initiation.

This chapter argues that youthful same-sex experiences imply not only a process of learning how to exchange gifts, letters, and secrecies, but also an understanding that same-sex practice constitutes an acquired form of knowledge that thrives on its tacit circulation. This knowledge of the affective depth and intensity possible between girls shapes the erotic subjectivities of women who continue to have samesex lovers as adults. I thus refer to those adult women who are articulate about their same-sex practices and emphasize the significance of female same-sex passion as "knowing women."

\section{From Supi Girlfriendship to Supi-Supi Lesbianism}

Since the mid-1990s, the term supi has been widely discussed and increasingly connected with lesbianism in popular weeklies and in Ghanaian and Nigerian video films. The sexualization and demonization of the term makes tracing its origins difficult. In order to sketch out its genealogy, I rely on oral history, notably informal conversations and taped interviews with four elderly secondary school graduates. In addition to the scarce written references to supi, these oral sources offer important insights into the everyday meanings ascribed to supi within secondary schools during colonial and postcolonial eras.

\section{Remembering Supi Girlfriendships}

Though I overheard the term supi on Accra's Makola Market among bantering female traders with little formal education, the earliest written evidence of supi I came across situated the term in the boarding school context (Mensah ca. 1970; Warren 1975). The first girls' secondary schools in Ghana were established in Cape Coast, some eighty miles west of Accra. As one of the first outposts of European trading activities and the center of British colonial administration in the Gold Coast between 1700 and 1877, Cape Coast has long been a hub for 
school education (Osei 2009, 11). It is home to some of the oldest and most prestigious secondary schools, including Wesley Girls High School, which was started by the wife of a Wesleyan Methodist in 1835 (Graham 1976, 28). As my father E. Akurang Dankwa recalled, he frequently heard Wesleyan Methodist Girls refer to each other as supi, when he attended a neighboring boys secondary school in the 1950s. ${ }^{1}$ According to Irene Bonsu, a recent "Wesley Girl," the term supi seems to be outdated, instead her friends spoke about having a "girling," or used the English-Twi phrase "me tu girl" (literally: "I dug up a girl”) to brag about a new girlfriend. While Irene did not involve herself in girlfriendships, she was aware of the amorous dimension these bonds could have. She explained that supi girlfriends may wash each other's dishes, write love notes at the end of the day, and "tuck" each other "under" before sleeping - meaning, one tucks the mosquito net under a girlfriend's dormitory mattress, thereby building a private tent. ${ }^{2}$

Two of the four elderly ladies whose life histories we recorded were schooled in Cape Coast, including the queen-mother of Suakrom. Queen-mother is the Ghanaian English term for the sbaapanyin, the female elder who advises and may instruct the chief, to whom she is the symbolic mother. ${ }^{3}$ In charge of affairs pertaining to girls and women in her locale, she also arbitrates and organizes educational and recreational gatherings for girls and women. We met the frail seventy-threeyear-old lady at a Sunday dance she hosted for the women of her locality, an event she used to stage more regularly, when her health was better. In the 1940s she attended a Roman Catholic Girls School in Cape Coast and befriended one of her tutors. Asked whether she had a supi at secondary school, she exclaimed that she had "plenty," before specifying, "yes, I had a supi. She was my teacher. She liked me so much, she was caring and I also liked her." 4 The queen-mother too referenced gift exchange as a sign of friendship that transcended the classroom. "Even sometimes, when you're returning to school, you buy

1 Personal Conversation with Edward Akurang Dankwa, February 2007.

2 Personal Conversation with Irene Bonsu, April 2009.

3 The queen-mother, the translation of the Twi term shemaa, is usually not the shene's (chief's) uterine mother, but the elder who occupies the female stool (symbolizing political office) and thus the highest position in the female Akan hierarchy.

4 Fieldnote on a conversation with the queen-mother at Suakrom, May 23, 2008. 
something from home, and you go and give it to her." Her gifts included oranges, biscuits, toffees, or tins of sardine, but she also shared provisions and money received from her uncle, a chief who was in charge of her education. Yet even in the 1940s, Senior Secondary School was not only attended by elite daughters - such as daughters of chiefs, pastors, traders, doctors or lawyers - but also by girls who were funded through a missionary house or one of the colonial trading companies for whom their fathers labored. Since boarding schools are attended by students from all strata of society, the practices of sharing and trading gifts and provisions that are integral to boarding school life could be understood as a mode of redistribution.

The eldest respondent, an eighty-three-year-old seamstress in Suakrom, fondly remembered her time at a girls' boarding school in the 1930s. As the daughter of a police officer she was sent to Krobo Girls School, run by Scottish Mission Sisters. After completing her schooling, she went through vocational training with Afro-European elite women at the Castle School in Accra and became a seamstress. Whenever I visited the retired seamstress together with my research associate Josephine, she enjoyed telling us anecdotes about the missionary sisters and boarding school life. On one of these visits she showed us a picture of herself and her best friend on confirmation day. They spent holidays together and, she added, whatever the two of them received from home, they shared. In the picture the two of them are wearing dresses made from the same material by the girlfriend's mother. Only two weeks later, when I dared to ask if she used to have a supi, she happily told us that it was the girl in the confirmation picture. ${ }^{5}$

My inquiries with respectable female elders were complicated by the fact that the word supi is increasingly connected to sexual practice. Initially, both the seamstress and the queen-mother seemed happy to be reminded of their supi. Once they realized that I knew of the term's erotic connotations today, however, they refused to go into more detail. Instead they strongly reacted against my allusions to the possibility of erotic intimacy and distanced themselves, or they reiterated normative statements about the sexualization of today's youth. During

5 This paragraph relies on fieldnotes on conversations with Nana Yaa,

December 2007. 
their school years, supi was understood as a specifically close form of friendship between educated girls, in the then new boarding school environment. These girls comforted and protected, fought and admired each other, far away from siblings and family networks. If this closeness did lend itself to erotic feelings, they were not interpreted as inherently sexual, but considered part of a larger spectrum of girls' boarding school intimacies. The female elders we interviewed condemned the possibility of a sexual dimension to supi. Their reactions suggested that they were aware that schoolgirls' attachments could lend themselves to erotic or sexual play. They seemed to worry less about the bodily intimacies themselves, but about the reduction of supi to sexual practice.

One elderly assemblywoman whom we interviewed was outspoken about the fact that female same-sex intimacies are by no means limited to boarding school. The assemblywoman was actively involved in communal politics and in developing her neighborhood in Suakrom. She also spent a lot of time in the market with her friends, including my respondent Adwoa Boateng. The assemblywoman who was aware of and tacitly complicit in her friends' same-sex intimacies, claimed that supi has undergone a change in prevalence. "It was there," she asserted, remembering the time she attended secondary school in the 1960s, but "it was not as much as these days. In our time I know supi will be your best friend. You will sleep with her, you will do everything with her, but I don't think it comes to this stage of going to sleep with them." Today's "going to sleep," as she explained, implies that women "will get their feelings [...] their satisfaction through their playing," whereby one of them is "performing the rite as the man [...] fingering or doing the act of a man" and buying "provisions for the other woman." ${ }^{6}$ Like Adjabeng in the opening quote, the assemblywoman made an analogy with male-female intimacy to convey that supi can imply sexual fulfilment as well as material support. As such, she believes supi bonds can cross over from youth into adult life and continue into the lives of wives and mothers.

The only woman who spoke about how she continued this kind of girlfriendship in adulthood was Rose Asuku, a striking Suakrom townswoman known for her extravagance. I first noticed Rose at a Sunday afternoon women's gathering held at the queen-mother's

6 Interview the assemblywoman at Suakrom, December 11, 2008. 
house, which happens on Akawsidae (usually every sixth Sunday). Rose stood out for her height, for wearing a short Afro and Europeanstyle clothing. She had gone through several marriages and was known to have an alcohol problem. Above all she claimed that she used to be "rich" and respected and was now "frustrated for so many reasons." According to Rose, supi was done openly "in the olden days." Remembering her own first same-sex experience at the age of sixteen, she recalled how she and her friend bought gifts for each other, paid for each other's food at the school canteen, and scribbled amorous notes on small pieces of paper that they tucked under each other's desk. Not least, she emphasized the sexual aspects of their friendship and related how they first touched each other after school in an empty classroom. She maintained that people dislike supi matters today because they have received far too much media attention, and because nowadays young women refuse to marry men. Rose herself got married in her early twenties but continued to keep a female lover to the extent that her jealous husband took them to the police station one day. Apparently, the police officer sent them back home, with the words "if woman and woman are in relationship it is not a stealing matter." 7

While Rose possibly invented some of the flowery stories about her youthful same-sex adventures, as well as her exploits during a two-year stay in the Netherlands, the point she makes is significant, namely that supi was not a topic of public discussion during her youth. She asserts that it used to be common for women to meet and mingle in homosocial spaces such as the dances, gatherings, and educational events regularly hosted by queen-mothers for the young women of their locality. Asked if she visited any lesbian clubs or meetings in the Netherlands, where she had a relationship with a fellow dishwasher from Suriname, Rose exclaimed: "Lesbian clubs, for what? I also met you at that queenmother's party. Women meet at funerals all the time, no need for such meetings." While funerals are by no means women-only events, they offer some space for female sociality.

Funerals are family affairs, and family in southern Ghana is primarily structured by either one's paternal or maternal line of descent. For the largely matrilineal Akan, this implies that spouses do not marry into their partner's family, but remain part of their abusua, their mother's

7 The quotes in this and the following paragraph are based on fieldnotes from conversations with Rose Asuku at Suakrom, April 29, 2008. 
extended family. Therefore, wives may well attend funerals without their husbands. Further, funerals often take place in faraway hometowns and last for two or three days. They provide opportunities to travel and meet up with a best (girl)friend for the weekend, and to find some privacy in the folds of mourning and celebrating the deceased person's life. ${ }^{8}$ Despite changes in funerary practices, funerals remain important sites of sociality beyond family. Especially if the deceased was rich, the festivities accompanying the burial amount to public social events, where townspeople who barely knew the deceased enjoy the food and alcohol that is distributed. Akyeampong outlined that alcohol played a central role in Akan funerals both in rituals and for drinking (1996). While the ritual use of alcohol, for example, in practices such as pouring libation, helped to transform the relations between the living and the deceased, intoxication was encouraged as "an expression of grief and solidarity among the living" (1996, 38-39). Today, it could be argued that the solidarity, the passion, and liminality that persist in the face of death create hiding places for intimacies and lend a certain "queerness" to funeral spaces that some of my respondents readily embraced to celebrate their own secret relationships.

\section{Girls' School Intimacies in Comparison}

Girlfriendships and supi intimacies are not limited to boarding school. Some of my respondents associated the term supi with their intimate experiences at (co-ed) day schools, at afterschool sports clubs, or outside any structured activity altogether. The term's particular association with boarding-school education, however, begs comparison with boarding-school intimacies in other parts of the world.

Basic school education in Ghana is free and structured into six years of primary school and three years of Junior Secondary School (JSS). Those who pass the final exams at JSS can enter into a Senior Secondary School (SSS). ${ }^{9}$ Today, these middle schools last three years and charge

8 As Rachel Spronk mentions, this holds true for men who desire men in Ghana. They considered funerals as well as other occasions to travel for social purposes, such as church events, as moments that could facilitate erotic same-sex encounters $(2018,893)$.

9 Secondary schools have been called high schools since 2008. Because all of my respondents who attended secondary school did so before the name change, I will use the older terminology. 
a small fee. An additional fee is charged for using the sought-after boarding facilities provided by most of these institutions. Introduced by missionaries, the establishment of the boarding-school system was part of the European civilizing mission to educate and discipline colonial subjects. Thus, even before the formal onset of colonial rule in the late nineteenth century, boarding schools, modeled on the British system, amounted to colonial institutions that imposed racialized hierarchies, values, and a distinct set of power relations (Foucault 1975; Stoler 2002). Within these institutions, not only formal, but also informal practices were introduced through school education. Some of the common features of African, European, and North American nineteenth- and twentieth-century girls' boarding schools are the practice of gift-giving, the writing of love letters (in English), and the use of kinship terminology.

Examining the letters and diaries of students and teachers at Victorian boarding schools in England, Martha Vicinus found a system of "surrogate mothering that could often turn into a rave" (1984, 606). Through this institution, older girls were assigned to mother the newcomers. Introducing their admiring junior to the norms of the school, the senior girl "received her first taste of power" (Vicinus 1984, 606 ). As Vicinus argues, the hierarchies made for a "longing distance" between junior and senior girls whereby "the most common form of devotion was to make the beloved's bed or to buy her flowers or candy" (Vicinus 1984, 607). Nineteenth-century schools and families encouraged these friendships between students and even between students and tutors. These close bonds were considered essential to the girls' emotional and spiritual development as well as to the fostering of school (as opposed to family) loyalty. On the other hand, underlying fears that girls' excessive affection could undermine "family duties" (i.e., affect their marriageability) challenged the general desirability of boarding school friendships (Vicinus 1984, 603). Girls were advised to "guard against extremes" and their "raves" were considered beneficial only as long as they prompted them to shift emotional satisfaction away from familial models and toward individual discipline, independence, self-control and the sublimation, and spiritual idealization of worldly, personal desires (Vicinus 1984, 618).

Carrol Smith-Rosenberg argued that eighteenth- and nineteenthcentury white middle-class women in the USA inhabited a homosocial universe in which men played a marginal role. Boarding school thus 
worked as a continuation of the emotionally and physically intimate female world in which girls were immersed at home. The intimacy of the mother-daughter relations at heart of this "separated female sphere" was replicated in patterns of "adoption" and "mothering" between older and younger school girls. Idealized in her school "daughter's" imagination, the nurturing "mother" gave advice and purchased such items as shoes, corset covers, bedding, or harp strings for her dependent "daughter" (Smith-Rosenberg 1975, 19). They wrote tender letters to each other, rife with "confessions of loneliness and emotional dependency" (Smith-Rosenberg 1975, 26) and "routinely slept together, kissed and hugged each other" (22). Somewhat nostalgically, Smith-Rosenberg holds that such friendships continued and were acceptable throughout a woman's life.

Lesbian historiographers have been concerned with the question of when and how female boarding-school intimacies became labeled as lesbian and sexual (Vicinus 1984, 601). This concern also surfaces in feminist ethnographic accounts of women marriages and secondaryschool intimacies. Judith Gay (1986) who studied "mummy-baby" relationships in Lesotho hinted at the erotic dimension of the bonds between a slightly older and more active "mummy" and her "baby." She was, however, quick to assume that these relationships terminated with the end of school years and were not understood as sexual. Henriette Gunkel (2010), on the other hand, who interviewed selfidentified lesbians in contemporary South Africa found that some school girls did understand their "mummy-baby" friendships as sexual, although their intimacies were not subjected to categories of sexuality at the time.

In the 1950s, John Blacking (1978) explored the use of kinship idioms at South African Venda and Zulu schools. The "mother-child game" he focused on was played among girls at both boarding and day schools. A senior girl could choose or be chosen to mother one or several children; she protected them, settled quarrels, offered advice, and gave gifts and extra food. The girls considered this "game" helpful in adjusting to the new school environment and in avoiding loneliness: it provided "emotional stability during a period of physiological change and fleeting fancies" (Blacking 1978, 111-14). The "motherchild game" existed alongside other pairings, such as bed-mates (sharing a bunk bed) or eat-mates (sitting at the same table in the refectory), and could be combined with the "husband-wife game." Characterized 
by the writing of English-language love letters and the pretense of being lovers, the "husband-wife game," however, provoked criticism or was banned by the school authorities. To the girls, as Blacking sees it, pillow talk, the exchange of romantic cards and presents, and the status accruing from being a "husband" to many "wives" were more important than the sexual play it could involve, including the use of improvised dildos (Blacking 1978, 108-10). In the boarding school world in particular, a girl could simultaneously be a child, a mother, and a husband toward different girls and integrate these positions into intricate webs of fictive kinship. Thus, a mother would consider her child's husband her son-in-law or a child would call her mother's husband father. In addition, male brothers and boyfriends could be included into these families. Since there was no distinction made between internal (female) and external (male) boyfriends, a "child" could have two fathers, once her mother married a "real boyfriend" (Blacking 1978, 111-12). These "families" reinforced the girls' allegiance to a new way of life with correspondingly new (educated) social groups in black South Africa (Blacking 1978, 102).

Similarly, mother-child practices have a structuring effect on Ghanaian boarding schools (Göpfert and Noll 2013). Thus, studying a Catholic girls' boarding school in northwestern Ghana, Andrea Noll was told that schoolmates used to choose daughters, mothers, and grandmothers among each other. A remainder of the schoolsanctioned use of kinship terminology are the "mothers" of the refectory, that is, the two girls whose duty is to distribute the dishes (Göpfert and Noll 2013, 128). While Noll did not come across husband-wife games, it used to be common that older students chose a "darling" among the younger ones. The older girl shared food with her darling or they played "having a romance together"(Göpfert and Noll 2013, 128). ${ }^{10}$ According to a Mrs. Ibrahim, a teacher and former student at the school, these darling bonds were forged much more frequently in the past. In fact, Noll's informant deplored that the "darling matter" has lost steam due to the importance placed on (male) boyfriends.

Our time, we used to hold so strong to darlings. When you come, form one, a senior would pick you as a darling. Oh, whatever (...) when you are sick, she would take care of you, week-ends, you visit each other in your

10 Translation from German by Serena Dankwa, emphasis by the author Andrea Noll. 
dormitories and we were so nice to each other. And our time, they were also our boyfriends, we took them as our boyfriends and we used to love each other. But this time, their darling matter is not so strong. They rather attach more importance to the boys then their fellow girls. (Göpfert and Noll 2013)

Mrs. Ibrahim's description of "darling matter" corresponds with the meanings my own elderly respondents attached to supi. Rather than condemning the possibility of sexual practice between darlings, Mrs. Ibrahim is critical of the perceived hetero-sexualization.

Today's boarding-school relationships are structured not least by the dormitory "partner" setup (Göpfert and Noll 2013, 125). A first-year and a third-year student or two second-year students are considered partners if they share a bunk bed and "boxroom," the lockable boxes where they can store personal items (Göpfert and Noll 2013, 124). It is standard practice that the junior partner is in charge of everyday chores such as fetching water for the two of them or washing the senior's school wear. Although in some cases the juniors are bullied by their seniors, this hierarchical form of partnering is generally sanctioned by the school: it gives the senior student more time to prepare for her final exams, whereas she introduces her junior to the formal and informal rules of the school (Göpfert and Noll 2013, 126-27). Such pairings and kinship practices extend from school education into other spheres of young women's lives.

This came to my attention when doing research within Suakrom's semi-professional female football team (see Chapter 4), where senior "team mothers" distinguished themselves from their junior "team daughters." What mattered was not necessarily age difference (most players were in their early twenties), but the "mother's" senior status in the team and her ability to take under her wing a chosen "team daughter." These mutually supportive bonds can be casually extended into larger families. In one instance a player playfully referred to her "team mother's" female lover as her "team father."

When I asked Ma'Abena Oppong, a secondary school graduate and former football player, about boarding-school mothering, she strongly distinguished between being "the child" of a school mother and being someone's "girl" or darling: "The normal one, that's what it is, school mother, someone who'll serve you [...] maybe that friendship thing isn't there." Serving implies that the "mother" chooses where she sleeps on the bunk bed, usually below, and that the "child" has to fetch water 
every morning. "But as her girl she wouldn't let her fetch water for her. You have to serve your school mother, that is different from (pauses)." While differentiating the senior-junior dynamics of bed-mates from an amorous girlfriendship, Ma'Abena's comment does suggest that "the normal" way of school mothering can develop into a supi relationship. "You see, when it gets to a point and the two of you develop that mind and contact that way, then it's the idea of the two of you. That's what they call supi. 'This is my supi, this is my girl." "11 Interestingly, despite interviewing many women about their understandings of supi, school mothering was not mentioned. It seems that especially those women who continued having same-sex lovers after school did not represent their intimacy through these hierarchical, school-sanctioned practices framed in kinship terms.

To Ma'Abena, supi implies the deeper connection developed in spite of the structuring power of school-induced senior-junior hierarchies. Her idealizing distinction between school mothering and supi as a loving relationship parallels the distinctions Blacking's respondents made between "husband-wife" and "mother-child" bonds. As one of his respondents mentioned, when her "mother" became so friendly to her "that she was more of a friend than a "mother'," she decided to refer to her as "husband," in order "to escape being proposed to by other girls" $(1978,110)$. Ethnographic and historical accounts of school girls' bonding practices speak of similarities in the ways in which senior-junior intimacies are formalized through kinship terminology and enacted through the exchange of gifts and letters. The concepts of family, the extra-mural homosocial institutions informing intimate friendship and kinship practices, and the larger histories they are shaped by differ considerably, however. In order to understand the particular formations of female friendships and same-sex desires in southern Ghana, we need to take a closer look at the shifting representations of supi and the term's gradual sexualization.

\section{Supi-Supi: Sexualizing and Nominalizing}

"In the secondary boarding school where hundreds of students live together, a female student may share the same bed with a girl friend; this female friend is called supi but the term does not have the sexual

11 Interview with Ma'Abena Oppong at Suakrom, April 25, 2008. 
connotations which lesbianism has in the West" (Warren 1975, 31). Dennis Warren, one of the few anthropologists commenting on supi in the 1970s, disassociated the term from sexual practice. Contrary to Warren's assumption, two Christian guide booklets published at the time did bracket supi practice as sexual (Konadu and Mensah ca. 1970; Mensah ca. 1970). In a section titled “'Supis' and Homosexuality," Reverend Ronald Mensah holds that "homosexual feelings" based on childhood or teenage experiences are common (Mensah ca. 1970, 26). He moderately advises young women with "homosexual tendencies" to avoid "college "supi' girls," but also Christian "bigots" who will "piously condemn your sin" and brand you as hopelessly "queer," but thereby only drive you into "deeper insecurity and, ultimately, into the arms of the gay community which offers security and acceptance" (Mensah ca. 1970, 30-31). Mensah encourages young women with a "homosexual problem" to seek pastoral help without, however, worrying too much about it (26). Interestingly, Mensah, who seems to be well versed in international gay and lesbian vocabulary at a time when there were no hints of queer activism in Ghana, deploys neither the term lesbianism nor the term identity. Instead he strongly argues that "the practice of homosexuality" is not worse than any other sinful practice such as "lying, stealing, committing adultery or bearing false witness against a neighbor" - all of which can be dealt with (27).

This sexual connotation of supi came up in an interview with Mrs. Dokua Hewlett, who was a dormitory prefect at the boarding school she attended in the 1960s in the Western Region. Mrs. Hewlett distinguished the "normal way" supi friends related to each other - as best friends - from the sexual type of friendship that was prevalent in her dormitory. In fact, as a prefect she struggled to prevent "innocent small girls" from being seduced by their senior supi; "they can act as lesbian," she said, "which is dangerous [...] excuse me, they will be fingering each other." 12 One measure taken to prevent such "acts" from happening was the prohibition of covering mosquito nets with cloth to provide hide-outs for secret intimacies. Hewlett clearly considers supi intimacies both sexual and immoral. It is unclear, however, whether she attached the label "lesbian" to these "acts" at the time or only retrospectively following the invention of "supi-supi lesbianism."

12 Interview with Dokua Hewlett at Accra, January 21, 2008. 
A decisive shift from supi as an endearing word for a close friend to the derogatory phrase "supi-supi lesbianism" occurred in the 1990s. This shift is reflected in a column in a popular weekly that sets out the tension between "ordinary" and "lesbian" intimacies and considers the former a necessary part of a girl's development. In this article "Apostle" Kwamena Ahinful discusses the comments of radio callers who disagreed over the question of whether supi intimacies should be banned. ${ }^{13}$ He reports that some callers described "lesbianism" as "the outcome of those supi-supi practices seen on the campuses of especially female teacher-training colleges and secondary schools," while others wondered if it is "possible to distinguish between student lesbians and ordinary best girl friends." The crux of the radio show and of Ahinful's commentary was the news about a "wealthy woman" who was "able to snatch away a poor man's dear wife, and is living with her comfortably in her house as 'husband' and wife." Ahinful attributes this woman's appeal to the financial capacity that allowed her to accommodate her female lover, thereby taking on the role of a husband. The comparison to a conjugal relationship echoes this chapter's opening quotation, as well as comments by women I met who likened supi relations to husband-wife bonds, which implied both a sexual and an economic dimension. In Ahinful's column, “'Supi-Supi' Lesbianism” is marshalled as the Ghanaian version of or an erotic pre-stage to (fullblown) adult lesbianism.

Whereas in intimate discourse the single word "supi" is deployed an endearing term that expresses the mutual adoration and closeness of two female friends, its reduplication as "supi-supi" in public discourse turns it into a generic label for a suspicious social phenomenon. In southern Ghanaian languages, including Ghanaian English, words can be intensified and turned into quasi-plurals through their reduplication (Osam, Marfo and Agyekum 2013, 45). "Supi-supi" works as a catchphrase that nominalizes and fixes supi on a meta-level and equates it with notions of the sexual and the immoral. Thus "supisupi" allows for the generalization of a variety of female same-sex passions and their being subsumed under the label lesbianism. By combining and correlating supi-supi with "lesbianism" - a term fiercely associated with sexual decadence and the immoral "West" - young

13 Kwamena Ahinful, “No 'Supi-Supi' Lesbianism,” The Mirror (Ghana edition) January 17, 1998. 
women's elusive intimacies were suddenly marked as (homo)sexual and classified as deviant.

In the mid-1990s, this deviance was enacted when the video-film industries of Nigeria and Ghana (known as Nollywood and Ghallywood or Ghanawood, respectively) began to tap into the commercial potential of female same-sex desire. Just like the films of Nollywood, Ghallywood is designed to stimulate the audience "by sensationally depicting religious, social and moral transgressions that contribute to everyday instability and uncertainty in the postcolony" (Green-Simms 2012, 28). Films such as Supi: The Real Woman to Woman $(1996)^{14}$ promise to show true stories about educated women in sexual cults, both in and outside the boarding-school context. Women in Love (1996) and Jezebel (2007) are the most wellknown Ghanaian melodramas that feature "supi lesbians." These films play on the audience's voyeuristic desire to see something that remains hidden from society, and on the alleged involvement of wealthy business women with Mami Wata (Green-Simms 2012).

The trans-African mermaid-like water spirit known as Mami Wata can take on different genders and identities and may bestow the men and women whom she "marries" with riches, while also rendering them sexually insatiable (Meyer 2003). ${ }^{15}$ Lindsey Green-Simms revealed how the hypersexual figure of the Ghallywood lesbian is charged with privileging "individual accumulation above familial, communal, and national bonds" and marked as a threat to biological and social reproduction $(2008,5)$. It would be difficult to establish the extent to which images of greed-driven "supi lesbians" who rob their youthful lovers of their fertility circulated prior to these film productions and to what extent they were triggered by them. According to filmmaker Socrates Safo, supi-supi stories involving Mami Wata are most common among Accra's fishing communities, although this rendition in itself echoes mainland Akan stereotypes about Ga and coastal Akan people being inclined to greed-driven and unrestrained behaviors, including same-sex practices.

Another arena in which the term supi has made appearances is the pamphlet or market literature, Ghana's most popular informal genre of fiction. The authors of these handy short novels - which are produced

14 Directed and produced by Ghanaian film maker Ashiagbar Akwetey-Kanyi.

15 This aspect of Mami Wata will be dealt with in more detail in Chapter 4. 
in small numbers and sold on markets, at roadside stalls and through the windows of trotro mini-buses - are quick to respond to topics of the day (de Bruijn 2008). Romantic relationships are a dominant theme, with love often associated with commodity accumulation and imagined "as a force to overcome adversity and radically alter lives" (de Bruijn 2008, 5-9). This promise features prominently in Love in the Girl's Dormitory: 'Supi' Palava (Mensah ca. 2005) a story about two university-trained female professionals, who fall in love with each other at a prestigious secondary school. The story is both cautionary and titillating. Though the protagonists' obsession with each other ultimately destroys their lives, they are portrayed as highly successful and autonomous women engaged in a meaningful and loving relationship. Furthermore, the moral of the short story - "lesbianism is a moral canker. Stamp it out!" - is undermined by the scanned internet images adorning the pamphlet, which show female hip-hop stars seductively smiling at each other. Indeed, Beyoncé and Kelly Clarkson sexily pose on the pamphlet's front cover, creating a "homoerotic allure" (de Bruijn 2008). Thus, the images of US superstars that serve as models of self-fashioning to many young Ghanaians are deployed to represent the story's supposedly morally objectionable lesbian protagonists.

\section{The Asafo Legacy}

Only late into my research did I find out that the term supi existed in certain homosocial institutions prior to the colonial boarding-school setting. "Supi" is the title referring to one of the senior officers or captains, of a male Asafo group. The so-called Asafo companies developed as military bands of young Akan men that defended their towns and villages against enemies and incursions (the word comes from "sa" meaning war and "fo" meaning people). A particularly complex version of Asafo organizing emerged among the Fante, the second largest subgroup of the Akan, in and around Cape Coast. Today, Asafo is regarded as a traditional Fante institution and known for its elaborate visual art, such as colorful flag banners and other European inspired regalia. ${ }^{16}$ Asafo companies, which organized communal labor and masquerades

16 Asafo companies played an important role in the Fante-Asante wars of the nineteenth century and in Cape Coast's cultural and political life. While defending their villages, they developed rivalries with other Asafo companies that were acted out during ceremonial occasions (cf. Yarrow 2011). 
and played a role in chieftaincy, have remained a "powerful expression of a religious, social and political identity" (Sackey 1998, 86). Although, there is room for older men and women, Asafo is primarily a field of activity for young men (Datta and Porter 1971, 280). Generally, Asafo companies operate through the principle of patrilineal succession. Under certain circumstances, however, young men affiliate with the company of their matrilineage. The mode of succession to higher offices, such as the office of Supi in particular, was often determined matrilineally (Datta and Porter 1971, 281). Further, the office of the Supi was associated with motherly qualities.

While it is widely assumed that Supi derives from "superior" (cf. Cape Coast Metropolitan Assembly 2006), an older ethnographic report points to other directions. In the early 1930s, De Graft Johnson noted: "Supi: as the name implies, is like the big water-pot, who, figuratively speaking, acts as reservoir for all the waters" (1932, 312). The Supi captain acts as the custodian of the group's money and ammunition and provides its members with strength. "He is their sbaatan," literally their nursing mother (De Graft Johnson 1932). This association with fluid nurture and pot-like motherliness resonates with the argument of religious scholar Brigid Sackey (1998). She holds that Supi does not derive from "superintendent," but from "supe," an iron sword implanted into a pot-like tortoise shell. This magical pot is placed on top of a sacred monument, in which the Asafo stored their insignia and is supposed to detect and neutralize evil medicine $(1998,75)$.

There is no discussion in this literature about a possible link between Supi as it refers to the Asafo world and the term supi as it is used among schoolgirls. Such a link surfaces in a remark made in an online panel discussion on feminist understandings of family. Catherine McKinley suggested that Ghanaian "lesbians are called Supi. And Supi means the place where your spirit resides. Literally, it refers to a stool. Everybody, when born, is given a stool and that's the place where your spirit sits. Your stool is your Supi; it's the thing you're closest to" (Baumgardner and Richards 2004). This comment is based on her personal interactions with elderly market women in Accra (McKinley 2011). Although most people are given a small bathing stool at birth (a stool to sit on while taking their bath), the suggested connection between Akan stools and supi is interesting, if only for the fact that some Asafo companies do have their own blackened, ancestral "stools." Blackened with blood and eggs, these stools are furnished with ancestral power and used in 
rituals that have played an important role in Akan chieftaincy matters (Sarpong 1971; Akyeampong 1996). ${ }^{17}$

Given that supi is associated with "superior," it is curious that the term applies to both the senior and the junior girl in an intimate, samesex bond. It raises the question of whether supi professes a hierarchical structure by which it does not abide: Sup $i$ indexes an intimate bond that reflects as well as transcends the junior-senior hierarchies by which they are framed. The script of one person being the mentoring senior is undermined by the fact that the two girls tend to be close in age and that supi attraction is by definition mutual: each girl is the other girl's supi, and it is not always clear who is the leading and who is the following partner. In this sense, the term seems to offer its own structure of Akan-inflected power. Since Cape Coast is home to both the first girl's boarding school in Ghana and to the most influential Asafo companies, one wonders whether different notions of supi moved between the boarding school and the Asafo environment. Descriptions of the Supi's function as an Asafo leader and a nurturing mother figure (De Graft Johnson 1932, 312) certainly resonate with the senior-junior roles played out within girlfriendships. ${ }^{18}$

\section{Adwoa Boateng: The Imperative of Gifts and Secrecy}

Among the majority of my Akan respondents, supi was associated with first time same-sex experiences. My interest in the question of whether they understood these youthful "crushes" as romantic and/or sexual was met with personal stories in which supi intimacy appeared as the outcome of a learning process. This process developed through different stages of becoming aware of one's sexual feelings and being taught how to negotiate intimate desire. In the accounts of Adwoa Boateng and of Ma'Abena Oppong in particular, the school environment frames this gradual learning process in significant ways. Ma'Abena's narrative of how she was ushered into "feeling" same-sex passion by a senior boarding-school friend reads likes an initiation and is fraught with feelings of excitement and profound confusion. At the heart of

17 In an informal conversation, an elderly Fante lady indicated that supi has similar stool-related meanings in Efutu, another version of the Akan language spoken among small fishing communities between Accra and Cape Coast.

18 The fact that "supi," pronounced as "supe," has appeared in Nollywood boarding-school dramas poses another conundrum. 
Adwoa's narrative is the process of figuring out how to read the erotic promises of giving, receiving, and reciprocating gifts. Equally central is the realization that the play and passion growing out of these exchanges need to be disguised and handled in secrecy.

\section{"Exchanging of Gifts"}

"At first, in school, we used to say that this is this girl's 'supi', she can give her a gift." When receiving her first parcel, Adwoa Boateng was in her last primary school year, about twelve years old. The gift was accompanied by a letter saying: "I love you, I want to take you as my supi." ${ }^{19}$ Upon receiving these words, Adwoa asked a friend what supi meant. The friend's reply that supi is "just a friend" was reassuring enough for Adwoa to "agree" and start befriending the school mate, still unsure of what she was actually agreeing to. She accepted a little parcel filled with sweets, "chocolates," and "different kinds of toffee." Victorian boarding-school girls gave sweets to each other too. Vicinus interpreted such "presents" as secret signs of devotion, characteristic of the romantic forms of distant desire fostered in nineteenth-century England (1984). In Adowa's context, gift exchanges are more than hidden acts of homage. Adwoa mentions provisions, sandals, clothes, and other "heavy gifts" that changed owners - gifts that were given in full daylight and begged for counter-gifts: "I was there when she brought a parcel, and put it on my desk, (hits a surface repeatedly) [...] she placed it on my desk, and asked me to also bring mine."

Adwoa's wording and her emphasis on the "exchanging of gifts" is reminiscent of Marcel Mauss's essay (2002 [1925]) on "the gift." Mauss delineated the act of giving, receiving, and reciprocating a gift as a threefold obligation that dominates all social relations, including intimate relationships. His gift theory relies on the distinction between gifts and presents; unlike presents, which are deemed to be a personalized donation free of intentions (and which, once received, are not supposed to change owners), "gifts" require counter-gifts and engender a hierarchical relationship between giver and receiver (Znoj 1995). As a "big man's" daughter, Adwoa had ample occasion to witness the importance of handing out and reciprocating gifts. She

19 Unless stated otherwise, the quotes in this subchapter are all taken from an interview with Adwoa Boateng at Suakrom, December 11, 2007. 
fondly remembered her father as a well-educated and savvy patron with a compound full of children and chiefly responsibilities in both Suakrom and his rural hometown. Upon receiving her first "heavy gift," she consulted him as to how to reciprocate. "She bought [drinking] glasses and other things and gave them to me as a gift. So I came to show them to my father, and my father said oh, I should also buy a mirror for her, a looking glass, so that any time she looks at her face, she'll remember me and say, 'Jewel ${ }^{20}$ gave it to me." Adwoa showed him the parcel, without telling him about the "long, long love stories" in its attendant letter. Adwoa's father suggested that a mirror would be an adequate response to the generous gift she had received, because it would always remind her friend of its giver through looking at her own face.

During our conversation, Adwoa kept stressing how, initially, she had no idea about "that deep thing" supi could imply. She (and her father) thought "it was just ordinary friendship," without imagining the erotic possibilities of same-sex intimacy. Embedded in Adwoa's "looking glass" considerations, however, was a sense that not only glasses and letters changed owners, but that gifts carried layered meanings and expectations. Since Adwoa herself uses the looking glass as an example of how she started to grasp the significance of gift exchanges, it needs to be seen against the Akan background in which gifts are often believed to be "vehicles for the unwitting or deliberate transmission of evil to the recipient" (Sarpong 1991, 63). Its defining feature being selfreflection, a looking glass reflects the need to decipher a gift's underlying intention, while mirroring the giver's pure intentions. ${ }^{21} \mathrm{Her}$ father's suggestion to respond with a mirror seems to be emblematic of the significance of reciprocation. Importantly, however, the process of figuring out what the exchanges were all about did not happen

20 Here Adwoa does not use her Twi day name but her cherished English name that I anonymized. Though most friends know both her English and her Twi names, and use them depending on the context, I heard her called by her day name "Adwoa" more frequently. In the context of receiving an English-language love letter, she uses her English name, hinting at the formality and romantic modernity of this exchange (cf. Mutongi 2009).

21 Mauss identified the idea that something of the giver's spirit is sedimented in the gift, by appropriating the Maori term "hau," a concept that gives every gift "a kind of individuality" $(2002,15)$. Endowed with its original owner's essence, the gift exerts a magical hold over its recipient, as long as it is not reciprocated. 
between giver and receiver alone but was fueled by her intimate conversations with a third party.

It was not the mirror girl who introduced Adwoa to the erotics of gift exchange. "It was later that someone showed me," Adwoa says. This someone was Mavis Marfo, an "age mate" from her neighborhood. Adwoa was about fourteen then, and Mavis was fifteen. "She's a very good friend of mine. As for her, true, she understood, you see. So the gift that my friend gave to me, she said, 'Hey, Adwoa, this and this and that." Mavis understood and introduced Adwoa to the erotic implications that gifts and romantic letters could harbor, by explaining to her that girlfriends could physically touch and please each other. Being attentive to Akan etiquette - according to which reproductive organs should not be named without prior excuses (Sarpong 1991, 68) Adwoa reiterates Mavis's explanations: "She was saying that when a lady sleeps with a lady, she be touching, excuse me, your breasts and things like that. But she didn't show me that (pauses) you can use your finger to do something, but - yes, she didn't teach me that." Though Adwoa considers the mirror girl her first supi, it was her "mate" Mavis who instructed her. Initially, this introduction was of an explanatory, platonic nature and did not include sexual touch. The teaching process soon became more physical, however, as Adwoa concedes in a second interview a few months later.

Not only was Adwoa's narration circular, but circulation seems to be at the heart of the formation of supi knowledge. Faced by my research associate's jokes and insinuations that her colorful sexual life must have begun early, Adwoa emphasized that she herself was oblivious to the erotic possibilities or expectations gifts could raise when she began trading them. "When she gave me the gift, then I [...] entered before I saw. As I was going through, then I started understanding it." This process of coming to understand is not constituted in Mauss's economy of gifts and counter-gifts (Znoj 1995, 38-39). While Mauss focused on the ways in which gifts transform into personal loyalties and enhance a "big man's" status, the significance Adwoa attaches to the act of "exchanging" points at a wider dimension of gift circulation. The actual gifts exchanged seemed to matter less than the knowledge gained in the process of interpreting these exchanges that transcend the dyadic reciprocation. Moreover, as Marilyn Strathern's research on "the gender of the gift" in Melanesia suggests, "knowledge is like a gift"; it is both an external resource and an internal part of the person (1988, 
108). Thus, in Melanesia, people are not construed as individual owners who negotiate their collective lives through gift exchanges, but as "dependent upon others for knowledge about themselves" (Strathern 1988, 132). This knowledge is constituted through "the impact that interaction with others has on the inner person" (Strathern 1988, 109). Similarly, Adwoa's "understanding" alludes to an emotional response and a knowledge gained through personal experience. By talking and interacting within growing circles of female friends, she "entered" a sensory way of knowing.

\section{"It Has Become a Spirit"}

One afternoon, Adwoa and Mavis were in Mavis's room when a cousin walked in on them. "[Mavis] was lying on me and we were both naked." The female cousin who happened to work with the police as a "CID" 22 took it upon herself to interrogate them and take them to the town's police station. Adwoa remembers how they defended themselves. "It was even I who spoke. I said that when she came to meet us lying there, we had gone to take a bath, and were in our pants when we fell asleep, and that when she saw us, she said we were doing something. And we said that we hadn't done anything, we hadn't done anything. They forced [pressured] us and later released us." 23 Adwoa capitalized on the fact that in many a small, dim sleeping chamber, the bed does serve as a fitting space for dressing after bathing, which is nothing unusual for two girls of the same age. As Fortes remarked with regard to the Akan context, "it is felt to be immodest for adults of different generations to bath together; siblings of the same sex may do so. The attachment and mutual identification of sisters is notorious" (Fortes 1975, 274). Whereas moral restrictions pertain to intergenerational bathhouse intimacies, it is permissible or even desirable for sisters, including cousins and female friends of the same age group, to share bath- and bedrooms. At the police station, Adwoa, who is a good storyteller, managed to evoke that sisterly dimension, thereby concealing the sexual feelings that may have been explored in a shared moment of afternoon privacy.

22 CID means Criminal Investigation Department and is part of the police department. Calling someone a CID is a casual way of calling someone a police detective.

23 Interview with Adwoa Boateng at Suakrom, May 11, 2008. 
Back from the police, Adwoa hid in her room, skipped classes, and avoided her family until her father confronted her. "My father got annoyed for about four days and then he came to me in my room and spoke to me, and told me that if that is the case, then it is spiritual and other things; it is not good, so I should stop it." After providing for Adwoa's gifts and thus supporting the consolidation of her girlfriendships, the father disliked what was reported to him. When I asked Adwoa how exactly her father told her that what she was doing was bad and "spiritual," she resorted to a standard phrase that is thrown at Ghanaian girls who love girls: Have you seen "woman and woman sleeping [together] before?" In such questions, same-sex desire is rhetorically attributed to the non-natural world. Generally, spirits are understood as possessive forces, which haunt their victims and get hold of their personal lives and identities. As mentioned above, in film and other popular representations same-sex desire is often associated with the voracious appetites of female water spirits and thus relegated to the occult, "spiritual" realm. Invisible to the human eye and thus to society and the social world at large, this realm seems to engender intense, unhealthy attachments.

Having to bear the anger of her beloved father and resisting the police both constituted key moments in the formation of Adwoa's erotic subjectivity. In Suakrom, most people have been to the local police station - if not as accused or accuser, then as onlooker. A lively place, where petty crimes and contestations are arbitrated, officers take on the roles of mediators: they calm people down, delay a case, or support the party by which they have been bribed. Though many issues are solved at the police station, it must have been unusual in the mid-1980s for the intimacies of two naked girls in their room to have been reported. ${ }^{24}$ Without an ambitious cousin, keen on furthering her detective career with the police, the matter of two girls lazing on a bed would not have been worthy of investigation by either police officers or radio journalists. Adwoa asserts that these things are different today: "If it had happened by now, we'd have also come on the FM [radio], don't you see?" Adwoa's comment hints at the increased media attention (and the resulting sanctions) that schoolgirls garner if "caught" in sexual acts at boarding houses today. This heightened attention, as seen

24 For the legal framework concerning homosexuality in Ghana, see Chapter 1. 
in Chapter 1, results not least from the proliferation of competitive private radio stations.

The significance of the radio in making supi a sensationalized topic of public interest and part of the non-natural, "spiritual" world was evinced in many informal conversations. Like Adwoa, Comfort Otu, a fruit seller in Suakrom, refers to the "spiritual" and its mediatization as key to the condemnation of same-sex bonds. I had heard that Comfort had or used to have a same-sex lover. When I asked her whether she had a current girlfriend, she replied: "You mean supi? No, I don't do that, it's not good. It's a spirit." Like other respondents who had experienced homophobic exclusions and a difficult breakup from a female lover, Comfort claims not to "do that" anymore. She also holds that having a supi "doesn't do you good because people talk about it. You hear it on the FM stations and everywhere." In Comfort's pragmatic formulation, same-sex intimacy has a negative effect, due to the gossip and media attention it triggers. Notably, in her rendition, supi only becomes a malign spirit when it is exposed to the public and mediatized. In response, I related how things are different in Europe and that in some places, women could marry each other officially. She answered: "I've heard about that. It's better to do it there than here. Here it has become a spirit because people talk about it, although it is something concerning your own innermost parts [only]." ${ }^{25}$ As I understood her, the innermost parts is where your feelings and desires reside. These parts of your inner self should not be subjected to public debate about the natural and the non-natural.

\section{"The Real Love"}

While the police episode did not terminate Adwoa's connection to Mavis, it suspended the introduction and learning process for at least a year because soon after Adwoa fell pregnant. ${ }^{26}$ " [My father] said he won't give me food to eat, chop money. It was through that that I got

25 Fieldnote based on a conversation with Comfort Otu and Josephine Agbenozan at Suakrom, May 2, 2008.

26 Retrospectively, she attributes her relationship with the father of her firstborn to this event - although it was not clear whether it happened before or after she fell pregnant. This incident speaks to her appreciation for adult lovers who are discreet and know how to conceal their same-sex relationships, rather than creating suspicions by fighting in public. 
my boyfriend, called Alex. He's the father of my eldest child. He used to tip me. I didn't take him as a boyfriend. But he took me as a friend. Once in a while, he gave me tip off, some little money, chop money." Adwoa pragmatically constructs her teenage pregnancy as a direct outcome of her father's punishment. It was not his admonishments that she should stay away from supi, which drove her into the arms of Alex, her loyal friend and admirer, but rather the father's withholding of "chop money" - the spending money which she would have needed to cover daily expenses, school lunches, and transport. At that time, Adwoa was a "sports girl," the best table tennis player in her region. She had known Alex for a while through after-school sports activities, but hardly noticed him. This changed when he stood up for her in class one day. They became best friends and Adwoa gladly accepted the monetary gifts he offered. The mirror girl and other girlfriends ridiculed Adwoa once her pregnancy showed. "They laughed at me that I had done the wrong thing. So, they even gave me herbal medicine, traditional medicine to, (pausing) to drink, to abort it." But Adwoa did not abort. She gave birth to a healthy baby boy at the age of fifteen. In order to keep the pregnancy under wraps, she was sent to her father's hometown in the mountains. After weaning, she returned to Suakrom, leaving her son in the hands of a "senior sister" - possibly meaning a paternal cousin. Meanwhile, Adwoa's family threatened Alex's family with "knives" and "sticks" and pressed them to pay compensation, until Alex migrated to Germany. Adwoa and Alex's son has since completed school. He is staying with Adwoa's mother in Accra and occasionally receives money that Alex sends from abroad.

Interestingly, Adwoa mentioned Alex and her pregnancy when I asked her about the general "difference between friendship and love." Adwoa used Alex as an example of how friendship can effectively grow into something else, something passionate and sexual. The nostalgia about her impeded "love" for Alex certainly bears upon her failed marriage with the genitor of her second child and her ongoing search for a presentable, providing husband. While wistfully remembering Alex, Adwoa flirts with the idea that giving birth at a young age gave her greater liberty in continuing to pursue girlfriendships. As Adwoa coyly reasons, today, after having given birth to a second child with a man who refused to marry her, it "will be fair for [her]" to avoid men. "And I started going near the lesbian. That's how come. Yeah, this is my story." Adwoa reconstructs her story along the lines of 
her current focus on female lovers. Similarly, many of my younger respondents reasoned that their fear of teenage pregnancies and of losing respectability by being seen with boyfriends drew them to women. As one feisty, young mother who claimed that her husband lived in the USA asserted, it was better to satisfy her economic and erotic "needs" with girlfriends than by having boyfriends.

Adwoa's pregnancy only briefly interrupted her school career and her same-sex activities. In fact, it was in her father's rural hometown that she completed Junior Secondary School and kissed her first girl. Trying to make sense of Adwoa's multiple "first" times, I asked about her "first kiss," assuming that it must have been the mirror girl or Mavis, the neighbor, with whom she was taken to the police station. ${ }^{27}$ Yet, without hesitation Adwoa calls up a fellow sports girl - "the runner" - whom she met at JSS. The fact that "the runner" died a few years later adds to her fond memory. ${ }^{28}$ Clicking her fingers in excitement, she exclaims: "that girl, I can see her before my inner eye, eh, Chale! ${ }^{29}$ I miss her. May she rest in peace!" When I inquire what she liked about her, she raves about "the runner's" responsiveness: "I attract her during the bath time. So I started to kiss her [...] She's a sexy girl, you know, sexy girl. Very good girl. She understands everything. [S.D.: Like what?] Vagina and vagina," Adwoa jokes and joins my research associate in an outburst of laughter. "You see, through the mountain girl [the runner], that is how I came to see the love, the real love." Beyond the inquisitive gaze of policing cousins and concerned fathers, and aware of (opposite-sex) genital intimacies, Adwoa realized that girlfriendships can be taken to another level of romance and sexuality. From this "first kiss" in the bathhouse, she moved on to her first "big love," a schoolmate at SSS who even came to stay with her in her father's house for some time.

Adwoa's reconstruction of her youthful erotic experiences offer a number of insights. Her discovery of supi pleasures was soon

27 Adwoa replied in English to my question about her "first kiss" - a EuroAmerican motif charged with symbolizing the beginnings of a romantic relationship.

28 Adwoa only mentioned in passing that someone had bewitched her friend and put aduro (herbal medicine) into one of her running shoes, which caused her foot to swell up and eventually led to her death.

29 Chale or Charlie is an exclamatory appellation that has become a Ghanaian trademark, known throughout Anglophone Africa. I have been told that it was once a generic term for the colonial British man. 
followed by the realization that certain gifts need to be wrapped particularly well and handled with the utmost discretion. If caught, however, denial presents itself as the sole option. Like most girls and women, Adwoa went by the unspoken rule that the sexual dimension of supi practice must be disavowed. Increasingly, secondary school authorities expose girls who are caught kissing; they are ridiculed by their mates and in some cases suspended or expelled. Adwoa, however, made her first same-sex experiences beyond the confines of a boarding school and at a time when sup $i$ was less of a public concern. She realized that it was in her power to "revert" the sexual encounter with a girl by testifying to her knowledge of what is considered morally right or wrong. Second, while her naked intimacies with another girl was punished only when someone walked in on them, the consequences of having sex with a boy were far-reaching even if they happened behind closed doors. When Adwoa's "friendship" with Alex became manifest in her pregnancy, she was sent to a rural town and her entire family became involved in safeguarding the family's good name. Had this happened a hundred years ago, her punishment could have been much more severe. Akan girls who conceived before going through puberty rites (bragoro) were ostracized. According to Peter Sarpong, they were made to undergo a series of purification rituals and were sent to the forest away from their community for forty days (1991, 47-55). However, as was the case with Adwoa, the stigmatization ended once a girl had successfully given birth.

Her public exposure and her father's disapproval constitute the driving elements in Adwoa's narrative. Both the hushing up of her erotic girlfriendships and her pregnancy are key moments of her story. Not only did her father's reaction impart to her that supi practices are considered spiritually wrong and need to be concealed, she also learned that supi accusations can be defused quite effectively by pointing at the legitimacy of homosocial intimacies, such as sharing a bath, with a female age-mate.

\section{Ma'Abena Oppong: Learning How to Feel}

Whereas Adwoa does not go into detail about the unease that can accompany the process of identifying and learning how to express same-sex attraction, Ma'Abena Oppong's life story addresses emotional challenges directly. In Ma'Abena's recollection, her discovery 
of same-sex attraction takes the shape of a slow dance in which two girls evaluate each other's responsiveness. Although Ma'Abena avoids the term supi, her narrative captures the affective challenges of being called into sup $i$ intimacies by a more experienced girl she refers to as her "senior."

"The first day, it was difficult for me, because [...] she was leading me by so many years," ${ }^{30} \mathrm{Ma}$ 'Abena remembers her beginnings with Efua Aikins. They met at a prestigious co-ed Senior Secondary School that draws students from a large area. Ma'Abena had just completed her first year, Efua was about to enter her final year. It started when they had "free exeat" ${ }^{31}$ and Efua asked Ma'Abena to accompany her to celebrate the graduation of the final year students. Ma'Abena was the only one of her class invited. "We went to sit on the park and she brought drinks, foreign drink! And I told her that I don't drink, it's only Coke that I drink." But Efua brought a glass and mixed Ma'Abena's Coke with alcohol, in fact not with local brew, but with classy imported drink. Efua was in a jolly mood that evening, she was smoking "jot" ${ }^{32}$ and cajoled Ma'Abena into drinking with her. Obliged to accept, Ma'Abena drank and even ate the boiled eggs Efua fed her after soaking them in alcohol. ${ }^{33}$

After an exuberant night of "outing," as it is called in Ghanaian English, Ma'Abena became unwell and vomited. Early the next morning Efua woke her up and urged her to drink a little more. "She said that if I didn't drink, I get sick. So when I drank it, within five minutes, I vomited again and slept. But after that, I even think she sent me to the hospital, the way I was reacting," none of which Ma'Abena remembers. As she was throwing up, Efua took her to the bathhouse to wash her. "She went to bath me. Even that, I didn't know it. She was the one who told me of it the following day that when I vomited yesterday, she went to bathe me [...] So that made me feel shy. You know, [she,] as a senior, I've vomited and she's gone to bathe me. But she asked me not to fear, 'Why, am I not a woman?'” Ma'Abena was shy about bathing

30 Unless noted otherwise, this and all other quotations in this subchapter are taken from an interview with Ma'Abena Oppong at Suakrom, April 25, 2008.

31 An old-fashioned term for school permission to go out and leave campus.

32 A casual Ghanaian name for cigarettes, thereby stylized into something more secretive and bombastic than the mere tobacco of which they consist.

33 I have observed mostly men at funerals soaking boiled eggs in alcohol before eating them. 
with a schoolmate whom she looked up to and ought to respect. After having been pushed to her limits, Efua worked to let her know how selflessly and devotedly she took care of her. With her rhetorical question, she positions herself as a fellow "woman" - as opposed to a man, with whom such intimacy would not be permissible. While Ma'Abena self-consciously shies away from her "senior," Efua styles herself as a caring, complicit sister, thereby creating the atmosphere of a twosome. However, as Ma'Abena emphasizes, the night they went out was by no means the start of their sexual relationship. "She didn't do me anything; from the party, we went to sleep at one of her friend's house, so there were a lot of us in the room." Often allusions to having stayed together with a friend in "the room" serve as an index for sexual activities, whereas bathing with a friend indicates the beginning of sensual and erotic attraction. This demands a closer look at the spatial contours of the bathhouse, before further exploring Ma'Abena's and Efua's interactions.

\section{Queering the Bathhouse}

While sleeping rooms are scarce, the bathhouse is accessible to many and affords a certain degree of privacy in crowded residential compounds. Attached to an assemblage of rented one-bedroom quarters, the bathhouse is much less a house, than an unroofed, walled structure with a drain. Ideally it is located next to a water tub where the bucket can be filled. It also serves as a urinal, and as the place for brushing teeth and washing underpants. To block the view of passers-by, it is built in the shape of a labyrinth. In Central Accra such bathing facilities are often shared with at least a dozen other tenants, plus visiting friends or relatives who all cook and wash in the compound facing their rooms. ${ }^{34}$ Yet, even in crowded compounds, it is not permissible to enter the bathhouse unannounced. When someone approaches, a slight clearing of the bather's throat suffices to prevent unwanted intrusion. While bathing intimacies are frowned upon if they occur between a man and woman, including husband and wife, there is nothing unusual about joining a female friend or sister in the bathhouse. Especially in the

34 Only one of my primary respondents in Suakrom, whose father sent home money from Germany every month, lived in a large more or less unfinished house and had her own bathroom attached to her room. 
mornings and evenings, when it is pressing and compound members queue to get to the bath, it is nothing unusual for two girls or women to bath together. Tucked away from people's eyes, bathing thus allows for sensual moments and acts of kindness: carrying the friend's bucket; heating up her water to make the bath more pleasant; soaping her back. Young girls in particular can take a long time in the bath without raising any suspicions about engaging in erotic activities. In my interviews, the bath emerged as a significant space not only for schoolgirls discovering same-sex eroticism, but for adult women who share their rooms with children, mothers, or husbands.

Wherever possible, adult women take their bath twice a day. It is often the only time they have to themselves and it may be shared with an equally busy friend. I asked Ameley Norkor, a working-class wife and mother in Accra with very little space to herself, how she "spots" potential lovers, or in the words of my research associate Josephine, how she "knows" if a woman "does it" or not. First, she confirmed in her native Ga that, indeed "there are those who when you start the friendship, they don't do it."

Do you understand? She doesn't know how to do it. The way that you build the relationship - for instance, when I get a friend - if we become friends and you don't do that, I can keep you for one week or two weeks; by the third week, I'll usher you into it. I won't tell you anything. We like each other and do everything together. You'll bath and dress in my room, I won't touch you, but by the third week, if you take your bath and you're in my room, it will be difficult for you to get out of my room. ${ }^{35}$

In Ameley's rendition of how she draws a "friend" into an intimate, sexual relationship, doing "everything together" implies taking a bath, changing together, and engaging in sisterly activities. To Ameley, whose school experience is limited to two years of primary school and who remembers making her first erotic girlfriendships as a child sleeping in her mother's compound, "this friendship thing" as she calls it is learned by doing. And if you have not done it before, you can be initiated into it. It would be both detrimental and redundant to explain the amorous and sexual protocols to a potential partner. Approaching a "friend" who has not been involved with women

35 Interview with Ameley Norkor at Accra, April 4, 2007. 
before is instead a matter of gradually establishing an erotically charged, confined space.

The bias of my question to Ameley about how she "spots" potential lovers lies in its assumption that women who "do it" are recognizable and somehow distinct from those who do not. To Ameley, however, it is not a question of identifying a woman's sexual inclination or releasing a "personal truth" in a Foucauldian sense. She accounts for the fact that a friend who she finds attractive might be unaware of the possibility of same-sex love on a sexual level, by trying to capture her attention and stimulate her curiosity. She is thus concerned with the question of how to spark her erotic interest, the implication being that any woman can be responsive to same-sex passions if she is initiated in appropriately. Ameley attributes her seductive power to her unobtrusive persistence, to the steady way in which she invites and shows care toward a female friend over weeks. Her notion of initiating in relies on the personal capacity to trigger the interest of a woman who "doesn't know how to do it." The goal is to transmit the joy of becoming knowledgeable and of knowing another woman erotically. Obviously, the ways in which women charm each other are as varied as their personalities. Yet the patterns emerging within narratives of seduction have similarities: an erotic context is established through repetitive acts within familiar and familial spaces, such as the bathhouse, that lend themselves to same-sex erotic intimacies.

Both in Ameley's strategy of seducing an unexperienced female friend and in Ma'Abena's narrative of being seduced, timing is a crucial element in engendering and eroticizing bathing intimacies. The queering of spaces by defamiliarizing and marking them as meaningful and erotic takes time. Ma'Abena portrays the process of understanding the erotic dimension of her own physical shyness as a step-bystep introduction orchestrated by her "senior." This introduction took place across different bathhouses. During term break Efua took Ma'Abena to her mother's house for "three days" and continued to instigate situations that made Ma'Abena feel shy:

I think the third time - it was the same, we were also on midterms. She woke up and asked us to go and bathe, and I said no, she should take the lead, and that I'd bathe after her. But she said in that case, I should rather go to bathe first. Do you see how she made me think? So when I was in the bathroom, she came to join me. But I couldn't even bathe well, like, if I see this senior I was 
standing with her in a bathhouse bathing together, like - it's not easy! There's nothing easy about it. It was through that thing that - (Josephine: So that day, did she touch you?) That day, she didn't do anything to me. It did take time, it did take time. ${ }^{36}$

In line with a general trend in Ghana to call up numbers and time designations in English while speaking Twi, Ma'Abena produces a chronology that structures the time it took to develop and identify her own and her "senior's" feelings: the "third time" at the bath during the "three days" at the house of Efua's mother. Ma'Abena's narrative is structured using time references. These time markers may be understood as a narrative device resulting from my interest in her life "hi/story" (Rosenthal 1993), for history requires a temporal dramaturgy. However, this time line also demonstrates that the bathhouse and other spaces can be "queered" and become erotically charged spaces, through repetitions and the re-signification of everyday practices (Halberstam 2005). In hindsight, Ma'Abena conceives of Efua's efforts as part of a carefully staged script, which introduces her into an alluring world of same-sex intimacy. Efua did not "touch" her but allowed Ma'Abena to grasp how Efua gradually "made [her] think." Efua took the lead and introduced her to the erotic potential of sharing intimate space.

"Nnye easy" (it's not easy), a "Twinglish" 37 phrase that Ma'Abena uses often, implies an emotionally or physically challenging situation which may be uncomfortable and exciting at once. Ma'Abena's unease seems to derive from the fact that she saw herself taken on a journey, without knowing where she was heading. The graduated quality of this process does not mitigate the uneasiness with which it may unfold, and the difficulty experienced in understanding and speaking about it. Before considering the affective dimension of first-time same-sex love, the way in which seniority is enacted (by Efua) deserves some attention.

\section{Enacting Seniority}

There are many questions engulfing Ma'Abena's first significant night with Efua. Why did Efua make her drink more when Ma'Abena was already sick? Was Efua drunk herself, or did she intentionally contrive

36 Interview with Ma'Abena Oppong, at Suakrom, April 25, 2008.
37 The Ghanaian mix of Twi and English. 
a compromising situation, so she could act as Ma'Abena's savior? If she intended to introduce her not only to boarding-school party life and wanted to capitalize on her seniority in order to orchestrate a sort of initiation, her strategy worked. Ma'Abena's needs during her sickness, and the closeness and embarrassment caused by sharing "foreign drink" and bath water, were at the heart of her ambiguous admiration of her attentive "senior."

Close relationships between senior and junior boarding-school girls echo the ranking of siblings. As Fortes (1975) noted, the most significant, socially recognized difference between Akan siblings, including twins, is that of birth order. An older sibling must be treated with deference, and is entitled to punish and reprimand a younger sibling while taking care of him or her (Fortes 1975, 273). The very notion that siblings belong to the same age group makes small differences in age significant. Ultimately, however, seniority is less about biological age than social age, which refers to a person's adeptness and experience relative to other members of that age group. ${ }^{38}$ The principle of seniority operates in any given context; it determines who takes the lead in both a domestic or dormitory setting. While the age of classmates at Senior Secondary School can be uneven, with children entering school at different ages, senior-junior hierarchies are fairly institutionalized. Within the boarding houses, comprised of students of all years, thirdyear students are expected to acquaint the first-years with the daily routines on campus. They are encouraged to rear and discipline their juniors (Göpfert and Noll 2013). This school-sanctioned educational dimension of senior-junior bonds is reflected in how Efua orchestrated their sharing of food and provisions.

As established above, an important feature of approaching a potential girlfriend is the exchange of gifts. Ma'Abena described how her "senior" made her realize that gift exchanges follow a certain script of mutuality and discretion. "If my senior comes, she'll say I'm the only one to buy the food for her. So all the time we get to campus, I ask her to give me the money in advance, so that at break time, by the time she comes from her classroom, I'd have bought her food. Sometimes she asks me to buy and that she'd pay me when she comes, but she doesn't pay, you see?" Efua professed her trust in

38 Social age connotes economic, cultural, social capacities, and prestige and corresponds to what Pierre Bourdieu termed symbolic capital (1985). 
Ma'Abena by asking her to buy her food, which she would then share with her. Eating together from the same bowl is considered a sign of great intimacy. If a man and a woman dunk their hands in the same bowl of soup, they are suspected of being lovers - "di," the Twi verb that means "to eat" or to "to consume" has multiple meanings, including "to have sex." If two women eat from one bowl, only insiders may suspect them of being lovers. Ma'Abena performs her service and does not complain if Efua "forgets" to return borrowed money, but she comes to understand this reciprocity as an integral part of their intimacy. It seems that, to Ma'Abena, not asking questions was not only a matter of deferring to, or accommodating, her lover-to-be, but a way of testifying to her understanding that there was more at stake in their exchange than material value. Ending her explanations by asking me, "you see?", Ma'Abena indicates that she assesses these practices as part of the process through which Efua introduced her into a specific kind of intimacy that thrives on emotional reciprocity while engendering mysteries.

Studying the bonds between "play mothers" and their "play children" in South African schools, Blacking suspected that these "games" were a continuation of "traditional "puberty" schools among the Venda, in which every novice was given a "mother" $(1978,101) . \mathrm{He}$ found similarities in the patterns of gift giving and the dominance of the senior partner, and the use of kinship terms was symbolic of a new status in both the school and the "traditional" setting. Eventually, however, he concluded that similar social situations may give rise to similar institutions, but that there was "no evidence of cultural continuity" (1978, 101-2). Although the puberty rites that used to be practiced in southern Ghana are less elaborate than the Venda practices, it is worth considering girls' nubility, such as Asante bragoro, or dipo puberty rites in southeastern Ghana (Steegstra 2004) as homosocial contexts in which female hierarchies and intimacies are instantiated. Since both Ma'Abena and Efua are of Akan background, I will focus on bragoro.

Bragoro nubility rites were practiced regularly until the mid'nineteenth century (Sarpong 1991). While girls went through bragoro individually upon menarche, their age mates were closely involved in the weeklong process. Officiated by an elderly woman, the day of the ceremony mirrored the enstoolment of a queen-mother, the ritual that initiates a female elder into the role of queen-mother. The girl was 
treated as chief-elect, she was required to fast, her head was shaved, and her friends were allowed to make fun of her (Sarpong 1991, 21-37). Besides a stool, an egg was an important symbol at different stages of the ceremony. It was supposed to absorb any evils contained in the gifts with which the initiand was showered (Sarpong 1991, 22). Later, handfed by the officiating woman, the initiand was required to taste small samples of food and to swallow a whole boiled egg, because biting it would jeopardize her fertility. Generally, bragoro features a complex use of symbolic foods and fluids. "Libations of alcohol informed the ancestors of this august event and secured blessing. The initiate was ritually bathed in a river to cleanse her of misfortune and she was served [a dish] made of sheep blood, arguably, to make her fertile" (Akyeampong 1996, 35). After being bathed by the officiating woman, the cleansed girl was dressed and beautified with beads reserved for adult women, before selecting the girls with whom she wanted to eat from the same plate. Far from suggesting that Efua was imagining herself as an officiating elder, Ma'Abena's emphasis on how Efua bathed and fed eggs to her gives their initial encounter a ceremonial character.

Sarpong interpreted bragoro practices as a preparation for a girl's life as wife and mother, conveying standards of morality and giving her a foretaste of the rights and responsibilities of motherhood. He focused on the "neophyte's" change of status and thus on her vertical relations to the adult women who admitted her into their company, "who have carried her, called her 'mother' and referred to her as 'queen-mother'" (Sarpong 1991, 76). He is less concerned with the horizontal ties engendered between the initiand and her girlfriends who joined her during a "six-day-confinement" that followed the ceremony. They bathed and spoiled their "six-day queen-mother," while she distributed food to her "maid-servants," gave them symbolic protection, and held mock courts if they misbehaved (Sarpong 1991, 39), all of which Sarpong interprets as an exercise for "motherliness." However, as he writes, "it cannot be without significance that the girls spend their nights with her when they could easily and perhaps more conveniently retired to the their homes to sleep and return to the neophyte's house in the mornings" (Sarpong 1991, 82).

Given that sharing beds and baths can be signifiers of girlfriendships, Sarpong's reading lends itself to some queering. Bragoro is erotically charged. Adult women beat the armpit donno, an hour-glass drum 
which is one of the few instruments women were allowed to play, despite menstrual taboos that prevented them from touching other types of drums. They sang sexually explicit songs and encouraged the initiand to take to the dance floor amidst her friends. Boys paid uninvited evening visits and played dance games and mock marriages, before eventually retreating to their homes and leaving the girls to continue playing on their own. As a "six-day queen-mother," the initiand is called into the role of a senior, who gets both teased, and served, by her "maids," of whom she is in charge. These junior-senior dynamics resonate with today's practices among girls at boarding schools, where ample opportunity to tease and test each other, and to taste the power and liabilities of seniority, are provided. On a less tangible level, ritual secrecies reverberate in the aesthetics of youthful same-sex bonding. I often felt that young women tried to mystify samesex attractions toward a junior by orchestrating peculiar circumstances and suggested that something extraordinary was happening that was beyond their physical control, by conjuring up moments of ritual significance (such ritual skills as pouring libations are taught as optional secondary school courses in traditional religious practice).

Stories of being ridiculed and confused by a supi, before winning her confidence, are common in the boarding-school context. Senior girls delegate arduous tasks to their juniors, incite them to go against the house rules, make them suffer small punishments, and play on their naivety in order to, sometimes, mercifully catch them when they break down. Upon entering Senior Secondary School, newcomers are subjected to fierce "bullying" games, which are to some degree sanctioned by the school authorities. This "liminal transitional phase" is concluded by a student entertainment night during which the status of the first year-students is officially confirmed (Göpfert and Noll 2013, 134). As I was told by same-sex desiring adult women, secondary school pranks, such as hiding or borrowing a junior's clothes without ever returning them, or cutting off her eyebrows at night, could amount to ambiguous markers of attraction.

At schools that seek to curb the perceived tides of supi infatuation, erotic intimacies have been restricted by prohibitive rules such as "no four legs on one bed." ${ }^{39}$ At Ma'Abena's school, however, it was not

39 Apparently, this phrase was more than an unspoken rule at the Catholic girls' school in Cape Coast, I was told by a university student who graduated from that school. 
hard to keep up the façade of "normal friendship." Ma'Abena herself suspects that her dormitory's "headmistress" looked away, because she "has done some before. As for her, when she sees a girl is standing with a boy on campus or something, the way she'll treat you! But if two girls are sitting there, midnight, chatting, she won't do anything." Notwithstanding the liberties Ma'Abena and Efua enjoyed under a headmistress who seemed to be more worried about unwanted pregnancies than about girls' nocturnal intimacies, it took time and extramural space to act upon their attraction.

\section{Teaching and Studying Feeling}

It was during a holiday at Efua's mother's that Efua sat Ma'Abena down and disclosed some secrets to her. She explained why a "lady" at school had been treating Ma'Abena so "badly."

She said she was coming to tell me why the lady hates me. So when she told me, I became sad, and she told me but that this issue should only be known between the two of us, and that if she [Efua] gets to know that I've told a third person, she'd be very disturbed, because, she told me, if she didn't like me she wouldn't have disclosed what she is doing with her friend, and so if I also feel that I like her, I shouldn't disgrace her, and that I should try to doAnd I told her that I've not done some before. And she said that nothing will happen to me. So she confused me for a long time, until she and I did it. ${ }^{40}$

Efua proposed a sexual relationship by disclosing what she has been doing with another "lady" who spurned Ma'Abena and competed for Efua's graces. This conversation happened away from the bustle and the intrinsic lack of privacy at school. While boarding school has been described as a quintessential space for adolescent "playground sexualities" (Janssen 2002), it was not the dormitory, but a room in a mother's house which eventually set the scene for sexual disclosure and intimacy in this case.

Ma'Abena used English-language adjectives to describe how she felt upon realizing that Efua had another "lady" with whom she shared a secret. But Ma'Abena's reaction to this disclosure and the webs of passion and jealousy in which she found herself, cannot be fully captured in language. "She used to teach me, she made me feel- like, sometimes you enter into something and don't know what to- I don't know

Interview with Ma'Abena Oppong, at Suakrom, April 25, 2008. 
how to put it." Whereas expressing emotions in Twi often requires verb constructions that refer to a person's physical or spiritual body (Gyekye 1995, 95), Ma'Abena captures her ambiguous emotions, by resorting to the English shortcut "feel." 41 Though Ma'Abena could not articulate how exactly Efua taught her to "feel," she knew that she was entering into a world of emotions that were new to her. Ma'Abena grapples with the inconceivability of what she sensed, before it could be packaged and channeled into emotional expression; she describes, in a sense, an affect rather than a clear-cut feeling.

The emotional states that Ma'Abena does name in remembering Efua's proposal - disgrace, sadness, confusion - reflect how unsettling first-time love, and non-normative love in particular, can be. In Feeling Backward (2007), queer theorist Heather Love argues that the unwieldy affects through which North Atlantic queers recognize and act on their desires have been written out of lesbian and gay history. Concerned with public rights and recognition, "well-heeled gays and lesbians" have tended to emphasize the liberating effects of coming out of the closet and obscured "the continuing denigration and dismissal of queer existence" $(2007,10)$. In order to overcome the "backwardness" of feelings, such as shame and melancholia, that inhabit the shadows of queer (as in unruly) encounters, "modern" homosexual politics flatten out the repertoire of feeling (Love 2007, 8). Love is concerned with the loss that accompanies these "demands of queer history" and the sexual politics of liberation compelling us to "transmute shame into pride, secrecy into visibility, social exclusion into outsider glamour" (Love 2007, 28). ${ }^{42}$ Similarly, Sara Ahmed (2010) advocates for the transgressive pleasures, hence the joy and mischief that could lie in deviating from the politics of normalizing homosexuality as happy and respectable (cf. Mesquita and Nay 2013). ${ }^{43}$

41 For instance, m'ani agye ("I am happy") literally means "my eyes have received," and m'ani abre ("I am upset") literally means "my eyes have turned red."

42 In North Atlantic metropoles this tendency has been countered by ever new, queer assemblages that take issue with the logics of liberal gay assimilation and opt for anti-consumerist "gay shame" rather than "gay pride" marches.

43 Heather Love (2007) argues that the domestication of negative feelings has been integral to the project of casting a positive gay and lesbian past and present a present inhabited by homosexuals who matured from being what psychoanalysis has considered the infantile, perverse, sterile, immature, and melancholic "queers" and grew into "out and proud" citizens equipped with the technologies to manage their gender and sexuality. 
In the Ghanaian context, where historical norms of discretion clash with contemporary representations of supi as a haunting "spirit," queerness is not contained by happy visibility politics. Ma'Abena's "sadness," and the menace lurking in Efua's demand for absolute discretion, or else she would be "very disturbed," betray any straightforward narrative of gay (as in happy) self-narration. The process of acknowledging an erotic attraction that could bring "disgrace" is uneven and unpredictable and speaks of both the joys and the pains of subverting an assumed norm. Its secrecy cannot be attributed or reduced solely to a lack of positive notions of homosexuality on offer or to the results of "internalized homophobia." It is rather integral to the push and pull of desire through which these young women come to "understand" first-time same-sex desire. The inconceivability of firsttime (supi) love is reflected by Ma'Abena's difficulty in grasping her feelings. Through the confusion and uncertainty of what her "senior" expected from her, Ma'Abena came to understand erotic intimacies as an expression of unspeakable feelings. Not only did she learn how to interpret certain affective conditions, she also became aware of the importance of waiting before articulating sexual feelings.

After completing secondary school, Ma'Abena forged a same-sex bond herself, in the single-sex environment of a semi-professional female football team. She befriended a teammate who had moved to Suakrom in order to further her football career. Talking of their trajectory of becoming involved with each other, Ma'Abena highlights how challenging it was to find the right setting and the right words to instantiate the erotic dimension of their friendship. They carefully observed and "studied" each other long before acting upon their mutual attraction.

I slept, in the same room with her six months before I did anything with her. I ate together with her, we bathed together, we returned from [football] training, we came home and all. But it took time before I did anything with her. For her, she was - the first day that I did it with her, I asked her whether all along, she loved me. And she said she had been studying me. That same thought was in my head, that I was studying her. That's why I said that different people have their different thoughts. If peoples' minds were like coconut or pineapple, it could be opened to see what was in there, because it takes time. ${ }^{44}$

Interview with Ma'Abena Oppong at Suakrom, April 25, 2008. 
In a context where same-sex desire is not usually discussed and categorized on a meta-level, there are fewer shortcuts to express same-sex attraction and propose love. Young women who are cautious and inexperienced in reading each other's minds and feelings express the need to "study" each other first. During this period of studying, an eroticized context arises from the sensuality and the careful attention given to everyday practices. This intimate "study" is by no means a standardized process of "coming out," for what is in people's "minds" cannot be neatly categorized and only manifests over time.

Ma'Abena's boarding school experience taught her to evaluate a friend's responsiveness, before articulating and exploring her desires. The process of grasping and acting out her feelings is not framed in terms of finding a sexual label or orientation to apply to them. Ma'Abena does not even use the term supi to talk about her girlfriendships. Her path toward learning how to "feel" is inscribed in the temporal and spatial framework in which senior-junior bonds can go beyond comforting or guiding each other and turn themselves into "something else." In her study of black lesbians in New York, Mignon Moore (2011) notes that women who grew up in the Caribbean considered the beginnings of same-sex attraction as the continuation of a best friendship that became "something else" over time. She concludes that in "many areas around the world" where same-sex desire is not legally sanctioned, intimate friends are compelled to take their time, keep their intentions veiled, and follow a vague and "more obscure and longer path" toward acting on and naming their feelings $(2011,39)$. Through the lens of queer affect theorists, however, Moore's argument could be reversed to argue that in some parts of the world a standardized language of sexual rights and identity may in fact serve to obscure the affective turmoil of (first) samesex love and conceal the length and the particularity of the path toward a personal queer self-understanding.

Unlike Ma'Abena, Adwoa portrays herself as knowledgeable and in control of things, ever since her explorations brought her to the police station. Such taken-for-grantedness emerges particularly in the stories of women who account for having had their first bathing or sleeping experiences with a female neighborhood friend or cousin prior to the social world of secondary school. The challenge of having a supi in a dormitory with dozens of girls stacked in bunk beds lies in carving out spaces of intimacy and trading secrets in an environment that is fraught 
with the vagaries of group dynamics among junior and senior students. Knowing how to veil heartbreaks, jealousies, and intrigues from headmistresses and policing prefects is vital to having a supi. This informal knowledge, and the capacity to establish meaningful spaces in which to foster twosome intimacies, while steeped in larger webs of social relations, is at the root of the bonding networks of those who continue to pursue same-sex desires as adults.

\section{Conclusion: Knowing Women}

In this chapter, I examined the figure of the (cinematic) supi lesbian and the Asafo Supi captain, and explored stories of having a supi at school. What connects these different discourses on supi are the notions of seniority, knowledge, and secrecy. In Nollywood and Ghallywood, the supi lesbian appears as the misguided, corrupted, and domineering "senior" who ensnares her junior lovers and introduces them to evil same-sex cults. The Asafo Supi is represented as a mothering and nurturing leader figure and the custodian of the secret objects of a young men's society. At girls' schools, supi amounts to an oldfashioned word for a close friend who is much more caring than a "school mother" or a bunk bed "partner," yet somehow superior. While we can only speculate about the etymology of supi, its associations with Mami Wata gesture toward Tinsley's imaginative archive of a black queer Atlantic (2008).

Sensing the intimate nexus of sharing food and drink and compelled to reciprocate, inexperienced girls may find the process of becoming someone's girlfriend or supi deeply unsettling. The mothering "seniors" who make erotic allusions and engineer intimidating situations may capitalize on the legitimacy of the school setting and, importantly, senior dominance. Gift theories are useful in thinking through the ways in which knowledge itself emerges as a gift that circulates, rather than being reciprocated in a vacuum between two girls alone. Following Strathern, we depend upon others for knowledge about ourselves (1988, 132). Both material gifts and the gift of knowing about the eroticism of same-sex intimacy are relational and do not take place in a dyadic. Thus, supi practice is a socializing process, which extends beyond learning how to reciprocate gifts. Since every secondary schoolgirl may become a senior herself, the passing on of "the gift" is an integral part of practicing supi. 
Secondary school girlfriendships are forged across regional, ethnic, and social groups. These school connections have considerable cultural support. They are encouraged by school authorities and by parents who allow their daughters to invite poorer girls to come and spend the holidays at their place. The language of kinship lends itself to girls' informal practices at boarding houses and in other close-knit homosocial environments, such as female football clubs. In these environments, far from home, senior-junior dynamics structure complex webs of friendships and the reproduction of kinship. The personal ways in which kinship is inhabited, however, and the meanings specific girls may attach to terms like mother and child, vary. At schools the formal language of kinship may either refer "to the status of a relationship, which might be formal and not particularly affectionate," or to the quality of a relationship (Blacking 1978, 113). Such terms as "school mother" or "team daughter" do not reveal what they mean to a specific girl and whether they can develop into "something else." Though Ma'Abena draws a line between the hierarchical "mother-child" constellation and the mutual supi attraction, her own reference to her girlfriend as her "senior," reveals that the boundaries between different sets of pairing are not as clear-cut - they are certainly difficult to distinguish for outsiders, parents, and school authorities. To girls themselves the boundaries become blurry with the development of erotic feelings. Learning how to veil the sexual dimension of their attachments is vital, especially to those girls whose same-sex desires do not terminate with graduation.

Interestingly, love letter-writing emerges as a common feature of the boarding-school girlfriendships described in different parts of the British postcolony. As Jennifer Cole and Lynn Thomas showed, the promotion of a "modern" economy of love was at the heart of the civilizing mission, as it aimed to replace flexible marriage arrangements with monogamous conjugality and nuclear family households (2009). This emphasis on companionate marriage as a modernizing force went along with the "idealization of verbal over instrumental expressions of attachment" (Hirsch and Wardlow 2006, 5) and a new language of courtship featured in love letters not least in Anglophone Africa (Mutongi 2009). In southern Africa, love letter writing emerged as the epitome of a new type of "romantic love," while remaining closely tied to older, non-written forms of expressing love (Hunter 2010). As this chapter shows, the practice of exchanging love letters could go along with conjuring older aesthetics of secrecy and initiation. 
Though this chapter focused on what supi implies in the school context, the term is also associated with and used among older market women with little school education. Especially in Accra where negative media representations have circulated at least since the 1990s, trendy young women dislike the word supi. To them it sounds "too local" or like a "dirty word." They prefer to use English terms such as "my girl" or "my dear" in referring to a same-sex lover. But mostly, my respondents referred to women who sexually involve themselves with other women, as those "who do it," or those who "know (how to do) it." Rather than verbally marking an explicit distinction between sexual and non-sexual female friendships, same-sex passions are invoked through a language of allusion that is consonant with Akan norms of indirection.

Despite the widespread association of supi with boarding school and hence with a legacy of the British colonial education system, supi is not regarded as a foreign import. Rather, prior to the term's correlation with lesbianism, it might have been understood as a desirable form of intimate friendship, the assumption, however, being that it could not be of public significance. Given its association with higher education and, more importantly, the fact that women themselves uphold the reciprocity of same-sex practice as something they were "taught" at secondary school, "knowing" offers itself as a trope to describe supi practices. On many levels, same-sex passion is hailed as an embodied form of knowledge - yet not as a Foucauldian "ars erotica," but rather as an awareness of the possibility that a woman can passionately love, and awaken the desire for this love in another woman. The knowledge about how to conceive and eroticize same-sex intimacy, while at the same time veiling it, is acquired through practice. Despite its elusive character, this practice is constitutive of the informal networks of selfassertive women, whom I refer to as "knowing women." Many of the women I met who used to have a same-sex lover were not ready to talk and reflect on these intimacies. The women whom I consider "knowing women," however, are women like Ma'Abena or Adwoa, who are articulate about the power of the erotic. "Knowing women" emphasize the meaningfulness of female friendships and desires and the knowledge embedded in a tacit same-sex culture. 


\section{3 "The One Who First Says 'I Love You'”}

\section{Dbaa Barima, Gender, and Erotic Subjectivity}

When we first met in 2001, she stood bent over the open bonnet of a car, her white overalls heavily stained with oil. It was in the center of Accra, in the improvised car repair shop of a friend, who - like many other young Ghanaian (for the most part) men - had specialized in disassembling car wrecks and building "new" cars out of the functioning parts. Janet Aidoo, the stocky young woman who was responsible for re-spraying the cars, was flattered when I congratulated her on doing such a hard "man's job." When shaking hands, she scratched my palm with her right index finger a quick, but firm gesture of erotic interest which up to that point, I had only experienced from Ghanaian men.

Six years later, in search of possible research participants, I remembered Janet Aidoo. It took several attempts to track her down. Meanwhile, she had spent two years in her rural hometown recovering from a respiratory disease caused by the inhalation of toxic car paint fumes. Back in Accra, she stayed in the densely populated neighborhood where she grew up. With her mother and younger brother she shared two rooms (a hall and chamber), the cooking and washing facilities were situated in a narrow compound and shared with a dozen other households. Periodically, Janet's infant nieces, her elder sister, and her mother's boyfriend joined them. But Janet was not home much and eventually her brother brought us to her friend's place where she spent most of her time. The friend, Vida, who rented a "hall-and-chamber" in an airier compound around the corner, turned out be more than "just a friend."

This chapter is a revised and expanded version of Dankwa, Serena (2013). 'The one who first says I love you': Gendered Female Relationalities In Postcolonial Ghana. In Nyeck, S. N. and Marc Epprecht, eds., Sexual Diversity in Africa: Politics, Theory, Citizenship. Montréal: McGill Queen's Press, pp. 170-87. and

From Ghana Studies vol. 14, 223-64 ( 2014 by the Board of Regents of the University of Wisconsin System. Reprinted in this book by permission of the University of Wisconsin Press. All reprint rights belong to the University of Wisconsin Press. 


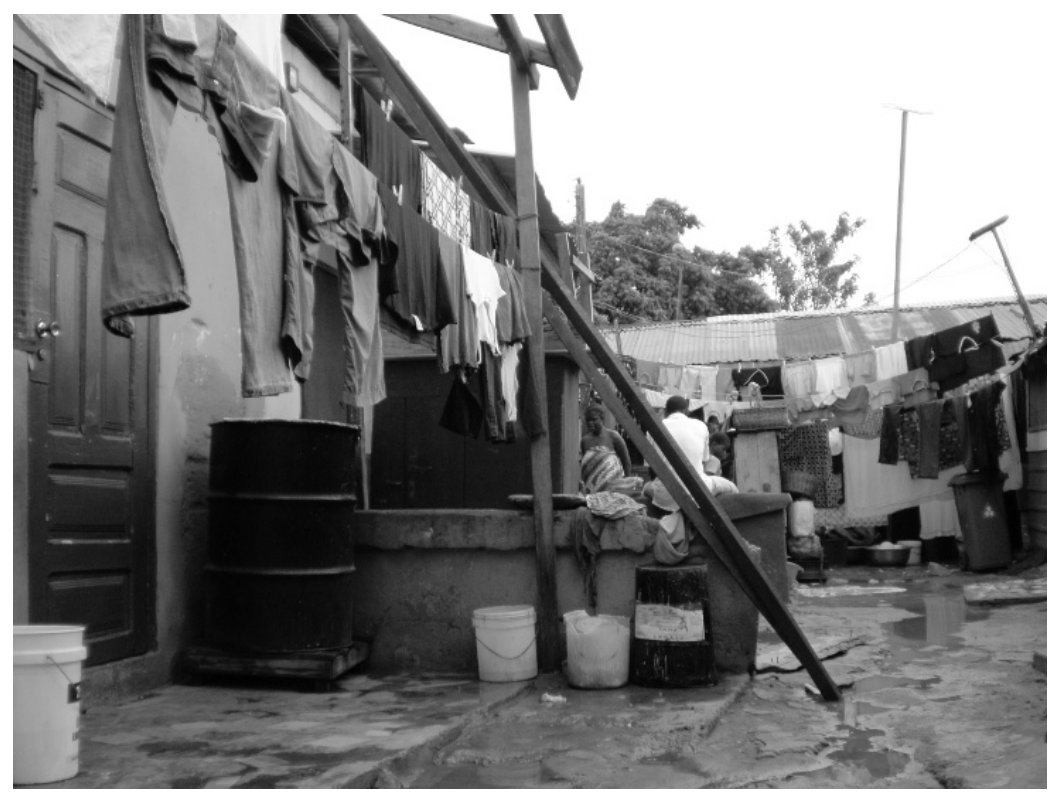

Figure 1 Janet Aidoo's living quarters during rainy season in Accra (2007)

As a native Twi-speaker and a Christian, Janet belongs to Ghana's largest and dominant group, both in terms of language and religion. In her pulsating Muslim neighborhood, however, she is part of a proud minority. More significantly, she is known as sprayer and is notorious for roaming about with young men, talking big, cracking jokes, and being quick-tempered and effusive. She is also somewhat notorious for frequenting drinking spots, having one too many, and boasting about it with her male friends - all behaviors indicating youthful masculinity. Some people recall that she was once detained by the police and friends and family pleaded for her release. Apparently, she was street fighting over a girl whose father happened to be an army officer. When the angry father turned up at her place, Janet responded to his interference by telling him "It's not you who I love, it's your daughter."

1 Fieldnote based on a conversation with Janet's neighborhood friend Habiba in Accra, November 28, 2007. 


\section{Situating Gender}

\section{Masculinity without Men}

The way Janet carries herself, her gait, her gestures, her demeanor, combined with the trade she proudly pursues, reminds me of the phenomenon Halberstam describes as "female masculinity." Referring to "women who feel themselves to be more masculine than feminine" (1998, xi), this term challenges the widespread notion that masculinity in women is "a pathological sign of misidentification and maladjustment" (Halberstam 2002, 360). It suggests that "women" who understand themselves in masculine ways cannot be considered bad copies of cisgendered $^{2}$ men but generate distinct modes of masculinity, on their own terms and in their own right. Based on the assumption that female masculinity can occasionally mark "heterosexual variation" but is mostly "the sign of sexual alterity" (Halberstam 2002, 360), Halberstam's work focuses on self-representations of specifically butch and queer embodiments of masculinity.

Halberstam's Female Masculinity (1998) reads as a critical response to earlier analyses by lesbian-feminist historians who sought to retrieve the voices of "women-loving women" across time and space. They subsumed a variety of gender non-conforming female writers into a unilinear history of a (pre-feminist) lesbian sexuality, whether or not these "women" identified as such $(1998,53)$. "A term like female masculinity," Halberstam suggests, is more apt for cross-cultural comparison than the figure of the lesbian, because "it allows for description rather than the absorption of the queer subject into a pre-existing category $[\ldots]$ in a variety of trans-local contexts" (Halberstam 2008, 9-12). Certainly, female masculinity reaches much further than the notion of a sexual lesbian identity with its firm historical links to the emergence of North Atlantic consumer capitalism (D'Emilio 1983). "Female masculinity" critically engages with homo-heterosexual binarism. Still, in referencing the separation of (biological) sex and (social) gender, the term "female masculinity" is perforce held in the Cartesian body/mind split.

The question of how female masculinity is negotiated relationally has been the subject of butch-femme discourse. Put simply, butch-femme theory offers a lens through which to understand gender in the context

2 Cis-gender is used to describe individuals whose gender identity aligns with the gender they were assigned at birth. 
of lesbian relationships. Butch-femme operates as a category of practice that differentiates between masculine-presenting women (butches) and their feminine lovers (femmes) who may not visibly distinguish themselves from straight women. Butch desires have variously been interpreted as a denial of the butch person's assumed womanhood. Lesbian-feminists considered this "denial" problematic for two reasons: firstly, it ran counter to a feminism that insisted that lesbians are women who embody an autonomous form of femininity (in response to scientific discourses, which tagged "lesbian" with "mannish" attributes). Secondly, butch masculinity seemed to be conflicted with the feminist critique of hegemonic heterosexual roles, (male) power, and violence. Masculine selfidentifications seemed to indicate self-hatred and "an identification with the patriarchal enemy" (Schirmer 2007, 193).

Queer theorists challenged the lesbian-feminist rejection of butchfemme identities and exposed the feminist middle-class norms of respectability that cast butch-femme dynamics as an imitation of normative genders. In particular, Joan Nestle's (1992) characterization of both femmes and butches as choosing to go into exile from gender (Martin 1994, 118) echoes Judith Butler's argument that femmes and butches are implied in but not determined by a dominant heterosexual framework (Butler 1991). In their quest to understand internal female power dynamics without drawing on masculine-feminine or activepassive stereotypes, theoretical interrogations of gender within lesbian relationships have explored the affective complexities overlooked in structuralist paradigms of gender-differentiated homosexuality.

In this way, critical butch-femme theories resonate with discourses of "knowing women" who do not use butch-femme terminology (or any other standardized gender binary) and offer a useful theoretical starting point for examining the lived experiences of same-sex desiring women like Janet Aidoo. As Halberstam notes, "the very notion of a female masculinity has been contained and managed by its inevitable relationship to lesbianism" (2008). "This inevitability is premised on what Butler (1990) critiqued as the "heterosexual matrix" - the conflation of sex, gender, and desire, implying that the sexed body determines not only a person's gender identity but also whom s/he desires. Within the terms of the heterosexual

3 I am referring to assertive women who are articulate in describing the intricacies of same-sex passion as "knowing women" (see Chapter 2).

4 I am indebted to J. Jack Halberstam for entrusting me with the English version of their introduction to Masculinidad Femenina (2008). 
matrix, this conflation has given rise to the assumption that female masculinity indicates homosexuality. But what if the relationship between female masculinity and lesbianism was not inevitable? What if masculinepresenting women were subjected neither to "the heterosexual matrix" nor to the stereotyped image of the perverted butch lesbian? What if female masculinity was not treated as a medical and psychological condition calling for psychiatric intervention? What if, moreover, female masculinity was translated into an African context where "'masculinity without men' (Halberstam 1998) can be ordinary and part of accepted gender experiences" (Miescher and Lindsay 2003, 5)?

In this chapter, I explore the varying practices and implications of "masculinity without men" in southern Ghana through the lens of three, quite different, "knowing women": Janet Aidoo, Ameley Norkor, and Adwoa Boateng. To do this, I begin by offering some further context on gender relations and forms of gender variation in West Africa and in Ghana specifically, as they relate to language, age, and kinship arrangements.

\section{Situational Gender}

African feminists have provided ample evidence that gender in Africa transcends biological sex. Nigerian anthropologists and sociologists in particular have sought to destabilize gender as a significant analytical category altogether, and argued that the primacy given to bodies and the fixity of sex in the global North does not hold for African societies (Amadiume 1987; Oyéwùmí 1997; Nzegwu 2005; Achebe 2011). Ifi Amadiume and Oyèrónké Oyéwùmí argue that in "western" societies, female-bodied individuals have been framed as dependent wives, whereas in many African societies male and female need to be understood as relational and situational categories. Their radical critique of "western" feminist investments in sex/gender as a key category of difference echo Butler's performative theory of gender (Arnfred 2011). Arguably, as African scholars, their critique of "the woman" as a universal concept was launched from a position of marginalization resembling that of queer feminists like Butler, who critiqued the heterosexual matrix underpinning the Second Wave feminist concerns with the white, middle-class woman (Arnfred 2011, 205).

Oyéwùmí insisted that, historically, sex was not a foundational category in West Africa. In The Invention of Woman she disqualified what 
she calls body-reasoning, that is, "the assumption that biology determines social position" $(1997,17)$ and blames feminists for reproducing the "biological determinism" and the mind-body split inherent in EuroAmerican systems of knowledge. Further, feminist theories concerned with the nuclear family model, in which sex/gender functions as the primary source of hierarchy and oppression, do not apply, for example, to the Yorùbá culture of southwestern Nigeria. As she argues, the extended Yorùbá family is "non-gendered because kinship roles and categories are not gender-differentiated $[\ldots]$ The fundamental organizing principle within this family is seniority based on relative age" (Oyéwùmí 2004, 4). Foremost in her argument that social categories in Yorùbá culture are not gender-specific is the lack of a grammatical gender distinction in the Yorùbá language between male and female pronouns. Instead, age is marked linguistically as a relational category, and hinges upon a person's seniority, regarding the person's sibling position, marital status, parenthood, lineage ties, ritual authority, or vocational skills. Oyéwùmí concludes that Yorùbá power is tied up with seniority rather than with maleness. This provocative thesis represents the far end of a spectrum of Africanist interventions that deprioritize sex/gender (Bakare-Yusuf 2004; Miescher, Cole and Manuh 2007).

A classic example of West Africa's gender flexibility are its institutionalized "woman marriages," as explored in Amadiume's landmark study Male Daughters, Female Husbands (1987). This work highlighted the extent to which the primacy of lineage ties and their reproduction among the Igbo outweighed a person's physical sex. For purposes of succession and inheritance, daughters could be designated "male" and wealthy women could climb the ladder by acquiring wives and becoming the legal and social "fathers" of their wives' children. Concerned with reproductive factors, most feminist Africanists (Krige 1974; Smith Oboler 1980; Tietmeyer 1985) neglected the close affective bonds emerging in these marriages. This focus on instrumental and economic factors feeds into assumptions that African family relations are "based on practical considerations alone, such as access to resources, as opposed to having a significant emotional aspect" (Njambi and O'Brien 2000, 5). Complying with the moral norms about female propriety and the heteronormative assumption about the naturalness of opposite-sex desire, feminist anthropologists criticized Melville Herskovits (1937) for even offering "homosexual tendencies" as a possible motivation for women to become "female 
husbands" and overlooked or rejected the possibility of sexual intimacy (Smith Oboler 1980; Tietmeyer 1985).

The practical constraints on becoming a "female husband," however, have received less attention than the question of their sexuality. Conditional to attaining a masculine status was self-aggrandizement and the taking of titles, which made the husband position a viable option only to a minority of female individuals. Since titles were awarded based on economic success, the incidence of women's titletaking among the Igbo was much lower than that of the men. A wife's duties as mother and head of the matrifocal unit of her husband's or father's compound made it arduous to accumulate capital and pay bride-wealth. Her cash turnover went back into the subsistence economy and household needs, which hampered her capacity to acquire titles and occupy senior roles (Amadiume 1987, 39).

Like the Yorùbá and Igbo languages, the Akan language, including Ghana's lingua franca Twi lacks a pronominal gender distinction, but cherishes appellations that indicate a person's seniority. As suggested by the editors of Africa After Gender? "seniority is a category as central to identity in Ghana and indeed throughout Africa, as gender is" (Miescher et al. 2007, 10). Indeed, among the matrilineal Akan, women, especially senior ones, have occupied important political positions, which now carry increasingly masculine connotations. Nonetheless, in our quest to correct Eurocentric misconceptions about African women's oppression by highlighting the fluidity of gender, we must resist the temptation to idealize the power of female elderhood (and not forget that matrilineality is both a blessing and a burden). As the following analysis indicates, it is the entanglement of both the material and the affective, the economic and the erotic, that so profoundly mediates the practices of women in Ghana who identify as seniors or husbands within their same-sex relationships.

\section{Age and Akan Matrilineality}

Since Akan culture traces descent through the female line, both men and women should give absolute priority to their matrikin. Regardless of marriage, one remains part of the (extended) matrilineal family, the abusua, and, even if children are to be conceived in marriage, conjugality is not conditional to a woman's social advancement. In this setting, duo-local residence is an accepted norm; a wife's main conjugal 
obligation, cooking for, and being sexually available to, her husband, does not require the establishment of a joint household. Akan matrilineality implies that a man is responsible for the upbringing of his sisters' children, rather than the children from his own marriage(s). Wives, therefore, are less at the mercy of their husband, than closely tied to (classificatory) matrilineal brothers and uncles. As Bleek argues, despite overt deference, a married Akan woman "hold[s] a considerable amount of power [which] is chiefly located in her genealogical and economic position. The former is always and the latter often independent of the husband" $(1976,144)$. The resulting instability of marriage is a phenomenon of "extreme lineality, whether matrilineal or patrilineal" (Bleek 1976, 91). Companionate marriage and the nuclear family model, an ideal sought after not least by urban Christian middle-class couples, has complicated this lineal logic, without, however, achieving resolution (Clark 1999, 718). As this chapter reveals, matrilineality, in particular, remains an attractive societal structure for women with little romantic interest in men.

According to Elizabeth Amoah, Akan culture invokes maleness and femaleness as basic modes of procreation applying to all beings. "An animal or plant is described as nyin [male] if that animal cannot produce its own kind or that plant cannot bear fruit" (1991, 131-32). This reproductive matrix configures gender ideals and shapes male and female experiences of the life cycle: youth, adult, and elderhood. These categories are flexible and refer to status above and beyond age (Adomako Ampofo and Boateng 2007; Miescher 2007). Firstly, marking the period between physical maturity and marriage, youth tends to last longer for men than for women. Youth is thus a "liminal category" that grants young people certain liberties in gender expression and may allow especially boys and male students to engage in institutionalized cross-dressing practices at yearly school or campus events (Geoffrion 2012, 1; 8).

Second, though children are deemed particularly essential for a woman's happiness and personal fulfillment, both men and women become fully recognized adults through parenthood (Woodford-Berger 1997). As Clark points out, adult femininity does not assume romantic notions of motherliness, and the ability to provide for one's offspring is more integral to motherhood than breastfeeding and physical childcare (2001, 303). The ideal Akan woman pursues income-generating 
activities and, committed to the working world, she strives to become a "big woman." Just like the "big man," a figure who has an enduring appeal in Ghana's history, urban women can become "big," and assert their autonomy, by accumulating and displaying wealth and large numbers of dependents (Akyeampong 2000).

The third age group is comprised of senior men and women, whose moral and social achievements are recognized by their lineage, and their larger community. As elderhood is not gender specific, women can attain elder status and take on public roles of leadership and authority. Yet, as Stephan Miescher concedes, the power of female elders and lineage heads tends to be more hidden and indirect (2005, 195). Accounts of the ambivalent positions of queen-mothers and female elders suggest that matrilineality effectively translates into male gerontocracy, transmitted through the female line (Gilbert 1993; Akyeampong and Obeng 1995; Allman and Tashjian 2000). These scholars have further shown that patriarchal tendencies were buttressed during the colonial period, when governors and missionaries privileged men as their business and political partners. Today, men access public power and accumulate wealth more directly and more overtly than women.

\section{Sbaa Barima}

In Twi the semantic flexibility of gender is reflected in the phrase sbaa barima, composed of the terms sbaa (woman) and sbarima (man). In Clark's translation, an sbaa barima is a "manly or brave woman." Barima serves as adjective and connotes young male bravery, "but is also the most polite positive way of referring to sexual virility" (1999, 722). The Asante (Akan) market women whom Clark heard called sbaa barima in 1979 and 1994 were "those who had achieved the level of financial independence, considered essential for men, not those showing unusual physical strength, bravery, or sexual prowess. The Akan image of womanly beauty already includes more strength than in western beauty ideal, consonant with historic female responsibilities for farming, so physically strong women did not attract particular comment" (Clark 1999, 722). As a compliment for an industrious female trader, the phrase conveys the masculine ideal most often transferred from men to women: the positive capacity for economic selfaggrandizement. 
The connotations of sbaa barima as I came across it in 2008 encompassed physical and even erotic overtones. Asked about its meaning, a retired secondary-school teacher first declared that an sbaa barima was a tough woman, stern and self-contained, who would not let herself be "cheated" by anyone. Then she added, not without pride, that she herself was called sbaa barima in her late teens, when she was climbing trees and playing football still. As an educated and unmarried woman she could afford to pursue leisurely activities firmly associated with male youth. Among my younger respondents the term was less common. I was, however, told that girls who look or act like boys and assertive young women who express and present themselves in ways associated with men, are teasingly called barima. When I asked "knowing women" in Suakrom about their associations, they pointed to tough and slightly aloof female footballers, who project a hard shell and actively pursue their same-sex interests - gender-bending women who, in EuroAmerican queer contexts, might be considered butch.

James Christensen's ethnography of the Fante suggests that at least during the colonial period of his research, certain women were associated with sexual alterity (1954). In his discussion of the term sunsum - a person's "spirit" - he mentions the qualities of a baa banyin, the Fante term for sbaa barima: “A man with a 'heavy' or strong sunsum is said to be aggressive, while a 'light' or weak sunsum is ascribed to the introvert. A 'light' sunsum is characteristic of a woman, while an extroverted female, or one with homosexual tendencies, thus having a 'heavy' sunsum, is referred to as a baa banyin (female man)" (1954, 92). Christensen's comment indicates the ways in which non-physical qualities are constitutive of not only the Fante but the larger Akan concept of personality (Gyekye 1995). However, since nothing is said about what homosexuality implies, one is left wondering whether Christensen represents his own sexualized reading of heavy- and light-spiritedness or that of his, probably male, Fante informants.

Christensen's comment suggests that gender variance (at least that of "female men") was associated with sexual practice. This contrasts with Clark's careful observation that an sbaa barima's subservience to her husband might be reduced, but "the sexual conduct of an sbaa barima was not suspect" (1999, 722). Obviously, their different perceptions may reflect ethnic and chronological differences: Clark 
worked among urban Asante women in the 1970s and 1990s; Christensen studied the coastal (Akan) Fante in the early 1950s. Furthermore, as mentioned in the introduction, the Fante and the Ga have been stereotyped to be sexually less discreet than the Akan groups of the interior. Reflecting on Clark's considerations, I would argue that at the time of her research, even more so than today, rumors about an sbaa barima's same-sex intimacies were not easily brought to public attention. This would be the case especially if suspicions concerned a mature woman vested with a network of friends, relatives, and dependents. Due to norms of discretion and indirection that are particularly revered among the Asante, the person uttering such rumors could be considered more dubious and indecent than the suspect herself - with the qualification, of course, that this reticence would not inhibit either unspoken suspicions or damaging gossip.

Besides historical differences in the overt and tacit meanings of sbaa barima, junior and senior notions of sbaa barima are generational. Young female urbanites and in particular footballers who appropriate cosmopolitan masculine styles are noticeable and attract comments that mark them as deviant. Among women who have exceeded their junior status by virtue of complying with the imperative of motherhood, it is economic capacity rather than physical appearance that determines whether they are considered manly in a positive sense. It is this adult version of "female masculinity" that Clark grasps when she says that a woman's "economic performance of gender appears more central and more notable" than her sexual behavior or bodily gender presentation $(1999,727)$. The significance of a person's socio-economic power and status informs my analysis of both the self-fashioning and the gender roles played out between female lovers.

In the remainder of this chapter, I explore the gendered terms through which women in southern Ghana speak of their same-sex relationships. When talking of "masculinity without men" in this context, then, I am particularly interested in the complex interrelationship between performances of masculinity, the striving to become an sbaa barima, and the language deployed to render intelligible shifting same-sex dynamics. Through a reconstruction of Janet Aidoo's life history I examine the practices constitutive of her erotic subjectivity. 


\section{Janet Aidoo, Working Masculinity}

\section{Football and Cars}

"The time I was kid, I started with football. So anytime you would see me, I hold a football." ${ }^{5}$ Thus, Janet begins to recount her story. We are sitting in the dimmed hall of Janet's lover whom she refers to as "Sister Vida." It is a hot afternoon. Vida is working at the market; Janet has just returned from the military campus where she hopes to find work in the vehicle repair services department. Narrating her life history she draws a direct line from her favorite childhood activity - playing football - to the vocational training for which she opted: "I was twelve years of age and I decided to play the football and my mother told me if I play the football I will not give birth, so I should stop the football and go and find something better to do. So I said, I decided that I would stop the football and go and learn spraying. That's why I've become an auto sprayer." Football and cars are inextricably and consistently linked in Janet's narrative. Janet positions herself as an autonomous subject who makes decisions and sticks to them, while suggesting that she has always been attracted to spaces and activities associated with boys and men. She even claims that she could have joined the "Black Queens," Ghana's national women's team. "After I stopped playing the ball, about one year [later] I heard that all my friends went to Germany to play football. It pains me a lot, but that time, it was too late."

Janet's desire to travel the world and perhaps find greener pastures outside Ghana is only one part of her nostalgia over her abandoned football career. In the football arena, youthful displays of female masculinity flourish and same-sex intimacies are tacitly tolerated. Certainly, Janet's mother's worry that football could endanger her daughter's capacity to give birth is rooted in the notion that football is a "modern" leisure activity associated with cis-gendered men, and thereby opposed to more "traditional" girls' activities that privilege motherhood. But she may have also been aware of the erotic possibilities emerging in an all-girls environment. Upon my inquiry as to whether her mother, a savvy trader in her late forties, really believed football causes barrenness, Janet insists: "Because I'm woman, if I play the football I can't give birth, you understand? She said my, this thing,

5 All of Janet Aidoo's statements in this subchapter are taken from an interview with her in Accra on February 20, 2006. 
my womb will turn and I can't have birth." Whether the threat of a turning uterus is her mother's or Janet's own image, the fact that this explanation is plausible speaks to a flexible understanding of the body, including the mutability of bodily organs through repeated exposure to (non-normative) social behaviors.

Janet's mother, I suspect, knew that her daughter's anatomy would not be affected by her physical activities but worried that her youthful masculinity might thrive in the football arena and eventually prevent her from becoming a respectable person, through motherhood. However, if she hoped that her daughter's masculinity would decrease without the influence of football, she was wrong. The fear of losing her reproductive powers may have compelled Janet to give up football, but it did not prevent her from pursuing a vocation that is gendered as male. She told her family that she wanted to learn auto spraying. "They said no, they would not let me, $[\ldots]$ because spraying is not a job of women, it's only men who spray so I should go and learn sewing, and I told them

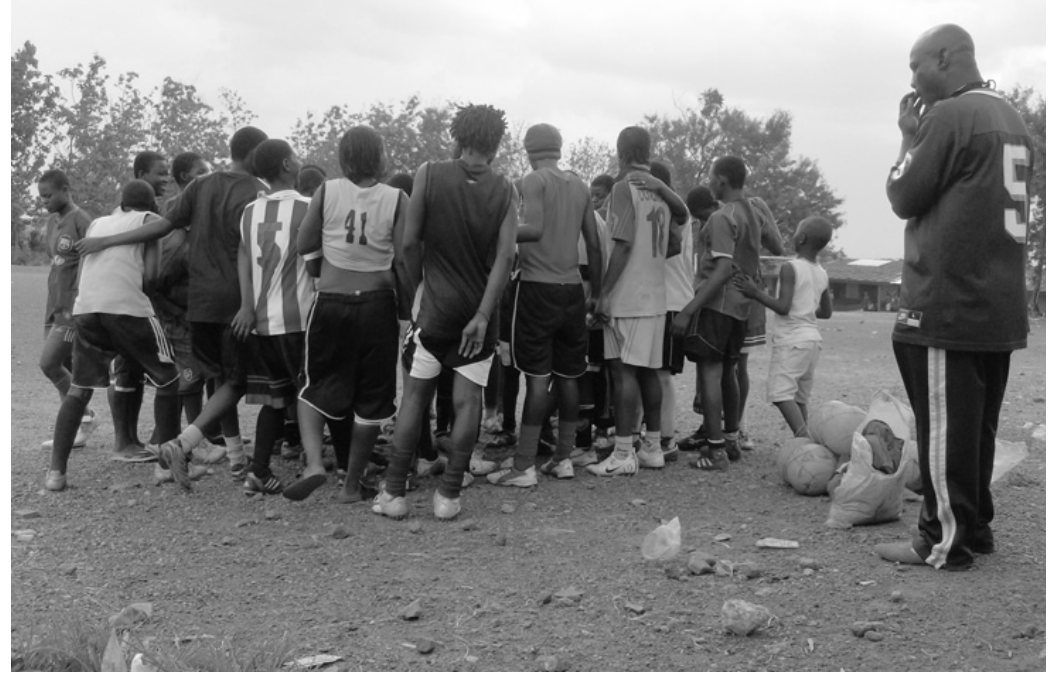

Figure 2 An Under-20 semi-professional women's football team gathering before a friendly game (2008) 
I can't learn sewing because I don't know how to do woman's job, only job that I can do is [a] job that men do, that one I can do it." Janet does not argue that she did not want to learn a woman's job, but that she could not. Similarly, her desire to be an auto sprayer does not seem to be motivated by the actual skills she would acquire but by the fact that they are associated with men. In her narrative, spraying cars seamlessly emerges as the sequel and alternative to playing football.

The question of how gender takes shape in childhood activities and work preferences has been discussed in a growing anthropological literature on "toms" and "tombois" in Southeast Asia (Sinnott 2004; Wilson 2004; Blackwood 2010). Evelyn Blackwood's descriptions of tombois in Indonesia resonate with Janet's enactments of masculinity. Blackwood (2010) asserts that tombois in Indonesia perform a context-bound "contingent masculinity" that weaves in and out of different spaces in which different presentations of selves are permissible and desirable. By conceptualizing these masculinities as contingent, Blackwood reminds us that personhood in many places is understood as relative and contextual, rather than fixed. Thus, the masculine aspects of tombois' subjectivities are "conditioned by the material effects of particular spaces and gendered expectations" (Blackwood 2010, 160). In the day-today practices through which they perform a "contingent masculinity," work emerges as a "key indicator of tombois' identification with men." Although Janet is not part of a network of self-identified tomboi culture, her statements echo the words of Blackwood's Indonesian respondent Robi, a tomboi who always engaged in activities carrying male connotations. Robi states, "I feel like a man because the things I do are more like what a man does" (Blackwood 2010, 96). Similarly, Janet's self-portrayal draws on the certainty that she is destined and appointed to do work "that men do." Janet interprets her ongoing interest in activities bearing male connotations as evidence of her masculine entitlement.

This determination brings Janet into conflict with normative gender expectations and impels her to challenge her family. The authorizing "they" who opposed her desire to become a sprayer is her abusua. In the lives of many Akan young people, senior matrilineal relatives hold more authority than their actual father, especially if the parents do not co-habit. For her professional training, Janet needed the support of her 
matrilineal uncles, who initially declined her request and wanted her to become a seamstress. But Janet passively resisted. "I sat down [for] about six months, and they thought about it and they said, ok [ ... ] they will take me to learn it." Janet stayed at home, "sat," and refused to cooperate until they reconsidered and found her an apprenticeship. She suspects that they gave in because they realized that people would be impressed to see a woman working with cars. People would say: "Hey, I didn't see a woman who is learning this job before." Being a novelty, she would be in their good graces. Indeed, Janet revels in the memory of the party that was organized when she successfully completed her training. Men and women praised her and shared their astonishment about her ability to do the "spraying work." Janet's successful performance eventually made up for her waywardness. Her strength and sense of rightness enabled her to avoid seamstressing and do men's work. Indonesian tombois, as Blackwood found, frame their practical enactment of masculinity as proof of their status as men, and as all the evidence needed to understand them (Blackwood 2010, 94-95). This "doing" of masculinity, against all odds, makes tombois authentic in their own eyes, and in the eyes of their girlfriends, families, and men friends.

While Janet attributes the respect of friends and family to her skillfulness and perseverance in following her vocational calling, her family's eventual consent and investment were equally motivated by pragmatic economic considerations. Her ambitions must be read within a context in which most women struggle to make a living within the informal sector. As elsewhere, "jobs that men do" are more likely to be formal, stable, and better paid. Whereas most women who braid hair, sell petty items, or home-cooked food lack social security (Adomako Ampofo 1997, 18) Janet hopes for a salaried, formal position with the state, preferably as a soldier - and in fact she has taken the first step in that direction by taking an unpaid internship on the military campus. By strolling around in her work overalls and flaunting the military campus identity tag in her neighborhood after work, Janet not only enacts masculinity but also presents herself as an upwardly mobile citizen with a formal and supposedly paying job. The ideal of being selfsufficient and climbing the social ladder complies with the modern myth of the male breadwinner, but also references the image of the maternal provider that still holds "immense reverence and authority in Akan culture” (Clark 2001, 303). 


\section{Marrying and Mothering}

Janet often looks after her sister's daughters. Like many young men and women, she engages in the collective parenting of the children in her compound, yet giving birth herself is also of paramount importance. While Janet defies normatively gendered professional expectations, she is determined to have at least one child. When asked if she can imagine "to marry a man," she affirms evasively. "You know, because of the birth. Everybody wants to have a baby." Janet's hesitant readiness to "marry" needs to be understood within a Ghanaian setting that allows her to "marry" without ever signing a contract or establishing a conjugal household. In everyday usage the term "marrying" is very broadly interpreted and used synonymously with engaging in a longterm opposite-sex relationship (Clark 1994, 343). These fluid understandings are consonant with historical Akan models of marriage in which marriage happens in stages. It may take years to complete the gradual process of formalizing a conjugal relationship, and in some cases a marriage is never completed (Allman and Tashjian 2000, 53).

Marital unions have been considered to be of less importance than family ties (Bleek 1976, 88); as an Akan proverb says: "Marriage is a bond of friends, not a bond of family." ${ }^{6}$ Bleek describes three types of unions between opposite-sex lovers in Kwahu, the Akan region from which Janet hails. Customary marriage is performed through a series of formal visits and tiri aseda (literally: head thanks) payments from the husband and his family to his wife's family. As long as the presentation of tiri aseda in the form of drinks and money is not fully completed, it is up to the woman's family to define the relationship and decide whether the man can claim exclusive sexual rights (Allman and Tashjian 2000, 55). Alternatively, mpena awades, literally "lover's marriage," or what Bleek refers to as "free marriage," enjoys some degree of public recognition and the couple may live and raise children together. ${ }^{7}$ The man is known to the woman's family or has announced marriage intentions by paying the initial "knocking fee," usually consisting of a bottle of schnapps. This type of "free marriage" has been considered "an integral part of the system of marriage" (Bleek 1976, 100, citing Tetteh 1967, 209), rather than a pre-marital stage only. Lover relationships

6 The Twi proverb is "awadec ye yenko, cnnye abusua."

7 Today, the informal unions sought by men who lack the income to provide for a legal marriage are termed "lover marriages" (Adomako Ampofo 1997, 182). 
avoid disclosure, are secret in character, and even if they are known to everybody, they are still talked about as secret (Bleek 1976, 103).

Today, the globally pervasive ideal of companionate marriage is gaining currency throughout urban West Africa, where romantic love is seen as the epitome of progressive individualism (Masquelier 2009, 227). Still, many women remain tied to their own (lineal) family and, as Clark notes, look to marriage primarily to provide them with "children, economic support, and sexual satisfaction" within a respectable framework (1994, 338). This primacy of motherhood and material survival has also allowed women with little interest in sexual intimacy with men to retain a grasp on pragmatic forms of conjugality.

Dede Kpobi, for instance, who meets all the characteristics of a successful sbaa barima, got married to a man who migrated to the USA. A hard-working, tight-lipped jewelry trader, who travels to Togo every other week for new supplies, she is devoted to her female lovers. In light of her financial autonomy and the fact that she mothers two boys - her late sister's children - I was surprised when she eventually got married in her early forties. But Dede waved away my question as to how she met her husband and simply remarked that she still does not like "penises," and that it is therefore better for her to have a husband abroad with whom she does "not have to do it" all that often. ${ }^{8}$ At the time, expecting his annual visit, Dede was driving his car and taking care of the house he had started building. While yielding to the normative pressure to marry, and thereby deflecting rumors about her samesex passions, she managed to maintain her autonomy by opting for a long-distance husband.

In Janet's case, she eventually chose to start a relationship with the married man who would become the genitor of her child in neither a conjugal nor a particularly secret way. Her partner was not one of her age mates, but rather, as one of her neighbors and drinking mates put it, an "old soldier man." According to the neighbor, everyone was surprised about Janet's pregnancy, because "she makes [acts] like a man." When I mentioned this remark to Janet, she added that some people believed she had both a penis and vagina. Her "soldier man," however, turned out to be a medical assistant in his fifties. They met at the military hospital where he fondly treated an ankle injury she had sustained, and which the doctors had dismissed. Upon visiting Janet at

8 Fieldnote on an informal conversation with Dede Kpobi, January 17, 2012. 
home, he also proved to be an effective herbalist. He noticed immediately that Janet's mother had been ill for years and diagnosed a spiritual affliction. The "black medicine" he prescribed, to be purchased in her hometown, led to her speedy recovery. In light of his healing skills, he soon found himself in Janet and her mother's good graces. The fact that he was married with three adult children already might have even worked in his favor as a testimony to his respectability and fertility.

Janet suggested that he was attracted to her not least because of the questions with which she drilled him during their initial hospital encounter. Certainly, her inquisitiveness indicated that she considered the romantic interest implied in his caring attention, and her interrogation regarding his background testified to her sense of tradition. As their relationship became more serious, Janet asked him to rent a room for her and he found her a room located in his own locality just outside Accra. A room of her own had long been a wish of Janet. His occasional visits did not deter her from inviting her girlfriend, a mother of three, who "understands" Janet's need of a male lover. Before long Janet became pregnant and threw away the abortion medicine with which he provided her. While he insisted that his impending retirement would not allow him to support another child, she maintained: "God will take care." Their relationship continued in line with the hospital's recommendation to have sexual intercourse during pregnancy at least once a month, which according to Janet, alleviates the need for prenatal vitamins. Her belief that the father's seed nourishes the unborn ties in with older Akan beliefs that semen helps to build up the unborn "and to 'open the womb' for an easy delivery" (Sarpong 1991, 53). Sexual activity during pregnancy is further underpinned by the belief that it strengthens the ntoro, the spiritual aspect of paternity that is transmitted to the child at conception. ${ }^{9}$

Up until recently in Akan thought, while the child's physical composition and ascribed social position are received through the mother's mogya (blood/line), the totemic ntoro spirit was thought to determine much of a child's temperament and moral character. Thus, in the 1930s, pregnant women were expected to engage sexually with their child's genitor in order for the child's ntors to develop well (Miescher

9 Ntors, as the patrilineal spirit, was much debated among anthropologists who grappled with the father's role in Akan society. For Rattray, for instance, matrilineal affiliations were "manmade" while a father's role was original, natural, and essential (Allman and Tashjian 2000, 104). 
2005, 17). Allman and Tashjian refer to ntoro as a motivation for women in colonial Asante to be married to their children's father, as a woman's sexual activity in marriage was supposed to give her and her children spiritual and economic protection, and was central in defining rights and obligations between a father, his children, and their abusua (2000, 97). Effectively, the husband's "shadow" (ntors) could protect a woman from unwanted sexual attention, gossip, ill health, and death, while good relations with the abusua of her child's father gave the child a good head start in life (Allman and Tashjian 2000, 48).

In many ways ntors could be considered part of a male-orientated moral substructure of matrilineal Akan society. Today, as Clark remarks, the moral charge of fatherhood has been replenished with Christian values and paternalistic institutions that motivate women to "marry" their child's genitor. Correspondingly, urban fathers ought to live up to their traditional responsibility for a child's moral education and occupational training by paying for formal schooling and apprenticeships (Clark 1994, 336). Ntors rituals are not performed anymore, yet a child's spiritual and physical health is still chiefly associated with its father's acceptance and public recognition. This is performed at a child's name-giving ceremony (abadinto). Mostly referred to in English as the "outdooring," it signifies the child and mother's first public appearance. At the outdooring the genitor is given the chance to acknowledge paternity by giving the child a personal name - usually the name of a close relation of his. During the outdooring he provides the mother with the necessary items of childcare and he is expected to furnish her with cloth for the occasion (Lowy 1977, 20).

The outdooring of the healthy baby girl Janet gave birth to took place in her mother's tiny hall. While the baby's first name marks the father's ethnic affiliation, her fie din, literally her "house name," honors Janet's mother. Mamee'Aba was born on a Thursday, just as Janet's mother. "Mamee" means mother and "Aba" is the name for a Thursday-born, though in the child's father's native Fante language. The outdooring pictures Janet shows me testify to Janet's capacity to unite seemingly conflicting areas of her life. Janet sits between her girlfriend and the child's father, her mother smiles next to him. The child's father is joined by two elderly men wearing Akan cloth in the traditional men's way; ${ }^{10}$

10 The Akan men's outfit consists of a six-yard piece of cloth, draped in a tunic-like way, with one shoulder that is not covered. 
Janet herself wears a wide, embroidered agbala with pants underneath, all in white. Usually worn by Muslim men, this Nigerian-style robe is an attractive, unisex compromise for southern Ghanaian women who are not comfortable with the obligatory confining skirt. Then Janet brings out yet another outdooring picture. It shows the woman who tailored Janet's outfit and happened to be her lover, as Janet tells me with a witty smile. The outdooring brought together discreet intimate relations that matter to her: girlfriends, lovers, and family members.

Janet's daughter is barely two months old when we reconnect. Janet abides by the postpartum role to abstain from (hetero)sexual intercourse while breast-feeding and stays with her mother. When we step out for a minute, her mother gives the baby its evening bath. Leisurely strolling through the streets of her neighborhood for the first time after birth, Janet bumps into her mates who come up to her and pat her shoulders in recognition of the freshly graduated mother. As if to testify that she is on equally good terms with the baby's father (despite his having stopped renting a room for her) she gives him a quick call. As we sit down in a drinking spot, Janet summarizes the orchestration of her journey into motherhood: "I was quick, I am intelligent, you know that I'm intelligent? I have born and now I'm back" in the streets. ${ }^{11}$ Janet highlights how she assessed her options strategically, in order to avoid too much "marrying." She seized the situation of having a mature, married suitor, to become a mother without having to abandon other aspects of her subjectivity, such as her identification with the young people she roams the streets with.

Her independence is facilitated by her professional training, but also by her mother who had always urged her to have a baby and is now prepared to look after the child while Janet takes up work after a brief maternity leave. After not having been with men for many years, choosing a man her mother highly approved of is indicative of Janet's devotion to family (values) and their reproduction. Her ongoing erotic autonomy is also enabled by the fact that her baby's father lives far away, beyond the reach of rumors about Janet's backstreet reputation and her drinking and smoking habits. It is to be expected that he will not bother to interfere with her personal life much, not least to stay on good terms with his primary wife, who was aware of and apparently "OK" with her husband's extramarital fatherhood. Further, based on

11 Fieldnote on a conversation with Janet Aidoo at Accra, January 17, 2012. 
his age, he might not read her toughness as a sign of "lesbianism," but rather as part of the no-nonsense attitude of a prospective sbaa barima with a keen awareness of the need for discretion.

The male connotations of Janet's work help legitimize her masculine demeanor, which appears to be an inevitable part of her vocational identity. At the same time her wit and her strategic "intelligence" paid off. Her motherhood helps deflect from her ambiguous gender and confers upon her the status of a fully fledged adult. Her ability to take on the responsibility for a child makes her "bigger" without compromising her desire to express herself in manly terms. It would be pointless to debate the extent to which her wish to be a mother was fed by an intimate longing to mother a child, and to what extent she was eager to prove her child-bearing capabilities in order to establish her respectability and enhance her upward mobility. Besides, motherhood is bound up with class and gender expectations and underpinned by social, cultural, and economic considerations in every quarter of the globe - not least in the global North, where the wish for a child is romanticized and represented as a primordial, yet wifely desire.

\section{Liking Life}

When we first met, Janet, like the majority of urban Ghanaian women, chemically straightened her medium length hair. Instead of attaching elaborate extensions, however, she wore it down or in cornrows. This practical hairstyle has been the signature of shorthaired Ghanaian schoolgirls and elderly and poor women who cannot bear or afford chemical treatment anymore. During the last two decades, cornrows have undergone a transatlantic shift in meaning. Worn by AfricanAmerican hip-hop artists, they have come to represent a form of black masculinity that is fashionable among Ghanaian hiplife ${ }^{12}$ musicians who see themselves as part of the black Atlantic world. At the same time, the simplicity of this style paired with its gendered polyvalence makes it popular among West African sportswomen, not least female footballers.

12 Hiplife became highly popular in the 1990s when Ghanaian artists fused hiphop with highlife, Ghana's older popular dance music genre (Collins 1996). Using the local languages, mostly Twi and Ga, hiplife has not been able to reach an international audience. 
When we last met, Janet had started dreadlocks. Previously, only the hair of akomofos (diveners) and people who live on the street in Ghana, were understood to be permanently "matted." Recently, dreadlocks or locks have received some acceptance as a hairstyle, spearheaded again by a wide variety of young musicians who look over the ocean and wear them as part of their professional artist outfit. Still, dreadlocks are associated with drugs and sex work and worn with caution. Young Ghanaian women in particular tend to opt for manicured imitations of dreadlocks that can be undone, clashing with the original statement of matting or locksing ${ }^{13}$ as a statement against artificiality. I was surprised when Lydia Sackey, who adopts a neat feminine look, complimented my shoulder-length locks at the time. I was not the first queer woman she had met with locks and she was certainly aware that locks have been popular among black feminists and lesbians in South Africa and the USA, the two places Ghanaian sexual rights activists were looking toward. Lydia herself claimed that she will stop straightening and start locksing, but only once she has found stable employment. The image of the unkempt, loose woman seems to prevent especially unemployed, childless women, who are pursuing a feminine look, from growing locks.

Masculine gender presentations, displayed in hairstyle, clothing, and adornment, became key markers of identity within transgender and butch-femme subcultures in postwar North America. Today, as Mignon Moore's study of black lesbians in and around New York City shows, butch-femme roles have lost some of their importance in structuring sexual interactions, but continue to organize lesbian social worlds as "a visible expression of a distinctive lesbian eroticism" (2011, 89). While African-American working-class butches avoid figurehugging clothes (Moore 2006), Janet does not shy away from tightfitting jeans and, drawn to the social and cultural capital of motherhood, makes no attempt at disguising her ample bosom. Janet's off-work clothes are not strikingly masculine. Rather than fashioning herself in the style of a (potentially morally objectionable) male youth, she goes along with Ghanaian fashions. At weddings, outdoorings, and formal festivities, women wear a combination of slit and kaba, the national dress

13 Locksing refers to the gradual process of growing dreadlocks by rolling hair into tightly coiled spirals. Depending on the climate, the hair texture and the desired size of the locks, the locksing process can take several months. 
consisting of a skirt and a short-sleeved blouse of the same material, plus an extra length of cloth usually worn around the midriff, mainly to make it appear fuller (Ruschak 2006). On formal occasions, most young men combine plain western trousers with a colorful Ghanaian-style cotton shirt. Janet resorts to shirt and trousers, but both in West African print or tie-dye cloth (just like the slit and kaba). This unisex two-piece outfit is gaining popularity among women who have a preference for wearing trousers. At less formal parties, such as the Easter Street festival in Janet's hometown, she evoked the image of the colonial-era bachelor by wearing a sandy suit, sturdy shoes, and a man's wristwatch, an outfit that would earn her comments about being "colo," marking an outmoded supposedly "colonial" style. Janet's style is sometimes reminiscent of the prototype of an old-fashioned gentleman working in colonial administration who, due to his bookishness was called krakye (literally: scribbler) or scholar. Unlike the attire of hip-hop culture, this masculinity seems to be too antiquated to be morally objectionable.

The imperative to cultivate a "life" and have "style" preoccupies many young urban Ghanaians amidst precarious living conditions. "Ope life," which means s/he likes or enjoys life, is a standard Twinglish ${ }^{14}$ expression that hails a person who emphasizes a distinct personal appearance. "Liking life" is used mostly in positive reference to the cultivation of a sophisticated urban style, and the love of going out with groups of friends and displaying one's "life." Similarly, standing for lifestyle, the term "style" goes beyond self-fashioning through dress, hairstyle, and adornment. Particularly for people with little expendable income, "style" encompasses dimensions of bodily expression that do not require the purchase of consumer goods: particular ways of walking, dancing, gesturing, telling jokes, and being verbally artistic - in short, of staging a public self. As Paulla Ebron (2007) elaborates, in West African cultures, complex meanings are assigned to both bodily and verbal expressions of self. These enactments of an innovative aesthetic self are highly significant. Physical and linguistic practices are thereby produced and interpreted as intentional performances $(2007,177)$. In impoverished neighborhoods that are configured by restrictive living quarters, remarkable features in a person's presentation of self testify to her resourcefulness and capacity to carve out niches for a distinctly personal "life." The invented and constructed

14 Classic southern Ghanaian mix of Twi and English. 
nature of someone's "style" is emphasized rather than disguised. It speaks to the ability of creating uniqueness in spite of high levels of social and moral control among neighbors. Thus, Janet's sometimes peculiar way of fashioning herself follows a cultural ideal that she reconfigures in a gender specific way.

On the street, Janet attracts both disapproving and admiring glances for her stocky posture and composure. She takes pride in her ample bosom and its association with fertility and prosperity. While a slimmer body ideal is catching on, in impoverished neighborhoods it connotes frailty, sickness, and boyishness - and hence juvenile powerlessness. Instead, Janet claims dominant adult representations of Akan womanhood. Not without pride she points out that men regard her as a desirable match. To me, however, it seemed that some of the male passers-by whom I witnessed commenting on or bemusedly complimenting her "strong structure" could read Janet's gendered and sexual alterity. Nonetheless, the way Janet carries herself and playfully, even strategically, engages with a series of contrasting styles - "modern" and "traditional," womanly and manly, "western" and Ghanaian, junior and senior - allows her to express a contingently masculine "life" without suffering overt stigmatization.

While Janet's dream of becoming a soldier indicates masculinity, it also conveys a desire to buttress her sense of being a Ghanaian national with middle-class aspirations. In postcolonial African nation states, with their relatively short national histories, women in uniforms tend to be associated with officialdom, authority, and modernity, rather than with gender transgression. The fact that women who distinguish themselves in team sports stand higher chances of being employed in the armed services is another reason why Janet regretted having given up football prematurely but felt compensated by learning a trade that allowed her to dream of a military career. While Janet's masculine sense of self is configured by her female body - and can thus be understood as a form of female masculinity that challenges hegemonic masculinities she is also steeped in a context in which urban women have always sought autonomy and displayed their wealth conspicuously (Akyeampong 2000, 223). Although accounts of Asantewa and other powerful queen-mothers suggest that, even precolonially, "big women" had to contend with patriarchal forms of control (Akyeampong and Obeng 1995), their manliness was not considered deviant per se. A stable job in the civil service would equip Janet with 
the tools to become an honorable, "big" woman and perhaps resist the animosities often faced by independent urban women today.

Janet's working sense of self confirms that, from a trans-local perspective, masculinity needs to be understood as a social and cultural expression of maleness that is not tied to the male body. Yet the societal assumptions to which she is exposed differ from the stereotypes she would face in North Atlantic metropoles. Unlike in Euro-American concepts of masculinity, the enactments of her masculinity are not seen to be at odds with her desire to give birth and to tap into the power of motherhood. She is also compelled to pursue independence and accumulate wealth in the context of her relationships with men. Notably, her digressions from a gendered norm are not necessarily interpreted as signs of sexual alterity, at least not explicitly. Janet did not grow up with images of the "mannish lesbian" and her masculine demeanor has not been considered misogynist, as it could be within both hetero- and homonormative spaces in metropolitan North America (Cvetkovich 1998). Rather, her physical appearance makes people regularly believe she is older than her actual age, which enhances her status and enlarges her scope as an erotic citizen.

\section{Doing supi}

Janet's invocations of her "style" include the ways in which she sees and does things, as well as her "tactics" in spotting, courting, and seducing women. Erotic skills are part and parcel of what she considers her unique style. My attempts to convey to her that female same-sex practice is a global phenomenon were met by her conviction that her intimate practices are beyond generalization. Instead, she described how skillful and inventive she is in gradually seducing, nurturing, and pleasuring her lovers. Referring to her relationship with an inexperienced girlfriend who had not had female lovers prior to meeting her, she tells me: "I'm a striker." Certainly, rhetorical allusions to her unique sexual skills appear to constitute her repertoire of seduction, in this case directed toward me. Still, there is a further dimension. Although Janet was vaguely familiar with the term "lesbian" when I first interviewed her - she had heard of "lesbians" abroad and was curious to learn more about their liberties and lifestyles - she seemed 
skeptical of the extent to which this signifier could grasp her own erotic subjectivity.

This skepticism correlated with certain representations circulating in Ghana, which appear to deploy a stereotypically lesbian visual language. These consist of sleazy girl-on-girl fiction geared toward straight men and sensational reports of the supposed bisexuality of skinny white celebrities who do not match Janet's image of womanhood. Janet, like many Ghanaians, deems lighter skinned black women more attractive than darker ones, but finds white women, at best, exotic. ${ }^{15}$ More significantly, her unease with being subsumed under a global category for female same-sex sexuality, regardless of its name, echoes Judith Butler's unease with such categories. "If a sexuality is to be disclosed, what will be taken as the true determinant of its meaning: the phantasy structure, the act, the orifice, the gender, the anatomy?" $(1991,17)$, she asks. Rather, the invocation of a signifier like "lesbian" obscures the specificity and indeterminable lines between "sex, gender, gender presentation, sexual practice, fantasy and sexuality" (Butler 1991, 25). Janet's insistence that her "tactics" and skills are beyond categorization resonates with Butler's assertion that "sexuality is precisely that which does not appear and that which to some degree can never appear" (Butler 1991). The search for a specificity to homosexual identities obscures how they are implicated in heterosexuality without, however, being determined or derived from it.

"I don't joke in the bed. I play my work very well, I play my role very well," Janet tells me during our interview. Later she chips in over a beer, "because I am good at doing men's work, I am also strong at doing my work in bed." The analogy between occupational work and work in bed is not uncommon. Elderly wives in rural areas may refer to conjugal sex as a physically "tiresome work" after a day's work of farming (Van der Geest 2006, 227). Janet, however, intimates her sexual competence as a working subject by comparing herself to a potent young man, who ought to perform, and take on, an ostensibly active role. On an everyday level, this role implies the ability to wake up

15 My respondents' associations with white women ranged from images of skinny, scruffy backpackers to (neo-)colonial wives, who represent an affluent lady version of femininity but are also considered too frail and unfit for same-sex passion. As a female footballer in Suakrom told Josephine, white women's "soft" skin would get bruised too easily, be it in sexual acts or in palpable lovers' fights. 
in the middle of the night and initiate sex - before going back to sleep. This is a necessity in an environment where bedrooms are shared, and one needs to be sure that one's room mates are fast asleep or can at least pretend to be sleeping. Janet prides herself on being particularly good at setting her inner clock and waking up when the time is ripe for the work of love. The pleasure she takes in raving about her amorous escapades, and representing her lovers as conquests, constitutes an erotic and emotional style that can be likened to what is understood as butchness in Anglo-American lesbian (sub)cultures and theories.

The term "lesbian" as such, with its Euro-American associations, did not bother Janet. In our initial interview, she equated lesbian with supi, when I asked about the meaning of supi. "In Ghana here, that is the name. We know, we call it lesbian, but in-, we, we, the Gas [rather], they call it supi. 'Hey, this one is my supi oh'." Janet, who did not attend boarding school herself introduces the term supi when she recalls her initial erotic experiences at her sister's boarding school. The day she visited her sister, wearing a Chicago Bulls t-shirt, white shorts, and shiny sneakers, as she fondly remembers, she immediately attracted the attention of the girl who "opened [her] eyes." This girl said "she wants to be supi, and that time I don't know what is supi. I went to the girl, the girl do me fine. She would serve me, she would give me everything; she would say that I should sleep with her in the school. We would sleep there, after that then I enjoyed and I started to make some." Janet aligns her teenage experience with the "work in bed" she is strong at today. Without me asking, she further substantiates why she started and continued to engage in female sexual intimacies. "Because I like the supi very well, because I enjoy in it. From the time, I'm small then, I started to do this thing. I take a boyfriend but I did not get enjoyment in it than how I enjoy the (pauses), so I think I choose the -." Janet portrays her same-sex activity as a conscious and ongoing choice but stops when it comes to naming what exactly she chooses - a blank space that reflects how unusual it is to name same-sex desire on a meta-level and to be explicit once the context is established.

Notably, Janet does not compare the boyfriend of her late teens to a specific girlfriend, but instead generalizes on doing supi on its own terms. "I think the supi is something great. If you are doing supi with someone [ ... ] you can love the person very well." While she does not invoke supi as an identity, her oscillating between supi as practice 
(something she does), and as preference (something she chooses), complicates the "acts-to-identity trajectory" cast by queer historians (Kunzel 2002, 266). Regina Kunzel uses this phrase to critique the teleological, and implicitly evolutionary, trajectory that has been charted in the wake of Foucault (Halperin 1998). Whereas in modern regimes, "sexual object choice bears a privileged relationship to identity and selfhood," historians have suggested that "premodern" samesex practices were "not constitutively linked to a notion of identity" (Kunzel 2002, 256). As noted earlier, even in the absence of converging psychiatric, psychoanalytical, and sociological ideas about "the homosexual," individuals integrate and conceptualize their practices and desires on their own subjective terms. Halperin holds that the alleged chasm between (premodern) sexual practices and (modern) sexual identities is partly the result of a narrow concept of identity. With Roger Brubaker, I would rather argue that the popularity of the term "identity" makes it a "category of practice" that is too multivalent and diffuse to serve as a useful category of social analysis (2004, 33). With regard to sexual identity, its firm link with gay and lesbian politics thwarts any trans-historical and trans-cultural analysis that seeks to account for a variety of erotic self-understandings.

Janet struggles for words when comparing the pleasure of doing supi to the boredom of having a boyfriend. Her emphasis on "enjoyment" suggests a belonging to herself that echoes Audre Lorde's vision of the "erotic as power" (1984). To Lorde, searching to feel and live "in accordance with that joy which we know ourselves to be capable of," is a powerful site of knowledge production and political attentiveness. Her extended vision of the erotic and the sensual as a powerful resource has inspired queer ethnographies of the black Caribbean that seek to understand identifications that arise from the erotic, but are more inclusive, and not burdened by the concept of a universal (homosexual) identity. For Lorde, as Jafari Allen writes, the erotic is a transforming force, a "lens through which we scrutinize all aspects of our existence" (Lorde 1984, 57), and a site of knowledge production alternative to regimes of the state (Allen 2011, 96). By drafting an "erotic subjectivity," Allen seeks to grasp Lorde's holistic understanding of a subjective agency, in which the erotic is at the heart of "an embodied human resource composed of our personal histories and (sexual, social) desires" (Allen 2012, 231). 
My interest in this framing of an erotic subjectivity is less about the distinction between practice and identity - a distinction that undoubtedly serves its purpose in light of globalizing concepts of homosexuality and certain gay and lesbian lifestyles - and more about the potential of subjective desires to blur the analytical gap between gender and sexuality. Anthropological writings that posit a gender-stratification (in which one partner takes on the gender of the opposite sex), as precursor to an egalitarian, "modern" mode of homosexuality, drew on the juxtaposition of sexual versus cross-gender identifications. The contingency of gendered and sexual categorizations struck me in conversations among sexual rights activists in Accra. In their efforts to build up a female wing of the envisioned LGBTI movement in 2006, they casually referred to "the masculine ones" as "lesbians" (and not butches) and to "the feminine ones" as "bisexuals" (and not femmes). This distinction was not based on the women's stated or unstated sexual preferences, but on their gender propensities. This collapse of sexuality and gender presentation highlights not only how unstable these categories are, and how easily they take on new meanings as they travel, but suggests that gendered and sexual roles and desires, and their representations, are indeed unpredictable and intertwined. ${ }^{16}$

The chronology of discovering the enjoyment and power of same-sex eroticism prior to sexual encounters with men is common in the narratives of self-confident "knowing women" like Janet. Not all women view their adult same-sex love life as a direct continuation of their teenage girlfriendships. Desire, pleasure, and autonomy are highlighted specifically by those who recognize same-sex passions as an integral part of their coming of age. These are not necessarily the most masculine looking women, but rather it is the self-assertive and seemingly most sexually experienced ones who make claims about their erotic knowledge and seniority in doing supi. While knowledge about sexual styles and practices was often enacted through a masculinist language of gender binaries, age and sexual experience figured as crucial tropes in claiming erotic seniority.

\section{Relational Manhood and Erotic Age}

My initial impression that women who claim cross-gender identifications tend to portray themselves as the ones who touch their lovers, and

16 This is by no means to suggest that cross-gender identification indicates samesex desire, but rather that our gendered desires do have a bearing on our social, sensual, and erotic sense of self. 
refuse to be touched themselves, was soon to be revised. Even Lydia Sackey, one of my most feminine presenting respondents mentioned above, compared herself to a man, when portraying herself in terms of her sexual experience. When Josephine, my research associate inquired about her sexual role, she asserted "if I'm harder than her, I'll do it to her and I am the man." Lydia exemplifies the significance of being "harder" and more experienced by bringing in her ex-lover Adizah, or Adi, Cortey, a masculine-styled footballer, as an example.

Adi always thinks she is good at playing the role of a man but I realized that she can't do anything. The day I had sex with her I was rather doing it to her. She is just rushing [showing off]. I taught her how to do it and now she thinks she is the champion, so she goes about sleeping around. [...] She didn't know anything so I didn't want her to do it to me. And I'm also older. ${ }^{17}$

While Adi recites her amorous escapades, Lydia calmly maintains that she guided Adi's growth and introduced her to sexual intimacy. With Adi, younger and inexperienced, Lydia positions herself as the doer, the one who digitally stimulates her partner, without allowing the reversal of such touch. She stresses that genital touch needs to be done artfully and hygienically, which requires attention and expertise that she did not credit Adi with. Besides the unpredictable relation between claimed and effective practices, butch-femme theorists destabilized the assumed correlations of masculine/feminine gender presentations with touching and being touched (Hollibaugh 1983; Nestle 1987).

Nevertheless, Janet's and Adi's sexual expressions of self seem to be fundamentally different from Lydia's. While Janet hails herself as a masculine striker who works in bed and "brushes" her women, Lydia construes herself as "the man," only when invited to talk about sex. She positions herself as expert in the context of complaining about Adi's inexperience, which stands in sharp contrast to Adi's masculine swagger. Lydia resorts to the image of "the man" when portraying herself as the one who knows how to take the lead and teach her partner how to touch. Janet, however, is invested in an erotic and emotional style that is bound to initiate touch, and to resist being touched.

17 Fieldnote by Josephine Agbenozan based on a conversation with Lydia Sackey at Accra, April 17, 2007. 
In butch-femme lesbian discourse Janet would be considered untouchable or a "stone butch." Questions over the emotional and sexual intimacies of touching and being touched have been the subject of butch-femme theorizing, in which the butch takes "erotic responsibility" (Nestle 1987). As Biddy Martin summarizes, both butchness and femmeness are first and foremost "different ways of enacting feelings of power, competence, and strength, as well as vulnerability and pain." Even if such feelings are enacted through deep-seated gender stylizations, they amount to expressions of "more fundamental aspects of self and relationship [... ] irreducible to the grasp or reach of gender differences" $(1994,118)$. On the heels of the butch-femme theories of the 1980s, Butler destabilized the patriarchal logic that links masculinity with activity, and femininity with passivity, by illustrating the inversions played out in butch-femme dynamics.

A butch can present herself as capable, forceful, and all-providing, and a stone butch may well seek to constitute her lover as the exclusive site of erotic attention and pleasure. And yet, this "providing" butch who seems at first to replicate a certain husband-like role, can find herself caught in a logic of inversion whereby that "providingness" turns to a self-sacrifice, which implicates her in the most ancient trap of feminine self-abnegation [...] On the other hand the femme $[\ldots]$ who "orchestrates" sexual exchange, may well eroticize a certain dependency only to learn that the very power to orchestrate that dependency exposes her own incontrovertible power. (Butler 1991, 25)

Likewise, Ann Cvetkovich asserts that the butch, in her eagerness to tend to another person's desires, could just as easily be considered feminine as masculine. The femme, on the other hand, who is "at greater ease with sexual expression or loss of control," provides ways of being open without being passive or stigmatized, and throws into question "the presumption that to be touched is to be feminized or that feminization is to be resisted" (2003, 68-70). Cvetkovich and other femmeidentifying scholars have emphasized that the femme's responsiveness needs to be framed as a (physical) activity, through which the meanings of vulnerability and receptivity are rewritten, rather than reproduced (Cvetkovich 2003, 81). The fact that Lydia's soft-spoken responsiveness did not stop her from touching, and claiming to be the teacher, endorses butch-femme rewritings of feminine desire, that seek to liberate femmeness from Euro-American ideas about feminine passivity. 
Musings on "stone butchness as emotional style" (Cvetkovich 1998) resonate with the styles of Janet, and other Ghanaian women who claim to be on top of their lovers. Through their readiness to feel, and respond to, their lover's desires, these "tops" expose a desire that implies its own dependencies and vulnerabilities. The desire to pleasure marks and puts them in a precarious position vis-à-vis a feminine lover, especially if the latter is more heavily resourced, or if she happens to be less drawn to engaging in same-sex intimacies. The ambiguity of such butchness is framed, but not determined, by its adaptations of behavior conventionally gendered as masculine. This notion of butchness as first and foremost an emotional style, needs to be kept in mind when considering the language through which my respondents asserted their relational manhood. The fact that in Ghana this position is not premised on visible insignia of masculinity also evokes Oyéwùmí's critique of the powers attributed to the visual in the West, where sight is privileged "over other senses for the conception of reality and knowledge” (1997, 15).

When sketching out the implications of "butch" and "femme" in Europe to "knowing women" in Ghana, I was told there is no word to make such a distinction, but, as Ma'Abena put it, "we know the difference." The informal terms women conjured up to conceptualize difference within same-sex relationships varied. I was offered explanations that framed "the man" in ways that could be interpreted as consisting of certain (butch) traits, such as "the one who commands," or "the one who takes responsibility." But most women who engaged with my attempt to understand the power dynamics between same-sex lovers, told me "it depends," before adding that "the man is the one who proposes," or as Janet put it, "the one who first says: 'I love you.'”

Before returning to Janet, I will focus on another respondent, Ameley Norkor, who considered herself "the man" in relation to her female lovers. My interest in grappling with the power dynamics between same-sex lovers and understanding how these were framed in gendered terms was met by explanations that foregrounded the economic dimension of claiming manhood. Finally, I will focus on how Adwoa Boateng in Suakrom coins her own terms when elaborating on female same-sex dynamics. She distinguishes between "the king" and "the queen" and clearly relates these positionalities to erotic roles (and not to their visuality). As such, this discussion further illustrates how 
the socio-economic dimensions of being "the man" intersect with assertions about erotic age and agency, while undermining the visualness often attributed to gender differentiations within same-sex relationships.

\section{Ameley Norkor, the Man Struggling to Provide}

At the time we first met, Ameley was a thirty-eight-year-old mother of two known for being outspoken but warm-hearted and generous, and, for having what she terms "women friends." After attending primary school for three or four years she started selling petty items. Today she works in a field chiefly occupied by women: she walks the streets with a basket full of nail polish and gives women manicures and pedicures. Her living quarters, in an impoverished neighborhood of Accra, consist of a stuffy room that she inhabits with her amiable and hard-working husband and their two sons. As the room is getting too small for the four of them, Ameley prefers sleeping in the airy, but noisy compound that is shared with compound neighbors and domestic animals. Despite her impaired sight, caused by an eye disease she suffered as a child, Ameley is energetic and assertive.

Although Ameley wears dresses and does not distinguish herself from other working-class women of her age, she clearly positions herself as "the man" when it comes to women. She is also very clear about the fact that women are her primary erotic passion. The fantasy of sleeping with a female lover enables her to be sexual with her husband. "When I do it with him - at times when he does it, you have to give yourself over; and when you give yourself over, you don't give him your whole mind, you see? You have to go - you have to remember somebody [female] you do that with, and then you'll discharge and get up, and he'll finish. Yes!"18 Not only does Ameley fantasize about female lovers in order to be able to perform sexually for her husband, she also "trained" her husband to have intercourse only occasionally.

Regardless of her marriage and her capacity to satisfy her husband, Ameley is known for her same-sex passions. At the time of our first interview however, pregnant with her third and last child, she conveyed to me that she did not have any present lover. Based on what she experienced during her previous pregnancy, when her long-term

18 Interview with Ameley Norkor at Accra, June 2, 2008. 
girlfriend was jealous, bewitched her, and thereby prolonged the pregnancy by three months, Ameley holds that having a girlfriend while pregnant can harm the unborn. In the course of our interview, however, she claims that she stopped seeing women altogether, for yet another reason.

If you're a man and you have a girlfriend, you have to spend for the woman. If the woman also has some money, then you'll be helping each other. But all the people I was meeting were poor, so the burden always falls on you the man. Once you don't get money to cater for them, you need to stop. Because I don't want anybody to say that 'I'm going out with you and you don't give me money. ${ }^{19}$

According to this logic, initiating a sexual friendship requires the capacity to offer something to the prospective lover. The ability to invite her out helps to arouse her interest - especially if that friend is not in the know. Ameley, however, is not alluding to the early stage of an erotic connection, as she knows how to seduce inexperienced junior women through her care and charisma, as opposed to monetary spending. She is, rather, concerned with the later stage of love. Being on the "man side," as she also formulates it, requires a certain level of socio-economic power that allows Ameley to take care of her lovers' needs and lay claim to an ostensibly dominant role. Her capacity to assume a provider role ought, by these means, to prevent her lovers from dating other, more gainful female "men." As Ameley explains, in the worst-case scenario, not providing sufficiently for her lovers could result in them presenting her with money they had received from an "outside" suitor.

Ameley's statements need to be read against a background of persistent poverty where the question of survival is crucial in all relationships, whether or not they are erotically charged. Framed by the obligation and desire to cater to one's close relations, all serious bonds - be they between relatives, friends, or lovers - involve the exchange of monetary and material gifts. Friends are expected to house each other if the need occurs and share food and personal items such as clothes, shoes, phones, and beds. Between lovers, material "transactions" assume additional meanings. More than once I was told that at least one person in a relationship must be able to ensure the couple's survival. The vital necessity and the casualness of material

Interview with Ameley Norkor at Accra, April 4, 2007. 
exchanges do not deflect from the dependencies that emerge from these "transactions." The resulting power dynamics are read as signs of a couple's passion and commitment to their relationship.

There is yet another factor that plays out between same-sex lovers, which enhances Ameley's seniority in spite of her relative lack of financial sufficiency. As stated above, seniority is relative to someone's maturity and experience in a certain field. Between female lovers, seniority relates not only to a woman's (social) age but also to her sexual age and insight. Like many articulate and assertive women, Ameley posits that her same-sex "knowingness" dates back to her girlhood. Her seductive powers, her knowledge of the intricacies of same-sex passion, and her capacity to conceal this knowledge from outsiders (while "transmitting" it to a junior lover) are constitutive of Ameley's seniority. While she dates back her first "serious" adult samesex experiences to her age of physical maturation around sixteen, she remembers kissing and playing with girls from the age of seven. Again, she ascribes the fact that girls liked coming over to her house to her generosity and her capacity to bestow them with little gifts. "I was getting money from my mother. [...] She had enough for me, such that when you're my friend and you don't have money and you come to me [...] I was able to provide. Even as a child, you knew that you needed to give the person something. So they used to come to me more than I went to them." ${ }^{20}$ Ameley reflects upon this provider role not only through a gendered language but also by deploying language that references her social age. I ask her: "How do you mean you are the man in the relationship?" She replies: "In everything there should to be a head." Referring to the dramatic relationship with the jealous lover who bewitched her, I argue that her girlfriend might have been the head. But Ameley interrupts me somewhat theatrically: "She won't dare! She can't be given that right? If she does that outside, then fine, but not on my side." I insist: "How do you mean 'the head'? What does it mean?" Ameley replies: "As we are sitting here, there should by all means be an elder, there should be an elder amongst us."

In explaining roles to me, Ameley resorts to age and asserts that every social situation - whether an intimate one involving a relationship of lovers or an interview situation involving a small group of women sitting around a table like the one in which we found ourselves -

20 Interview with Ameley Norkor at Accra, April 4, 2007. 
needs its senior head or elder. Vested with symbolic power, elderhood is both a privilege and a duty. Being the leading elder implies the capacity to take charge of others' wellbeing, to give smart guidance and take wise decisions under challenging economic circumstances. Ameley's boastful comment that her ex-girlfriend could have only taken on such a power position vis-à-vis another lover "outside" their relationship, indicates how relational and situational this position is. It speaks to the possibility of having multiple lovers and being the senior within one relationship, the junior in another. As Ameley concedes, she has been the junior in relation to women older and more well off, while simultaneously engaging with lovers who were socially younger and less resourceful. The older Ameley grows, both socially and in years, the more she is eligible to claim the senior role with which she identifies, a role, however, that is always subject to negotiation.

The way in which seniority and claims to being "the man" tie in with erotic subjectivity emerge in Ameley Norkor's life hi/story. What she elaborates in her speech underpins how self-evident it is for "knowing women" to refer to relational as opposed to visible embodiments of masculinity. While her spoken statements emphasize the socio-economic dimensions of her relations with lovers, her performances of being in charge of them hint at an affective dimension that is harder to put in words. This is evinced in an omission she made in our first interview, when she asserted that she stopped having "women friends" due to her monetary shortcomings. But a year later, in our second interview, she amended this claim. In fact, she had started seeing a "lady friend" at the time of our initial interview, her pastor's wife. And, since this friend was working at the hospital, Ameley even allowed her to give "chop money" 21 to her children to buy school lunches. Still, Ameley maintains that she would never ask her new lover for money for herself - this would undermine her sense of "being on the man's side."

\section{Janet Aidoo, the Man Saying "I Love You"}

Janet highlights the economic dynamics between female lovers and portrays herself as committed to the provider ideal implied in

21 As mentioned earlier, the phrase "chop money" (chop being a word for eating or consuming in West African Pidgin English) colloquially designates the spending money regularly given to a dependent to cover everyday expenses. 
initiating a relationship. "The man is the one who first says 'I love you'," she tells me, the one who verbally enacts her attraction first. The consequences of such a declaration became clear when she introduced Josephine and myself to a mature friend of hers whom she adored, a married mother of five who runs a small hair salon. Janet was single and childless at the time and we asked her why she does not propose to the woman. She explained:

Hey, do you want me to be in trouble? [J.A. What kind of trouble?] You see, if I go first to tell her I love her, then I will be the man and I will have to take care of her. I have to give her money and me too I don't have the money. So I was waiting for her to tell me she loves me, but she was not saying it. [ ... ] At the end nobody told anybody anything and we are now close friends. ${ }^{22}$

Janet's statement testifies to the insight shared by "knowing women" according to which declarations of love carry certain dangers. The one who engages courtship must be able to handle the expectations triggered by her advances. Janet understandably shies away from tapping into the ambiguous power of the spoken word. If she were to hastily disclose her erotic interest and make the first move, she would be taking on a role she could not live up to, vis-à-vis a woman who is more resourced than herself. As a "man" without money, who is young, effusive, and not always discreet enough, it would be difficult to secure herself a respectable position. The fact that they managed to settle in friendship, however, suggests a mutual awareness of the performativity of their roles.

Since Janet cannot afford to be "the man," she needs a woman who allows for her assertive personality without making monetary demands. This was the case in her relationship with Sister Vida, mentioned earlier in this chapter. Even though Janet cannot learn "jobs that women do," she happily fulfilled a junior role in respect to Vida, who was more established and over ten years older. Since Vida was busy all day, running her stall, Janet performed domestic chores usually assigned to wives and children. She took it upon herself to get up at dawn, sweep their room and compound, prepare the bucket of water for Vida's "shower," and iron her dress; in the evening she would make sure dinner was ready upon Vida's return; and on Sunday she would

22 Fieldnote by Josephine Agbenozan based on a conversation with Janet Aidoo at Accra, April 20, 2007. 
wash clothes - even Vida's panties, an unmistakable sign of devoted love, as Janet emphasized. Vida, on the other hand, made it possible for Janet to undergo an unpaid internship on the military campus by meeting the costs of her food and transportation. Based on their mutual assistance, which corresponds with the Akan understanding of marital love - an understanding that thrives on a couple's reciprocal support rather than on pure romance and verbal expressions of love (see Chapter 4) - Janet considers the relationship to Vida a "true love," even long after it had deteriorated.

Vida claims that they eventually separated because one night, when Vida had a male "friend" visiting, Janet insulted her in front of all the neighbors. After asking Janet to serve beer and then leave her alone with the nocturnal visitor, Janet exclaimed that Vida was only interested in having sex with him. In hindsight, Janet believes it was her incapacity to contribute financially to their household that made Vida pick this quarrel. Janet was perfectly willing to accept Vida's "friend" as the genitor of the child Vida was after, if only she had consulted Janet first. If informed, she would have helped Vida look for a man; indeed, she had done so for a previous female lover. Janet's comment speaks to her desire to be in charge of her lover and to orchestrate and perform emotional control, even if she cannot provide money or children.

Janet's readiness to take on a "wifely" domestic role highlights the structuring effect of age and the high levels of flexibility that poverty requires. Both Janet and Ameley consider their stifling economic situation - rather than their sexed bodies - as a hindrance to the manliness they invoke. Their identification with the role of the initiator and the concomitant obligation to attend to their own and their lovers' need put them in a vulnerable position, which is only partially veneered by the relational masculinity to which they lay claim. Their considerations resonate with the frustrations of non-salaried young men in West Africa who struggle to compete with older and wealthier men by engaging in the language of romantic love. What they lack in economic stability they attempt to make up for through the mastery of the "modern" language of emotional intimacy (Masquelier 2009, 219). This primacy of socio-economic status prompts Ameley and Janet to employ a variety of flirtatious strategies in order to smooth over the gap between ideal and precarious reality. They both draw on their verbal versatility when proposing love. 


\section{Adowa Boateng, the Hustler King and Queen}

There are different strategies of coping with the imbalance between an ideal of monetary autonomy and the precarious reality of everyday life. Adwoa Boateng, the thirty-six-year-old mother in Suakrom, who had her first supi experiences as a child, is less bothered about living up to the ideal of a provider. Still, she asserts that she has always been the king in her same-sex relationships. "I don't like [to be] that queen. Me, since I start this thing I don't want anyone to cheap me [take advantage of me]. [ ... ] I want to be a big, big, big man." One day however, Adwoa surprises me by happily telling me that she met an onion seller who wants her to be her queen. At first, I was not sure if she was mixing up her own king-queen terminology. But Adwoa insists: "I want to be her queen." As I ask: "Why should she be the king?" I am told: "Because she has money." 23

Adwoa is the daughter of a foreign trained contractor, whom she fondly remembers as a "rich man" and patron of many. Even though Adwoa was the sixth and last child her father had with her mother, he was an important figure in her life, at the time when she started doing supi. Adwoa's description of him as a quintessential "big man" is complete with the mention that he had many children and was a "womanizer" with "a lot of money, so he had a lot of women." 24 Adwoa's mother came to Suakrom to attend a catering school. She returned to her native Fante region after getting divorced from Adwoa's father. As the lastborn of her parents' children, Adwoa happily remembers the time her father was still alive. He "pampered" her and gave her "everything [she] wanted in this world." Regardless of her matrilineal background, Adwoa is closer to her father's abusua (family) with whom she stayed for some time during her teenage pregnancy. Today, Adwoa is in charge of the deserted family compound he built and of a market storefront she inherited, and strongly identifies with her father and his properties.

Adwoa had her first child at the age of fifteen. After completing Senior Secondary School, she attended a vocational school for cloth design. Although she never worked as a designer, her fashion-consciousness is reflected in a careful presentation of self and her frustrations about being "fat," as she says. Her hair is short with a neat, little parting and she

23 Fieldnote taken in Suakrom, March 31, 2008.

24 Until stated otherwise the quotes from Adowa Boateng are taken from an interview conducted with her in Suakrom, December 12, 2007. 
dresses smartly, by combining "western" unisex attire with African materials and designs that feature Akan symbols of power. Constantly short of money, not least due to sending her daughter to a semi-private primary school, she relies on the remittances sent by her siblings who live abroad or in bigger Ghanaian cities. As I ask her how she "manages," considering that her store was never exactly busy, Adwoa tells me that she is "very bold" and a "hustler woman."

I have heard other junior women in Suakrom who struggle to make a living proudly referring to themselves as hustlers. These women are entrepreneurial, flexible, and witty as they juggle different networks and work to build up social and economic capital. They run errands for better-off friends and relatives; they act as loyal and serviceable couriers; they pick informal jobs; if necessary, they reduce their age by a few years or augment the number of children on a health insurance card; they know when it is permissible to embezzle some money and when it is time to look for a new patron - and so on. In popular usage the notion of hustle has "a dual morality, defining both life's possibilities and its constraints, legal aspiration and illicit value accumulation" (Shipley 2013, 223). Hustling, as a mode of survival, has become both a necessity and a lifestyle among young Ghanaian urbanites. As Jesse Shipley (2013) observes in his book Living the Hiplife, the need to hustle is celebrated and lamented in the lyrics of popular and mostly male hiplife musicians.

When Adwoa is short on money, she says of herself that she can be "a little wicked," and tricks her lovers and friends, including myself. Indeed, in many ways Adwoa reminded me of the trickster figure Kwaku Ananse, ${ }^{25}$ the witty spider in Akan folk tale that gets off scot-free more often than not. With her wide-eyed charm and portly joviality Adwoa often made up for being a trickster and a hustler. At the same time, by playing friends and lovers against each other, she consolidated her position as someone who cannot be overlooked. As a native townswoman, Adwoa has the cultural capital to cover up for her failed business endeavors. Some market people take her to be a "big woman," despite critical comments about her gender-ambiguous appearance or rumors about her non-normative sexual conduct. Being a "big man's" daughter helps her to claim a social status that less established "hustlers" cannot. As a mode of

25 Kwaku Ananse oscillates between man and animal. Although he is a trickster, who sometimes fails and sometimes wins and is usually forgiven, he is a hero, hailed for his wittiness (Yankah 1983). 
getting by with pride, Adwoa's hustling corresponds to the organization of her erotic life and her gendered selfhood.

Adwoa deploys her linguistic skills not only to seduce women. She delights in her word creations and verbal artistry and conjures up her own same-sex discourse through which she identifies herself and others. This intimate discourse revolves around the figures of "the king" and "the queen." In some instances, the king is constructed as the one holding economic power, at other times he is marked by an erotic and emotional style, and often Adwoa refers to all these elements in their intertwinement. I do not know how she first came to use these terms, although I have heard self-identified gay friends of hers flamboyant young men oriented toward the capital city, who dream of living a metropolitan gay lifestyle - refer to themselves as queens and their male lovers as kings. The appeal of these terms may also hint at the royal Asante background to which Adwoa lays claim. Though the Asante have no queen, the chief (ohene) or king (omanhene) is backed by a so-called queen-mother (ohemaa) who is in charge of the female population. A spin on this division of roles is the children's game ahenahene ("kings"). In this game children paired and elected a king, a queen-mother, as well as their elders, who presided over what used to be the "commonest 'love' game" in colonial Asante (Sarpong 1991, 41). According to Sarpong, girls became "wives" and cooked with the little amounts of money that their "husbands" passed on to them. The mock spouses had "reciprocal obligations and duties in everything except the marital act. When a 'wife' or 'husband' offends a partner, a complaint is lodged with the 'elders' who restore amicable relations." Approved by their parents, mock marriages could last for days (Sarpong 1991).

In 2008, Adwoa often referred to friends and lovers by categorizing them as queens or kings. The following instances help elucidate the implications of these terms. When Adwoa introduces me to Dede Kpobi, the newly married sbaa barima mentioned above, she whispers to me: "This woman is a lesbian. She is the king of kings. She is more a king than myself." ${ }^{26}$ Adwoa highly respects Dede, who has several female lovers and goes to great pains to court the ladies in which she is interested. Here, Adwoa connects kingliness with erotic power and the readiness to pursue female lovers no matter what. She does so by interlacing the lesbian category (with which she knows I am familiar),

26 Fieldnote taken in Suakrom, November 21, 2007. 
with her own image of the king. In another instance, Adwoa emphasizes the socio-economic dimension of the rhetorical figure of the king. Adwoa, the king without cash, also considers her best friend Dina Yiborku, whose grandness she admires, "more of a king" than herself. This made sense to me once I had witnessed how Dina passed on money to Adwoa to go and purchase fish, which Dina's sisters later worked into a soup for all of us. As an educated, enterprising teacher and businesswomen, Dina is more mobile than Adwoa, both spatially and socially, and has the means to position herself as patron.

But Adwoa herself was not always sure who to consider king and queen. On one of my last evenings in Suakrom in 2008 I invited her out together with Ma'Abena and Esther, Ma'Abena's girlfriend. Adwoa knew the two of them only loosely. As always, Ma'Abena was wearing a black baseball cap, jeans, and a printed T-shirt. Esther on the other hand, who had come straight from Accra, was made up in a feminine style, with a long weave-on (unbraided hair extensions), a blouse with little mirrors on it, and tight white trousers. Not having seen each other in a while, Ma'Abena and Esther were lovingly huddling together and catching up with each other sotto voce. When Esther got up to make a phone call, Adwoa asked: "Who is the queen and who is king with the two of you? Are you the queen?" Ma'Abena replied: "Hey, just because Esther is drinking, that is why she seems hard?" Adwoa did not respond. ${ }^{27}$ Surely, she was aware that Esther, a mother of two with a job in Accra and a husband abroad, is economically stronger than Ma'Abena. At least, Esther had already bought a beer for herself, while the others were waiting for me to pay.

Another aspect of the making of kings and queens is age. One evening, when passing by Adwoa's place in the company of Stone Addai, a footballer in her early twenties, Adwoa started teasing Stone by telling us: "Look at his/her ${ }^{28}$ face, the face of a child. S/he is a queen not a king." Stone, who moves and dresses much like a male youth, did not react to Adwoa's provocation. The appeal of the king-queen imagery occurred to me when Stone herself, half a year later, employed it. Asked why she wears one earring only, she tells me "kings wear one, and queens wear two earrings" and

27 Fieldnotes in this paragraph were taken in Suakrom, May 25, 2008.

$28 \mathrm{I}$ am using the slash because in the Twi language, all personal pronouns are gender-neutral. Thus, Adwoa did not refer to Stone as either he or she. 
ignores my follow-up comment whether in that case, practically all women in Ghana qualify as queens. She too had been spending much time with gay-identifying young men who wear earrings and who pay reverence to Stone's masculinity, by calling Stone by the male version of their day name, Kwabena instead of Abena.

The erotic aspect of Adwoa's king-queen rhetoric is evinced in a phone conversation Adwoa had with my research associate Josephine. In this conversation Adwoa, not for the first time, flirtatiously tells Josephine that she is "interested" in her. Josephine cleverly evades her advance by arguing:

J.A.: But Sister Adwoa, you just told me you've got a young girl, how are you going to manage the two of us?

A.B.: $\quad$ Oh, in fact the small girl I love her, but I made a mistake by allowing her to go free when she spent a night at my place. Now she might think I am good-for-nothing-king. ${ }^{29}$

Indicating that she did not manage to seduce the "small girl," Adwoa's reply speaks to the sexual implications of king-dom. Whether or not Adwoa literally used the term "good-for-nothing-king," in her conversation with Josephine, being the king is construed in terms of catching a girl and initiating sex. Adwoa craves to be desired and prefers that to having to impose herself. Part of her fascination with Sandra, the "small girl" in question, is the fact that Sandra is a footballer and sportswoman, just like Adwoa used to be. And just like her, Adwoa smirks, Sandra is really "a king, but does not want to admit it." If Sandra revealed her desire to have a queen at her side herself, she would lose her entitlement to ask for money and "lorry fare." ${ }^{30}$ Negotiations over who is the king and therefore the one supposed to provide points at the emotional charge and the (economic) luxury of openly committing to one's intimate desires. For, although money is decisive in structuring gendered subject positions, money is not everything. The very power of being moneyed makes kings susceptible to being manipulated by their queens.

29 Fieldnote by Josephine Agbenozan based on a phone conversation with Adwoa Boateng, September 27, 2007. The following block quotes are also taken from the phone conversation she had with Josephine.

30 It is customary to reimburse a guest of a lower economic standing with the money they spent on transportation. Previously, traveling was often done on socalled "mami lorries," hence the phrase "lorry fare." A more contemporary term to refer to the expectations of being reimbursed for boarding and transportation costs is the phrase "T'n'T" (tea and transport). 
Interested in the relationship between physical enactments and embodiments of masculinity, Josephine strategically inquires as to who was the "the man" in Adwoa's relationship with Maa'Evelyn, a "big woman" in her early sixties.

J.A.: But Maa'Evelyn looks like a king, because to me she has some hairs around her mouth and under her chin.

A.B.: Oh, but still I am the king. I said, I have never been the queen and I will never be. But I think if I can be a queen, then maybe I have been with you for so many years and I then decide to give you that chance, to be a king, but all the same I will be in control. ${ }^{31}$

Adwoa's dramatic assertion that she will always be "the king," amounts to a performance of never being out of control. Her vision of being the master of her lovers and, perhaps more importantly, herself, stands in contrast with the little control she has in her day-to-day economic life. Adwoa's concession that she may allow a long-term lover to make her a queen resonates with Cvetkovich's assertion that the exchange of power in sexuality can be much "more important than the actual physical acts." To Cvetkovich the complex intersubjective dynamics of giving and receiving go beyond the question of which body parts are involved in such acts $(2003,64)$. This is evinced in a comment by Adwoa's friend Dina Yiborku. An inquisitive black lesbian friend of mine, who was visiting from abroad, asked Dina about sexual role divisions. In responding to my friend, Dina who otherwise tended to refer to herself as "the giver," and to her younger girlfriend as "the receiver" took up Adwoa's king-queen terminology. She explained that there are kings and queens "and those who do both," before conceding that she too has "received" in sexual relationships with women, because "sometimes it doesn't matter." 32 While Dina's concession has to be seen in the context of her flirtatious conversations with my visitor, it also speaks to the interdependence of corporal and psychic acts.

Following Cvetkovich's suggestion that the willingness to risk losing control is the chief feature of a femme sexuality, and the desire to be in control the signature of butchness, I did catch myself thinking of Adwoa in butch terms. Unlike the popular metropolitan assumption that butches desire female-bodied lovers only, Adwoa desires male

31 Fieldnote by Josephine Agbenozan based on a phone conversation with Adwoa Boateng, September 27, 2007.

32 Fieldnote taken in Suakrom, December 31, 2008. 
lovers too. While distinguishing between (female) lovers who are older and wealthier or younger and needier than herself, she insists that she likes men and women in the same way. As I ask if there is a difference between loving a man and loving a woman, and if so, which one she prefers, she unwaveringly replies: "I like both of them because it's the same. [...] I don't like this one and dislike the other one. The way I love the woman is the same way I love the man." "While Adwoa's assertion needs to be understood against normative ideas by which women cannot find fulfillment with each other, her reply is more than a claim that same-sex and opposite-sex love are equally valid. ${ }^{34}$ Ever since Adwoa's brief marriage to the genitor of her second born, she is in search of a suitable husband. Even if this search comes across as less passionate than her interest in women and in twisting and tweaking her king-queen rhetoric for this purpose, opposite-sex desire seems to be an integral part of her erotic subjectivity as well.

Let us return to the phone conversation in which Josephine critically enquires about the implications of Adwoa's "king." She reminds Adwoa that Maa'Evelyn used to be her "sugar mother," and the one who gave her money. Although money does help in claiming to be a "king," Adwoa's response indicates that kingliness is primarily an emotional style and strategy.

J.A.: But you are the king, so you have to give her money?

A.B.: Yes, I am the king, but I don't believe in the system of kings always giving money to queens. This is the mentality of many women in this town $[\ldots]$ They always think the kings are the ones who have to give money. But as for me Adwoa I will only give, if I have but I also find a way of taking money from them [the queens] without them realising it. I like hand go, hand come. ${ }^{35}$

Replying to Josephine's clever questions, Adwoa emphasizes that being "the king" is not simply about monetary riches. Indeed, when Adwoa, the hustler, is in a trickster mood, she knows how to take without

33 Interview with Adwoa Boateng at Suakrom, May 11, 2008.

34 While readily invoking an abundance of amorous feelings and intimacies in relation to women, Adwoa's desire for men remains vague and is also motivated by the status she hopes to cement through a marriage to a respectable townsman. The emphatic descriptions of her love life explored in Chapter 5 pertain to samesex passion.

35 Fieldnote by Josephine Agbenozan based on a phone conversation with Adwoa Boateng, September 27, 2007. 
giving. When she does come by some cash, preferably "pounds and dollars," she considers herself "soft-handed" and almost insanely "generous." She once illustrated this by relating an episode, where she instantly spent some seventy dollars received from the USA on Gifty. In her nostalgia and identification, with the young sportswoman, Adwoa bought her a mobile phone, only to find out later that Gifty handed on the prestigious gift to a girlfriend of her own age group. In a moment of self-reflection Adwoa ironically concludes that, in fact, she herself was doing to Maa'Evelyn what Gifty is doing to her: extracting money by capitalizing on unequal levels of attraction. Material motives are pardonable; they are an avenue for the "king" to eventually trigger intimate feelings and desires.

In Adwoa's universe, being tricked seems to be the price a committed king needs to pay in return for the power he claims. At the end of the day, however, things should balance out somehow: "It has to be give and take, hand go, hand come." Deploying a Ghanaian Pidgin English phrase, Adwoa conjures up an image of reciprocity that places her kingdom in a perfectly valid situation within the larger flows of erotic and material gifts. Just as gifts ought to be in constant circulation in order to regenerate and remain valuable, Adwoa's king-queen terminology circulates and takes on different meanings depending on who uses and will continue to use it.

\section{Conclusion: Gendered Relationality}

This chapter grapples with queer understandings of butchness and "masculinity without men" in relation to the erotic subjectivities of my respondents in Ghana. It has shown that the antagonism between sex and gender - specifically between the female body and masculine gender presentations - which so potently constitutes notions of female masculinity in the Euro-American context, loses some of its conceptual power in the Ghanaian context. A number of Nigerian feminists claim that in West Africa gender was of a secondary social importance prior to patriarchal missionary and colonial interventions (Amadiume 1987; Oyéwùmí 1997; Nzegwu 2005; Achebe 2011). The question is whether their argument that age and seniority used to be the main principle organizing social life can be held, given that a person's age-based status hinges on their (re)productive capacities. A term like sbaa barima does not dissolve gender boundaries. It does, however, indicate that 
masculinity is not understood as being intrinsically tied to certain bodies; gender appears as derived from but not predicated on sex. More importantly, as Ebron argued, the social construction of gender is highlighted, and subjects are constituted through performative acts in a variety of gerontocratic West African settings (2007).

Through their verbal and physical creativity, "knowing women" in Ghana appropriate a range of powerful metaphors when styling themselves as devout "men" or responsible "kings." While these terms resonate with butch and trans-masculine expressions of self, they are deeply intertwined with West African understandings of seniority. Discussing the contingency of female masculinity in Indonesia, Blackwood emphasizes how tombois enact versions of womanliness in order to respect and maintain family ties and in line with their fondness of immersing themselves in large social gatherings $(2010,158)$. Likewise in Ghana, women like Janet take up seemingly contradictory manly and womanly subject positions, while cultivating (a) "life" that takes pleasure in being part of outdoorings, funerals, and other festive occasions that gather friends and family. Their sociability and their delight in the relationality of their subjectivity extend into a desire to have children. Thus, while tombois in Blackwood's Indonesian context consider marriage the most troubling challenge to their masculinity (Blackwood 2010,154), many an sbaa barima goes to considerable lengths to conceive children and is less bothered by "marrying." As I see it, the masculinity of "knowing women" is not only contingent but highly relational.

Although my research did not look for ethnic and regional differences regarding marriage, variations between the situation of Ameley, who belongs to the patrilineal $\mathrm{Ga},{ }^{36}$ and Adwoa and Janet, the Akan women, do seem to be shaped by patri- versus matrilineal family models to some extent. While Adwoa and Janet both stayed with their (matrilineal) abusua and never established conjugal households, Ameley shared rooms with her Ga husband. His threat to take away their children and bring them to his relatives does thrive on patrilineal understandings of kinship affiliation; it contributed to Ameley's staying with him when she was in the situation of having to choose between him and her jealous female lover. When I last met Ameley she had just

36 Chapter 4 focuses in more detail on the largely patrilineal kinship arrangements of the Ga. 
moved out of the room she used to share with her husband and children. She left not so much because the husband had started spending money on his new girlfriend, but because he started bringing her to their compound without making any effort to disguise his extramarital relationship. Only a few weeks later he died. Supported by matrilateral sisters and "women friends," Ameley withstood the ensuing rumors that connected her separation to his sudden death.

In the intimate discourse of "knowing women," manliness emerges as an elastic metaphor for patronage, elderhood, and erotic seniority. Though these roles ostensibly apply to a person's socio-economic and symbolic power, they must not correlate with visible enactments of masculinity. The style of Adwoa, the king without cash, appears to be much more masculine than Ameley's own. Concealed by a grand sbaa barima attitude on the other hand, Adwoa relatively comfortably receives money from her lovers and can afford to buy clothes that signal metropolitan masculinity. What Ameley, who wears simple dresses and engages in activities that have feminine connotations, calls the "man's side" does not refer to a particular bodily styling but to her ideal of assuming a provider role, both erotically and economically. As she conveys, passionate same-sex bonds are configured by constant negotiations over leadership that are not mediated or obfuscated through superficial understandings of power. Relationships emerge not only as sites of mutual care and support but also as particularly dense transfer points of power that do not fit neatly into popular notions of butch-femme relations. Unlike Ameley, who shies away from relying on her "women friends," Adwoa does ask for money, making it part of her smooth "hustler" style, while enumerating what she will bestow on her benefactors, once she does have money.

Visible differences between butch and femme styles in the global North are often seen as structuring community and lesbian relationships, which resonates with Oyéwùmí's critique of the privileging of the visual and the physical in "western" gender perceptions $(1997,2)$. Role division among women in southern Ghana are indeed not considered to be visual. The primacy of relational power is reliant on a person's social and erotic age and configures and curtails the significance of gender stylizations. Butchness as an emotional style, however, which cannot be cast in terms of masculinity and is irreducible to the "reach of gender differences," does resonate with the practices of women like Janet, Adwoa, and Ameley. Is it their readiness to articulate and act upon 
their desires that makes them "men" in relation to their lovers? Or, is it their endurance and pride in pursuing same-sex desires? Regardless of their physical appearances, an understanding of butchness as an emotional style could be applied to Ameley's and Janet's provider ideal and their passion to be in charge of their lovers' needs and desires. Cvetkovich advocates for a notion of butchness that is not bound up or circumscribed by certain visible insignia of female masculinity. Instead she suggests that "the relation between butchness and hypervisible styles of masculinity must remain unpredictable" $(1998,169)$. Not only were the styles and practices I came across shifting and unpredictable, but the very concept of masculinity, visible or not, loses some of its potency when there is a certain awareness of the performativity of gender (Ebron 2007) and difference is conceptualized through varying figures of power. Relationality rather than visibility determines the agency of the sbaa barima who seeks to be the first to say, "I love you." 


\section{Sugar Motherhood and the Collectivization of Love}

It took me a while to realize that Maa'Evelyn, the sixty-two-year-old lady Adwoa introduced to me as her "mother," had not given birth to Adwoa, and was not a relative. Rather, they were occasional lovers and, as Adwoa once mentioned, Maa'Evelyn, or Maa, was her "sugar mother." One day, in conversation with Maa, I heard her complain about Adwoa being "a naughty girl." She opened her explanation as to why they were currently not talking by telling me, "I took her as my baby and I'm her Mama." A little later, I was looking for accommodation in Suakrom and Adwoa offered to inquire with Maa'Evelyn if I could stay in her spare room. When I moved in with Maa and her helper, a thirteen-year-old girl, I was introduced to the neighbors as a "friend's daughter" from overseas. This was plausible since Maa had lived in Italy for two years, looking after her grandchildren. One evening after dinner, Maa went to the bathroom and called to me to bring her an additional bucket of water, which I did, not knowing she was already naked. "I'm your mother, just come," she reassured me, as I put down the bucket without looking at her. When I told one of Adwoa's friends that I felt Maa was making advances, she exclaimed, "this old woman?!" And after some reflection, she roguishly added, "then you will have to cope with it." ${ }^{1}$ Soon after, Maa urged me to move out.

Maa and Adwoa became friends just after Maa was laid off from a state-owned enterprise during "redeployment." As Akosua Adomako Ampofo discusses $(2007,186)$, women were the first to be laid off when public corporations were sold and "rationalized" under the "Economic Recovery Program" in 1983 and the IMF's subsequent structural adjustment program. Maa took over the drinking spot of her bedridden mother, next to Adwoa's market store. I gladly accepted Maa's offer to accommodate me at a local rate in her small, government-owned

1 Fieldnote taken in Suakrom, December 10, 2007. 
bungalow. Her invitation to make use of her live-in helper, though, made me more uncomfortable than her flirtatiousness. Although she sent the thirteen-year-old girl to primary school, she allowed her hardly any time to rest or do homework. Often the girl looked after the drinking spot until late at night, long after Maa herself had returned home. "Mama" Evelyn's lack of motherly affection stood in sharp contrast to her appellation, as well as the charming hand kisses and volleys of "sweethearts" she bestowed upon adult "daughters" like myself. During my brief stay in her house, I began to question to what extent respectable, postmenopausal women capitalize on the authority that goes with their age, in relation to subordinate, younger women, to whom they might be attracted. I did not speak with Maa or other women of my mother's or grandmother's age about erotic desire, due to my own, as much as their inhibitions. Instead, this chapter's reflections on motherhood and on the material and emotional flows of love are informed by the stories of women in their twenties and thirties who have had considerably older or considerably younger lovers, or both.

The vertically constituted bonds between "mothers" (like Maa'Evelyn) and their adult "babies" imply a flow of goods and services that could be considered a continuation of the "motherchild" intimacies and the horizontal gift exchanges between senior and junior boarding-school girls, as discussed in Chapter 2. Crossgenerational female intimacies, however, harbor the added dimension of financial support and "motherly" mentorship. The economic "sweetness" of this dimension is implied in the expression "sugar mama" that some of my younger respondents used to refer to a mature female lover. By the same token, "sugar motherhood," as a metaphor for same-sex intimacy across a considerable age difference, can veil the abuses and violations experienced by younger women in these relationships. Paired with the stereotypical Akan notion that postmenopausal women are restrained and less sexually desiring than younger ones (Van der Geest 2006), the concealment of ambiguous or abusive dynamics works particularly well across generational configurations.

In the introductory section of this chapter, the real and imagined power of motherhood is explored through West Africa's "motherhood paradigm" and by considering different analytical approaches to (same- and opposite-sex) age-mixed relationships. I then consider the context that drew my attention to the significance of "sugar motherhood" in Ghana: the female football world and the marketplace. 
Usually, when the semi-professional footballers in Suakrom teased each other about having a "sugar mama" who "sponsored" them, they were referring to an established female trader in Suakrom's market. This sheds light on the role of "the market woman," a contested figure in Ghanaian history, and the ways in which this connects to popular, sexualized representations of the selfish "big woman." In the remainder of the chapter, I examine how age difference in female samesex intimacies is inhabited, first from the perspective of three women born in the 1980s: Adizah Cortey, Lydia Sackey, and Okaile Allotey, all based in one of the seven old quarters of Accra, each of whom in their mid- to late teens, became the lover of a considerably older woman. Their accounts speak to the inequalities and mutual dependencies involved in having a lover who could be their mother, either by age or in terms of the "sugar" provided. These stories are contrasted with the perspective of a "sugar mother" in her thirties. Dina Yiborku is a secondary-school teacher, who considers herself "the giver" in relation to girlfriends, often college students, whom she supports. She feels it emotionally and socially safer to approach (or be "given") a younger women rather than women of her own age group. At the same time, my analysis reveals that the overarching hierarchies implied in giving and receiving do not prevent a multitude of affective bonds between older and younger women. Rather, within relationships where sexual intimacies need to be concealed, such relational exchanges constitute intimacies that are both materially and emotionally significant.

The relational practices emerging from the narratives of the four women discussed in this chapter often involve a circular element. What I consider a collectivization of love pertains not only to the classic love triangle, but to practices of involving friends and family, and allowing them to go in-between, thus making them part of one's love life. For instance, (genealogical) mothers and grandmothers often appear in these stories, actively discouraging or backing their daughters' same-sex intimacies. More importantly, friends of the same generation may give or pass on a lover and have a say in making or breaking each other's friendships and intimacies. Again, these circular practices came to my attention in the female football arena, where "team mothers" provided their "team daughters" with food, clothes, and accommodation as the need arose, but also with male and female lovers. In these tight networks, love is never a "private" matter; female friends gossip about, monitor, and arrange for each other's intimate 
attachments. While this chapter acknowledges the inequalities and abuses that can emerge under the sign of motherhood, such manipulative practices are as much part of women's same-sex sociality as are the tender ways they cater to and take care of each other's emotional and material needs.

\section{The Motherhood Paradigm}

\section{Motherhood in Southern Ghana}

In urban West Africa, globally pervasive notions of wifely, bourgeois femininity co-exist with older concepts, by which motherhood is an important avenue to become a woman and accumulate power. As Nigerian feminist Oyèrónké Oyéwùmí argues, the status of an adult woman is associated with her being a mother and not a wife, because "motherhood is defined as a relationship to progeny, not as a sexual relationship to a man" (2004, 4). Ifi Amadiume points out that Eurocentric anthropologists have overlooked the structuring power of motherhood. In particular, she accuses Meyer Fortes of masculinizing his data based on an underlying "patriarchal monologic paradigm" $(1997,29,84)$. On the other hand, she confronts Second Wave feminism, with its implicit framing of all women as wives, and thus social subordinates. In her own study of the dual-sex political system among the Igbo, she demonstrates how the logic of motherhood structures even patrilineal African societies (Amadiume 1997, 17-19). In the Igbo village she studied, the "matricentric" mother-child unit of a compound, headed by a communal mother, was as important as the male-focused "ancestral or family house" or compound (Amadiume 1997, 83). Interestingly, Amadiume's "motherhood paradigm" suggests a shift away from "the woman" as an analytical category to the mother-child relationship and thus moves our focus "not to a female subject, but to a social relationship" (Arnfred 2011, 208).

The bond between mother and child has been considered to be the most intimate kinship connection in many African societies. Matrilineal Akan ideals firmly place the mother-daughter unit at the heart of kinship-making. As Meyer Fortes describes, an Akan "woman grows up in daily and unbroken intimacy with her mother, learns all feminine skills from her, and above all derives her character from her" (Fortes 1975, 263). His image of a natural transfer of femininity based 
on growing up with one's uterine mother is contradicted by the fact that an Akan child's aunts also qualify as mothers, as well as by high levels of residential mobility during childhood. The more children a woman has, the less likely it is that they will all grow up at her side. Rather, they may circulate through different households; staying with a great-grandmother in a hometown for a few years, becoming the helper of a wealthier or childless relative, or growing up as the protégé of a teacher, pastor, or other benefactor. In many African and black diasporic communities, the exchange of children, including pawning and fostering, is common. For instance, it has been standard practice among African-American (Stack 1974) and Afro-Surinamese working-class women (Wekker 2006) to activate and reinforce friendships and family ties by letting children grow up with mothers, sisters, or dear friends, in the hope that the children will strengthen and continue the bonds between friends and their families.

The matrilineal Akan culture, which has dominated southern Ghana for centuries, is an exemplary case of the motherhood paradigm. Though the abusuapanyin, the decision-making family head, is usually a big man, mothers and female elders are regarded as the custodians of genealogical knowledge who contain his power. While Akan ideals of the mother-daughter bond thrive on the primacy of matrilineal kinship transmission, the matrix of female transmission also matters among the largely patrilineal, but matrifocal Ga. As Claire Robertson has explored, the dominant relationship expressed in the Ga residential system in the section of Accra, where Adizah, Lydia, and Okaile reside, is that between mother and daughter. In the Ga community, multigenerational households commonly consist of female matrilateral kin. Boys are sent to their fathers and uncles by the age of twelve (1984, 57). Thus, although the Ga overwhelmingly trace descent and inheritance patrilineally, residential rights are passed on patrilineally for men and matrilineally for women (Robertson, 1984, 59).

\section{Age as a Relational Category}

In comparative anthropological volumes on homosexual formations, the relationship between Adwoa and Maa'Evelyn might be categorized as age-differentiated, or age-stratified (Adam 1986; Greenberg 1988; Murray 2000). In these structural anthropological terms, "age-differentiated," "gender-differentiated," and "egalitarian" same-sex 
relationships signify different models of homosexuality that correlate with different types of social organization. Thus, age- and genderdifferentiation are construed as the main markers of "homosexuality" in "kinship-based" societies, whereas "modern egalitarianism" is attributed to gay and lesbian couples (Murray 2000). In Murray's model in particular, gender (and not age) is "the major African idiom of homosexuality [...]. Where there are age disparities, the younger [partner] is generally cast in the feminine role" $(2000,248)$. While rejecting the epistemological premise that prioritizes gender over age and generalizes on Africa, this chapter critically engages with the assumed "femininity" and subordination of the younger lover. Rather than deploying age difference as a structural signifier, I am interested in age as a social relation and tool to rethink the power dynamics unfolding in all sexual relationships. Because gender and age articulate each other, this chapter cannot go without considering gender roles.

"Age-differentiation" was chiefly associated with relationships between men and boys in ancient Greece, where homosexuality amounted to a second stage of parenting (Dover 1988), and with initiation rites in Melanesia, in which slightly older bachelors "implant" their seed in the bodies of younger bachelors. Both sementransmitting practices and the "ancient model" with its pedagogic core between an older "inspirer" and a younger "inspired" partner (Adam 1986, 21) have been theorized as masculinizing cultural institutions that ensure the reproduction of male homosocial culture and group solidarity (Herdt 1984). Parallel intergenerational female homosexual institutions were regarded to be less common, supposedly because women were married earlier than men (Adam 1986). Descriptions of female mother-daughter intimacies across smaller age gaps, however (Blacking 1978; Gay 1986), were not thoroughly theorized. Moreover, obscured by spectacular accounts of male "pederasty" and semen rites, women's age differences appeared to be less hierarchically structured than male ones. The latter corresponds with feminist-inspired assumptions about women's tendency toward harmonious, egalitarian social formations (Greenberg 1988). However, most of the same-sex bonds I encountered between working-class women in Ghana resisted a "nonegalitarian" classification.

Africanist work on age-mixed relationships has analyzed the complex "transactional" relationships between young women and (local) 
sugar daddies (Nyamnjoh 2005; Cole 2010), or focused on the transnational ties between "beach boys" and their older white tourists in Kenya or the Gambia (Ebron 2002; Meiu 2009). Yet the real and anecdotal power of African sugar mummies, and figures such as "Mama Benz" in Francophone West Africa (Khor 2009; McKinley 2011), have rarely been examined and never regarding their same-sex involvements. Such an exploration would have to address the ways in which "big women" and not only "big men" bring together clients. The language of service and the intimate strategies through which female protégées seek, as "small girls," to establish mutual dependencies with their "sugar mother" also needs to be taken into account.

Like the expression "small boy," "small girl" works to infantilize the subordinate subject in a patron-client relationship and invokes images of colonial domination. A "big woman's" counterpart is her "small girl." While local Ga and Twi terms for helpers do not mark gender, the English terms "girls" and "boys" are deployed among female traders when distinguishing their assisting younger relatives or employees by sex. As Clark writes, "using the English words not only makes the senior trader sound more sophisticated," it also "emphasizes the subordination rather than the paternalism of the relationship by invoking colonial images" (1994, 198). The prefix "small" intensifies this subordination. Despite the erotic sweetness implied in a phrase like "sugar mama" it does not imply that every "mama" consummates the relationship with her "girl" sexually. While seeking youthful company, a big woman's desire to mentor and support a subordinate, younger woman speaks to modes of intergenerational identification beyond sex and seduction. It does, however, provide ample grounds for unpredictable intimacies between sugar mother and their (helping) daughters - but also between the youthful daughters themselves. This came to my attention in the female football arena.

\section{Female Football and Team Mothers}

With its relatively simple infrastructure, football is a popular sport in many African countries. Since the Confederation of African Football organized the first FIFA-supported African Women's World Cup in 1991, football has also become a way for women to claim public space. Ghana has been among Africa's strongest women's football nations. In the late 1990s, spearheaded by what was then known as Ghana 
Telecom, state-owned companies began building up semi-professional female football teams as part of their advertising strategy. While football training for girls is only gradually being institutionalized at secondary schools, these clubs attracted football-crazy young women, mostly from poor economic backgrounds, from as far afield as Guinea and Nigeria. With the privatization of Ghana Telecom, many of these teams have collapsed. Today, private companies and enthusiastic patrons, including charismatic church leaders, sponsor their own clubs. On a more sinister note, some of these patrons had been sued for trafficking female players to fictive football clubs in southern Europe.

In Ghana, as in other countries, the arena of female football is a space in which young women's masculine gender presentations and same-sex intimacies have been tacitly tolerated (Burch 2013; Crémieux 2013). In Suakrom, I witnessed training sessions in which coaches advised their protégées not to have boyfriends, since a pregnancy could put an end to their football career. In several instances I felt that coaches were well aware of their players' amorous liaisons but, as some of my respondents conveyed to me, only intervened when heartbreaks or jealousies disrupted training sessions. Proudly seeing themselves as footballers even off the pitch, my respondents cultivated masculine forms of expression, assumed male football names, wore trainers and oversized t-shirts, and bragged about having a "sponsor" or "sugar mother." Although the cliché of football lesbianism has started taking root through the media, and some national players have been tagged as "lesbian," the players I met did enjoy a certain respect for their successful masculine performance as footballers. In Suakrom, the overt criticism female footballers faced for challenging gender boundaries was relatively benign. One morning, for instance, walking back from the training grounds with a few players, I noticed that a group of male students sitting under a tree started teasing them. From afar I could not make out what exactly they said, however, they mentioned Adjoa Bayo, who was part of the Black Queens, Ghana's national women's team at the time. Overhearing her name, one of the players swiftly turned to the guys, waving her index finger in front of her crotch as if it were a penis, as she jokingly exclaimed "Adjoa Bayo? She has a penis as long as a rope!" ${ }^{2}$ We all laughed. Certainly, such parodic moments, in

2 Fieldnote based on conversations at Suakrom, December 5, 2007. 


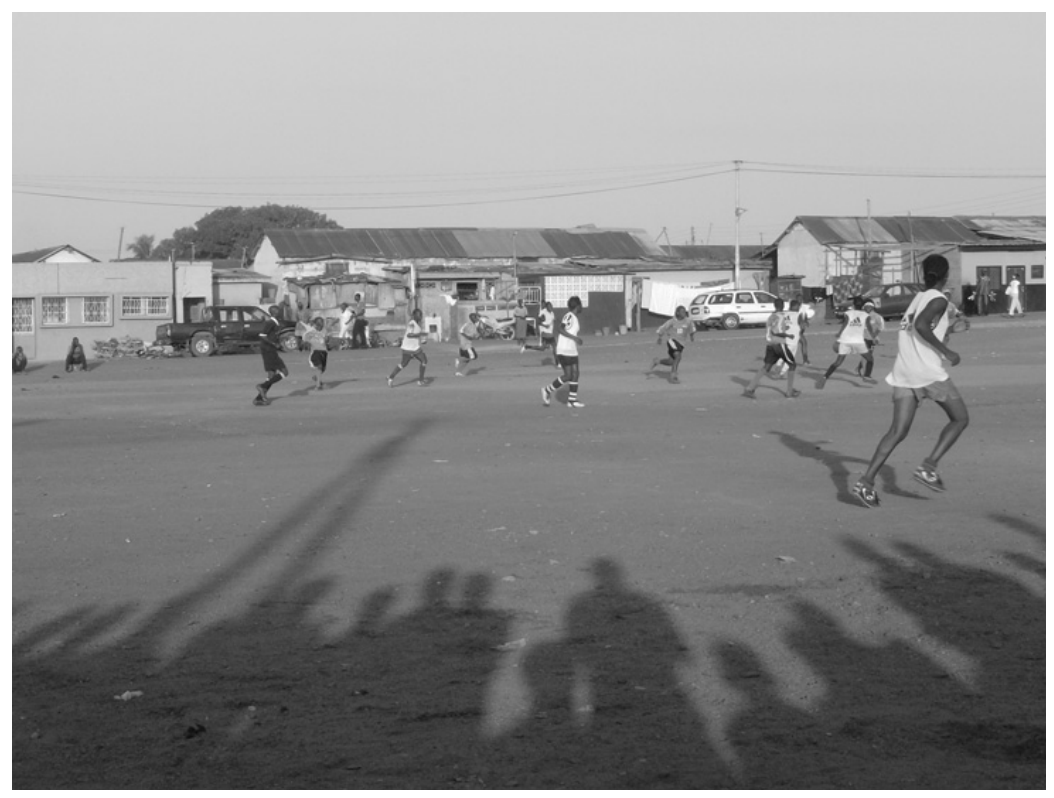

Figure 3 Two women's teams being cheered at by young men from the neighborhood (2007)

which masculine-presenting women point at the incongruity between their bodies and those of "real" men testify to young women's "contingent masculinities" (Blackwood 2010, 172).

In 2008, when I heard Suakrom's female footballers boast of having a "sugar mummy," the team's players came from all over the country, as well as from Togo and Nigeria. Most stayed in a half-finished structure that served as a makeshift boarding house. Early in the mornings, and in the late afternoons, they jogged to their training sessions at a school pitch on Suakrom's outskirts. During the day, some of them sold prepaid phone cards provided by the company running the club, and they all received a small monthly allowance on the condition that they attended all the training sessions. Still, I wondered how they survived on the meager profits of petty trading, especially if they came from neighboring countries and lacked local kinship ties and occasional job opportunities. Other than comments about "managing it," or jokes about having "someone" who "sponsored" them, my questions regarding their livelihoods did not yield 
straightforward answers. As I began joining them at training sessions, I realized that on our way back to town, some of them, still in their kick boots and jerseys, took a detour through the market. They returned from these visits with "chop money" (to buy food), and sometimes with an invitation to join a "sugar mother's" evening meal.

The market connections made by these footballers spanned not only age gaps, but also ethnic, national, and religious differences. Some Christian girls had Muslim "sugar mothers" and vice versa. Others made connections based on sharing the same ethno-linguistic backgrounds. An Ewe-speaking Togolese player, for instance, was provided start-up capital to begin petty trading by a slightly older fish trader of an Ewe background. Though these liaisons were not always sexually intimate, they drew on flirtatious, erotic banter. The market women seemed to enjoy the company of these well-toned footballers, many of whom hailed from bigger cities, and cherished their urban, masculine youthfulness. While relying on "sugar mummies" and some on "sugar daddies," the players also deployed kinship terminology among themselves. The terms "team mother" and "team daughter" distinguished junior, from senior teammates, and Stone, a particularly masculinepresenting player, introduced me to the goalkeeper as her "team father" because the goalkeeper used to be lovers with her "team mother." In another conversation, Stone claimed to have stopped visiting a certain Muslim cloth trader in the market because the teammates were constantly teasing Stone about being a "small girl" in need of a "big mama."

\section{Market Women and Mami Wata}

Throughout West Africa, the rhetoric of "sugar motherhood" points at the historical capacity of women traders to accumulate and control their resources (Ebron 2007, 182). At the onset of colonialism, rapid urbanization increased women's commercial activity in foodstuffs and rendered their autonomy particularly visible. For Ghana, the backlash to this autonomy has been documented in the literature on female trading in post-independence Accra (Robertson 1984) and Kumasi (Clark 1994). Between 1975 and 1985, local retailers in the big market towns

3 The term "chop money" can designate a husband's monetary contribution to his wife's cooking, and may have sexual connotations, see also Chapter 2. 
suffered humiliating, physical attacks under successive Ghanaian governments. Most notably, Accra's famed Makola Market was demolished in 1979, and its traders portrayed as wicked, "human vampire bats" under the rule of Jerry J. Rawlings (Clark 2001). These attacks have been considered a reaction to the fact that market women were less affected by the economic disasters of the 1980s than male workers, including cocoa farmers and salaried workers. The latter struggled to survive the economic depression of the 1960s and the effects of structural adjustment programs in the 1980s. The mostly female traders, however, seemed to prosper. Though few actually reversed the steep general drop in the inflation-adjusted standard of living, their relative well-being earned them accusations of hoarding and violating price controls, which swiftly drew government attention.

Today, the image of the all-powerful, predatory market woman reappears in sexualized rumors about her alleged greediness. As I was told by a taxi driver in Accra, for instance, voracious market women like to seduce innocent taxi drivers by giving them precious gifts. Through this sexual relationship, the women apparently steal the drivers' sperm and turn it into "sikaduro," a Twi term literally meaning "money medicine" to make themselves rich. Ironically, market women have been legendary for supporting young men through university. The years of military rule and structural adjustment which took place during the 1980s, saw a rise in so-called "Makola scholarships," as female traders covered the university tuition of their boyfriends with money gained through trading, supposedly at Makola Market. In practice, when a woman takes the lead in expressing her feelings for a man then he may be considered as having been given a "scholarship." The term thus refers to romantic or sexual attention that has come his way easily. ${ }^{4}$ At the time, Makola traders, who had often only attended a few years of school themselves, valued higher education and were instrumental in investing and arranging for young men's educational training. Tales of "Makola scholarships" betray the patriarchal anxieties about independent, "wicked women" (Hodgson and McCurdy 2001), whose capacity to follow personal sexual desires earns them the accusation of refusing their responsibilities as care givers and providers.

As discussed in Chapter 2 on supi and secrecy, the image of the selfish "big woman," who can afford to do whatever she pleases, has been

4 Email conversation with the sociologist Kofi T. Asante, March 17, 2012. 
homosexualized in Ghanaian video-films, in which well-traveled business women receive their powers through Mami Wata. This mermaidlike figure is found in ocean myths throughout West and Central Africa and is often associated with the invisible "satanic" forces of the market. Mami Wata gained popularity in the 1980s when structural adjustment programs imported fashionable commodities to Ghana without, however, enabling ordinary people to buy them (Meyer 2003). Investigating Accra's fishing communities, the Ghanaian filmmaker, Socrates Safo, discovered stories on wealthy women's alleged associations with Mami Wata, which he embellished to make them marketable. ${ }^{5}$ His film Women in Love (1996) portrays a "big woman" who is "married" to Mami Wata. This marriage pact inhibited her from desiring men. Instead, she was compelled to report and detail her sexual encounters with young women to the water spirit.

Such films left a strong impression on some of my respondents, including Lydia Sackey, one of the protagonists of this chapter. Talking about the dangers of same-sex love, she said "we see it in films" and refers to the scene in Women in Love in which a monied woman washes her hands in a glass bowl filled with water, after having sexually touched her young girlfriend. As Lydia puts it, such women use their lovers' sexual fluids "to siphon your luck [...] they'll use the money to take care of you, but your life won't be good." Corrupted by Mami Wata, such women are believed to become powerful at the expense of their small girls who, just like the sperm-deprived taxi drivers, remain poor. Furthermore, they rob their younger girlfriends not only of their financial luck but also of their fertility, thus denying them a respectable adult life as a mother. ${ }^{7}$ Based on films about Mami Wata, seventeen-year-old Lydia was initially scared of getting involved with Ruby, the wife and mother with whom she eventually became lovers. While reflecting the patriarchal and sexist anxieties captured by filmmakers, the presence of Mami Wata in women's personal narratives highlights the discursive power of rumors and of Nollywood and Ghallywood representations.

5 Fieldnote on a conversation with Socrates Safo at Accra, May 14, 2007.

6 Interview with Lydia Sackey at Accra, June 26, 2007.

7 More recently, aggressive versions of these narratives hold that the use of dildos and penetrative objects, such as deodorants or bottles, destroys women's sexual and reproductive health, and leads to irreversible infertility. 
Beyond these derogatory representations "sugar motherhood" and the desire to take care of each other, as a provider or a helper, or, as Dina Yiborku puts it, as "giver" or "receiver," is, I suggest, an integral part of intergenerational female intimacies.

\section{Sugar Motherhood and the Materiality of Love}

\section{Adi Cortey, Consuming without Affordability}

Adizah Cortey is nineteen years old, and goes by the nickname of Adidas, or Adi. Like many young people in southern Ghana, she puts on a thick American accent when speaking English and uses slang expressions. In her own words, she has been "dating girls" but wants to stop "fucking around" and "that kind of shit." Her father, who was a seaman, "kicked the bucket." Adi has five older brothers and grew up in a matrilateral family house in Accra Central, a section of town with a reputation as a haven for immoral behavior and for the susceptibility of its youth to sex-money exchanges. Like her parents, who converted to Islam, Adi professes to go to the mosque five times daily, although this is a somewhat idealized version of her everyday life. For religious festivals, however, she diligently exchanges her masculine sports outfits for feminine attire. In her frequent normative statements about how wrong it is to have same-sex lovers, and how she will stick to her boyfriend instead, she points to the Qur'an. In the next sentence, however, she could laughingly tell me about last night's sexual adventure with a female cousin with whom she shares her rooms.

At the time we met, Adi was about to complete senior secondary school, but she was more committed to football training in a local club than to excelling at school or helping out in her mother's kiosk in front of their house. Her dreams of playing football in the USA, and joining two of her former teammates who played for a college team and were therefore provided with free education, had given way to the slightly less ambitious goal of finding employment in Ghana's national "forces." Female secondary school graduates who are good at team sports stand a better chance of being recruited into the immigration, the military, or the police services. Besides playing football, Adi spent a lot of time roaming about with her friends. One hot Friday evening, as we were strolling through the crowded streets of Accra Central together, Adi began raving about her sexual adventures. Both her fifteen-year-old girlfriend, Yinka 
Okafor, and her twenty-five-year-old ex-girlfriend, Lydia, were within earshot, when Adi told Josephine, my research associate, and myself, that she liked "sugar mothers."

I call them rich mama because they give me money and they like my fucking! [S.D. Oh, don't use the word fuck] But I've stopped, because I have Yinka now. I've played with many, many sugar mothers, even Yinka's aunty is my former woman. Yinka's mother knows about it. And also, I separated with Lydia because of her sugar mummy; that very night I slept with one of Lydia's sugar mummy's friends. ${ }^{8}$

While talking, we walked through a lively section of the night market, where Adi kept calling out to young kajal-wearing ${ }^{9}$ male friends who do "women's work," such as preparing and selling light foods popular in the evening - Indomie noodles, hot beverages, scrambled eggs, bread topped with margarine ${ }^{10}$ - and who claim to have "sugar daddies."

Finally, Adi sat us down at a street drinking spot. All the while, Lydia feigned boredom, playing with her phone. Since the night of their separation, she took to quietly ignoring her ex-lover. Boisterous Adi, however, pointed to the other side of the road, where a few grim-looking women in their forties were sharing beers and bottles of Malta Guinness. Judging from the nets and curlers in their hair, and the fact that they sat on their own plastic chairs, it seemed that they lived close by and had come out to catch the late evening sea breeze or a glimpse of the noisy stream of passersby. "They are all in the soup," 11 continued Adi, "sugar mothers are very wild. They like beating their girlfriends. When they see you with a new girl you are dead." The story she then confided to Josephine tells of Adi's own wild part in the "soup."

8 Fieldnote by Josephine Agbenozan based on a conversation with Adi Cortey at Accra, April 17, 2007.

9 Kohl or Kajal is a black eyeliner that is also used by (especially Fulani and Hausa) men in the Sahel and Sahara regions.

10 In recent years, the visibility of young men in Accra who prepare night foods has increased. Unlike more "traditional" foods sold by women in the evening, such as kelewele (hot fried plantain, sprinkled with spices), these men sell more "modern" foods. More on Ghanaian cuisine in footnote 23.

11 This phrase refers to a state of being immersed in a difficult situation that involves a jumble of people. Given that groundnut soup and palm nut soup, two of Ghana's most popular dishes, are especially thick and nutritious (ideally containing a variety of meat and fish), the image captures both the richness and hustle of tight-knit informal networks. 
Lydia was my woman and we went to a party together at Locco. I did not know she had a sugar mother so at the party and unluckily for me, Lydia's sugar mother was there with her gang. The moment she set eye on Lydia she just came over and started ordering her to come with her. All her gang were making fun of me because they realized I was Lydia's girl. In fact, Lydia didn't want to leave me but her sugar mum and friends were pushing and pulling her till she gave up. I couldn't say anything, because these women are older than me and they can easily attack me if I said jack [i.e. a word]. I was left alone, very disappointed.

Fortunately for me, a lady approached me, who introduced herself as one of the friends of Lydia's woman. She sat beside me and told me not to be worried about Lydia and to forget about how her friends were treating me. She told me I look very beautiful and asked me why am I wasting my beauty at this party. She opened her purse and showed me a lot of money in there. She asked me to leave with her and have fun. Because I was lonely, I followed her. She picked a taxi and we drove to [the place] where she lives. She is very rich and has a big apartment. We entered and she asked me to feel at home since I'm in safe hands.

Initially I tried to refuse what the woman asked me to do, but when I remembered what Lydia's sugar mummy did to me I decided to teach her a lesson by sleeping with the woman. Also, I wanted Lydia to know that she is not the only person who likes sugar mothers but I am also in the squad. I sexed the woman that night. "She really believed [enjoyed] me." I spent the night there and came home the next day. At home I learned that Lydia came searching for me during the night. I had a call from her and she asked me to see her. When I met her, she started fighting me. She accused me of sleeping with that woman. She said I am a cheap girl. Since then there is always trouble, so I stopped with her. ${ }^{12}$

I am quoting Adi's narrative, mediated by Josephine's, at some length here, because it speaks to the alluring power of "sugar motherhood" and the competitive junior-senior dynamics between girlfriends of the same age-group. In this account, Adi portrays herself as "Lydia's girl," Lydia is Adi's "woman," and Ruby is Lydia's "sugar mother." What is at stake in this triangle? Was Adi really unaware that Lydia had another lover? Was Lydia playing on making Ruby jealous by showing up at Locco, a bar Ruby had introduced her to?

Locco, a popular bar among working-class women in Accra, consists of a walled outdoor space and a small stage where local bands perform

12 Fieldnote by Josephine Agbenozan based on her conversations with Adi Cortey at Accra, April 17, 2007. 
neo-traditional Ga music. Unlike more cosmopolitan gay bars in Adabraka or touristy Osu in the center of Accra that attract mostly male clientele, Locco caters to local women, who drop in at all hours to enjoy beer and spicy goat kebabs. Neither Lydia nor Adi can afford to charter taxis or invite their girlfriends as they please. It was probably the money Lydia received from Ruby that allowed her to take Adi out. This outing was harshly interrupted when Ruby made an appearance in the midst of her "pompous" friends. Frustrated and fascinated with the imagined powers of these well to do "mamas," Adi herself managed to capitalize on her youthfulness. Rather than being the loser in this love triangle, she proudly tells Josephine of her appeal to "sugar mothers" enabling her to effectively get one up on Lydia.

Adi's selfhood was only momentarily unsettled when faced with Ruby, Lydia's provider. Soon, her disappointment with Lydia gave way to the realization that she herself was attractive to older women. Adi readily tested her erotic allure and demonstrated that she too, like Lydia, was not just a "small girl," but knew how to apply herself to the bonding networks of seasoned, same-sex desiring women. Certainly, Adi's youthfulness, her deep, husky voice, and her welltoned, slender footballer's body, provided her with erotic capital. Since that memorable night, Adi claims to have had several sugar mothers, alongside girlfriends of her own age group. Five years later, when I joined her at an outdooring - a baby's name giving ceremony - I realized that she was not just boasting. Adi was friends with the baby's young mother, stretched out in the middle of a stuffy room. The all-female guests, who had planted themselves on the plastic chairs against the blue painted walls, were in their forties. Upon entering the room, Adi jumped onto the lap of a woman who was wearing much make up and a tight leopard print Lycra suit, giggling and whispering to me that the lady was her "ex." As if to give proof, she began to joke and make sexually suggestive movements on the woman's lap. When Adi conveyed to her that she was penniless, the straight-faced "ex" started fumbling in Adi's trouser pockets. On finding only one cedi, she promptly slipped a five cedi-bill into Adi's back pocket (the equivalent of a day's salary for an unskilled worker), followed by a slap on Adi's butt. Like Adi's feminine-presenting male friends, who sell food in the night market and juggle several "sugar daddies" at a time, Adi delights in her juvenile liberties and the extra cash she receives through her erotic conquests. 
Adi's interest in sugar mummies needs to be seen in a context where young urban women, including university students, look to sugar daddies to cover tuition fees, daily living expenses, and small luxuries such as lingerie or cosmetics. In a public health framework, sugar daddy/ mummy relations have been defined as sexual relations between "adolescents and older people that are associated with the practice of having these relationships in exchange for money, presents, favors and other material benefits that adolescents receive" (Kuate-Defo 2004, 21). Policy-oriented studies have asked about the conditions under which cross-generational sexual relationships can be defined as consensual, or coerced, and how they affect a population's reproductive and sexual health. They point at the difficulty of "measuring" emotional abuse and mutuality within the spectrum of the "free, transactional, exploitative, coercive or unlawful" (Kuate-Defo 2004, 14). While the actual difference in years and the younger person's age are seen as decisive factors in determining the legitimacy of such a relationship, the ways in which sexual difference or sameness factors in are not considered.

The perceived increase in non-marital sex in Africa has been attributed to the materialism and the moral corruption of greedy African youths in search of global consumer opportunities (Masquelier 2009; Cole and Thomas 2009). Indeed, the idea that consumerism is accessible through erotically motivated patronage circulates across Africa's urban centers. The anthropologist Francis Nyamnjoh, for instance, attributes the pervasiveness of sugar daddy/mummy relations to an "accelerated consumerism [that] is producing consumers without affordability" (2005, 303). As he argues, young urban Africans, both male and female, are increasingly looking for well-heeled "sugar mummies" and "daddies" in order to secure their livelihoods, support friends and lovers, and shop for consumer opportunities (Nyamnjoh 2005, 296). In Dakar, the idealization of this phenomenon manifests in a rich collection of sugar daddy metaphors. A thiof (the name of a much prized fish) is a comfortable big man, with an "appetite for younger women, preferably pretty university students and schoolgirls of modest social and financial backgrounds," and a disquette (as in floppy disc) is an educated, fun-loving young girl fascinated by western consumer tastes (Nyamnjoh 2005, 296). While being strategic and opportunist in their search for autonomy and social mobility, disquettes are exposed to physical and health hazards within a "phallocentric and consumerist (dis)order" (Nyamnjoh 2005, 317). 
Similarly, Adi's desire to boost her consumer style makes her susceptible to the cash in the hands of seemingly "rich mamas," which she spends on sports jerseys, trendy sneakers or "Calvin Klein" boxer shorts, if not on the young women she herself is attracted to. Adi's positioning as a "small girl" who competes for the attention of other girls is not captured in descriptions of young women who are exposed to the (hetero)sexual whims of "big men." Despite her vulnerability to "big women," Adi is enamored with the economic and erotic autonomy of "sugar motherhood" and delights in her own desirability. Inscribed in these intersecting desires is the prospect of occupying the position of a "sugar mother" herself one day. Further, unlike sugar daddy girls who rarely dare to inquire about their sugar daddies' marital status (Kuate-Defo 2004), Adi is fully aware of her lovers' husbands and children. She also knows that HIV/AIDS is not considered to be relevant to female same-sex relations. Generally, young women assume that their sexual health is much less at risk when sleeping with a "sugar mummy." A young Muslim woman in Suakrom even rationalized her preference for female lovers by pointing to the then widespread slogan "AIDS is real."

One way in which age-mixed relationships have been analyzed and assessed is by asking whether the liaison is a secret one or whether marriage and reproduction is envisioned by the older partner (KuateDefo 2004, 14). But how do we account for age differences when legal marriage prospects are missing? How can we understand the intimacies forged across a generational gap but not across a sexual difference? This matter will be explored by focusing on the life story of Lydia, who was at the heart of the love triangle between Ruby and Adi.

\section{Lydia Sackey, Reciprocating Provider Love}

The age difference was not big enough for Ruby to have been Lydia's mother. Lydia was in her late teens, and Ruby, according to Lydia's estimate, "about 11 years" older. ${ }^{13}$ However, the fact that Ruby's oldest daughter is only four years younger than Lydia, and Ruby is a successful business owner, suggests a considerable difference in status. This difference is reflected in Lydia's invocations of Ruby as a "big woman." Nevertheless, their relationship diverts both from the instrumentality

13 Given that Ruby's oldest daughter is not much younger than Lydia, it is possible that Lydia's estimate offers a slight reduction of their actual age difference. 
attributed to sexual relations between "sugar daddies" and their girls, and from the conjugal provider model.

When we first met, Lydia was upset. She had recently walked in on Ruby and a female cousin of Lydia's. Sulky and absent-minded, she explained that this discovery had prompted her to go on a two-week drinking binge: Ruby was bossy, jealous, and controlling and Lydia felt stuck, because she depended on Ruby financially. One and half years later, when we met again, she had separated from Ruby and looked much happier. Surprisingly, she was full of praise for the practical domestic, business, and sexual skills Ruby had transmitted to her. Knowing that I was interested in the parts of her life history relevant to her erotic subjectivity, she started by telling us what led her to become interested in women, and in particular in her first adult lover, Ruby.

My name is Lydia Sackey. I live at Accra Central. ${ }^{14}$ And the type of friendship that we have at Accra Central, it's good (.) for the environment that we're in. Because when we were growing up, our parents were afraid that we'd bring pregnancies home. So me, for instance, my mother advised me and put fear into me, because at the age of 11 years I already had my menstruation coming. ${ }^{15}$

As stated earlier, the fear of falling pregnant is vivid, not only among city girls. Yet in stressing her inner city "environment," Lydia insinuates the particular roughness of Accra Central, the city's main trading district, which has been considered a bad place to bring up children (cf. Robertson 1984, 65). In this crowded, commercial area, bustling with markets, formal and informal businesses, drinking spots and lorry stations, everything is traded, including sex. While the fear of losing respectability by "chasing men" during "hard times" 16 looms large among young working-class women, the anonymity and consumer opportunities of downtown Accra add to the temptation of engaging in sexual transactions with (potential) sugar daddies and thereby falling pregnant.

"So the way [my mother] talked to me, fears entered me," Lydia continues her story. "And along the line, when I was like seventeen

14 Lydia is referring to what used to be "British Accra," the densely populated area between James Town, one of the old Ga settlements on the coast, and Makola Market.

15 Interview with Lydia Sackey at Accra, June 26, 2007.

16 While all other quotes in this section are taken from conversations and interviews with Lydia, I am here quoting an interview with Ma'Abena Oppong at Suakrom, March 16, 2008. 
years, I met someone, and we became friends, and I saw that it helped me, till the time that I saw that, maybe, I'll marry." This someone, who prevented her from having boyfriends and seeking gifts of men, was Ruby. Lydia is not explicit about whether their involvement "helped" her because it stopped her from seeking male attention. Clearly, however, Ruby set the material foundations for a stable relationship. As Lydia continues in the present tense, Ruby took care of her: "The one I am there with, she helps me, she's fine with me. Everything I want, she provided me with it. We are living happily." Before considering Ruby's provider role, and the configuration of their enduring relationship, I will look at their extended period of courting. "She chased me for over six months before I accepted," Lydia remembers. As mentioned above, Lydia was wary of Ruby, due to the films and rumors about "big women" being connected to Mami Wata and using "juju" on their youthful lovers. It took months before Lydia managed to let go of her fears and started engaging with Ruby.

Initially, they met through Lydia's cousin who lived in the same compound with Ruby. At the time, Ruby was selling meals at her chop bar, an informal eatery down the road from Lydia's family house. Because Lydia avoided Ruby, and rejected her invitations to visit her, Ruby took to visiting Lydia at home. "Because she is old enough to be my elder sister or my aunty, I can't snub her in front of my (pauses) people in the house [and she too] knows that if she comes to my house, I can't snub her, so all the time she used to come to my house till the time we became close." 17 The hierarchy implied by their differences in social status worked as a cover in Ruby's courtship. As a business owner, wife, and mother, Ruby could present herself in the best light and with the noble intentions of an older sister or aunty. Lydia, however, knew that Ruby was wooing her. She showered Lydia with gifts and good advice, for instance, warning her to stay away from the "gang girls" of her rough quarter (the female equivalent of the unemployed, roaming "area boys"), until Lydia herself, alongside the people at her house, considered Ruby a helpful and "good woman,"

Lydia is the daughter of a Ga mother and a Fante (Akan) father. ${ }^{18}$ Like other women of this common mixed ethnic background, she tends

17 Interview with Lydia Sackey at Accra, June 26, 2007.

18 Although the Fante are an Akan people, their kinship system has been considered ambi-lineal, rather than matrilineal (Robertson 1984, 28). 
to refers to herself as Fante, possibly in reaction to the bad reputation of Gas as the greed-driven landlords of Accra Central. She is also her father's beloved first-born child (her mother had children from a previous relationship). Lydia was fifteen when she moved from the suburbs to her maternal family house in Accra Central. By this time her parents had divorced and Lydia's father worked in the neighboring harbor city. Her mother, who traded plantain in Accra's Makola market, had always spent a lot of time at her family house. In her study of Ga women's history in Accra (1984), Claire Robertson shows that most women lived with their husbands early on in their marriages - previously as farmers in ancestral Ga settlements outside the city - but returned to their family houses once the children started growing. Although conjugal living in the suburbs is associated with relative wealth, women were not willing to commit themselves permanently to it. Considering the high divorce rate, conjugal living was regarded as a temporary arrangement $(1984,66)$. In Robertson's 1972 survey, only 1.3 percent of all women lived with their husbands. Those in Accra Central lived with their (female) relatives rather than with their spouse's relatives because of potential conflicts and their lack of authority (Robertson 1984, 65).

Lydia first started wondering about female same-sex passions as a child when she observed the women in her compound quarrel, kiss, and do "many things [...] I just looked at them, I thought about it but I still didn't understand why they were doing that." Once at Accra Central, however, mingling with female footballers, she "heard a lot" more about "it" and retrospectively interpreted the quarrels she had witnessed as a child as lovers' fights. Thus, by the time she entered secondary school, she "knew it already." In fact, she was hoping to attend Accra Girls Senior Secondary School in the city, but her father believed that "Accra Girls people are lesbian." He sent her to a small-town Catholic boarding school instead, not knowing that:

They are the worsest- worst people over there! Yeah, because- so when I went there, I had many girlfriends, but we don't do anything, yeah. We only, we kiss, buy gifts and- till the time I completed. And when I- completed, that time all, I've grown wings! So, that time I met my- the woman [Ruby] I was living with for a, for about five years before we break up, yeah! (.) She teach me how to do it well, yeah. ${ }^{19}$

19 Interview with Lydia Sackey at Accra, June 26, 2007. 
Though Lydia alludes to how she was taught to "do" sexual things "well" and thus gained the knowledge she would later pass on to Adi, she also acquired a range of everyday and professional skills under Ruby's supervision.

Upon completing Senior Secondary School (SSS), Lydia "stayed at the house" - a standard phrase indicating a lack of formal or informal employment - and no one intervened when Lydia moved in with Ruby and her three daughters. "She cooked and I washed. She doesn't do much in the house [...] I like it that way, when I wake up in the morning, I do everything. Her children were there but I didn't bother them. So her children liked me. Because I helped their mother. And sometimes I helped their mother to sell [food]." ${ }^{20}$ The oldest of the three children was almost Lydia's age, and the second born attended secondary school where she had a supi and was hence "in it herself," as Lydia put it. ${ }^{21}$ The daughters knew that Lydia was more than a domestic helper, and even reprimanded and "insulted" their mother when she attempted to bring home other girlfriends. Toward other relatives, who were aware of Ruby's same-sex passions and talked behind her back, Ruby used the strategy commonly deployed by "knowing women": she ignored speculations about her same-sex life as much as possible and, if the gossip became too public, she fiercely denied any accusation.

Lydia readily helped with regular household chores but having specialized in "Food and Nutrition" at SSS, she preferred to assist Ruby with the chop bar. The preparing and selling of home-cooked food is a popular trade among women in Accra Central. ${ }^{22}$ Although it is not very lucrative, a majority of women engage in it at some point in their working lives. It is particularly convenient for mothers of young children, who have to cook anyway, and whose children can help grinding vegetables for the soup, or peeling and boiling cassava for the $f u f u$ (Robertson 1984, 109). ${ }^{23}$ Besides assisting Ruby, Lydia was also taught how to organize and time the preparation of large quantities

20 Interview with Lydia Sackey at Accra, June 26, 2007.

21 As suggested in the previous chapters, supi is something you are "in," something you become part of and not something that is "in" you.

22 Unlike trade in produce, fish, or imported goods, the entry requirements for food preparation, such as capital and contacts, are low and the access to cheap labor was afforded by compound organization (Robertson 1984, 106).

23 Fufu and soup, the ideal Akan evening meal, is typically served in chop bars throughout southern Ghana. Fufu is made of boiled cassava and plantain, yam, 
of food. Sometimes Ruby would "sit and tell me to put this here, you see, and to wait before doing that. I should add this to that and all." The female apprenticeship system was the chief means of training girls prior to formal education and a continuation of the sexually segregated residential Ga framework within which mothers passed on basic skills to their daughters. If a mother wanted her daughter to learn a trade which she did not follow herself, or if she felt a friend or sister was better at teaching a trade, she could give the daughter to this woman to bring her up (Robertson 1984, 134). Had Lydia followed her mother, she would have become her trading assistant, traveling to "the village" to purchase plantains, transporting them to Accra, and storing and distributing them, thereby gaining bargaining skills, knowledge about how to update information on price levels, and supply and demand conditions. In this way, she might have eventually accumulated enough working capital to start trading on her own account. ${ }^{24}$ But, rather than becoming a trader, Lydia chose to be her lover's informal apprentice in a chop bar and thus follow a less prestigious trade.

Apart from Ruby's need for helping hands, their domestic intimacy was predicated on a husband who worked outside Accra. As Clark notes, duo-local residence was preferred not only because it was believed to prevent quarrels and jealousies over the use of time and money, but also because it gave a woman more freedom to invite (female) friends and relatives to live with her $(1994,340)$. The location of Ruby's chop bar, and the fact that catering for meals around noon requires an early start, makes separate living arrangements a necessity that obviates further explanation, even now that conjugal housing has become the ideal. Among working-class spouses, the need for independent incomes often outweighs romantic ideals of marital homes and shared budgets. Lydia helped in the chop bar, but she also helped to prepare meals for Ruby's husband at his place. "She will go to her husband every Saturday night," says Lydia, "I will come there in Sunday morning. We cook together but her husband didn't know, me and [his] wife were something like this (pauses) and me too I don't do something that, her husband will see me, me and [his] wife are doing this thing."

or cocoyam, that is pounded in a mortar until it takes on a viscous texture. The preparation is labor-intensive (it takes up to three hours).

See Gracia Clark $(1994,200)$ on the trajectory of becoming a trader. 
The fact that Lydia assisted Ruby in serving her husband is a meaningful, and perhaps subversive act, given that many wives are reluctant "to delegate cooking to potential sexual rivals, such as housemaids, in case the sexual implications prove too strong to resist" (Clark 1994, 346). In southern Ghana, as elsewhere, cooking in marriage is a highly symbolic act. Preparing a husband's evening meal implies sex on the female side, and the provision of so-called chop money, a husband's main financial contribution to his wife (Clark 1994, 345). Historically, "giving chop money to a wife and cooking for a husband were the reciprocal acts at the very heart of thriving conjugal relationships" (Allman and Tashjian 2000, 66). As wives were expected to spend the night after the evening meal at their husband's, preparing meals for an unrelated man could imply adultery. Lydia's inclusion in the marital nexus of food preparation and consumption, speaks not only to Ruby's and Lydia's mutual trust. It is also an expression of their own cooking for and eating (with) each other, hence of their own intimate nexus of appetite and consumption. At the same time, although Lydia never referred to Ruby as a "sugar mother," there was a gap in power that manifested itself not least upon their break-up.

Remembering how shattered and heart-broken Lydia was when we first met, I asked her how she "survived" their break-up. Her reply was short and simple: "my father gave me money." It reminded me that my concern with emotional survival is not conceivable without examining their material practices and the imperative of what Mark Hunter calls "provider love" in the southern African context $(2010,16) .{ }^{25}$ Fueled by the need to address the HIV/AIDS pandemic, the phrase "transactional sex" has been coined to highlight the centrality of material exchanges in opposite-sex intimacies that are not understood as sex work (Arnfred 2004). This materialist approach was anticipated by feminist studies on African women's agency in the 1970s. Recently, anthropological and historical works have shifted from a transactional approach to a focus on love and emotion (Cole and Thomas 2009), while challenging the assumed primacy of romantic love in the "West"

25 The question of how exactly emotional and material needs are intertwined poses itself throughout the world. In The Purchase of Intimacy (2005), Zelizer, for instance, challenges the assumptions that the romantic and the material occupy fundamentally different spheres of life and shows how intimate relations affect the way economic life has been organized in North America. 
(Hirsch and Wardlow 2006). Writing against the materialist limitations of notions of "transactional sex" and Africa's purported "lovelessness," Hunter notes the historical pervasiveness of marital choice and passion, prior to, and alongside, the forces of individualism that came to Africa. He introduces the term "provider love" as an emotional bond that used to be instigated by bridewealth and "became directed toward building a marital home," always depending on men's wage labor (2010, 37). This notion of providing love resonates in Lydia's sense that Ruby's provision prevented her from going after men and enabled their romantic togetherness.

The closeness between Lydia and Ruby did not go unseen. At some point, people's "gossip" about the extent to which Lydia had involved herself in Ruby's life prompted Lydia's mother to call the police. Lydia's father tried to dissuade her from doing so, but her mother ignored his interventions and asked the police to come and "warn" Lydia. Luckily Lydia was never home when the police arrived. Often, as seen in Chapter 2 , it is the family of the providing partner who engages the police (by possibly bribing them). Lydia's case is different. Neighborhood gossip inspired her mother, who was not all that bothered about her daughter's intimacies prior to the gossip, to take action. Yet Lydia chuckles as she tells us about the police incident and ponders at her mother's ability to "feel" that Lydia's girlfriendships had an erotic dimension. She remembers how it always puzzled her when certain female friends came looking for her and her mother would, upon their arrival, start "preaching" and taunting them: "So you too, you're in this?" Lydia even suspects that her mother's awareness and keen criticism derived from her own same-sex experiences. She seems to interpret her mother's ability to discern and criticize her erotic friendships as a sign of her own "knowingness." It is widely assumed that those who preach and blame others for their vices the loudest may not only seek to put their righteousness on display, but also to distract from their own transgressions. Her mother's sixth sense (or her "gaydar" as North Americans might say) suggested an experience-based familiarity with same-sex passions. The fact that Lydia had become Ruby's helper did not divert her mother's attention from their erotic intimacy.

Lydia emphasizes the reciprocal aspects within her relationship with Ruby. Rather than seeing herself as having been treated as an insignificant "small girl," they were partners assisting each other. Moreover, she appreciated that Ruby introduced her to a new adult world. She 
acquainted her with mature women's same-sex bonding networks by taking her to bars and to her friends' private parties, to "outdooringslike places where I never expected to be, she sent me there, because her friends are big people. And I sit among them. She was never harsh on me and she never allowed her friends to speak rough with me." ${ }^{26}$ Lydia accompanied Ruby to festive occasions at which a young woman would not usually sit in the front row, among the honorary guests. Lydia had known of the passionate dimension of same-sex friendships before meeting Ruby; she had witnessed the lovers' fights of her "aunties" as a child and exchanged gifts at secondary school. Yet she strongly distinguishes her relationship with Ruby from the erotic friendships of her secondary school days.

We don't have sex. We only kiss, buy me biscuits [...] we love each other [but] it wasn't very boisterous, that time. It was nothing, you see, that time, I only saw it as a plaything. So it was the woman who came to have a serious relationship with me. [...] We went out, ate together, bathed together, like we were living fine. And she's good in bed. She's very skillful. She doesn't hurt you. Yeah, she'll have sex with you, and you'll feel like you've really had sex! She's fine. ${ }^{27}$

The seriousness Lydia attributed to her intimacy with Ruby lies not only in the fact that Ruby provided money, but that she was a good lover too. Lydia strongly marked off supi girlfriendships from her first "serious" relationship.

Before returning to the specific relational dynamics with Ruby, I will now consider Lydia's distinction between erotic play and genital sex instigated by older and more "knowing" women against the background of the sexual health workshops she attended. Inspired by an educational program taught by international gay and lesbian activists, Lydia emphasized that the wellbeing of female lovers would improve if they were provided with information about (lesbian) sexual technologies. Her request for washable vibrators, silicone dildos, ${ }^{28}$ and dental

26 Interview with Lydia Sackey at Accra, June 26, 2007.

27 Interview with Lydia Sackey at Accra, June 26, 2007.

28 Lydia's quest for technology and information is informed by the spaces of male peer workers doing HIV outreach work among MSM that lend themselves to conversations about sexual practice, pleasure, and identity, and to the use of dildos, if only to demonstrate the correct handling of condoms. Lydia hoped to extend the sexual health framework toward the inclusion and sophistication of female same-sex lives. 
dams, stand in both for the double improvement of women's sexual health and pleasures. Another aspect of Lydia's vision of a sophisticated lesbian love life in Ghana is her conviction that women must stop engaging in love triangles and thereby reproducing negative supi stereotypes. If women refrained from having multiple lovers and from enacting the resulting jealousies in the streets of Accra, the quality of their relationships would improve and the popular beliefs about sinister supi cults and pacts with Mami Wata could be undermined. As mentioned above, Lydia herself was affected by the cinematic portrayals of "big women" involved with Mami Wata. Such beliefs were projected onto Ruby and herself, as Lydia bemusedly remembered. Apparently, Ruby was besotted with Lydia and their bond became so tight that some of Ruby's friends suspected that the two had committed to a blood friendship, claiming that Lydia had a big scar on her thigh as a result of a blood sharing practice.

Mindful of the powerful reality of widely shared "spiritual" beliefs, Lydia's rejection of blood friendship stemmed less from fears of transmitting disease, than from the notion that blood bonds do invite haunting spirits and bind souls together in ways that breed unhealthy obsessions, leading to fights and public disclosures. Once tied through blood friendship, such spirits may take hold of a couple forever, even if one lover wanted to separate, or grew to loathe the other. Lydia's investment in reducing the appeal of occult same-sex bonding practices and in showing that women's erotic intimacies can amount to a respectable form of love, beyond the gloomy spiritual entanglements and love triangles among friends and cousins, seemed to suggest a wish for a public framework recognizing and confining same-sex passions. However, Lydia did not share my rationalizing hypothesis that secrecy itself, hence the need to conceal, may be the actual problem. If same-sex unions could be lived in more openness, I offered, blood friendships might not turn into messy love-hate-affairs. My reporting that same-sex marriage is legal in some countries did not convince her either, as she seemed to associate same-sex "marriage" again with unhealthy pacts with the spiritual world. If a lover privately gave her an engagement ring that would be nice, but anything more public, she would reject.

Despite her interest in an international lesbian rights politics and in improving the love lives of same-sex desiring women in Ghana, Lydia hesitated when using the term lesbian. In fact, she never applied it to Ruby, who had conveyed to her a sense of successfully juggling 
same-sex desires alongside marriage and motherhood. Rather, she reserved the term lesbian for unmarried women like Adi, her cousin, or herself. The stylish young women she bracketed as "lesbian" had less to lose than their established "mothers" who highly valued discretion and had the means to rent venues or organize women-only parties inside their compounds. This relative power allows "big women" to veil the encroachments of their "small girls." This, however, does not figure in Lydia's idealized rendition of her first adult love. Rather, Lydia cast the power that comes with age difference in a sisterly way.

At first Lydia did not even understand my question as to whether she ever felt "abused" by Ruby. Josephine's translation did not yield an immediate understanding either. "She's asking whether you felt used. Like she used you, the woman," Josephine translates into Ga. "Like she used me? [J.A. Mhm] Oh, no she is not like that with me, she's good to me. She's always good to me, but just that she's a womanizer. She loves women. Whoever she sees, she feels like, having her way, you see? But she's good." ${ }^{29}$ While the term abuse is not commonly used in Ghanaian English, to "use" someone implies a lack of reciprocity and respect. ${ }^{30}$ Because Ruby was committed and providing, Lydia resigned herself to Ruby's womanizing, just like a wife may tacitly tolerate her husband's extramarital affairs, as long as she felt respected. This acceptance only faltered once Ruby stopped hiding her adventures and started taking Lydia's cousin to their room. Busy "fooling around," Ruby did not seem to take into account that Lydia "grew wings" and started having her own (junior) lovers. As reflected in the scene at Locco, Adi had to contend with the fact that Lydia gave priority to her "sugar mother." Thus, Lydia not only passed on the erotic skills she had gained through Ruby, but also implicated Adi in a triangular situation, similar to the one Lydia herself had to suffer Ruby.

While looking to a romantic ideal, Lydia rejects the idea of consolidating same-sex love through blood or "marriage" rituals (and legal marriage appears as both inconceivable and undesirable). Rather than seeing homophobia as being responsible for the possible detrimental effects of lovers locking their unions with a public or occult vow, she

29 Interview with Lydia Sackey at Accra, June 26, 2007.

30 The Ghanaian sex workers interviewed by A. Adomako Ampofo, for instance, evaluated their work in the light of unresponsive husbands and lovers who were "sexually (ab)using them 'for free"” and felt that they did not want to be "used by any man again” $(2007,195)$. 
worries that same-sex pacts in general may interfere with motherhood, reproduction, and respectability. Instead, she asserts that women who are faithful to each other are on a healthy path toward stable, peaceful relationships. This vision of partnership requires one partner to be able to provide financially. Contrary to the idea that "modern" homosexual relationships are egalitarian and do not exhibit major age differences, here difference is not considered a stumbling block, but the prerequisite to a fulfilling relationship.

\section{Okaile Allotey, Working for Love}

I met Okaile Allotey on the backstreets of a touristy Accra neighborhood. Okaile was with her cousin, a young, blind man, who followed her at every turn, and with Stella Odamten, who had worked with Okaile on forming a "ladies social club" in the past.

When I explained to them that I had rented a room in Suakrom, where I was hoping to find "older women" to interview, Okaile intervened. In her mid-twenties, Okaile immediately associated my quest for "older women" with her own interest in "sugar mothers," and claimed that there was absolutely no need to go to Suakrom. She could easily put me in touch with older women in Accra, as she had started looking for a "sugar mother" herself.

I will only go with the ones from thirty-five, forty going now and stop with the young ones. The young ones chop money. ${ }^{31}$ I buy them phone credits, this that. But the old ones, you may bring food and prepare it at their house, you can fuck them and they even sponsor you. (An elderly lady in funeral attire, perhaps in her sixties, passes by.) This is just my type. These old women['s vaginas] are tight, they haven't had sex in a long time (all laughing). ${ }^{32}$

Five years later, when I asked Okaile how she was coping with the increased levels of hostility toward same-sex relationships in Accra, she responded that she had stopped going out with women of her own age; they were not only too demanding, but also too jealous and too impulsive, and thus unable to veil their same-sex passions.

31 The verb construction "to chop" or consume "money," hence to spend it lavishly, echoes the sexual connotations in the noun "chop money."

32 Fieldnote based on a conversation with Okaile Allotey at Accra, November 30, 2007. 
Okaile is a gifted wordsmith who constantly, both intentionally and unintentionally, makes up new Ghanaian English expressions. She says of herself that she used to be a "hard call" girl, but now she likes to refer to herself as a "bachelor" and to her networks of same-sex desiring friends as "girls in the woods" - for "anything can happen in the woods." "As a child she was called "funny" names in Ga, such as " поо уоо [literally:] man-girl, boy-girl." Everything boys did, she did too, when she had to wear a dress, she changed into jeans as soon as she left the house, and, gesturing to her sizable bosom, she claimed that she was "surprised" about ending up with breasts. Okaile's female boyhood was facilitated by a lack of care and supervision in the house of her "old lady," her ageing grandmother. "You know this grand mum they don't care about anything and you know, girls in our area also were also going out with men." At the age of fourteen or fifteen, Okaile had her first sexual relationship, with Mrs. Anarfi, who was at least fifteen years older than her.

I'm lesbian. It started when I was in JSS 1. At first I was like, likely like a man but I don't know what is call that. When I was in JSS a French teacher, Mrs. Anarfi yeah, she introduced me to it. She likes me very much, she does everything for me. You know this French I'm not good in that. Sometimes she gave me good marks about it. One day, she [took] me to her house [...] I went and then I cooked for her, after that she asked me to eat in the same bowl with her, which I didn't refuse. So, I eat, I ate with her. I ate, we had a nice time she bought me a drink. So after that I told her my time is up, because we- I also have another subject to [study]- so I have to go back, and she said: "oh, what kind of subject am I going to learn that is so more important than, her?" I didn't understand. In fact, that day she was-she was on top of me. ${ }^{34}$

Asked to tell me her life history, Okaile starts head on with her erotic self - unlike other interviewees who were less direct or did not make their gendered and erotic life the starting point. Okaile considers her masculinity a sign of being "lesbian," which she, however, did not have a name for when she was growing up. Okaile befriended the "area boys," joined them in going to clubs with "white girls," played football, and gambled as early as primary school. "I smoke, I drink. It's like I don't like men in natural. When I was tender age, I've been telling

33 This and all the following quotes in this section are taken from the interview I recorded with Okaile Allotey at Accra, May 25, 2007.

34 Interview with Okaile Allotey at Accra, May 25, 2007. 
myself I will never marry or give [birth]; so I didn't know the connection, when it started, but I'm very tender age, but I'm hard call girl at that time." Okaile identifies her preference for boys' activities and her intention never to become a wife or mother as part of a masculine disposition that she retrospectively connects to her sexual preference.

Okaile spent much of her secondary school years serving her "mistress." "Your mistress?" I pick up on her term. "Yeah, because she give me food. She buy me dress everything. I- I- I don't even pay my school fees." There was no need for the French teacher to take her time or to woo Okaile. Even if Mrs. Anarfi had sought permission from Okaile's aunties and grandmother, they might have been glad that Okaile was supported and "mothered" elsewhere, and by a teacher who could help with schoolwork and school fees. Unlike Lydia, Okaile did feel "used" in this relational configuration.

She asked me to fetch water to her place and I did that, she asked me to cook, and I did that. [Then] she will say, "oh come and eat with me" and I ate and then things started running. At that time she was on top of me, because I didn't know anything. I had the idea of that, but she was on top of me alright, she was, she was using me - (pauses) everything. ${ }^{35}$

Following the invitation to eat from her teacher's bowl, Okaile became part of an eroticized nexus of being fed and of being sexually consumed. The "idea" that her gender identification and her feelings for girls might transpire into something sexual predated her teacher's advances. The thought of having female same-sex relations was not novel or unappealing to her, but she had not envisaged being dominated and coaxed into sex by an older woman.

Okaile's story of how she was subjected to her teacher's desire needs to be seen in the historical context in which young girls have become "small girls." Schoolteachers have always been encouraged to take in a pupil. Both male and female teachers, especially those who are unmarried, childless, and stationed away from home, rely on the domestic help of a live-in pupil who, in exchange, they are supposed to mentor. According to Claire Robertson (1984), live-in helpers in Accra in the 1970s were to be raised and treated as foster children, ideally by betteroff relatives and mentoring benefactors. The arrangement by which educated, elite women obtained domestic helpers was supposed to 
benefit the helpers, because they were taught European housekeeping skills and sent to school in exchange for their help. In practice, however, child helpers were often raised by unrelated mistresses, with little accountability for the child's wellbeing $(1984,135)$. As I realized when living with Maa'Evelyn, the boundaries between fostering and exploitation are slippery. Though Maa'Evelyn sent her helper, who hailed from a poor rural background, to school, she worked her hard, barely acknowledged her presence, and made disparaging comments about her being stubborn and stupid. This slipperiness extends to the erotic analogies between practices of eating, feeding, and seducing, through which sexual abuses can be disguised. As Robertson revealed, the "seduction" of child helpers already appears in accounts of pawning in Accra, written in the 1930s. At the time, and until the 1950s, it was common for children who lacked a strong family network, to be given as helpers in payment for debts. This practice was inherently gendered and "girls were more likely to be given as pawns than boys, since if a girl's master seduced her, which often happened, the waiving of bridewealth was a convenient method for her lineage to rid itself of the debt" (Robertson 1984, 134). While pawning is no longer legal, pervasive poverty and the demands of the global economy have made young women in southern Ghana even more vulnerable to "seduction," often without any marriage prospects (Adomako Ampofo 2007, 191).

Okaile appreciated her French teacher's support. They were "managing" their sexual relationship during her first two years of secondary school. Problems started when Okaile entered the final year of JSS and "became the girl, the guy himself." As Okaile says, she stopped going "for her [teacher's] money," because she needed her own "freedom." By then she had started "running people" (not to say "chasing girls"), and realized that she herself could initiate erotic bonds, without having to compromise her masculine sense of self. Mrs. Anarfi did not take it lightly. She began to attack Okaile in front of the whole class for no apparent reason - ironically, she often ridiculed her for her unusually deep, masculine voice - gave her unfairly poor marks, and verbally abused her to the point that her schoolmates realized that something was wrong. As Mrs. Anarfi began exiling her from the classroom for entire lessons, Okaile decided to avoid "embarrassment" in front of "certain girls" in her class and stopped going to French classes altogether. Surprisingly, however, Okaile ends her account by expressing thankfulness to the "mistress" who victimized her. 
O.A.: I was a victim too for her [but] let me say it has helped me in one way or the other.

S.D.: How?

O.A.: How? Because she (pausing). I now go for fish myself.

S.D.: Hmm (laughing)

O.A.: I now know how to fish. She taught me how to fish [...] so that's helped me.

S.D.: Mhm, but you don't do it like her?

O.A.: No no no, it's a free will, mine it's a free will. I make sure you know [...] what I'm up to. [...] It can take me about three months, four months before touching them. ${ }^{36}$

Despite Okaile's limited agency and the victimhood she experienced, her sense of being "likely like a man" was consolidated through her involvement with the French teacher. Coaxing Okaile into having sex, Mrs. Anarfi made her aware of her own desires and of a way of acting on them sexually. She brought her, albeit roughly, into the world of "knowing" same-sex passion. Though Okaile claims that she is more cautious when approaching a girl and always verbally proposes before she becomes physical, she sees herself as following in her teacher's path, in terms of making the first move and taking the erotic lead. Certainly, at the time I met Okaile, she did not have the domestic space or the financial means to be as imposing as her teacher was. She shared a room in her grandmother's compound, and while working in occasional informal jobs she could not afford to rent hotel rooms, as is done even among conjugal couples in Accra with an acute lack of privacy.

So far, Okaile's trajectory into desiring women plays into the hands of a standardized homophobic narrative, rehearsed in popular Ghanaian discourses about how minors are brought into "homosexualism." Christian educational booklets that tackle the question of whether same-sex attraction is a matter of choice or genetics list "admiring an older teacher or mentor who is homosexual," as one of the main scenarios that "can seduce" a youngster "into homosexual behavior" (Akagbor 2007, 75). What is at stake in the seductive power and authority of a mentoring patron has not yet been contextualized outside the terms of ensnarement and moral corruption. Besides,

Interview with Okaile Allotey at Accra, May 25, 2007. 
heterosexual sex with a minor is punishable by law ("defilement"), while sodomy and, by extension, all homosexual acts can be considered abominable, even if they happen between adults.

Beyond the language of condemnation, it is challenging to grasp the violence that may occur in age-mixed same-sex relationships. In order to fight, rather than fuel, the fire of homophobia, gay and lesbian activists have focused their energies on more upbeat aspects of homosexual "love." Anthropological classification schemes of age-stratified homosexuality gloss over the vulnerabilities of younger partners to the benefit of describing "ritualized homosexualities" or theorizing classic accounts of boy-men relationships as cultural institutions. Such classifications focus on structural explanations for age-mixed same-sex practices, rather than their affective dimension or the possibility of abuse. In her rich ethnographic account The Politics of Passion (2006), Gloria Wekker points at the asymmetries of female relationships across generational configurations among Afro-Surinamese "mati" women in Paramaribo. Wekker's personal account hints at the joys and complexities of being involved with a much older "mati." She describes her sexually intimate relationship with her landlady Ms. Juliette, who could have been her grandmother. Ms. Juliette did not shy away from drawing on the authority that went with her age and forcefully enacted her jealousy when Wekker fell in love with a woman of her own age-group.

Historically, in Paramaribo, birthday parties were often thrown by an elder for a younger woman lover, in the communal yards of femaleheaded households. These birthday nights amounted to crucial sites for symbolically recognizing a same-sex bond, but also for enacting jealousies and heated (lovers') fights. Melville and Frances Herskovits described the dancing, singing, drinking, and gift giving, as well as the fist fights that unfolded during these celebrations and held that the fights added "to the zest of the party" (Herskovits 1936, cited in Tinsley 2010, 56). Exploring the eroticism between women in Caribbean literature, Tinsley touches on these women's dramatic fights, as described by Wekker and the Herskovitses. To Tinsley, the violent conflicts over a birthday girl are not always staged or playful, even if they happen in the midst of joyous celebrations. She places these "slippages from seduction to aggression" (Tinsley 2010, 56) in the context of a patriarchal colonial logic, in which market women, domestics, and washerwomen, of all age groups, had little to claim as 
their own. Acting out "their hunger for at least one prized possession," in spite of a legacy of slavery that refused their right to ownership, was a way of venting and dramatizing desire (Tinsley 2010, 57). In Ghana, the intimate maneuvering room even of powerful market women and educated teachers, is often limited and confined to female hierarchies. Taking a break from their multiple responsibilities as mothers and workers, their violent tensions are sometimes acted out within eroticized female spaces. These conflicts and rivalries need to be contextualized, but cannot be idealized away by attributing them to the oppressive colonial and neocolonial regimes in which these women are implicated.

The relationship with her French teacher prompted Okaile to test and contest the limits of her subordination, without having the means to provide. Like Adi, Okaile portrays herself as someone who draws not only on her erotic capital as a masculine female youngster, but on her attentiveness to, and her recognition of, adult women's daily needs and duties. "People call it working for love," she explains, continuing that, even if you don't have money to assist your partner, you can still "help" her by doing a "small small thing." You prepare breakfast, tidy up, do laundry on Saturdays, Okaile recites, "you cook for her, take her water, it doesn't mean anything, or does it mean anything?" Okaile works to contest the idea of being subjugated and expresses her agency by conveying that life requires serving others at times. "It's lively sometime right? You understand? [S.D. Mhm], that doesn't mean she's ruling over you, she doesn't," Okaile reassures herself. The relational position Okaile tailors for herself draws on the serviceability expected from clients toward their patrons, and on the language of mutual respect implied in Ghanaian notions of conjugal reciprocity and the idea that modern spouses are supposed to support and serve each other in any way possible.

My follow-up question, "but in the bed, who does the work?" further allowed Okaile to portray herself in a top role, as the worker, rather than a "small girl" helper. "Yeah, you does the work. You does the work alright [not] because she gives you money, no no no no, you didn't propose to me I proposed to you, but I'm helping you out, you are helping me by helping yourself taking care of yourself fine [...] but at the end of the day I will be on top of you, that one here no palaver." 37 As the wordsmith she is, Okaile tweaks her helper role, and turns the

Interview with Okaile Allotey at Accra, May 25, 2007. 
tables by equating monetary and domestic assistance. Her work concept does not determine who can lay claim to being in charge sexually. Okaile puts herself on the same level with an older partner by gendering her own position. She considers herself a worker (for love) rather than a subordinate helper. This entitles her to propose and follow up on her proposal by initiating sex. Alluding to the ideal of mutual assistance that has historically been at the heart of Ghanaian notions of conjugality, she smooths the way to construct herself as a potent "bachelor," destined to satisfy female partners. Although she cannot "help out," a phrase that usually implies financial support, she provides domestic services, analogous to a dutiful wife who lovingly serves her husband, while he attests to his love by paying generous "knocking fees" (the gifts of alcohol and monetary contributions a man makes to the family of his bride to be) and provides "chop money" throughout marriage. ${ }^{38}$ These transactions do not make a couple less loving: quite the opposite, they are the signs of a relationship to which spouses are committed through respecting and "serving" each other; the man does not see himself as buying his wife's sexual services, but seducing her. ${ }^{39}$ Just like Janet Aidoo in Chapter 3, Okaile seems to liken herself to a modern husband who helps with domestic chores, especially when he cannot provide financially. These images of love as work, reference Ghanaian norms of conjugal (and intergenerational) reciprocity, and amount to a way of gendering and thereby balancing differences in age and status.

The resort to an idealized notion of working for love, as opposed to working for material gains, looms large when young women like Adi or Okaile portray themselves in relation to an older, comfortable "lady." Both Adi's boastful "sugar mother" rhetoric, and Okaile's sexualized emphasis on the attractiveness of postmenopausal women, is spurred by what could be considered "emotional butchness" (Cvetkovich 2003). This does not preclude that Okaile, according to her ex-girlfriend Hamda, sought provider love not only with female, but also with male lovers. Perhaps Okaile's dependence on the "sugar" of better-off men and

38 The historical connotations of "chop money" are discussed elsewhere in this chapter. See also footnotes 3 and 31.

39 This of course does not take into account the unequal stakes regarding procreation that undermine conjugal reciprocity. Okaile's assertion of the equivalence of monetary and domestic exchanges and her ideal that this does not prescribe sexual roles is undermined by many a woman's desire for having children- a desire that can amount to her primary motive for marital sex, which husbands may take advantage of. 
older women is counterbalanced when she seduces "girls" herself. Yet even feminine Lydia who "grew wings" hinted at how she upset Ruby by looking for girl lovers of her own age group. In these stories, a pattern emerges whereby the younger partner seeks to distance or emancipate herself from a nurturing or overbearing "sugar mother" by striking up erotic adventures on her own terms.

Often, heart-broken young women try to console themselves or win back a philandering "sugar mother's" heart, by testing their own erotic powers. The emerging dramas are triangular not only because of the number of lovers involved, but also because of the number of friends involved as matchmakers and go-betweens. The final part of this chapter looks more closely at the roles female friends and relatives play in each other's love lives. On the one hand, the interference of these brokering third parties could be considered manipulative; on the other, by monitoring dyadic affective intensities, they also keep in check the abuses that may occur within couples.

\section{Gifts and Givers}

\section{Dina Yiborku and "the Natural Law of Compensation"}

The frustration about younger lovers spreading their wings and eventually moving on is part and parcel of being in the "sugar mother" position. This dawned on me through conversations with Dina Yiborku, a thirty-seven-year-old "sugar mother" (although she does not apply this term to herself). Dina is a sports teacher, smart and energetic, and an expert handywoman, who masters the art of keeping separate the different domains of her life, and making different spaces available to different sets of relationships.

Dina splits her weekends between the man she recently married, a policeman in Accra, and the house where she grew up in Suakrom, where she still has her own room. Often, she picks up her girlfriend Monica Ankrah to join her in Suakrom when she checks on her ageing mother and her many nieces and nephews. Monica is in her early twenties and attends a technical college on the coast. The weekdays Dina spends mostly at her workplace, a secondary-school campus an hour away from Suakrom. Occasionally, she invites her twenty-oneyear-old "outside" female lover, Becky, to keep her company in the room she rents on campus. In "small girl" fashion, Becky, who is of 
little means, does Dina's laundry. Besides being mobile, autonomous, and rather reserved about the details of her personal life, Dina's ability to create spatial divides between different friends and relatives emerges as a prerequisite to becoming a respected "big woman" with multiple girlfriends.

Dina was the only one of my primary respondents who went through tertiary education. When we first met, she was enrolled at a technical university, studying toward a degree in physical education. She was also the only one who owned a car and who, industrious as she is, hired it out as a taxi whenever she did not need it herself. Prior to becoming a sports teacher, Dina was well on her way to becoming a sister in an order of Christian nuns. After six years at the convent, she undid her vows and followed her call to independence. She found that life had more in store for her than the routine and uniformity of the convent. Despite this, she is full of praise for what convent life taught her, and how it broadened her cosmopolitan horizon; she picked up some Greek and Tagalog, from Filipino Sisters, and she calls up meditation techniques and lessons in psychology and philosophy that she chiefly applies to her own life. Above all, she learned how to "deal with many things inside you and control emotions, like your anger and loneliness." Her mobility and her professional and educational aspirations reflect her declared aim to be "the boss of [her]self" and "the giver" in her relationships. ${ }^{40}$

Reflecting upon her first intimate same-sex friendship at age twelve, Dina considered herself a "receiver." Her "giver" was a table tennis player about seven years older than her. They were in the same training group and Dina "fell in love with her," but as she emphasizes: "We didn't have any relationship like sex, no, but what I meant [by calling her the giver] was I remember sometimes I cook and I sent it to [her] place and we ate but he - she didn't bring it to me, bringing of food or something, no but I remember I cook for us to be eating [S.D. OK.] I remember that one." ${ }^{41}$ It is the intimacy of serving and sharing meals that Dina remembers as the sign of first being involved in a specific type of intimacy and in a dynamic of giving and receiving. She was the one receiving money and instructions and bringing the meals to her friend's place. The term supi was in use at the time, Dina recalls upon my inquiry, but avoiding its connotations with lesbian sex today, she

40 Interview with Dina Yiborku at Suakrom, January 17, 2008.

41 Interview with Dina Yiborku at Suakrom, January 18, 2008. 
does not refer to the non-sexual table tennis friend as a supi-only later, did she experience sexual intimacies under the mosquito net tents in the bunk beds of a private boarding school.

Remembering her first committed relationship with a classmate at teacher training college, Dina positions herself as the giver. Eighteen at the time, she was one year older than her girlfriend when they were "living like husband and wife. We had sex, we shared things together, we sat down with each other and that was when I felt I loved the person really." 42 The next day, as I tried to follow up on Dina's mention of having lived "like husband and wife," she corrected herself by saying "I didn't say we were husband and wife [...] what I meant was we were together, we were doing things- everything together." After three years of "doing everything together" the relationship ended with the classmate's marriage. This experience was "bitter" and formative to Dina's erotic subjectivity. If she had just been "doing things for doing sake," for fun, their separation would have been less painful. But Dina struggled "to let go." She holds that most young, unmarried women treat same-sex attraction as a passing thing and are correspondingly careless. This ties in with the public attitude toward female same-sex passions as a transient, adolescent experience, or, as Dina put it "a game, when you get somewhere you just forget about it." Dina sees this attitude reflected in the love affairs of the female football friends of hers. They boast about sleeping around with several women and "do it because it's a fashion among them." This superficiality she believes, makes it easier for them to eventually say, "fine, the person will move on and I will also move on to another, so that's was what went on in my mind then." Dina, however, considers herself "that type who likes to pick one and keep the person till whatever time, you see, so in case you have somebody you develop that kind of love for the person, and you have to let go the person, it is not easy." Dina paints a picture in which her desire to love a woman is deeper, and her commitment to this desire stronger, than that of most young women who do not give much significance to their teenage same-sex experience.

As noted, Dina hesitates with the image of husband and wife. Rather, she construes herself as the "giver" in relation to a "receiving" partner who exhibits "feminine qualities." The gendered roles of "giver" and "receiver" become apparent when Dina invokes the sexual advantage

Interview with Dina Yiborku at Suakrom, January 17, 2008. 
of "receiving from the lesbian." Physically, she argues, female lovers have more stamina at giving sexual pleasure than men. Dina conjures up the limitations and contingency of male phallic desire, or in her own words, the fact that after releasing "sperms, the penis relaxes," whether or not "the woman" has had an orgasm. A woman's sexual "tool or [...] the hand she is using" to please another woman, never tires unless "the heart is weak and she cannot go again." Dina casts herself in a position where she invests labor into ensuring her partner's sexual satisfaction. Rather than portraying herself as the receiver of her lover's trust and devotion, she negotiates and confirms her own (ostensibly self-less) desire to please and provide. While working-class butches in the global North have been represented as dependent on the softness and healing comfort provided by their emotionally more expressive femme partners, Dina was not the only "knowing woman" I interviewed who considered herself a "giver" both in sexual and emotional terms.

Rather than attributing the instability of same-sex couples to the social pressures of getting "somewhere" in life by following the imperative to marriage and parenthood, Dina pragmatically concludes that women's casual attitude prompts her to be strategic in her choice of lovers. On the one hand, she deems it advantageous to propose love to younger women who are less educated, and less asserting, than herself. On the other hand, resigned to the fact that younger women would always leave her at some point, she opts for multiple lovers as a preventative measure to avoid loneliness and reduce the pain of eventual heartbreaks. These considerations echo Wekker's account of AfroSurinamese women in their late thirties and forties who spoil their girl lovers with gifts. These women consider it an advantage to initiate a young woman, who they can "mold and train," thereby introducing her to the mutual sexual and material obligations of the "mati work" (Wekker 2006, 186). While expecting absolute fidelity from "the girl," the older woman may not keep to such standards herself (Wekker 2006). At the same time "it is taken for granted that as an older woman one does not become too attached to a younger partner, since there is always the chance that she will begin a relationship with a peer" (Wekker 2006, 187). Dina herself had to learn the lesson of not becoming too emotionally attached to a younger girlfriend.

Dina met Gladys Agyeman, her "second girlfriend," at the secondary school at which she was teaching temporarily. While coaching Gladys 
during the school games, she realized that the girl was in the process of breaking up with a female lover. "Well, she was my student, but I knew she was doing it and when I saw her, I liked her that was all, so I proposed to her and she accepted." A few weeks after the interview, Dina corrected that it was in fact not straightforward and that she herself had reported Gladys' other female lover to the police so Gladys could move out and become Dina's girl. Dina made it her responsibility to support Gladys and pay her school fees. She paid them to Gladys' mother, rather than to Gladys or to the school directly. Her generosity gave her access to Gladys' home and ensured Gladys' mother's approval of their friendship. "When I go there the mother calls me and says 'hey, your sister is here, your friend is here' that is all sometimes she says." By putting kinship terminology into Gladys' mother's mouth, Dina's comment suggests that the mother was aware that their bond was more intimate than that of mere friends and that she might have tacitly agreed with the less platonic aspects of their sisterly closeness. Unlike Lydia's mother, Gladys' mother never went to the police to report her daughter's "friendship." On the contrary, she was the one who begged Dina to come back and to continue paying Gladys' school fees after their breakup.

Dina and Gladys broke up over similar circumstances to those of Ruby and Lydia. Gladys began to explore her erotic powers by indulging in her own adventures. She left Dina for a peer, a fellow footballer, to whom Dina had once introduced her. Perhaps it was mostly a tease, an act of provoking the all-powerful Dina, who does not shy away from flirting with other women herself. Dina, however, was deeply upset and took sleeping pills for a while to calm herself down. Eventually, Gladys and the footballer broke up and Gladys asked Dina to reconsider her. Though Dina refused, they remained friends, and every now and then still spent a night together. This ongoing closeness disrupted Dina's (non-sexual) friendship with Stone, another footballer, who was Dina's confidante during the crisis with Gladys. Stone “didn't like that I went back to Gladys. But you have to take care of the people you have been with. You shouldn't hate them. If you don't do good, it will come back to you." In touch with the "radical humanist" principles her late father had followed and conveyed to her, Dina invokes what she refers to as the "natural law of compensation" that compels her to remain loyal. On a more pragmatic level, however, as a teacher, it is vital to make sure one is not blackmailed by a former student lover, especially if it 
was a same-sex lover. Dina and Gladys' story involves multiple actors. Besides Stone, who knew all the parties involved, including the footballer with whom Gladys had an affair, there is Gladys' mother. Despite Stone's advice, Dina continued to contribute to Gladys' school fees. She did not pay as diligently as she used to, but enough to appease Gladys' mother in view of her previous complicity.

Dina's attraction to younger women and her claim to protect herself from the inevitable heartbreaks by entertaining "outside" lovers, ${ }^{43}$ clashes with her dream of a monogamous companion of her own economic and educational standing. It needs to be remembered that this dream was articulated toward me, the interviewer, representing the economic independence and the feasibility of a "modern egalitarian" ideal of homosexual monogamy. In Ghana, it would be hard to find a lasting companion of her status who would commit to her, Dina believed. Instead, she hoped to find a sincere, younger woman whom she could mold and economically empower, in such a way that they could one day "share [their] money together," and "share everything together." Thus framed, "sugar motherhood" intersects both with a gendered provider ideal and the claim of "doing everything together" in the sibling-like fashion explored in Chapter 5.

Two months prior to our interview, Dina had started her relationship with Monica, with whom she was trying to do exactly that: initiating and empowering her so they could pool resources one day. Monica, an attractive sportswoman, was in her late teens at the time and about to complete secondary school. Spending term break at Dina's family house in Suakrom, she appeared to be the quintessential social junior, quiet and subdued. As Dina confirmed, "she will not sit down for me to sweep the room, automatically, because she is younger. The Ghanaian set up, when the older one and the younger one are there, it's the younger one [who] does all the work, most of the work." 44 When Dina, her friend Adwoa Boateng, my research associate Josephine, and myself were having lunch at Dina's compound, Monica did not eat but served us. Adwoa kept playfully commanding

43 With these less important lovers, Dina takes on a nurturing role too, albeit not as extensively. This attitude is much like that of the migrant workers in South Africa, who see themselves obliged to provide for different girlfriends to different degrees, thereby receiving home comforts in different places and keeping circulation flowing (Hunter 2010).

44 Interview with Dina Yiborku at Suakrom, January 18, 2008. 
her to bring us something, soft drinks, water, or soap to wash our hands. "Monica is just shy and likes to hide in the room," explained to me, while spoon-feeding her five-year-old nephew. Later that afternoon, as we walk to town to buy a pair of boxer shorts for the beloved nephew, Dina tells me that she is Monica's "first person," the one who took her virginity, and feels obliged to take good care of her. Monica was in fact "given" to her by a friend who went abroad. As we talk, Monica walks ten steps behind us.

Four years later, I was surprised that Dina and Monica were still together and quite happily so. Dina had just married, but was reluctant to talk about her husband. "He just needs to be presentable," she tells me as I ask her criteria in choosing a husband, "presentable, a good character and someone who loves me how I am." Having met at university, where Dina engaged in same-sex intimacies, she told him that she used to have female lovers but had stopped. Yet, she confesses, "I can't stop it, ever. Otherwise I will die. Because that is who I am."46 This conversation took place in her car, as she drove us back from the school campus to Suakrom. Dina's braided extensions were bundled into a ponytail, she was wearing flashy sunglasses, tight white trousers and red moccasins matching her bright red T-shirt that reads, "I'm into having sex, I ain't into making love." This print had caused some commotion at the teacher's meeting we stopped by. While her female

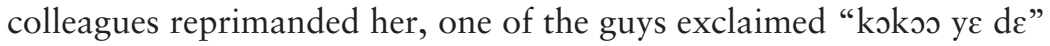
(red plantain or redness is sweet, which Dina interpreted to me as: "the red inside of the vagina is delicious") and another man supported her by saying, "she is married now, so she is allowed to do it." Both Dina and Monica dress in less masculine fashions than they used to. As Dina's “outside" lover Becky relates to me, Dina does so because she is married; she also asks her lovers to dress more girly, so as to avoid people talking about them. While Dina, Mrs. Anarfi, and other women who seek out younger lovers, recognize a "small girl's" inclination for same-sex desire by her masculine presentation of self, they ask them to tone down that gendered expression of self, in order to be less visible to an urban public that increasingly reads gender transgressions in clothing style as a sign of "lesbianism."

45 Fieldnotes taken in Suakrom, December 30, 2007.

46 Informal conversation with Dina Yiborku at Suakrom, Fieldnote January 12, 2012. 
Dina is paying for Monica to attend a technical university like she herself did and Monica is still the dutiful junior, though she jealously monitors Dina by constantly calling her phone. Dina believes Monica is good for her because she tries to "educate" her and holds her accountable to her own ideals of monogamy. Clearly, they had ample time to study each other, know each other's strengths and weaknesses, and have become attached to each other. Monica, who tells Dina to be faithful and mind the way she flirtatiously touches other women in Monica's company, has become much more than a subdued "small girl." Although they still cannot pool economical resources, Dina feels that their relationship may survive Monica's pending marriage. Perhaps Dina has managed to disbelieve her own prophecies that younger women will eventually leave her for someone else.

I did not probe Dina about the friend that gave Monica to her, and what the process of "giving" looked like. Several women had told me of a third party who had given, entrusted, or arranged for a lover for them, when they felt lonely or simply needed "someone" to keep them company in a deserted family compound, and the language of "giving" was used frequently by the "knowing women" I interacted with: Lydia was introduced or perhaps "given" to Ruby by her cousin (who eventually became Ruby's lover too, and ushered in Lydia's break-up). Lydia involved herself with Adi and Adi in turn, made Lydia jealous by finding her own potent "sugar mother." I was often irritated by the staged gossip, lies, and triangular arguments of my respondents. In search of stories of twosome togetherness, I was perplexed by the multitude of other voices that had to be included or filtered out and by the fact that it was almost impossible to locate and interview longterm couples with a straightforward love story to tell. Only after having convinced myself that these relationships were indeed sexually and emotionally significant did I begin to acknowledge the collective forms of self-expression emerging from the social practices of "giving," "stealing," "testing," or claiming back friends or lovers, as in the introductory vignette.

These practices that are framed as gift exchanges are more than just a by-product of overlapping love triangles. Perhaps, triangles through which passions and intimacies are being passed on (like gifts), liberate us from the dyadic logic of gift exchange, as sketched out by Marcel Mauss (2002 [1925]). As Heinzpeter Znoj argues in his critique of Mauss, gifts are not only given, received, and reciprocated, but also 
passed on and thus converted into a broader interconnectedness (1995, 46). Inasmuch as the attempts of directing a friend's desires limit and contain twosome intimacies and thereby terminate some and reinvigorate other friend- and loverships, they play a constitutive role in spawning same-sex bonding networks and making love a mode of sociality. Indeed, the close ties woven among women who know of each other's intimate bonds emerge as a social fabric in which love is much more than a twosome. The practice of involving additional "daughters," "mothers," and friends in relational negotiations, seems to provide the basis for queer forms of relatedness.

\section{Conclusion: Collectivizing Love}

Though most of my respondents made their first erotic experiences with a girl of their own age group, they considered their relationship with a senior and sexually more experienced female lover their first "serious" same-sex bond. A mature woman's capacity to mentor and provide for a younger woman, while knowing how to conceal their passion in public, makes her an attractive match for a less experienced woman. For Lydia, the age gap only became poignant when love ended and she had to contend with her socio-economic inferiority. And the end of a love relation does not necessarily mean that a "mother" stops supporting her "daughter" financially. To that extent, responsible "sugar motherhood" can indeed be considered a sort of motherhood that (as in Dina's and Gladys' case) may even be encouraged by the genealogical mother of the younger partner.

In West Africa, where the mother-child unit is understood to be at the heart of even patrilineal societies, motherhood is a powerful image. At the same time, the paradigm of motherhood has its limits. On the one hand, there is the normative pressure for women to give birth and become respectable mothers. Although Dina and other childless "knowing women," took care of their siblings' children and were gladly mistaken for their mothers, they felt that it would be advantageous, if they gave birth themselves. On the other hand, derogatory depictions of Mami Wata or the hoarding market woman as a selfish and greedy (rather than a caring and hardworking) mother undermine the power of motherhood and speak to the salience of patriarchal notions of submissive wifehood. This puts "big women" in a more vulnerable position than "big men." While both big men and women 
are expected to take care of their dependents, "big men" have much more leeway in spending their money on personal status markers and pleasures. In this regard the positions of sugar mummies and sugar daddies are fundamentally different. Moreover, in recent years young women have the power to denounce a "sugar mother" as a "lesbian," if their relationship ends on a bitter note.

In public health studies (male) homosexual bonds tend to be portrayed as particularly "transactional" and the younger person's motive as purely material (Broqua 2009, 65). It has also been argued that the bigger the age difference, the higher the risk of coercion and abuse (Kuate-Defo 2004). Though neither Okaile's nor Lydia's same-sex bonds figure in this literature, this equation does apply to their intimacies to some degree - Okaile felt "used" by her teacher and "mistress" who was twenty years older than her, while Lydia is full of praise for her "woman," who could have been a senior sister. Still, this equation does not factor in gender or sexual "sameness." On the one hand, it could be argued that Okaile's sense of being sexually "the same" and sharing an erotic subjectivity might have prevented her from exposing or reporting her abusive teacher. On the other hand, even though the lack of a public framework to formalize same-sex bonds can be oppressive, the unexpected queer affinities arising across intergenerational intimacies are as real as the masking and unhealthy effects of secrecy. Even if age-mixed intimacies are indexical of mother-daughter, patronclient, or teacher-pupil hierarchies, they also subvert these configurations through secrecy, and through a sense of erotic similitude and intergenerational solidarity.

The materiality of love within these relationships defies celebrations of the postmodern individualism of love manifest in Anthony Giddens' notion of "confluent love." The British sociologist argued that today's "confluent love presumes equality in emotional give and take" and seeks egalitarian (sexual) fulfillment (1993, 61-64). While the contingency and fragmentation Giddens diagnoses pertain to love under precarious postcolonial conditions, Hunter notes that egalitarianism is predicated on autonomous bodies that can enter and leave relationships as they please $(2010,198)$. Especially where bodies cannot defend themselves from undesirable communal expectations, love is care and resides in practical and committed acts of support (Hunter 2010,16). "Provider love" is useful in accounting for the ways in which love is evoked among female same-sex lovers in Ghana. Given that especially 
intergenerational same-sex relationships (both male and female) have been branded as the antithesis of love, it is important to point out the acts of care, kindness, and assistance characterizing these bonds.

My findings refute structural mappings of homosexuality that assume that gender is the main vector of difference in African samesex relationships, while age difference is insignificant. In contrast to Murray's comments about the femininity of the younger person in an African same-sex relationship (2000, 248), the self-understandings of the younger women I met were not exactly feminine: rather the opposite. While their financial dependency, and their "wifely" roles vis-à-vis an older woman, put them in a subordinate position (which Murray might have read as feminine), their assertive erotic and gender styles carried strong masculine connotations. In a more complex way, gender alongside age did play a role. While "sugar mummies" were invoked in a bantering manner, I felt that such banter served as a way of reducing the younger person's socio-economic powerlessness. Often, the bantering chat about "sugar mothers" among female footballers seemed to counter-balance the "mother's" authority. Moreover, some younger women contested their alleged subjugation by declaring themselves as sexually dominant or by claiming to be doing the work of love in a mutually dependent partnership. Making such claims they drew on Ghanaian notions of reciprocity, rather than on egalitarianism. The attendant squabbles and power dynamics were read as signs of passion and deemed constitutive of a sincere same-sex love relationship.

I started this chapter by reflecting on how elderly women like Maa'Evelyn flirt with adult women who could be their daughters and by asking what goes unseen in the exchanges between "big women" and their "small girls." I ended by highlighting the love triangles and jealousies that unfold among these networks. Whilst these dramas could simply be attributed to the youthfulness of the protagonists, they are more than that. The same-sex relationships I encountered were framed by intense negotiations that constantly involved (nonsexual) friends and even genealogical family members as advisors, mediators, or go-betweens. Practices such as "giving" a lover to a friend, or a friend to a (former) lover, are predicated on the seniorjunior dynamics instantiated within tight-knit social networks. Through this "gift economy," senior friends and "sugar mothers" may keep in check others' amorous togetherness, while at the same time engendering new interconnections. The resulting fights and 
tensions are certainly considered problematic by cosmopolitan women, who are looking for a committed, monogamous partner, while in the meantime having back-up lovers themselves. The fights and competitions over friends and their resources can be violent, painful, and destructive. But fights, both playful and dramatic, can also be a way of staging intimacy, and, to borrow Herskovits' words, they can add to "the zest" of life and the cohesion of same-sex bonding networks (Herskovits 1936, cited in Tinsley 2010, 56). In postcolonial Ghana, through circulating material and erotic gifts among working-class women, passionate desires are grappled with and made "public" to those "who know." Thus, the passing on of materially relevant friendships and intimacies could be understood as a mode of weaving queer family networks - networks through which the materiality of love is being collectivized. 


\section{"Doing Everything Together"}

\section{Siblinghood, Lovership, Incest, Family}

I'll copy her, because I like her. Whatever she does, I like to-she's my girl proper, we sleep in the same room, we do everything together. I remember we once went somewhere, me and Korkoi. Korkoi was smoking cigarettes, smoking, smoking. So I decided to test it and see, what is inside. When I just tried it, the way I conghed! You see, when she was doing it, it looked nice, so I just wanted to do it (imitates sound of inhaling) [...] because I love her, I had to learn what she does, we had become one, siblings, one blood, (taps the crook of her arm) you see, one blood. So we had to do each and everything together, bathing together. Korkoi and me, we bath together, everything. Korkoi?! Ahb! ${ }^{1}$

After seven years of "doing everything together," Adwoa Boateng and Korkoi Okudzeto were on the verge of breaking up. They had not spoken for weeks. Nonetheless, asked to talk to us about love, Adwoa dramatically conjured up their togetherness: whatever Korkoi was up for, whatever suited her, and whatever gave her pleasure, no matter how silly or ordinary, Adwoa was compelled to "see," and "test" it herself. They were meant to share and experience all things together. Over time they became siblings.

"Doing everything together" is a phrase I frequently heard when a woman swooned over a female friend and alluded, with an exaggerated emphasis on doing "everything," to their erotic intimacies. The strength of this word lies in its ambiguity. It allows "knowing women" to convey all-encompassing same-sex intimacies whether or not this intimacy has a sexual dimension. A few days after making the statement above, Adwoa introduced a childhood friend to me as her "intimate friend," and added, as if to quote herself, that they were "doing everything together." This soft-spoken, married woman whom she sees on a daily basis has been her loyal confidant for years. As children they used to be "wild." Accompanied by a third friend, they would run away

1 Interview with Adwoa Boateng at Suakrom, December 12, 2007. 
from school and spend their days in the market. According to Adwoa, this intimate friend used to have female lovers "but stopped it a long time ago." Now their market stalls are around the corner from each other, and they talk on a daily basis but are not sexually intimate. With Korkoi on the other hand, "doing everything together" does imply sexual attachment - with all its pain and pleasure. Not only did they bath together, but as Korkoi once told me, Adwoa used to spend every Wednesday night at her place. "I love Korkoi. Because if she sees me, Korkoi asks - [...] like the kind of pleasure that I'll give her, it will not be small. Like we wouldn't go through all those [arduous] things." Adwoa prided herself not only on copying and learning Korkoi's ways, but also on pleasing her sexually. Adwoa's sense that "doing everything together" made them "one blood," points to a form of relatedness, to which the catch-all term fictive kinship does not do justice.

\section{$*$}

If motherhood brackets intimacies between females with a notable difference in age or/and socio-economic status, sisterhood is a metaphor for the companionship of girls and women of the same age-group. This chapter explores the everyday acts of togetherness through which a same-sex "friend" becomes a sibling, as opposed to being born one. It elaborates "siblinghood" as a key framework through which closeness may be imagined, expressed, and engendered among same-sex lovers in southern Ghana. The chapter thus asks how the idiom of kinship is put to work in describing sexual and non-sexual forms of closeness: What spaces are constitutive of the lived and the idealized intimacies between "sisters"? What practices are the prerequisites of relating to each other by "blood"? And how are we to understand the relationship between love and siblinghood, if "doing everything together" is more than a euphemistic way of referring to sexual intimacies?

First, given that onua, the Twi term for sibling, and the gendered English term "sister" are key words for women who share the impulse of doing "each and everything together," I attend to historical notions of siblinghood and in particular to the closeness and mutual attachment accorded to sister relations, in the literature on the Akan. Second, I focus on Adwoa Boateng's understandings of love that resist and intersect with North Atlantic notions of romance.

2 Interview with Adwoa Boateng in Suakrom, December 12, 2007. 
While passion and pleasure take center-stage in Adwoa's intimate discourse, the idea that love should eventually lead to a monogamous long-term relationship does not. Third, I examine understandings of "incest" and the circumstances under which same-sex intimacies are dubbed incestuous by the women themselves. The stories of women who inadvertently fell for a female cousin and worried about the legitimacy of their amorous feelings seem to conflict with siblinghood as a handy metaphor for closeness and sexual intimacy. In the absence of official recognition and regulations on same-sex unions, I am interested in women's agency in deciding whether a same-sex friend is too close to home to be a lover.

Finally, I explore the family formations emerging from the "siblinghoods" of "knowing women," whose notions of love and familiarity defy rigid distinctions between friendship and kinship. Concerned with the ways in which "siblinghood" is actualized and enacted, the chapter also reveals how intimate same-sex discourses reproduce normative Ghanaian ideas of kinship, while re-contextualizing and transgressing them.

\section{On Siblinghood}

Referring to someone as me nua ("my sibling" in Twi), expresses different ways of being related. First, it is used for a sibling or lineage sibling, hence a relative of the same generation. In Twi, as in many African languages, there is no single word distinguishing cousins and siblings of the same parents (although the absence of the term cousin does not imply that lineage siblings are unaware of these differences). "Cousins," in particular, who grew up in the same compound together and refer to each other's mothers as mothers, would only indicate uterine differences in conflicting situations in order to dissociate. Second, addressing someone as me nua is a way of engendering a certain closeness with a person of one's generation and of a similar status, irrespective of one's sex. In order to distinguish male and female siblings, the female suffix baa (sister: nua baa) or male barima (brother: nua barima) needs to be added. Third, the English terms "sister" and "brother" are popularly used when young people greet each other, summoning up a certain respect. It is also common to prefix a friend's name with sister or brother. If it makes for a pleasant sound, these prefixes are standardized into compound names such as Sist'Akos or Bro'Yakub. 
In keeping with Janet Carsten's (2004) rejection of the dichotomy between biological and social kinship - for all kinship is socially constructed - I distinguish between "genealogical" and "metaphorical" siblings. Genealogical siblings are those understood as siblings or lineage siblings (including cousins). It is not biology that connects them, but knowledge of a shared genealogy. I refer to long-term lovers or friends who speak of each other in sibling terms, but whose connections are not approved "family" relations, as metaphorical siblings. The need to distinguish between the two arises from the salience of genealogy and the fact that my respondents themselves distinguish between these different modes of being related.

The relevance of differentiating between different types of "sisterhood" is manifested in Okaile Allotey's mention of how she broke up with her girlfriend. "I sacked Rita," she says, "the other night we slept in the same bed and she talked for hours on the phone with someone in Tema. I couldn't sleep. When the good God let it be morning, I told her that we are no more and that she is not my mother's daughter." ${ }^{3}$ Suspecting that her lover was talking to another suitor, Okaile asserts that their closeness is not necessarily a given. She dissociated herself from her girlfriend by making plain that they do not descend from the same mother. Sisters who grew in the same womb are often compelled to share beds, but the bond between Okaile and her lover is voluntary. Okaile's speech act relies on the fact that being explicit about a sister not being a mother's daughter can be highly offensive. Although Okaile identifies as Ga, an ethno-linguistic group that emphasizes patrilineal ties, her statement points at the affective dimension of being daughters of the same house and mother. In the Ga context, closeness between uterine sisters is facilitated by duolocal, gender-segregated residence, hence sisters tend to grow up among co-residing matrilateral kinswomen. While the rhetorical device Okaile uses highlights the distinction between prescribed and voluntary forms of relatedness, it signifies that the idea of a same-sex lover being a sister does extend into the arena of (one) "mother's daughters." It indicates that their erstwhile "sisterly" closeness in her matri-compound was enabled precisely by the blurry conceptual boundaries between friendship and siblinghood.

3 Fieldnote on a conversation with Okaile Allotey at Accra, November 30, 2007. 


\section{Intimate Hierarchies}

While much anthropological attention has been given to the jural equality Akan culture accords to (opposite-sex) siblings, little has been written about sister relations. Meyer Fortes, who devoted some attention to sibling relations among the Asante - the most highly researched Akan subgroup - states that "next to the bond between mother and child none is as strong as that between siblings of the same mother. Ashanti see that it is simply the tie between mother and child translated to the level of generation equality" $(1975,273)$. In his volume on Kinship and the Social Order, he attributes an indivisible "corporate identity" to the matrilineal sibling group. "Full matrisiblings are 'one person,' 'of one womb,' a corporate unit in the narrowest sense" (1969, 175). Fortes was concerned with what British anthropology considered the conflict at the root of Akan social and political organization: the split loyalties between descent and alliance. Thus, in line with the structural-functionalist paradigm, he implicitly focused on understanding the (jural) closeness between siblings of the opposite sex in juxtaposition to the relative distance between husband and wife. ${ }^{4}$

In his reflections about siblinghood, Fortes does not specify whether he has in mind opposite- or same-sex siblings. The fact that he uses sister relations in particular to illustrate the equal status of siblings in general, implies that sisterly bonds are considered to be even more equal than those between brothers and sisters. ${ }^{5}$ Furthermore, he attributes the intimacy between siblings to the mutual identification of sisters, sweepingly declaring that "this accent on equality is not found in any other kinship relationship. It is felt to be immodest for adults of different generations to bath together; siblings of the same sex may do so. The attachment and mutual identification of sisters is notorious" $(1975,274)$. Although Fortes invokes sisters' "notorious" attachment, his concern is with the intimacy of brother/sister relations. This is

4 In line with structural functionalism, Fortes was concerned with rules rather than lived experiences. Yet, as Van der Geest pleads, Fortes was well aware of lingering in the realm of "grammar and syntax" and less concerned with the realm of the "spoken word" (Fortes 1970, 3 cited in Van der Geest 2012, 53).

5 Fortes illustrates siblings' equality by emphasizing that uterine sisters are addressed as "mothers" (maamenom) by each other's children. Whereas there is a special term for a paternal aunt (sewa, literally: female father), the term "mother" designates not only one's mother, but also her uterine sisters. 
evinced not least at the point where he alludes to the incestuous dimension the closeness of siblings may harbor. "Complete frankness and intimacy are possible only between siblings. Great as is the horror of incest, there are no avoidances between brother and sister" (Fortes $1975,273)$. While hinting at the emotional and potentially erotic closeness of brother/sister relations, he leaves unquestioned the "very close identification" he accords to "full sisters" (Fortes 1975, 264).

Compared to mother/daughter, husband/wife, and other pairings invoked among same-sex desiring women, making reference to a female lover as a sister conjures up harmonious notions of youthful, sisterly innocence. The idealized likeness of sisters is contained, however, by the hierarchical constitution of birth order. As Fortes states: "the most important difference socially recognized between siblings is that of age. An older sibling is entitled to punish and reprimand a younger and must be treated with deference" $(1975,273)$. As outlined in Chapter 2, the order of birth among siblings is a blueprint for the principle of seniority. Junior siblings help their seniors with household chores such as sweeping and carrying water. Growing up together, older children are the caretakers of younger children; they carry them around and give them instructions, they are expected to protect them, buy their food and later help with paying their school fees (Van der Geest 2012, 60-61).

Both idealized sameness and hierarchical ranking figured in the female siblinghoods my respondents invoked. In one instance, Serwa Asiedu referred to her younger lover Adwoa Boateng as her "back born" sibling. Serwa liked to talk about Adwoa and did so in longing adoration and by using flowery terms. Self-conscious of her reputed infatuation, Serwa confided to my research associate and I during one of our first encounters: "Although I have grown, I like her a lot, she's my back born." Serwa, who claims to be five years older than Adwoa, but looks older, is a mother of four, works as a market trader six days a week, and takes cares of her bed-ridden mother and a Deaf brother. Her affectionate reference to Adwoa as her next born sister must also be read as an attempt to deflect the impression that her love is over the top. Being a fool in love is a privilege reserved for the young. Thus, Serwa's fellow traders in the market deemed it inappropriate for her, a mature woman, to be lovestruck, and some sneered at her sexual "obsession" on the quiet. Adwoa herself railed about Serwa being smelly, disorderly, and from a family that breeds mental illness, while 
capitalizing on Serwa's feelings by summoning unreasonable amounts of money from her. ${ }^{6}$ Nonetheless, by calling Adwoa her next born, Serwa invokes a certain closeness, as well as the legitimate authority and responsibility one holds for a "back born" family member. ${ }^{7}$

Addressing a younger lover as "small sister" rather than "daughter" signifies an intimacy that seeks to undermine the hierarchies implied in a generational age difference and the authority mothers hold over daughters. Between couples of a considerable age gap, referring to a lover as a sister must be read as an attempt at reducing their perceived hierarchical difference.

\section{Ambiguous Closeness}

Suppressed hostilities form the flipside to the equality that has been attributed to Asante sibling relations. As Fortes argued, underlying hostilities between maternal brothers and sisters are not collectively approved of. Instead, they are accompanied by frequent witchoraft accusations that are "felt to be an inevitable result of matrilineal descent" $(1975,275)$. Fortes' conclusion, that the accepted expression of these hostilities is "the belief that witchcraft acts only within lineage" $(1975,275)$ needs to be rethought taking into account gender.

Like Fortes, Van der Geest (2012) ascribes the bonds between sisters (and between brothers) to shared experiences during childhood, generated through separate sleeping arrangements and gender-specific domestic tasks. However, while considering the common upbringing of like-siblings a "favorable condition that fosters a close relationship between siblings of the same sex, particularly among sisters," he also observes that due to their closeness, sisters are seen to be particularly prone to fighting with each other. As one of Van der Geest's male respondents has it: "Women staying in the same house, whether they are from the same mother or not, they will quarrel and gossip" (Van der Geest 2012, 60). This statement speaks to the widespread idea that women are quarrelsome and bear grudges more than men. Such statements overlook the gendered inequalities fostering female

6 In fact, as events turned out during the time of our interaction, Adwoa continued to extort money from Serwa. It was only after Korkoi broke up with Adwoa that she started appreciating Serwa beyond her financial provider qualities.

7 The quotes in this paragraph are taken from a fieldnote taken in Suakrom, January 20, 2008. 
competitiveness in the first place. In the matrilineal Akan context, where women are blessed and burdened with being in charge of their offspring, it is believed that sisters, for their children's sake, turn into fierce rivals and compete for the patronage of moneyed brothers.

The reputed risk sisterly closeness bears is nowhere more poignant than in stories about envious sisters who are said to bewitch, attack or even kill each other. ${ }^{8}$ Many Akan proverbs stress how closeness is "inherently ambiguous and liable to turn into animosity and envy. One of them goes, 'It is the insect in your own cloth that bites you' (Aboa a shye wo ntoma mu, na ska wo)" (cf. Van der Geest 2012, 61). Generally, witchcraft accusations are frequent among close kin and siblings in particular, and female family members are much more likely to be accused of practicing witchcraft. Witchcraft accusations often follow on the heels of jealousies over material or social benefits.

It is due to the jealousies associated with closeness that the people Van der Geest spoke to believed that "the greater distance between brothers and sisters gave in fact more room for love and life-long affection than relations between siblings of the same sex" (Van der Geest 2012, 61). Though this sounds plausible, I would argue that the life-long bonds between sisters are much less visible than those between brother and sister. Due to the everyday intimacies of women who coreside, cook, work, and raise children together, their identification and solidarity - be it between genealogical or metaphorical sisters - is often taken for granted. Sexist beliefs about women's innate contentiousness and the subsequent risk of female closeness are underpinned by the patriarchal notion that women are to be first and foremost rivals. It also needs to be asked to what degree female closeness is feared or even envied by men such as Van der Geest's informants. These Akan men, unlike their sisters, stand at the end of their line. Since "lineage consists of all the descendants of a single known ancestress in the unbroken female line" (Fortes 1975, 254, my emphasis), men are doomed to become significant members of their abusua mainly by supporting their sisters' offspring. Within this kinship matrix, men can only reproduce socially. Whereas the capacity to give birth and raise children

8 This is the case in Kwei Quartey's internationally acclaimed detective story Wife of the Gods, set in Ghana's Volta Region, where cloaked lateral sisters kill each other over jealousies (2009). 
positions their sisters at the heart of the abusua, brothers need to find other means to enhance their status within the matrilineal family unit.

Talking with junior men, I sometimes got the impression that they felt excluded from the real and the imagined secrets between their mothers and sisters. While belittling their "gossip," they sensed the play and the affective bonds embedded in such talk and the circulation of gifts that enabled women to summon large networks of personal kindreds.

\section{Expressing Love and Passion}

While moral restrictions pertain to intergenerational bathhouse intimacies, it is permissible or even desirable for "sisters" in a shared domestic situation to take a bath together (Fortes 1975, 274). Fortes considered these intimacies an expression of two women's genealogical sisterhood, hence their kinship by "blood." But what if, as David Schneider (1984) argued, all kinship is "fictive" and "blood" only one among a range of "substances" imbued with the power to connect and engender kinship? New kinship theories have further extended this focus on "substance" and used it as an umbrella term to "trace the bodily transformation of food into blood, sexual fluids, sweat, and saliva, and to analyze how these [are] passed from person to person through eating together, living in houses, having sexual relations, and performing ritual exchanges" (Carsten 2004, 109). In view of the connectivity attributed to shared food and fluids, sharing bath water cannot simply be read as a sign of sisterly identification through preexisting kinship ties, but as a way of actualizing siblinghood.

Could Adwoa's passionate appraisal of "doing everything together," sharing bath water and becoming "one blood," be understood through the framework of "substance"? Anthropologists working on Malaysia and India in particular, use substance as means to understand kinship in more processual terms (Carsten 2004, 109). Carsten strongly advocates for understanding kinship as an active process through which "certain kinds of relationships are endowed with emotional power" (Carsten 2004, 161). Her own research in Langkawi (Malaysia) revealed that "people become complete persons - that is kin" through living and eating together over extended periods of time (236). Through sharing food and in particular rice meals cooked on the same hearth, people living in the same house come to understand each other as relatives who share the 
same substance. "The core substance of kinship in local perceptions is blood, and the major contribution to blood is food. Blood is always mutable and fluid - as is kinship itself" (224). As Carsten argues, kinship in Langkawi was derived not only from acts of procreation, but also from commensality, from sharing substance and "the heat of the hearth" $(1995,236)$. While kinship in Ghana seems to be less malleable than in Carsten's analysis of Langkawi, it is worth considering how substances (other than blood) are shared and imbued with meaning among same-sex lovers. Through an examination of Adwoa's and Korkoi's "siblinghood," I will now explore the relationship between "doing everything together" and becoming "one" by blood.

\section{Holding Breasts and Snatching Fish}

With her seven-year-old daughter, Adwoa inhabits the half-deserted compound house of her deceased father. Replete with a dusty "saloon," a couple of adjacent bedrooms grouped around a square angled courtyard, the compound has seen livelier days. An aunt occupies one section of the compound, another corner is rented out, the remaining rooms are only used when her older siblings visit. Adwoa, who is in her late thirties, keeps herself company by temporarily hosting younger friends who gladly give her a helping hand - a young gay man, for instance, who had problems with his birth family stayed with her and diligently cooked for her for weeks. A trained textile designer, Adwoa never worked in her trade. At the time of our first meeting, she was selling pad locks, chains, torches, bags, and soft drinks in the market storefront owned by a brother. Three years later, the store, which was not exactly lucrative, had been converted into a small barbershop offering "haircuts and phone batteries chargin'." With a hired barber, Adwoa was selling mobile phone credits in front of the store. All day and often until late into the evening she sat in the shade of a big yellow umbrella provided by one of Ghana's rapidly expanding mobile companies. A good day's work yielded a profit of the equivalent of 2.50 dollars, almost half of which she spent on shared taxis taking her to the market and back home. According to Korkoi, Adwoa chiefly relies on the support of relatives in the USA - remittances that allow her to send her daughter to a private school and uphold her father's cultural capital as a "big man." 
Korkoi Okudzeto, an energetic trader with a marked Ewe accent, is in her thirties too, yet she is much busier than Adwoa. Unmarried and childless, she is fully committed to her mother's smoked fish enterprise. With her older sister she takes turns traveling to the lake to buy fish, pre-smoke it onsite, and bring it back to Suakrom. Assisted by her younger sisters, the fish is processed in their compound before being sold in different towns on different weekdays, depending on their respective market day. Among her friends and customers, Korkoi is appreciated for her liveliness and her feisty wit. Her charisma and generosity make up for her loud and cheeky manner, or, as Adwoa puts it, her way of "talking harshly," without inhibition. Among samesex lovers, she is known to be a heart breaker, who can "kill" a woman like a femme fatale. When she really loves a person, she fights for her, she once told me, and I have seen her do so quite literally. Unlike Adwoa, Korkoi never talked about boyfriends or potential husbands. When people asked her when she will marry, she brushed away their questions with a joke about having some husband outside town. But Adwoa felt that Korkoi was into women too much and argued that for Korkoi's own sake she would let her go, so that Korkoi could have children - before redirecting her attention to female lovers.

Asserting that they "had to do each and everything together," Adwoa uses a phrase that I have also heard deployed by young opposite-sex lovers, when expressing romantic feelings. For married couples, however, a claim to special closeness can be ambivalent. Throughout southern Ghana, excessive conjugal intimacy has been regarded with suspicion. Since kinship is a lateral matter, spouses are not supposed to do and share everything together. Too much closeness may jeopardize loyalties to their respective lineages (cf. Van der Geest 2012, 64-65) and make them too similar. When female friends talk about "doing everything together," it is not usually assumed that "everything" includes romance or sexual attachment. And even if it does, two women's intimate familiarity are not necessarily considered a family threat. Among "knowing women," the mention of "doing everything together," however, does include intimacies that impact family relations and provide the basis for additional forms of relatedness.

The beginnings of Adwoa's and Korkoi's relationship seven years earlier do not exactly sound romantic. Passing by Adwoa's gate on her way to the market, nonchalant Korkoi caught Adwoa's eye. Adwoa began "monitoring" her, as she says. 
I had heard that Korkoi was doing that thing. So one day, evening time, I was standing in front of our house and Korkoi was passing, and I just called her: "Korkoi, come here: Go and buy me one Guinness." She said: "Let's go, let's go, I'll buy it for you." So we went to the [drinking] spot and started drinking beer. After that, I told her to come to my room, and I started holding her breast. And she said, (mutters) "hmm, I don't like that-oo, I don't like that!" And she removed her dress, and I started - started doing (giggles) that thing. ${ }^{9}$

In Adwoa's prosaic rendering, their courtship took the shape of a negotiation that promptly lead to a sexual relationship. Nevertheless, her reference to Korkoi's breasts marks their romance.

Whilst I heard young women arguing that men squeezed their girlfriends' breasts to destroy their beauty and make them less attractive to other men, the "holding" or "massaging" of breasts among women carries several connotations. Some women may pretend to be holding or sucking the breasts of a female friend or relative as a way of indicating motherly/daughterly feelings. ${ }^{10}$ An infant may be given the breast of her mother's best friend who does not carry milk, and allusion is made to the bond between mother and daughter when a woman fondly grabs another woman's breasts. Since it is not uncommon among working-class women to jokingly grab each other's breasts, touching a potential girlfriend's breasts can be a relatively innocuous way to probe her readiness to engage erotically. Once an erotic context is established, however, holding breasts can be a gesture that acknowledges a lover's womanly maturity and is considered a romantic gesture. At least among female footballers, who aimed at expressing their feelings in cosmopolitan terms, this practice was referred to as "romancing" or "playing romance."

Adwoa's mention of taking hold of Korkoi's breasts is in line with her gendered self-making as initiator and "king" (outlined in Chapter 4) who feels entitled not only to "romance," but also to be in control of her lovers. As much as she adores Korkoi, she blames her for being unbridled and unruly and takes issue with her economic independence: their relationship has always been fraught by negotiations over who pays for beer. Adwoa always liked to provoke and pick little fights with

9 Interview with Adowa Boateng at Suakrom, December 12, 2007.

10 In the context of girls' initiation rites among the Krobo in the Eastern Region, breast massages were supposed to delay the onset of puberty. It was an act a mother performed for her daughter every morning, "when she thought that the girl was becoming sexually mature too early” (Steegstra 2004, 206). 
Korkoi. In one instance she grabbed a bill out of the money jar on Korkoi's fish table to purchase phone credits and make a flirtatious phone call to her "new catch," Gladys, in front of Korkoi. As soon as Adwoa put down the phone, Korkoi started beating her, half laughing half serious, and teased her about chasing a girl of the age of Korkoi's youngest sister of nineteen years - Adwoa's prospective "catch" had just completed Senior Secondary School. While Korkoi herself does not shy away from flirting with her predominantly female customers, especially the young and educated ones, she accused Adwoa of being after "small girls," thereby suggesting that she was unable to court mature women of Korkoi's age and status.

At the time of our interview Adwoa's and Korkoi's usual benign way of teasing each other had exploded into a full-blown conflict involving friends and families. While staged provocations seemed to be an integral part of their relationship, this conflict had serious consequences. Dina Yiborku, Adwoa's best friend, was visiting from out of town and passed by Korkoi's stall to ask for some free fish for dinner. Korkoi gave her some small fishes, but the gift was accompanied by a snide remark. Dina felt insulted and called Adwoa onto the scene. Their bickering exploded. As Korkoi passionately narrates, when Adwoa grabbed the biggest fish on display, she bit into Adwoa's forearm until the white flesh under the skin started showing. In fury, Adwoa then tilted over the whole fish table and caused the loss of a week's income for Korkoi's family. Before long, Adwoa sent her friends to plead for forgiveness and spoke to Korkoi's mother about paying for the damage. But Korkoi was determined to make this incident the final straw in bringing an end to their relationship. Their increasing visibility as (fighting) lovers possibly contributed to Korkoi's determination.

Adwoa, however, worried that Korkoi would not forgive her and incited by my interview questions about love, was hoping we would put in a word and help to smooth things out again. However, her elaborations on love started by raving about Korkoi as "[her] everything" only to turn increasingly angry. Airing her discontent, Adwoa declared that Korkoi ought to be more docile instead of talking to her unrestrainedly like a "villager" - a standard term of insult. Her rant culminated in the dramatic claim that she is done with women and will stop "doing it" altogether. "Why I don't want to do it again? It's not necessary. If you do it-sometime the girls don't respect. When you go and take them, 


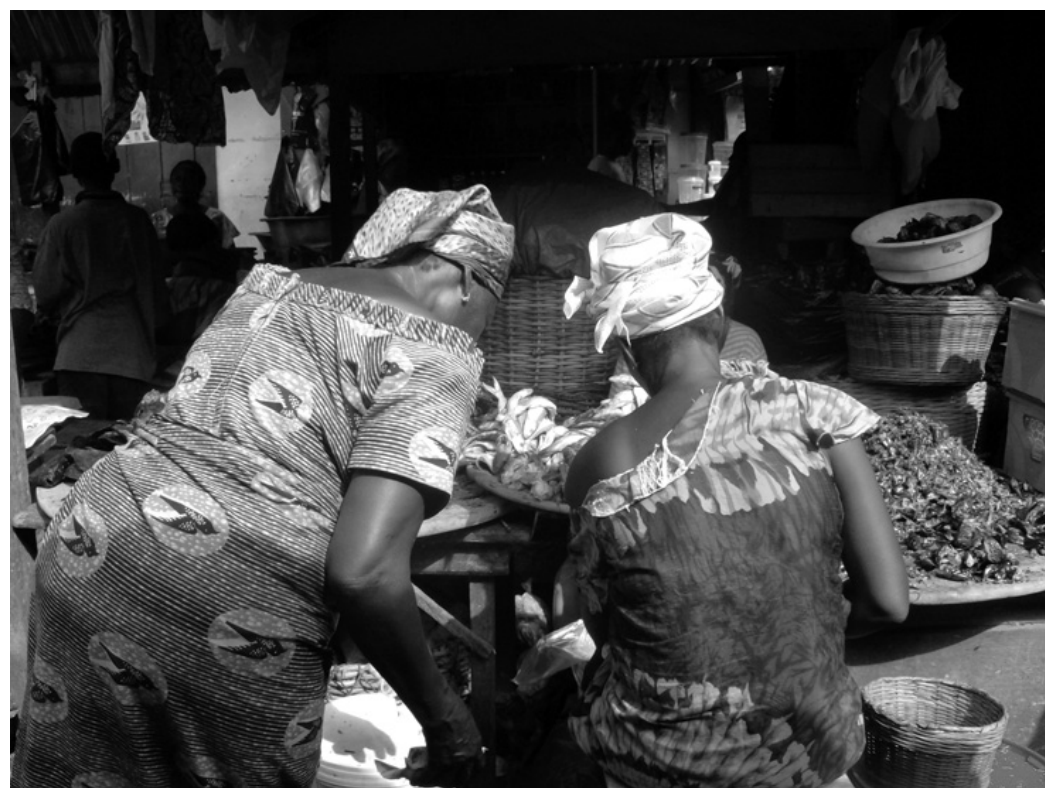

Figure 4 Older friends and neighbors selling fish in Korkoi Okudzeto's vicinity at Suakrom market (2008)

they take you for a fool [...] even when it comes to bed issues." ${ }^{11}$ Many women, reflecting on an impending break-up, asserted that they will henceforth stop doing "it" altogether or framed it like a bad habit they are giving up. Adwoa's claim that same-sex passions are an unnecessary nuisance is a prominent rhetorical trope in times of crisis. It implies that having a female lover is not an identity, but a practice that stops with the end of that specific "lovership" (though it must be said that by airing their frustrations and asserting that they are done, many of my respondents also went on to advertise their availability to my research associate and me). Adwoa did not stop having women lovers. The relationship with Korkoi, however, deteriorated in the aftermath of the fish incident.

\section{Sharing Substantive Practices}

Four years later, when I stayed at Adowa's compound for a week, she was hosting Connie Ofosu, a mother in her mid-twenties. They had

11 Interview with Adwoa Boateng in Suakrom, May 11, 2008. 
known each other for two years and although Connie had a husband, she often came to stay with Adwoa for a while. As we met, Connie was preparing to return to her husband's place.

"I will miss her," Adwoa tells me, holding Connie's five-month-old baby across her thighs like a log, "she has been helping me a lot." Connie is "a good girl," she adds, while watching her in the midst of buckets under pieces of laundry dripping from the line spanned across the compound. Connie is soaking cloths and shoes in foaming white washing powder, doing "everything" for Adwoa who has little patience for domestic chores. She already stayed with Adwoa during pregnancy. Apparently, she was jealous when Adwoa had other women at the time. Now there is not much passion. Connie complained that they hadn't had sex during her three-week stay, but Adwoa doesn't seem to mind. She is "tired," and does not "feel for sex. I talk, but I don't like it," she tells me. Adwoa's passion lies in holding court and spinning networks of desire and deceit, of lust and love and everything in between. ${ }^{12}$

While Adwoa lived, cooked, and ate together with Connie, there was no talk of love or desire at the time. Obviously, Adwoa was much less passionate about Connie than she used to be about Korkoi. Her connection to Connie looked like a partnership, or rather a sisterhood, of convenience: Connie in need of support during pregnancy and with her baby, Adwoa appreciating domestic help and company in her empty compound. Despite their sisterliness - the sharing of food and other substances on a daily basis - it is not Connie, but Korkoi, whom Adwoa referred to as a sibling of "the same blood."

On the one hand, the closeness Adwoa attributed to Korkoi derived from their similar status. They are two women of the same age group who stand on an equal footing with one another: Adwoa's proud sense of self, stems from being a native of Suakrom and the daughter of a foreign-trained, propertied "big man," while Korkoi has established herself as a successful trader who cut her teeth in the market. On the other hand, Adwoa's dramatic sense of having been connected to Korkoi through thick and thin is bound up with the seven years they have teased, loved, and challenged each other. Adwoa and Korkoi saw each other on a regular basis, but they never lived together. It seems the sustained intimate pleasures, the sharing of beds and bathwater, and

12 Fieldnote based on conversations in Adwoa Boateng's compound at Suakrom, January 9, 2012. 
their joint outings and secret hideouts gave substance to the passion and complicity Adwoa affords their siblinghood.

The act of becoming "one blood" indicates that to Adwoa, genealogical connectedness is but one source of relatedness. In view of Carsten's extended use of substance, one could make an argument about the symbolism of sharing bath water, blood, and sexual fluids as a mode of sharing substance. Yet, while sleeping together was an integral part of their "doing everything together," Adwoa does not expatiate upon sexual practice as contributing to becoming "one blood." In other women's narratives, blood and sexual fluids were mentioned in the context of love. Dina Yiborku for instance defined love as "some form of passion" that goes beyond "the just giving of material things," but implies the sharing of "the body," the "sharing of blood, sharing of- whatever you have inside." 13 Mary Awoonor, another young woman in Accra, mentioned oral sex as a particularly intimate and powerful practice not to be engaged in light-heartedly, because it connects on a deeper level. After entrusting to me how much she loved her girlfriend and how many struggles they had overcome together, Mary passionately added that she makes love to her with her tongue. Her rhetorical question, why should she "spit out" her girlfriend's fluids and her assertion that she "swallow[s] down everything," hints at the symbolic power of sharing intimate waters. ${ }^{14}$

Emmanuel Akyeampong (1996) has shown that fluids play an important role in Akan rituals. However, his investigation into "white" objects and colorless substances such as water, spit, and also semen remains silent on the constitution of ovarian and vaginal fluids. Considerations about the ambivalent meanings attached to menstrual blood seem to inhibit the cultural exploration of women's seminal fluids. This said, research on the cultural meanings of sexual substances that may engender certain forms of same-sex relatedness must be undertaken in a larger postcolonial feminist framework. Carsten herself warns that the new use of substance as analytical strategy to unsettle the dichotomy between biological and social/ "fictive" kinship tends to reify imperial dichotomies between "the West" and "the rest," by attributing mutable understandings of blood, breastmilk, and other fluids to the "non-West" only

13 Interview with Dina Yiborku at Suakrom, January 18, 2008.

14 Fieldnote on a conversation with Mary Awoonor at Accra, January 2, 2008. 
(2004, 134): While western blood stands for biogenetic substance and is considered permanent and immutable, malleability and relationality have been attributed to culturally specific non-western ideas about substance, kinship, and personhood (Carsten 2004).

Coming back to Adwoa, it would be tempting to construe the blood she shed when Korkoi dug her teeth into her flesh as the basis for their siblinghood. Listening to Adwoa, however, the "doing," the practice of sharing, emerges as the hallmark of a lovers' "siblinghood." Rather than invigorating food or other substances shared over time, in Adwoa's narrative, practices of fighting, pleasing, and desiring each other over time, created a bond that is thicker than "friendship." Fights and bites that leave scars do not make this connection less sisterly. As indicated above, competition, hierarchy, and jealousy are considered the flip side to the closeness and equality afforded to genealogical sisters. Adwoa's and Korkoi's sisterly contestations do not stem from growing up together and fighting over the favors and resources of family elders and "big" brothers. Their jealousies derive from a connection that flourished precisely because they were sharing many, but not all things. This puts a critical spin on Adwoa's claim to siblinghood: Is siblinghood simply the most readily available metaphor to frame the affective closeness between long-term same-sex lovers?

\section{Friendship, Love, and mpena twee}

The fact that same-sex romance in Ghana cannot figure as the prestage to legal marriage, calls for an examination of the relationship between love and siblinghood. Adwoa's statements on love bring to mind an Akan Twi term, mpena twee, which I translate as "lovership." It derives from mpena (lover) and references unofficial love as opposed to the attachment between spouses. Classic, postindependent Ghanaian highlife music abounds with songs about the sweetness of lovership that refer to the bonds between pre- and extramarital lovers who are not meant to become spouses. Yaa Amponsah, for instance, a highlife classic first recorded in many different versions in the 1970s, sings not only of the beauty of a certain Yaa Amponsah, but enshrines the difference between mpena twee (lovership) and aware (marriage). It proposes nonmarital love to a woman who is about to get married to another 
man, its punch line saying "Mpena $y \varepsilon$ dee, $y \varepsilon$ sen aware" (lovership is sweeter than marriage). Thus, lovership is sweet precisely because it does not represent a pre-stage to marriage.

While the word mpena has vanished from popular songs, $s d s$ the generic term for love has taken over. My respondents also associated ods with the mother-child unit, with purity, affection and attachment, mutual care and commitment. In contemporary Ghanaian songs, however, $s d s$ appears mostly in the context of romantic courtship leading to marriage. It pertains to the romance between heterosexual lovers, who seek to choose their spouses and aspire to fancy middle-class weddings. As historian Eva Illouz (1997) showed for North America, the emphasis on romantic courtship with its promise of companionate marriage and upward mobility is linked to consumer capitalism. In Akan culture, the public display of wealth used to be reserved for funerals, and marriage and marital love was not celebrated much. Now, associated with shared consumption activities, "romantic" weddings and marital ideals are displacing the notion that lovership is more desirable than marriage.

To many of my working-class respondents, same-sex marriage was unthinkable or undesirable. Some were bemused by the idea of marrying their female lover, others rejected the thought, and only a few women liked the idea, but equated it with living abroad and leading a radically different lifestyle altogether. Beyond the prospect of either customary or legal marriage, same-sex love quintessentially represents the principle of lovership and belongs to the realm of an unofficial, excitingly concealed passion that is both sexual and romantic. When Adwoa speaks of "the kind of pleasure that [she]'ll give" to Korkoi, which "will not be small," sexual pleasure emerges as an important pillar supporting their long-term connectedness. "Like we wouldn't go through all those [troubling] things." She attributes their ability to overcome fights and weather the storms of a long-term connection to her capacity to please Korkoi erotically, thus positing pleasure at the heart of their lovership.

My respondents did not use the old-fashioned Akan term mpena twee or lovership. Rather, "friendship" served as the umbrella term for a variety of non-marital (same-sex) bonds, the term friend being open to interpretation. Especially in Accra, many women referred to their female lovers as "woman friends" and to same-sex passions more 
generally as the "friendship thing." 15 On other occasions, inquiries into whether another woman was "just a friend" did hint at the possibility of a "friend" being "more than just a friend." 16 The meanings of being "more than just friends" are of course varied. As in other parts of the world, this phrase may indicate if two women have incorporated sex into their relationship, which can turn "serious" and into love or it can remain "partial," as Adwoa puts it. She associates friendship with erotic desire and emphasizes its distinctiveness from love. "Friends, it's only friends, partial, it's something that will pass. But love makes a person go mad. Love - you can easily die.... You know, 'mepswo' [I desire/like you] and 'medowo' [I love you] is different. 'Mepewo, I like you very much, 'Medowo' I love you in my heart." 17 Adwoa's correlation of friendship and desire indicates the blurriness and the openness that adheres to friendship, regarding its sexual content - since friends are potential sexual partners. Friendship can be sexual and pleasurable while remaining "partial." Love, on the other hand, includes an element of madness and self-loss. As expressed in classic Ghanaian highlife songs like "odo ye owu," love is [as strong and fatal as] death.

Often among my respondents it was not the term love, but rather the term friendship that was associated with sexual desire. This indicates an understanding of love that is not limited to romance or sexual exclusiveness but refers to closeness that extends from the erotic. And that is where siblinghood comes into play. While the term friend leaves open the possibility of a purely sexual liaison, someone who has become a "sibling" is more than a friend not necessarily due to sexual attraction (although that might have inspired emotional intimacy) but due to their affective intensity and commitment. Grace Tagoe, in Accra, distinguished "different kinds of love. We have sex love, and we have friendship love. And the sex love, we do love in it." 18 Sex love, as I understood her, refers to relations that center on the fulfillment of sexual desires, but has the potential to develop an element of romancing and amicability. Others, like Ameley and Adwoa emphasize the

15 Interview with Ameley Norkor at Accra, April 4, 2007.

16 Similarly, among lesbians in California, the phrases "just friends" and "more than friends" have been used "to indicate whether two people had incorporated sex into their relationship" (Weston 1991, 121).

17 Interview with Adwoa Boateng in Suakrom, May 11, 2008.

18 Interview with Grace Tagoe at Accra, May 28, 2007. 
madness and sickness that go with being passionately in love. This love exceeds mere "liking" and is driven by an intense affective condition that can turn dangerously obsessive or even life threatening. Thus indeed, in Adwoa's discourse, $\supset$ do (love) seems to extend beyond sexual friendships and flows into the realm of the heart, the womb, and the blood that necessarily implies the imperative of mutual material support in order to secure each other's survival.

Adwoa in particular brought up siblinghood (not friendship) when addressing my questions about "love." She framed love in sibling terms by describing how she and Korkoi did things with as well as for each other. ${ }^{19}$

\section{Holding Eggs}

Adwoa's and Korkoi's bond consolidated not only through passionate fights and reconciliations, but also through caring for and catering to each other. "I'll use Korkoi as a very example," Adwoa says about love, "to me, I know I don't have money, but I'll live with you in a certain way, I'll cater for you, I'll hold you like an egg." 20

Throughout southern Ghana eggs amount to valuable, symbolic gifts that have been used as pacification fees, in purification and puberty rites. As Sarpong writes, they stand for fecundity and easy labor, they are thought to have cleansing powers, their oval form makes them a symbol for female beauty and on account of their fragility they are made to signify carefulness. An egg carved on a spokesman's staff, for instance, is meant to caution those in power to handle their authority with care and prudence without letting it fall and break (Sarpong 1991, 61-62). Reflected in the metaphor of the egg is a desire to take on chiefly material care, while lacking the means to take out a lover or purchase signifiers of "modern," romantic love. Adwoa knows and holds up what is precious to her and deploys the egg to speak about her way of cherishing and nurturing what is dear to her without buying expensive gifts.

Of course, instrumental and material expressions of attachment are articulated by both same- and opposite-sex lovers of little means. However, when a woman loves a woman, and public, verbal

19 Interview with Adwoa Boateng in Suakrom, May 11, 2008.

20 Interview with Adwoa Boateng in Suakrom, May 11, 2008. 
attestations of love are perforce limited, the sister-like treatment takes center stage. Acts of mutual care form part of a sensual and romantic repertoire that goes unseen or remains ambiguous. When a woman takes care of a friend as if she were her baby sister, other "knowing women" may well interpret such dedication as the sign of two women's devoted love for each other and, at times, a sign of a dangerous obsession. In the context of a triangular jealousy drama I heard about, for instance, one of the women was seen feeding her new lover by hand and was therefore suspected of using love potions to lock her new "catch" into their relationship. As with kinship intimacies, such romancing is a liability, susceptible to fierce jealousies and accusations of witchcraft.

In many ways Adwoa's representation of love differs from experiences described as romantic in Euro-American contexts, where commodity consumption, individual self-crafting, and romance have become mutually constitutive (Illouz 1997 in Hirsch and Wardlow 2006, 18). The notion of holding a lover like an egg, rather than showering her with expensive gifts, seems to contradict the logics in which commoditization is constitutive of romantic passion. On the other hand, Adwoa's assertions reveal that a lack of means does not prevent women from considering themselves part of an individualized modernity. Yet shared consumption activities whenever the money is available do not replace non-commoditized ways of expressing feelings of attachment such as treating a lover like a "back born" sister: washing her hands before eating from the same bowl, helping her into her clothes, emptying her pee pot in the morning, washing her panties, spoon- or finger-feeding her; such signs of love can go hand in hand with "modern" verbal expressions of love. Underpinned by a language of care, the siblinghood of female lovers who have done many things together connotes a reciprocity that is best compared to the care, comfort, and closeness associated with genealogical sisterhood. Viewed in this light, it seems more accurate for female lovers of the same generation to refer to each other as siblings, rather than deploying the loose term "friend."

Sisterhood holds a specific kind of intimacy that differs from the gendered ("king/queen") and age-based ("mother/daughter") terminologies outlined in the previous chapters. While female lovers are conscious that their siblinghood stands on its own and is metaphorical, outsiders may assume that they were born as siblings. Often, lovers capitalize on this assumption in order to mask the more unapproved parts of their relationship and guard themselves against hostilities (see Chuchu 2014). 
The ambiguity of making siblinghood a strategy is particularly poignant when sister-lovers find out that they are indeed genealogically related.

\section{Incest and Similitude}

Same-sex sexual acts have a higher potential to subvert or undermine the morality and stability of our human societies. Why? Consider that one of the veritable reasons to support criminalizing incest is that consanguineous coitus gives rise to "in-breeding" that produces many genetic disorders. Since same-sex intercourse would not produce children, incest should not be applicable; and we could have father and sons, mothers and daughters agitating for the right to have same-sex relationships.

(Akagbor 2007, 5-6)

In his booklet titled "Same-Sex Attraction: Choice or Genetics?" Ghanaian author Sena Akagbor asserts the proposition that same-sex desire is inherently incestuous. Because same-sex relationships cannot manifest through illegitimate offspring, he argues, they provide the basis to argue against incest rules. Similarly twisted analogies between homosexuality and the legalization of incest and polygamy have been made by European bishops and prominent members of parliament who advocated against gay marriage, for instance in Britain and Germany. ${ }^{21}$ What is it about the assumed biological sameness of members of the same sex that inspires fantasies of messiness and incest? And should we even speak of "the same sex" and "the opposite sex," given the work of queer theorists like Butler in deconstructing the sex binary? These questions merit attention, since the specter of incest lingers among same-sex desiring cousins themselves.

The term cousin, let alone second- or third-degree cousin, does not figure in southern Ghanaian languages. In Ghanaian English cousin tends to be used for a more distant relative of the same generation. It can produce some distance and indicates that the cousins do not belong to the same linage or that exact genealogical connection cannot be traced without consultation of elder relatives. It is also common to

21 Daniel Boffey, “Argument for gay marriage would also legalize incest and polygamy, claim bishops and MPs," The Observer, June 23, 2012; Peter Rehberg, "Kramp-Karrenbauers Albtraum" www.zeit.de/kultur/2018-11/ehefuer-alle-homophobie-annegret-kramp-karrenbauer-cdu, Die Zeit, November 23, 2018. 
refer to a best female friend as a cousin, even if there is no genealogical connection assumed. (I have heard university professors deploy the term cousin to refer to a close friend. Conscious of the western biologically fixed understanding of "sibling" in Europe, educated women may use the term "cousin" as a metaphor for a closeness that cannot be captured in the fluffy term "friend.") Here, I am focusing on women who mentioned having fallen in love with a friend who did indeed qualify as a distant relative. The choice and agency involved in deciding whether or not sexual involvement amounts to incest hinges on the larger question of how sameness is constituted between women.

The place of gender within understandings of incest is at the heart of Françoise Héritier's incest theory (2002). The French anthropologist examined the Samo and compared her findings with kinship studies on other West African societies, including the Asante, and argued that bans imposed upon certain sexual unions are ultimately not concerned with avoiding contact among "the same blood," but with preventing the indirect transfer of intimate substance between relatives of the same sex. Given that incest was a lingering specter among some of my respondents, her argument is worth considering. Among the Asante, cross-cousin marriage, hence cousin marriage across lineages is encouraged, while sexual contact with a maternal parallel-cousin is considered mogyadie (literally: eating the same blood) and with a paternal parallel-cousin atwebenefie (literally: "a vagina that is near to the dwelling-house") (Rattray 1929, 29). ${ }^{22}$ Further intercourse with a father's, uncle's, brother's, or son's wife, and with a wife's mother or sister are also ruled out under atwebenefie, but are not considered to be as severe. The prohibitions on parallel-cousin marriage in particular, suggest that siblings of the same sex are considered to be more closely related to each other than opposite-sex siblings. For, even if two cousins belong to different lineages, once their connecting relatives are same-sex siblings, their union could be considered closer and therefore "too close to home."

22 According to Rattray's list of "sins or tribal taboos," having intercourse with a father's brother's child or a paternal half-sibling was considered as bad an offence as mogyadie (sex with "the same blood") and was equally punishable by death (Rattray 1929, 304-12). Rattray also lists a third prohibition that is punished by death: that of unions between any member of one's patri-clan (ntoro), which I am not taking into consideration here (for a discussion of $n t o r$. see Allman and Tashjian 2000). 
These are the bans that Héritier deems to be at the heart of all incest taboos. In her grand classification, mogaydie amounts to "the first type" and atwebenefie to "the second type of incest" (that is, the prohibition of a man having intercourse with two women to whom he is not related, but who are related to each other by either blood or marriage). Héritier rejects psychological explanations such as that which attributes prohibition to the competition it may cause if siblings share a lover or spouse. As she argues, the banning of love triangles of sexual partners, in which two parties are related, stems from the idea that through an intermediary sexual partner the fluids of two "identicals" (say mother and daughter or two sisters) would mingle. Understood as the transfer of corporal fluids, Héritier argues that this type of incest dreads the confusion of the natural (blood) and the carnal (sex). As it "saturates our individual and collective imagination," it is more fundamental and more universal than the "first type" (2002, 309), and it is bound to lead to a "confusion of sentiments" (Héritier 2002, 305). Presuming that sisters are prototypically identical figures, she tags this second type "the incest of sisters," on the basis of the imagined incest, hence the transfer of corporal substance (306). While Rattray loosely described atwebenefie in terms of the closeness emerging from sharing a "dwelling house," I take issue with Héritier's image of the indirect sexual contact between members of the same sex as the driving force behind West African incest considerations. Such reasoning easily lends itself to essentialist explanations of (homophobic) discourse that deem homosexuality a danger for society. What seems useful, however, to my discussion is the "confusion" that may occur when two women worry about connecting on different and intersecting registers of relatedness.

\section{"Like Sleeping with a Sister"}

If indeed a notion of indirect transfer of substance between relatives of the same sex constitutes the basis of atwebenefie, how does this inform "sisters" who have (direct) sexual contact with each other?

Helena Asamoah, an unmarried, childless businesswoman in her early thirties, suffered disapproval over her connection to a girlfriend who turned out to be a relative. Helena was sixteen when she brought her first supi, a friend at a prestigious girls' boarding school, to spend midterms with her at her parents' house. They had been "very close" 
for a while, as Helena puts it. "We eat together, you know those things," she adds, hinting at the key indicators of same-sex intimacy. ${ }^{23}$ One day they leafed through Helena's family's photo albums and realized that they had an uncle in common and were related through Helena's father's side. I did not find out whether they were cross-cousins or parallel-cousins. If they were parallel-cousins (i.e., related through both their fathers) this would amount to atwebenefie, but if they were cross-cousins and of the opposite sex, marriage might have even been encouraged in the past. I did not find out about the ethnic identification of Helena's friend (many urban Ghanaians are of mixed parentage) and why Helena identifies so strongly through her father's line. In spite of her keen interest in Akan rituals and customs she chose "traditional religion" as an optional subject at secondary school - the question of whether they were cross- or parallel-cousins did not seem to matter to her. The photo album, however, a visual document making their kin connection particularly tangible, also stands for Helena's middle-class status that requires safeguarding.

What struck me was Helena's assertion that "a cousin, is just like sleeping with a sister." It sounded as if the fact that they were both female, exacerbated their exact kin constellation; their shared gender making less important how exactly they were related. The emphasis on their sisterhood made me wonder to what extent she would bother with cousin taboos were she to fall in love with a male cousin. Helena firmly holds that what matters most to well-traveled, educated urbanites regarding love is their feelings for each other. "People who are enlightened a little or people who have the chance to be traveling," she believes, contract love marriages and know that same-sex love is a "normal sexual something." Nevertheless, Helena deems the attraction to her cousin wrong - not wrong enough though, to stop sleeping with her completely. "Even after that we used to sleep together once in a while (pauses) We do it and sometimes we all come back to our senses and we stop [...] because I can't be sleeping with my cousin."

Becky McCarthy, a twenty-year-old school dropout, told me that she only realized that she was related to her first big love in the wake of their painful break up. When I asked whether the fact that they were cousins bothered her, she shrugged. In hindsight, and since their

23 The quotes here and in the next paragraph are from an interview with Helena Asamoah at Accra, May 15, 2008. 
relationship had led to a broken heart, she took it as a solace that their bond seemed somehow out of place anyway. Grace Tagoe on the other hand, an unmarried mother of twins and of little economic resources, happily told me that her first and favorite "girl lover" was a distant paternal "cousin." She could not detail their exact connection, besides, Grace is of a mixed ethnic background - her mother belongs to the Ga, who privilege patrilineal affiliation, and her father is a matrilineal Akan - which makes the question of who qualifies as a relative all the more negotiable. ${ }^{24}$ She is still very fond of the cousin in question who is now married and lives in an adjunct neighborhood of Accra. "And do you know what God did? My cousin's birthday is the date I born my children, 14th January, Sunday. [...] That's my first girl lover. The same thing [day]. So if she is celebrating her birthday she knows that my children also - so she comes, comes and gives gifts to my children." By staying in touch not as jealous ex-lovers but as dear friends, Grace integrated their bond into her larger networks. Their shared teenage intimacy reinforced their "siblinghood," and so did the coincidence of birthdays. The fact that Grace, unlike Helena, treasures her bygone cousin love seems to hinge not on different degrees of genealogical closeness but, perhaps, on different degrees of sexual intimacy Grace considered her cousin a romantic friend (only) - and certainly on differences in class and social status.

$*$

Comparing Grace's and Helena's ways of recalling their cousin love, we must consider that Grace is materially much needier than Helena. Grace is jobless and depends on the caring attention of better-off married women like her cousin, and crucially relies on her ability to weave networks of personal kindreds for both economic and emotional support. Helena, on the other hand, may come to appreciate the connection to her cousin lover as an additional tie or resource within the family, but for now she is concerned primarily with her independence and upward mobility as a young businesswoman. Helena too relies on family networks, but she can afford to ponder about the legitimacy of a relationship that is at odds with the norms of respectability adhered to by middle-class families. She emphasizes her resistance toward consolidating a bond that doubly departs from social

Interview with Grace Tagoe in Accra, April 21, 2007. 
regulation and cannot lead to a recognized union. Nevertheless, she mentioned that they kept sleeping together occasionally. At the same time, Helena happily refers to another ex-lover, with whom she lived for several years, as her "sister" and proudly treats that "sister's" daughter as her own daughter. It seems the use of kinship terminology is ambiguous only when different modes of relatedness intersect: the one based on assumed blood ties, the other on hidden sexual ties.

Both Helena and Grace met their "cousins" at Junior Secondary School, in a youthful setting when they enjoyed at least some license to explore (and censor) themselves. To Hamda Ibrahima on the other hand, who fell in love with a cousin as an adult, questions of status and respectability were salient. When we first interviewed Hamda, she made no mention of her relatedness to Okaile Allotey. All she talked about during our first interview was her broken heart. Okaile was not "faithful," and was not even bothered by the fact that Hamda knew and was hurt. Longingly, Hamda related to us that Okaile was her first female partner ever and that she loved her the way she had only loved and desired men before. "I always get certain feelings inside me when she kisses me, I get feelings and it's like maybe, if I am feeling like a man kisses me, it's the same." ${ }^{25}$ Hamda says about herself that before Okaile, she was among those women who scrutinized and condemned women doing supi. Through Okaile, she discovered that she deeply desired women. To illustrate her "feelings," she mentions how she sometimes feels like stroking the swaying long skirts and pieces of cloth worn by beautiful women passing by, because their beauty reminds her of her feelings for Okaile.

As Hamda remembers, one evening when she was standing in the streets with some "sisters" (the women staying in and around her family house), Okaile flirtatiously started playing with her necklace and proposed love to her. While the sisters warned her that Okaile was penniless, Hamda declared on the spot that money did not matter, because she simply liked Okaile. Falling in love she also ignored the sisters' admonitions that Okaile was notorious for "womanizing." She was even planning to rent a room for Okaile outside their neighborhood, so she could freely visit her. When Josephine and I interviewed her during the process of breaking up, she insisted that they had only

25 Unless stated otherwise, the quotes from Hamda are taken from the first interview conducted with her at Accra, June 9, 2007. 
kissed and did not do anything "in the room." I assumed that they lacked privacy to sleep together, considering the crowded housing situation and the fact that Hamda's sisters aimed at protecting her. When I spoke to Hamda again five years later, she attributed her physical "shyness" with Okaile and their reticence to consummate their relationship sexually to their kin ties. It surprised me that Hamda brought forward their relatedness after all these years, especially since it took her some effort to trace how exactly they were related; they had a great grandmother in common and were second degree, most likely, matrilateral parallel-cousins.

Hamda Ibrahima is a polyglot petty trader who has done many things to make a living, from selling home-cooked food to juggling factory jobs. She is part of a group of young Muslim women who rotate their savings and organize for social events together. Whenever she has some extra money, she buys and sells between Lagos, Accra, and northern Ghana, just as her deceased father did, a Fulani herder and trader. When she is in Accra, she sleeps in the hall of her mother's family house in an old Ga quarter, usually sharing the couch together with one of her nieces. She herself has given birth to two sets of twins with two different men. In line with Ga custom, the three surviving sons stay in their fathers' compounds. While she hopes to find a respectable Muslim husband, her female lover's religious affiliation does not matter to her. Okaile Allotey is a Christian. Unlike Hamda who attended primary and Qu'ran school only until she was eight, Okaile went to Junior Secondary School. She is not formally employed, but she draws on her longstanding local connections to fetch occasional catering and decorating jobs. Of full Ga descent, Okaile stays with her matrikin in her native neighborhood. As mentioned above, she expelled a girlfriend from her bed by telling her she was not her "mother's daughter."

Centered around an old Ga quarter of Accra, the story of Hamda's passionate love for Okaile calls for a word about Ga kinship organization. The Ga are indigenous to the coastal areas of Accra and constitute an inherently urban group. As explored by Marion Kilson, the Ga emphasize patrilineality, thus contrasting themselves to their matrilineal Akan neighbors (1974, 17). Moreover, the Ga kinship matrix is less lineal than that of the Akan. This is reflected in the fact that crosscousin marriages are permitted on either side, though matrilateral cross-cousins marry more frequently (Kilson 1974, 28). Regarding residence and accession to property, the separation of sexes is at the 


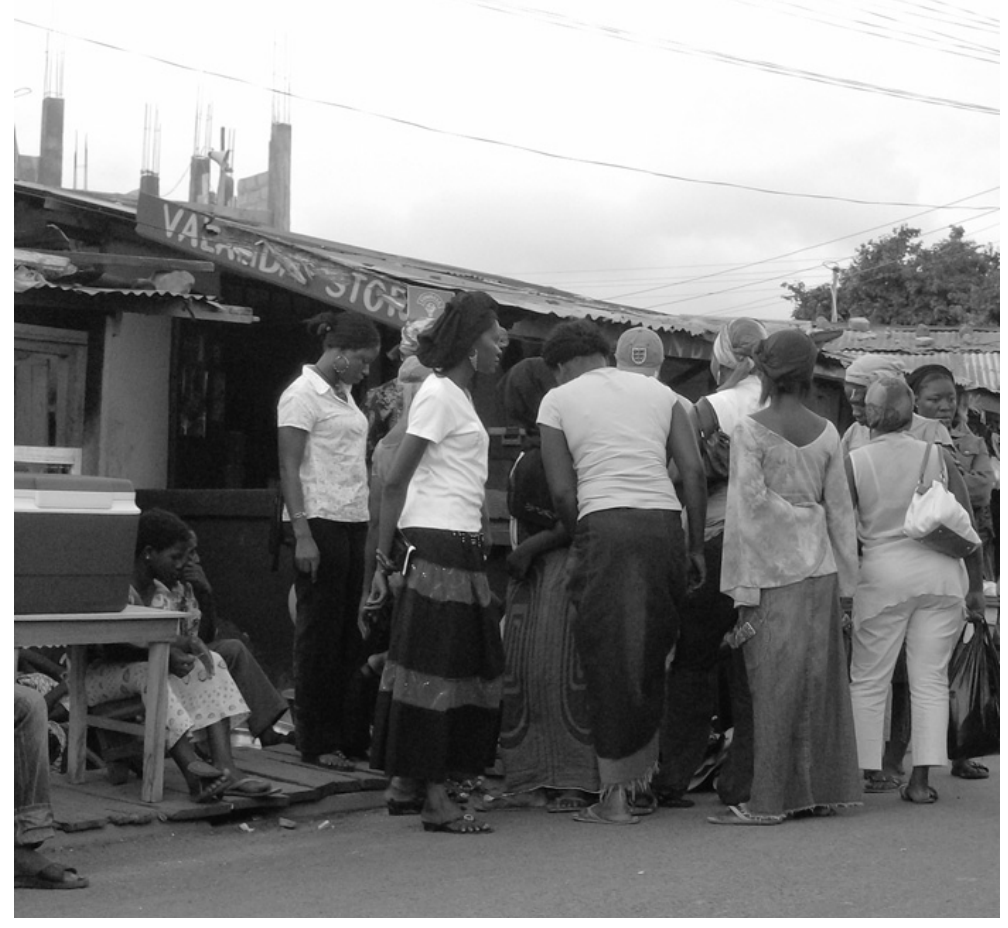

Figure 5 Hamda Ibrahima at a credit association meeting of her young Muslim women's group (2007)

heart of Ga organization, whereby men co-reside with patrilateral kinsmen, and women with matrilateral kinswomen. As Kilson suggests, as a structurally cognate descent system, Ga social organization is "more flexible and diffuse than one based on lineal principles. Within such a system, an individual probably has greater opportunity to emphasize those ties, which appear beneficial to his [or her] interest" (Kilson 1974, 20). Being of mixed Fulani and Ga parentage, Hamda could have pragmatically resorted to these relatively flexible principles. The fact that she worries about breaching a deduced incest taboo, or at least a taboo that has not been made explicit for relatives of the same sex, brings up the question of what inspires feelings of being incestuous. This, in turn, necessitates a closer look at notions of incestuousness. 


\section{Incestuous Doublings}

One aspect of Hamda's story that brings us back to Héritier's “incest of sisters" is Okaile's boyfriend. Apparently, he flirtatiously proposed love to Hamda too and was angered by her refusal. Hamda never informed Okaile about this incident. Situations where a wealthy man goes after two female friends are not so unusual and can be a major source of conflict. On the other hand, Rose Asuku, an elderly respondent in Suakrom, related to me that she remembers how her mother supported her father's decision to take her best friend as his second wife. While sharing a husband, the women remained close friends. Rose further suggested that some women might in fact encourage their husbands to marry their supi. However, for Hamda, a poorer and unmarried woman, this kind of ménage à trois was not an option.

If Hamda and Okaile were indeed genealogical relatives, sharing a male sexual partner amounts to an "incest of sisters." Héritier locates this secondary type of incest in a collective imagination that abhors the indirect contact of bodily fluids between "identicals," especially female relatives, who are supposedly of "the same substance, the same form, the same sex, the same flesh." This state is bound to bring about the characteristic "confusion of sentiments" reflected through the encounter of blood ties and sexual fluids (2002, 306-7). Could it be argued that Hamda's sense of committing incest was not necessarily stirred by her family connection to Okaile but by the confusion that Okaile's boyfriend could have brought to them? Perhaps the risk of becoming entangled in a love triangle through a potential husband may have alerted Hamda to the ambiguity of their closeness and to their "sameness" both in terms of gender and kinship ties.

Strictly speaking, according to their largely patrilineal backgrounds, Okaile and Hamda belong to different lineages and ethno-linguistic groups: Okaile is Ga, Hamda qualifies as Fulani. Yet, while Hamda does maintain her Fulani contacts throughout West Africa, Ga is her first language, she spends a lot of time among her mother's Ga relatives, and she seems to identify as Ga at least when she in Accra. At the time they were lovers, Hamda did not seem to consider their kin connection. Even if she was not fully aware of it then, the geographic closeness of their relations was obvious, with her maternal grandmother staying 
next to Okaile's compound. ${ }^{26}$ As I see it, their connectedness through a web of friends and loosely defined "sisters" mattered more than the exact kinship constellation. In order to grasp Hamda's concern, her subject position, and her erotic subjectivity need to be explored.

Whereas Adwoa and other articulate "knowing women" trace their same-sex awareness to erotic childhood experiences, Hamda fell in love as an adult and consistently portrayed herself as unknowing regarding the possibilities of sexual intimacy between women. She dubs the relationship with Okaile, who "opened her eyes," a one-time experience rather than the beginning of a learning process that would make her a knowing (and teaching) woman in her own right. This self-understanding as someone who is not "knowing," intersects with her self-portrayal as an innocent single woman who lacks formal education and as a neglected lastborn child. Hamda's social position is bound up with her difficult start in life: Her mother died after birth and her father was old when she was born. He gave her to her "[maternal] auntie's first born," a woman who had little interest in her. "I don't eat, sometimes I don't wear panties, sometimes, I don't wear shoes, not even sometimes, no slippers at all, even at home I don't wear slippers." At the age of eight Hamda started following luckier daughters to their homes. She learned how to sneak into the hearts and households of her best friends' mothers, making herself their child helper. Even today, she is highly attentive to other people's needs and readily assists her friends' families. "When I come to your house, I don't make myself like I am older than you, I will behave like I'm a child you understand me? If I'm staying with you and your mother is there, I will wash for her, sweep and do many things and others. People might think I am taking your mother away from you." Hamda attributes her ongoing success in making personal kindreds to her overall serviceability and submissiveness. The capacity to closely connect with both men and women and access their families allowed her to gradually overcome the precarious position associated with being an orphaned, youngest child. Hamda's quest for respectability, her hope to contract a suitable husband and extend her networks, conflicted with her soft spot for

26 The one case when a young "knowing woman" in Accra mentioned her sexual involvement with an elderly relative (her mother's cousin), their relatedness did not come up as an issue at all; the "aunty" lived in a far-away rural hometown. 
a dauntless cousin who might jeopardize her efforts to become upwardly mobile.

$*$

As Lévi-Strauss argues, incest rules are not originally informed by genetic rules or the fear of inbreeding, but by men's drive to enlarge their networks and transcend a descent-based "mechanical solidarity" $(1969,484)$. He considers incest taboos a way of ensuring that wider alliances are forged, and communication and exchange happens across different groups. Certainly, Hamda's sense of being related with Okaile stems from their overlapping social (and sexual) networks. Perhaps their relationship might have flourished had she found Okaile a room outside their local setting. Five years after their breakup, when Hamda first mentions Okaile as a "cousin," she was doing relatively well and self-assertively claimed that Okaile wanted her back now. Apparently, Okaile was jobless and involved with "ten women" in order to get by. Their relatedness served as a handy reason to explain why she did not engage sexually in the first place. Indeed, considering the intertwinement of their daily lives, Hamda's outright infatuation courted the danger of their relationship becoming too public. At least to their sisters, Hamda and Okaile were considered more than just friends; the tacit acceptance of their erotic bond could have tilted into shameful supi gossip. Nevertheless, Hamda does not represent her decision to stop their intimate involvement as a result of the public outcries against "lesbianism." She refrains from portraying herself as the victim of homophobia or other hostilities. Rather, she portrays their sexual reticence as a choice consciously made in order to avoid the trouble of simultaneously engaging and mixing different modes of relatedness.

Is Héritier right, when arguing that there is something inherently troubling about the duplication of being connected? Her theory about the "incest of sisters" relies on what she considered the "incontestable and irreducible character of sexual difference" (2002, 316). Derived from a structuralist investment in sexual difference, which she deems "necessary for biological as well as social reproduction" (Héritier 2002, 315), the social dynamics that produce sameness and difference (and thus prescribe which sexual unions are legitimate or not) do not seem to matter. Insofar as Héritier's theory validates the presumed "sameness" of members of the same sex, it uncannily aligns with circular homophobic arguments - like the one brought forth by 
Akagbor in the quote opening this subchapter - according to which same-sex desires are inherently messy, unproductive, and undeterminable because their legitimacy cannot be traced through biological offspring. Yet given the considerable genetic, physical, reproductive, and hormonal differences between persons considered to be of the same sex, the term sameness in itself needs to be interrogated. Boellstorff uses the term of "similitude" instead (2005, 26), thereby challenging homophobic constructions of sexual "sameness" as an utterly non-reproductive mode of being in the world.

In none of the above cousin loverships were the exact genealogical connections spelled out. The mere fact that there was some genealogical connection to be traced was sufficient to put a question mark over the relationship and to avoid sibling terminology. It seems that unwritten incest rules are more useful indicators on what could make a relationship wrong than the discourse in Ghana and elsewhere that considers same-sex desire an "ancient taboo" ${ }^{27}$ altogether. If Hamda had not found out about their common great-grandmother, would she have referred to Okaile as a (metaphorical) sibling? Incest considerations between female lovers point to the mostly unspoken but significant distinction women themselves make between genealogical and metaphorical forms of being related. By insisting on this distinction, they resist such folk fantasies and theories that tag as incestuous the (direct or indirect) transfer of sexual fluids between female bodies, whether or not they are genealogical related. The fact that the sisterhood of lovers remains in the realm of metaphor, however, does not reduce its relevance, for all kinship can be, and is, extended metaphorically. The realness of this metaphor manifests itself when same-sex lovers raise children together and share their networks of personal kindreds.

\section{Contingent Families}

Next to "love" in all its shapes and permutations, permanence and endurance are among the defining features of Kath Weston's understanding of "gay kinship." In Families We Choose, the pioneering anthropological study on gays and lesbians in California's Bay Area, Weston explored

27 See, for example, Kwamena Ahinful, “No 'Supi-Supi' Lesbianism,” The Mirror (Ghana edition), January 17, 1998. 
the "ideological opposition between biological families and families we choose" (1991, 118). The "chosen families" she portrayed included lovers, ex-lovers, and friends, who refer to each other as aunts and uncles, but overwhelmingly placed themselves in the relationship of siblings (Weston 1991, 117).

In Euro-American contexts, the practice of referring to a lover in sibling terms has undergone several shifts. For a long time, siblinghood was one of the few cultural categories that rendered strong feelings toward a "friend" of the same sex intelligible. As Weston states, the alliance between "the language of friendship and the language of kinship" served as a means to veil the erotic bonds between queer "friends" (119). This use of sisterhood and brotherhood was only eclipsed when the gay and lesbian rights movement pushed for political visibility, solidarity, and community, when "coming out as a lesbian or gay man entailed learning to discriminate between feelings of erotic and non-erotic love, drawing meaningful contrasts between sexual attraction and friendship" (119-20). Thus, the terms brother and sister began to designate exclusively non-sexual relationships within a growing identity-based, "quasi-ethnic gay community." 28 The shift back, from contrast to continuum between friends and lovers, occurred in the 1980s and laid the basis for a family-centered discourse. With the creation of "chosen families," erotic and non-erotic understandings of siblinghood realigned. These families took many different forms, encompassing different households, lovers and children, ex-lovers, and friends, whereby gay and straight friends were grouped together with lovers, and children "within a single cultural domain" (136). With the increased recognition of lesbian and gay identities and politics, kinship terms were re-appropriated and adapted into a family ideology that highlighted love, choice, and creativity as the organizing principles of gay kinship (41).

The extent to which struggles for the legal recognition of gay marriage thrive on a desire to be "normal" and lead to the assimilation of nuclear, "homonormative" families is much debated (Mesquita 2011; Nay 2017). As queer theorists have argued, the quest for legal rights and the increased visibility of middle-class families consisting of two

28 Stephen O. Murray coined this phrase in his article "The Institutional Elaboration of a Quasi-Ethnic Community“ (1979) where he compared urban ethnic to urban gay communities (Weston 1991, 230). 
lesbian or gay parents and their children, undermine the search for extended forms of family and communal understandings of queer kinship (Epstein 2005; Moore 2011; Mesquita and Nay 2013). When same-sex desiring working-class women in Ghana parent children and weave personal networks that span several households and generations, they tend to do so without assimilating or asserting themselves against a nuclear family ideal. While sharing rooms or compound houses, living in close proximity and attuning their everyday lives to each other, they cannot seek state recognition. Rather, their arrangements are as precarious and contingent as their overall lives are; they put into question sexual identity and same-sex marriage as the corner stones of queer family formation - all the more reason, therefore, that these "arrangements" deserve consideration from a (queer) family perspective.

\section{Sharing Rooms, Sharing Husbands}

Though the nuclear family is gaining popularity throughout urban West Africa, the extended family model is still widely available and often the only choice under circumstances of persistent poverty. Coordinating their lives, women who love women inscribe themselves into each other's birth families and friendship networks. Thus, their material realities translate into forms of relatedness, which contrast with the self-identified, politicized notions of "chosen family" (Weston 1991). In these accounts, shared housing arrangements and the joint care of children take on an important role in consolidating a sisterly complicity or even partnership without, however, implying the absence of male partners. Female lovers share rooms not only with their children but often also with the husband of one or the other. In Teley Kwao and Felicia Clottey's case, Felicia's husband was an integral and certainly inevitable part of their "family."

Teley Kwao, shy and skinny, with a strikingly deep voice and masculine self-styling, is a working-class woman struggling to make ends meet. Although her mother was a teacher, she only attended two years of primary school and only speaks $\mathrm{Ga}$, the main language spoken in her Accra neighborhood. As the youngest of nine children, she received little attention and spent most of her days playing football. While her sisters and neighbors pester her for being childless and wearing boyish clothes, she does not mind being mistaken for a feminine man. In fact, 
every now and then she puts on a fake diamond earring as she had observed flamboyant gay men doing. Her main resource is a large family network that she can fall back on. She used to hire out bicycles until they went out of fashion, then she took to selling phone cards, but none of her small-scale business endeavors were fruitful. At the time we met, she was out of work and living on the meagre monthly allowance a senior brother gave her. It was hard to find a good time to interview her; several times she had gotten drunk and was asleep when we visited.

Over a number of years, Felicia had been Teley's "best friend." Like Teley, Felicia is the lastborn of many children and only slightly more resourced than Teley, but she is married and has a child. Teley liked to spend her days at Felicia's little store, tending to Felicia's baby boy and selling petty items such as mats and children's slippers together with Felicia's ten-year-old niece. She was not paid, but occasionally she would ask Felicia to buy something for her - a fancy t-shirt she had seen in town, for example - and Felicia would buy it for her. At night Teley shared the hall with the baby, at Felicia and her husband's doorstep. Asked whether it does not pain her, when she hears them having sex, Teley replies, at first it did, but now "I am with them" and "when he leaves, it's left with the two of us." ${ }^{29}$ Indeed, there is a lot of time for the two of them, since Felicia's husband works at a drinking spot; he leaves the house early and returns around midnight.

Kinship terminology played a significant role when Teley first spoke to Felicia at a funeral in the neighborhood. She pretended she already knew Felicia and told her one of her brothers was looking for her. "I told her, 'I want to speak to you for a little while. My brother is standing in the corner, he wants to speak with you.'[...] When we got there, she asked where he was. Then I started complaining, 'Ah, this brother of mine! I've gone searching everywhere for him, but I can't find him!' So we had to wait a little to pass time. So we started conversing." Teley used her family as a pretext to approach Felicia and the ruse worked. They ended up going for a drink together and with the help of a mediating "knowing" friend, Teley managed to have a quiet moment where she finally disclosed herself to Felicia, by telling her that she herself was the "brother" who took an interest. Felicia seemed to be in the know already and they became lovers.

29 This and the following quotes in this section are taken from an interview with Teley Kwao at Accra, February 26, 2007. 
Five years later, Teley worried about Felicia's pending marriage and expected Felicia to break up. "When she got wedded, I really felt it, because it was like my friendship was going to be - It was like she was going to leave me." Aware of her own powerlessness, Teley was convinced that Felicia would eventually prefer her husband and freeze her out. But the break did not happen. Teley was even present during their wedding night, when she slept at Felicia's new place, in the same room with Felicia, her female relatives, and the husband. Soon Teley realized that still,

the love was there. [J.A. Love is strong!] And she came and kissed me once and told me not to worry. [J.A. Oh!] And she gave me 20,000 cedis and told me not to worry. She could see that the heart was boiling! [J.A. The heart was breaking! She was breaking her heart.] So she apologized to me. And even the following morning - we were all still there, and the room, like this, I could lie here and-when day broke- as for the man, after waking up, he went to work. [...] She used to say "When he leaves, aren't the two of us left alone?" Then I bluff; you know me already! I had to pretend that I didn't like the whole idea. But we're on very good terms. ${ }^{30}$

After the newlyweds had spent a few days by themselves, Felicia "pretended" to be harsh toward Teley, capitalizing on her newly found status as a married woman. Teley on her part mimed the angry one and warned Felicia "that 'Hey, I don't allow people to give me any heart disease [i.e. annoy me immensely]'." But Felicia managed to save Teley's face and ensured that her proud selfhood was not hurt, despite her lack of power. Teley became Felicia's permanent guest. Luckily, she got on well with Felicia's husband who, as Teley puts it, did not "bother about certain things." Rather, if Teley did not show up at their place for a few days, and the husband saw her in the streets, he would ask when she would be "coming back home." If she passed by his drinking spot, he would give her a tot and so did his assistant. Teley waved away my suggestion that the husband himself might have a lover at his workplace. Certainly, that the husband sensed how important Teley was for his wife and did not torpedo their relationship.

This is not the only case of female lovers sharing rooms with a husband, taking turns with household chores and co-parenting. With Teley and Felicia, however, this arrangement worked for quite a while, whereas other similar arrangements often deteriorated over

Interview with Teley Kwao at Accra, February 26, 2007. 
jealousies or financial problems. Perhaps this triangle worked particularly well because Teley's situation was precarious enough not to be threatening to the husband. On the other hand, precisely the fact that Teley relied on Felicia's slight income makes it surprising that the husband did not "bother" with Teley. (Even though separate property is culturally entrenched, "modern" husbands who cohabit with their wives may try to exert some control over their wives' income.) It seems their difference in gender identification - with Teley presenting herself as a brother in certain moments - coupled with Teley's material dependency, facilitated this triangle. In a similar constellation, a breakup between two female lovers occurred after the envious live-in lover tried to oppose her girlfriend's desire to beget another child from the husband. Teley, however, reluctant to sleep with men herself, treated Felicia's son as her own.

What puts an interesting spin on their arrangement is the fact that Felicia's son does not look like Felicia's husband at all. At the funeral party of Felicia's father, the rumor about a mutual friend of Teley and Felicia's, a gay activist, being the boy's real genitor, became plausible. $\mathrm{Pa} \mathrm{Koo}$, the activist arrived with an entourage of friends, and, as is suitable for a "big man," with two coolers filled with beer and soft drinks; apparently Felicia had asked him to bring drinks. Without objecting to my remark that he and the little boy looked alike, he jokingly told us he wanted to see Felicia's husband and "date him." Clearly, he enjoyed the idea of undermining a (supposedly straight) husband's territory. While Felicia's husband remained the mysterious absentee and never made an appearance at the funeral, the atmosphere turned exuberant later in the evening. Surrounded by a host of young men and women, dancing to pounding Ghanaian hiplife and American $\mathrm{R} \& \mathrm{~B}$ tracks, the gay activist exclaimed that "homosexuals are in the house, it's written everywhere, and I can see it from the [dignitaries'] faces that they know. But I don't mind. It's a youth culture now." ${ }^{31}$ At some point, $\mathrm{Pa}$ Koo tried to whisper into Teley's ear and dance with her flirtatiously. But Teley, who is otherwise full of admiration for him, did not look comfortable and neither did Pa Koo's boyfriend.

There are many question marks to this event: Was Felicia's husband infertile? Was Pa Koo thrilled by the idea of having female "wives" and invested in his own "queer family"? Did Teley and Felicia plan to have

31 Quotes in this paragraph are from fieldnotes taken in Accra, March 10, 2008. 
children by the same man? Like many childless women of her age, Teley was scorned for engaging other people's children to run small errands for her. During the weeks leading up to the funeral, she mentioned several times that she wanted and needed to have a baby, perhaps hoping that a child would reduce the criticism she received for her masculine gender presentation. The fantasy of sharing a donor does not seem farfetched, considering that female-bodied queers in Europe and elsewhere often try to conceive by the same donor, for both practical and (normative) romantic reasons. Yet, we need to be cautious about correlating ideas about reproductive practices across continents. Considering the chronic poverty and the animosities faced by childless, gender transgressing women like Teley in Ghana, the desire to have children by the same "big man," must not necessarily be about forging an additional, "biological" connection to their female lover, but could also be the result of searching for a powerful fathering patron for their children.

I was not close enough with Teley and Felicia to inquire either about their reproductive dreams and fantasies or their parenting ideals. All I sensed was that they were close confidants, sharing many secrets and taking care of Felicia's little son together. To date, Teley does not have a child. When I last saw her, she was recovering from a major car accident. Unable to afford the necessary surgical treatment at the time, her right arm was disabled. She stayed with her aunt and sisters and only visited Felicia occasionally and, as she claimed, only because she wanted to see the boy. Felicia, on the other hand, had started running her own drinking spot and had "so many friends," which pained Teley. There may be various reasons for their distance. One of them, considering Teley's bad health and her inability to work, is conceivably that Teley was too proud to be a burden on Felicia.

If we define "family" as an intergenerational constellation, with one or more adults raising children and caring for each other on a daily basis, then Teley and Felicia's setting could be considered a queer form of family. Their interdependence grew from their togetherness and affective attachment. Yet, unlike Weston's informants, this family arrangement is situational and has strong pragmatic aspects that are based neither on sexual identity nor on a claim to permanence, but rather framed by material precariousness. But does the fact that their relatedness cannot be intended to be permanent and that it appears less "chosen" than that of lesbian-headed families in California, make them any less family? 


\section{Sharing "One Mind”}

While Weston was inspired by middle-class lesbians and gays of the 1990s who claimed love, choice, and permanence as the pillars of their families, Carol Stack's take on kinship speaks to the exigencies of poverty and marginalization faced by black urban poor in North America.

In her landmark ethnography All Our Kin (1974), Stack describes the intense material and emotional flows within a black working-class neighborhood in the USA, where even in newly formed friendships, individuals begin to rely upon one another quickly. In this context precariousness does not allow for nuclear families but calls for the constant exchange and the renewal of living arrangements in which friends and neighbors take care of each other's children and elders across different households. Similarly among my respondents, the degree to which "kindreds" rely on each other blurs the distinctions between genealogical and metaphorical kin. Stack coins the term "personal kindreds," which are networks comprised of all those "who are socially recognized as having reciprocal responsibilities" (1974, 55). These "kindreds" may include those kin who "exhibit the interactive patterns of friends" and those friends who live up to one another's expectations and are thus identified as kin (Stack 1974, 53). "For example, if two women of the same age are helping one another, they call their friend 'just a sister,' or say that 'they are going for sisters.' Anyone in the community with whom a person has good social dealings can be classified as some kind of kin" (58). Kinship thus amounts to a way of activating jural rights and obligations and mobilizing support. Amidst "fluctuating economic needs, changing life styles, and vacillating personal relationships," the capacity to expand the networks into which one is born, by contracting and creating "personal kindreds" (94), is key to survival in the community Stack described. Similarly in Ghana, the bond with a same-sex lover can be strengthened through her gradual incorporation into personal networks that include affines and genealogical kin.

While questions over exchange were at the heart of Ma'Abena's adventurous introduction to doing supi described in Chapter 2, her adult relationship with Esther Gyamerah is construed along more pragmatic lines.

Even if she doesn't have enough, and I also don't have, we still feel good, because we've been together for long, we're now like siblings, so we have one mind now. When we're together, and I don't have enough, I tell her what is 
happening, and she does the same thing when she doesn't have enough. Even if it's Gari ${ }^{32}$ that we're going to eat, we don't have a problem. We don't allow people to know what we're going through. ${ }^{33}$

Unlike Adwoa, Ma'Abena does not engage the metaphor of blood. Her speech mode is calm and not heated with passion. By likening her relationship with Esther to the bond between siblings who are of "one mind," siblinghood emerges as a vehicle for the construction of endurance and continuity. This connectedness was built on practices of sharing, rather than exchanging (material and immaterial) things.

Though Ma'Abena stresses how they came to think the same thoughts and are able to communicate with a look and how they managed to overcome hardship together, her life history suggests that the fifteen years which she counts as years of being together had not been steady. During this period of time there were years when Esther and Ma'Abena were distant or went entirely separate ways. For instance, during the period of Esther's pregnancy and postpartum, Ma'Abena had another girlfriend for at least one or two years. At the time of our interview, Esther and Ma'Abena's passion had given way to what Ma'Abena likens to siblinghood. The everyday practices through which their familiarity, fraught with breaks and reconciliation, is enacted, provides the foundation for actualizing their siblinghood.

Growing up in the same neighborhood, Esther and Ma'Abena knew each other from childhood, but only befriended each other in their early twenties after having attended different boarding schools. Ma'Abena was then playing for Suakrom's newly established semi-professional women's football team. But neither the allowance she received for attending training semi-daily, nor the accounting she did for her mother's market store, was lucrative. Esther, on the other hand, found a white-collar job. She started inviting Ma'Abena over when she lived in a "self-contained" (an unattached single room), built by Esther's husband. "She said she was married, but her husband had traveled, so she was alone at home, and that I should be passing by to visit. [...] When I went to visit her, she made me feel good. She welcomed me and asked what work I was doing. So I told her my life

32 Gari is a staple food among poor people along the West African coast. Made of ground cassava that is fermented and dried, gari can be stored for years. It is easily prepared by mixing it with cold water.

33 Interview with Ma'Abena Oppong at Suakrom, March 16, 2008. 
history. So she told me to come to her more often. And she tried getting a job for me." 34 Although Esther and Ma'Abena are of the same age group, Esther is years ahead of Ma'Abena in terms of social status. Formally employed, with a room of her own, and a husband abroad, she is much better placed than Ma'Abena.

Ma'Abena used to stay in her father's compound. Upon his death, Ma'Abena's mother returned to her abusua and, the following year, Ma'Abena and her older sister had to leave too. Before long, Ma'Abena moved in with Esther and stayed "for about two-and-half years." During that time Esther urged her to stop playing football. "She kept complaining that why do I keep going [to training] and falling sick." ${ }^{35}$ Certainly, the reputed rowdiness of female footballers and their attractiveness to older women might have added to Esther's concern over Ma'Abena's bad health at the time. She asked Ma'Abena to run small errands for her and promised to reward her with the same small amount of money she could make on the football pitch. At first Ma'Abena tried to do both: She slipped away from training to run errands for Esther on her way home. Only during a prolonged bout of malaria, confined to bed, did she give in to Esther. "I decided to stop, because it was money that I needed, and she was prepared to give me that." In spite of this patron-client dynamic, Ma'Abena does not refer to Esther as her senior, let alone her "sugar mother." Instead, she portrays their relationship as a give and take between equals who have been through thick and thin, doing everything together.

\section{Sharing Kids and Kindreds}

Esther and Ma'Abena's "siblinghood" implied that they would not allow their neighbors to notice when they had "problems." If they fought, they did not change their routine of carrying each other's buckets to the bath, "wash and hang" together, or eat from the same bowl. Even if they were not talking for days they tried to prevent others from noticing that they were not on good terms, for a lovers' fight is a sign that two women are more than "just friends" and may be read even by outsiders.

34 Interview with Ma'Abena Oppong at Suakrom, March 16, 2008.

35 Interview with Ma'Abena Oppong at Suakrom, March 16, 2008. 
Once Ma'Abena was offered room in her father's house again, she returned. Soon after returning, Esther joined her for half a year. This time Esther " had a little problem. So I told her that she should let us all come, because, it's like, you've helped me," ${ }^{36} \mathrm{Ma}$ 'Abena says. Esther had many problems. Above all, her husband found out that she had misused his money to pay off a large sum that she embezzled at her company. Consequently, she had to leave the place he had built for her. Through all this, Ma'Abena was her loyal helper and confidant. Although Ma'Abena has never met Esther's husband in person, she became their mediator. He even sent Ma'Abena a mobile phone, so he could call her and check on his house-building affairs; he seemed to trust her more than his wife. Having a brother in Italy, Ma'Abena knew how to communicate long-distance, and, having many male (football) friends, she had learned how to work with men.

Ma'Abena herself is not legally married, but she refers to a family friend whom she used to work with at the market, as her "husband." $\mathrm{He}$ is the proud father of her ten-year-old son Will. Two years after Ma'Abena gave birth, Esther had a son and named him Will too. While other women name their children after past and present friends and lovers, their connection is evinced by a newly chosen name. Today the namesakes are close friends, a closeness enabled by the fact that Ma'Abena arranged for a room for Esther in a maternal cousin's compound, and their sons can visit any time. When Ma'Abena's son asks his father for a present, he would ask for two additional ones, to give to his friend Will and his little brother. The desire or duty to pass things on is constitutive of all alliance- and kinship-making. Ma'Abena and Esther's unofficial "alliance" resulted from many years of actively connecting their kids, kin, and kindreds.

Ma'Abena emphasizes her closeness with Esther by invoking the things they shared and experienced together, their vicinity and complicity. Meanwhile, they are not as passionately drawn to each other as they used to be. During our interviews with Ma'Abena, Esther was in Accra where she spends most of the week, looking for a new job and staying with a boyfriend. Every other weekend they catch up and spend much time with each other, to the point where Esther's mother would phone Ma'Abena, if she could not reach her daughter. But Ma'Abena is explicit about them having surpassed the stages of lovers' infatuation,

Interview with Ma'Abena Oppong at Suakrom, March 16, 2008. 
when she reflects on the fact that they are not compelled to constantly be in each other's company anymore.

At first, it was like, we were always together, it was good. But now, the pressure [urge to see each other] is not like at first. If I see her, it's good, if not, no problem. I feel like, I can go anywhere that I want to go. At first, even if I had to go somewhere, we had to do it together. Do you understand what I'm saying? Because I knew that there was something behind me. But it's not like that anymore. I can go wherever I want [...] without knowing her whereabouts; I don't have any problems. ${ }^{37}$

While the heat of passion and the jealous drive to be together at all times faded over the years, Ma'Abena counts all the fifteen years they have been in each other's lives as years of their togetherness. It was during these years that they shared substance and became "like siblings": they washed, bathed, slept, and ate together on a daily basis, shared their headaches, provided each other with room in their family compounds, cheated on each other, named their firstborns after each other, and were known as best friends by their husbands, mothers, sons, and friends. Along the way, Ma'Abena and Esther began to share their networks of personal kindreds and, just like many opposite-sex couples, they developed a sibling-like bond which to some extent undermined their erotic passion. ${ }^{38}$

In Ma'Abena's discourse, siblinghood emerges as a model for companionship and mutuality that is becoming post-sexual. Yet even Adwoa's passionate claim to siblinghood is fueled by a dramatic sense of losing Korkoi as a lover, which makes their non-sexual shared substance, their closeness "by blood," all the more compelling. Whether or not their relationships are tacitly perceived as erotic relationships by outsiders, having shared not only bath water but also bodily fluids, matters to their claims of having become "one blood" or being of "one mind" respectively. Yet, in Ma'Abena's account, amorous passion has lost its urgency and given way to a connectedness that hinges on a complicity forged through dealing with each other's husbands and having children. It seems that it is

37 Interview with Ma’Abena Oppon at Suakrom, March 16, 2008.

38 Comparable assumptions are made in the Euro-American myth of "lesbian bed death," which holds that female homosexual couples, much more than heterosexual or male homosexual couples, are prone to asexual long-term relationships. 
precisely the bread-and-butter intimacies and the loosening of the passionate grip, combined with the longevity of their friendship, that are the prerogatives of their relatedness.

Articulations of choice and permanence are not the markers of shifting same-sex family formations that span different households, include husbands or boyfriends, and are as contingent as the lives of the women who form them. While invoking each other as siblings, my respondents did not claim to raise queer families. Using the term family to describe the closeness of women who house or arrange rooms for each other, name their children after each other (or after a bygone cousin love), and take care of each other's elders, is thus a conscious effort on my part to evaluate the "arrangements" I encountered as more than "arrangements." By examining "lineages" and "domestic groups" rather than "families," anthropologists of kinship in West Africa reinforced ideas about the nuclear Euro-American model as the "real" family associated with safety and domestic comfort. Multi-generational, extended forms of living and belonging together have been in turn defined against this unspoken nuclear family norm. By considering the networks I found siblinghoods and families, I emphasize the affective element and the critical agency of women who attune their everyday lives to each other and share responsibilities, even if they cannot or choose not to co-reside permanently.

\section{Conclusion: Actualizing Siblinghood}

Female "friends" who refer to each other as nuanom (siblings) or sisters make nuanced distinctions between different forms of relatedness. To outsiders, they capitalize on the blurred and often unspoken boundaries between genealogical and metaphorical kinship and between best friends and lovers. Deploying siblinghood can be a way of avoiding the ambiguous term "friend," since a "friend," assumed to be a non-relative, is a potential lover. Among same-sex desiring women, claims to siblinghood allude to a mode of closeness and connection that exceeds "friendship." Such claims tend to connote the equality and harmony attributed to uterine sisters rather than the internal hierarchies and underlying hostilities that also prevail among siblings. Siblinghood may index a companionship that has ceased to be sexually passionate. Having weathered the storms of passionate love, material hardships, and the exchange of gifts, these 
bonds transcend the vagaries and vagueness associated with friendship and sexual attraction.

Carsten's concept of relatedness has been extended here to crystallize narratives of becoming siblings, which are inspired by shared substances: food eaten from one bowl, shared cigarettes, or bath water. Perhaps the sharing of bodily and sexual fluids is also implied in the raised eyebrows and the elongated "everything" common to the parlance of my respondents. Intimate notions of relating or becoming related do hold sensual and erotic meanings among "knowing women." Nonetheless, given that these women do not dwell on the materiality of the "substances" shared, but rather on the act of sharing, I prefer their phrase "doing everything together." Rather than focusing on substances, shared practices are marked as grounds on which female same-sex "siblinghoods" thrive in postcolonial Ghana. This emphasis on practice transpires in the phrase "doing everything together" mothers and daughters do not do "everything together," neither do brothers and sisters or husbands and wives. Without claiming family status, some women creatively seek out arrangements that allow them to share their everyday lives. Bound to engage with each other's boyfriends and genealogical kin, the disputes and the mutual assistance characterizing these "arrangements" are not restricted by a focus on one partner. Transcending the logic of the couple and the "chosen family" (Weston 1991), which tends to be small and economically independent, working-class women who love women in Ghana connect each other's networks of personal kindreds in significant ways.

The fact that the women themselves distinguish between metaphor and genealogy is nowhere more compelling than in the anxieties about inadvertently falling for a female cousin. Taking a closer look, however, the key question is not how exactly they are related and whether or not their unions would indeed be outlawed. Concern over what feels or might be considered incestuous hinges more on the degree to which two women's networks overlap, how entwined their everyday lives are, and how tangible and known their intimacy is to their immediate community. Conversely, anxieties over the lawlessness of same-sex unions are articulated not only among women who worry about being of the same sex and of the same family, but are also expressed by women who deplore the messy triangulation of love within their tight-knit same-sex bonding networks. Fears of inadvertently committing incest reflect the absence of public rules and rituals to formalize 
and regulate same-sex bonds. Public recognition would allow same-sex partners to frame their intimacies in terms of (marriage) alliance rather than (uterine) descent. This is not to say that the specter of incest would be banished if same-sex marriage was an option. Researching the question of what exactly engenders feelings of incest through the lens of relatedness - rather than structural notions of kinship - may reveal the existence of sibling-like feelings among long-term opposite-sex couples as well.

The fact that legal same-sex marriage is not available nor necessarily desired makes siblinghood the most likely and readily available metaphor through which to grasp the intimate attachments of female samesex companions. In these relationships, exchanging gifts, the key feature of youthful supi, gives way to intense forms of sharing. Thus, among adult women, sharing and "doing everything together," amounts to the symbolic expression of lovers' siblinghood in its many fabrics. 


\section{Conclusion: A Fabric that Never Goes Out of Fashion}

To begin this final chapter, I wish to return, momentarily, to Suakrom's football community and to the vignette about Edna, Aisha, and Naa that appeared in the Introduction. Edna, to recap, was looking to break up with her girlfriend $\mathrm{Naa}$, who was also her footballing "team mother." Sensing a change in Edna's feelings, Naa decided she would try to "test" Edna by asking her friend Aisha to propose to her. The outcome of this proposal, so the logic went, would reveal to Naa whether Edna had lost interest in their relationship. The test backfired when Aisha and Edna fell in love.

The footballers' "love triangles" would not, perhaps, seem out of place in a TV soap opera. Yet the schemes, squabbles, and sensualities that animate Suakrom's football team are, I think, more than youthful melodramas. Practices of "giving" and "testing" love and each other are materially and emotionally significant. They reveal something about the social fabric of same-sex networks, the secrecies, and the forms of "connectedness" through which they are constituted. By exchanging gifts and mediating girlfriends, women are limiting and keeping in check each other's twosome amorous bonds. At the same time, however, the emotional and material complications connect the women involved by creating new meanings and consolidating such contingent same-sex bonding networks. The social and cultural significance of these shared practices is easily overlooked when we confront racist notions of a "loveless Africa" and, relatedly, seek to rehabilitate romantic love in this context by asserting the universality of couple love in ways that privilege the dyadic dimensions of (hetero)romance and togetherness. Indeed, it is one of the central contentions of this ethnography that the shifting networks of same-sex friends and lovers, these webs of siblings and "personal kindreds," constitute a specific mode of sociality and of collectivizing love under precarious postcolonial conditions.

The language of kinship and friendship was vital to the parlance of my respondents. In many ways, friendship, secret mpena twee 
(lovership) and kinship formed a continuum in describing or idealizing different aspects of passion and intimacy and the different stages of relating and relatedness through which a couple may pass. Motherchild/baby or senior-junior sibling terminologies that call on or instantiated certain hierarchies are used alongside terms such as "my dear" or "my friend" or "girlfriend." I often heard the term "friendship" or "woman friendship" used when a woman referred to an intimate samesex bond, which accords with Ghanaian notions of passion and lovership beyond the desire for marriage. In Ghana, as elsewhere, "friend" can be a vague and highly ambiguous term because it leaves open whether the relation involves an erotic component. What became apparent through my research, however, is that kinship terminology is only seemingly more clear-cut, since a long-term lover could become a (metaphorical) sibling, and vice versa a cousin, hence a (genealogical) sibling, could become a lover. Indeed, the language of relatedness usefully lends itself to the representation of a variety of significant intimacies, including sexual ones. On the one hand, the assumed closeness and harmony between genealogical sisters or between mothers and daughters works to disguise sexual bonds or even to cover up abusive relational dynamics. At the same time, the use of kin terms also amounts to a way of professing the heat of passionate love or a deeply felt, affectionate connection to a person with whom one has shared many things, including hardships and the joys and power of the erotic.

Precisely because friendship is imagined as more negotiable than kinship in terms of hierarchy, the hierarchies friendships do (re)constitute are not opposed to but are framed by kinship terms. In the life stories of my same-sex desiring respondents, notions of family and friendship were deeply intertwined and held many shifting and contradictory meanings. Mostly, however, family and sibling practices were associated with sharing daily lives over extended periods of time and with relating and weaving joint networks of support, without necessarily living in the same household. This is consistent with historical patterns of duo-local residence among conjugal couples in southern Ghana. Stories in which a (genealogical) family member denounced their sister's female lovers were as frequent as stories in which mothers supported their daughters' same-sex intimacies or men who tacitly accepted their wife's "best friend." Especially if the female friend in question seemed to be caring and financially providing, grandmothers 
and mothers called them up and asked them for forgiveness on behalf of their daughter or appealed to their financial responsibility as "senior sisters." This sort of maternal support of a daughter's involvement with a wealthier woman speaks of the integrity of female bonding across generation, lineage, and class configurations, and its integrity with Ghana's historical social fabric.

My findings on the gendered materiality of same-sex intimacies suggest new directions for African studies of love and sexuality that have documented how questions of materiality configure a variety of heterosexual "transactional sex" and "provider love" (Hunter 2010). This book's analysis reveals what happens when the question of who ought to pay within a relationship cannot be answered by deferral to sexual difference. My focus on female provider love underscores the material provisionality of everyday same-sex intimacy. By focusing on sugar motherhood and considering it indeed as a sort of motherhood, I have extended the notion of provider love beyond the opposite-sex framework. The bitter sweetness of the "sugar" provided by these "mothers" often lies in the fact that the romantic and sexual aspects of their intimacies need to be disguised much more carefully than those between "sugar daddies" and their "girls." While the girl of a sugar mummy cannot afford either commodified or public expressions of romantic love, she may consider herself to be in a reciprocal relationship through the language of kinship and mutual care. The younger woman's claim to reciprocity often thrives on idealized notions of marital, sisterly, or mother-daughter affection and togetherness.

Another claim made especially among same-sex lovers of the same age-group is the claim of becoming siblings through a process of sharing. Two different modes of sharing emerged from this analysis: most women conjured the everyday intimacy of "doing everything together," while others emphasized the "sharing of blood" and "the body." Throughout the southern Ghanaian context, blood is a powerful metaphor in construing descent. In the matrilineal Akan context, blood designates the connection between siblings and relatives descending from the same womb that posit women as the carriers of blood. Among those of my respondents who stressed the difference between non-sexual and sexual same-sex bonds and the significance of sexual practice, blood was used as a metaphor for deep passion and the capacity of connecting the inside(s) of different female bodies. Blood was also considered a liminal substance (for instance, in practices of 
blood friendship) that invites overly intense same-sex connections. A second mode of sharing is embedded in women's frequent expression of "doing everything together." The phrase points to a range of everyday sensualities, shared food, and work practices and to the mutual support given in overcoming material shortages, health problems, daily struggles, and personal crises. In this parlance, siblinghood emerged as a metaphor for intimacies that unfold over a long stretch of time and that went through sexual and non-sexual periods or had ceased to thrive on erotic passion and sexual desire altogether.

My respondents' expressions of love and desire were informed and shaped by Ghanaian norms of indirection and verbal discretion. These speech norms facilitate the blurring of kinship and friendship, and destabilize the primacy of sexual acts or sexual identities associated with same-sex love. Notwithstanding, the togetherness of women "doing everything together" does include sexual practices that are highly relevant and form part of an intimate same-sex discourse. This togetherness and the cultural discourse it produces, however, is curtailed by the broader precariousness and the provisional nature of love relationships under circumstances of chronic poverty. In the context of same-sex passion in particular, stable, long-term couple love is something of a "luxury," given that it requires material and spatial certainties that are unaffordable to young West Africans (cf. Masquelier 2009). Access to private space is critical to those (same-sex) couples who need to disguise their erotic intimacy. While privacy is most accessible to those who are "wealthy, male, and married" (Gaudio $2009,115)$, subaltern friendship networks rely on and open up collective modes of sharing "private" spaces.

Given the role of spatial constraints in shaping non-normative erotic intimacies, space plays a significant role. With the increased media attention on homosocial bonding spaces such as girls' boarding schools or female football clubs - but also the gradual disappearance of women's gatherings at a queen-mother's house - same-sex socializing spaces are less readily available than they used to be. This is only partially balanced by the popularity of Christian women's groups and ministries, through which a number of my respondents met a female lover. Initiating erotic same-sex intimacies in religious spaces is premised on women's ability to overhear and not to identify with the evil portrayals of lesbianism or supi. This significance of homosocial spaces and sensualities is potentially obscured in studies of love that focus on 
heterosexual relations and that orient around twosome, middle-class understandings of conjugality in Africa. As my focus on friendship revealed, networks of female friends and metaphorical sisters are doing much of the affective work of love, which in North Atlantic societies is expected to be accomplished by individual couples and nuclear families. These friendships may include sexual intimacies without claiming either clear-cut sexual identity or formal kinship status, nevertheless forming contingent families and a culture of same-sex intimacy - a culture missing from the anthropology of friendship (Bell and Coleman 1999; Desai and Killick 2010).

My examination of age, gender, and notions of reciprocity, rather than egalitarianism, proved to be a productive entry point into the relational dynamics between female lovers in Ghana. In the discursive practices of my respondents, age and gender emerged as deeply intertwined social categories. A term such as "sugar mother," as well as the Akan Twi term sbaa barima, only applies to mature women who have achieved a certain level of socio-economic status and thus a certain social age. On these grounds, I am highly critical of the speculation that gender-stratification outweighs age-stratification within same-sex relationships on the African continent (Greenberg 1988; Murray 2000). Certainly, in contemporary queer ethnographies gender does indeed figure as a primary route to explore the complex role divisions among female same-sex lovers. This, however, pertains not only to Africa and its diasporas (Wekker 2006; Matebeni 2012), but even more so to ethnographies on toms and dees in Thailand (Sinnott 2004; Wilson 2004) or tombois and girlfriends in Indonesia (Wieringa 2005; Blackwood 2010), which have been likened to North Atlantic butchfemme constellations. These studies found gender to be the most significant category to think through paired differences. It seems that with the increasing commodification of sexualized body ideals and the global popularity of the nuclear family, a specifically gendered understanding of binary roles is being promoted as the primary model for same-sex love. The importance of gender within same-sex relations is certainly reflective of the normalization of companionate marriage as the necessary outcome of "modern" romantic love. At the same time, following Strathern (1988), research categories and analytical tools are inevitably linked to the epistemological cultures and subcultures by which researchers are rooted. The attention given to gender as structuring same-sex intimacies in various locations, however, 
may thus speak to the disposition of queer scholars socialized in metropolitan subcultures in which gender has been the main category of difference admitted, conceptualized, and cultivated within otherwise allegedly egalitarian lesbian (and gay) relationships.

Butch-femme theorists have teased out the power and complexity of gender within lesbian relationships (Kennedy and Davis 1993; Martin 1994; Cvetkovich 2003). Not least, they elaborate on the limited capacity of the binary gender framework to account for the negotiations around active and passive, giving and receiving, feminine and masculine within same-sex couples. My research revealed that looking at these dynamic positions through the lens of seniority and relatedness is yet another way to undermine the dichotomies between femininity and masculinity. It further contributes to a deeply relational understanding of intimate power and its aesthetics. Rather than assuming that sexual role divisions are primarily informed by a gendered selfrelation, the focus on seniority as a relational category tied to knowledge adds an additional dimension to how our selves shift as we age and move through different relational situations, not only in West Africa. Despite or precisely because a person's sexual self-expression is valued, sustained, and conditioned by situational concepts of what it means to be butch or femme or queer, our (gendered) selfhood may undergo considerable shifts throughout a lifetime. Inasmuch as we depend on others for knowledge about ourselves (Strathern 1988, 132), erotic self-understandings are always relational. They shift depending on who we are with and under what socio-economic and (sub)cultural conditions, and in which way a partner is socially older or younger, and more or less knowing than ourselves.

One term that reflects the significance of knowledge and seniority within same-sex relational configurations is supi. In the secondary school context the term, which has traveled along the coasts of Anglophone West Africa, is framed by the idea that there needs to be a more knowledgeable girl who leads her junior into "feeling," interpreting, and acting upon feelings of attraction. She effectively teaches her that love ought to be a give and take. At the same time, the expectation that gifts are to be reciprocated and handed on, means that the senior's knowing position is undermined once the junior starts initiating her own relationships and exchanges. First, I pondered the resulting love triangles in terms of their manipulative character and the boundaries they set to the togetherness of a (potential) couple. 
Increasingly, however, I realized that the negotiations over love and livelihoods tie in with women's notions of gift exchange and the imperative to share in order to get by. By passing on both material and immaterial gifts, including the gift of knowing same-sex passion and surviving heartbreaks, new bonds and contingent families took shape while constantly being tested and reconfigured. Intrusive practices and attempts to monitor the desires and intimacies of friends, lovers, and siblings also speak to the agency of women who have little to claim as their own otherwise. Especially within young women's informal networks and collectivities a certain freedom in being allowed, or even expected, to lie and make up stories (cf. Burch 2013, 64), extended their scope of performing and inventing a personal "life." Faced with the exigencies of everyday survival, some claims to being a "hustler" and a trickster can be vital to asserting one's power and retaining a level of inner "freedom" amidst the precarious and marginalizing conditions of unequally distributed global capital.

Though, specifically in Accra, many women referred to an adult female lover as their supi, either playfully or in responding to my questions, I decided not to coin supi as an overarching designation for female same-sex desires in Ghana. Instead of privileging one singular term, I was more interested in the many ways in which women interpret their practices and articulate their passions in verbal and nonverbal ways. What renders supi a compelling term is the fact that it is used in similar ways as the term motsoalle in Lesotho (Kendall 1999), or the Hausa term kawa in northern Nigeria (Gaudio 2009) that can refer to a female friend or lover. Such terms and especially supi, with its popularity on Ghana's coast, suggest a link to of the "black queer Atlantic" (Tinsley 2008, 192) in their reminiscence of expressions like mi mati in Afro-Surinamese Creole (Wekker 2006) or my girl in African-American English (Tinsley 2010) that span sexual and nonsexual expressions of female intimacies. Certainly, the vagueness implied in terms like friend, girlfriend, or the German Freundin is also deployed in a variety of rural and urban settings and situations where people are not "out" or reject the urge to label and single out a same-sex bond as distinctly (homo)sexual. What may be specific about the black queer Atlantic, as conjured in Tinsley's experimental writings, is the legacy of a multitude of maritime contacts between the continents. This maritime contact zone - fraught with violence and exploitation, but also with solitude, desire, and resistance - lingers on 
an ocean that obscures all origins $(2008,192)$. The grammar of queer intimacies forged on seas and oceans remains watery and in flux, undermining all fixities.

In various spaces and locations female same-sex lovers are described without explicitly invoking sexual connection. Indeed, "lesbian" seems to be the exception in its explicitness. As such it has gained transnational currency and is put to use within very different grammars. When my respondents in Ghana did refer to themselves as lesbian, they verbalized sexuality not as an identity but as praxis. Janet Aidoo's verb construction "doing supi" for instance implies erotic "enjoyment," without marking the sexual as foundational to her identity. Rather, an awareness of the power of the erotic, both within relationships and as an internal resource that emerges from "the joy which we know ourselves to be capable of" (Lorde 2007, 57) and the active pursual of such joy, seemed to be vital to her selfhood. Such a notion of actively doing and re-doing same-sex intimacies through daily action has the flexibility to include and absorb more static terms like lesbian/ism without losing its own culture as a practice. The term "knowing women" seeks to account for the articulate ways in which many women in Ghana, and perhaps across the black Atlantic, appeal to same-sex passion and intimacy as a knowledge that is acquired through practice and invigorated by passing it on.

This book began by discussing how working-class women in southern Ghana tend to dismiss the "noise" produced through the antagonism of pro- and anti-gay voices and how they object to the project of naming themselves in sexual terms. Their tacit resistance against an internationally driven activist project ties in with a more general reluctance to commit to prescribed identities. Many of my respondents not only pursued same-sex and opposite-sex intimacies in different locations, they also went by different personal names and nicknames, both African and Euro-American ones; they had several mobile phone numbers (without necessarily owning their own phone); they juggled different formal and informal jobs; and they consulted both western medicine and African traditional healers. While inhabiting different spaces that were governed by conflicting knowledge traditions, the idea of adhering to one single identity did not occur to the women I encountered; fixity in word and action seemed to be undesirable or unaffordable, and at odds with their critical agency. These multiplicities reflect the constant material uncertainties that shape their life praxis. 
But it is also more than that. As Achille Mbembe points out, the postcolonial subject is per se bound to navigate the different public spaces that constitute the postcolony. Each public space goes by its own norms and institutional practices and has a logic that is "liable to be entangled with other logics when operating in certain contexts; hence, the postcolonial subject has to learn to bargain in this conceptual marketplace." This requires "a talent for play" and a "marked ability to manage not just a single identity, but several - flexible enough to negotiate as and when necessary" $(2001,104)$. This multiplicity seems to hold particularly true for "knowing women" who proudly assert themselves as "hustlers" and describe how they juggle a variety of intertwined affective and material needs and desires. For these samesex loving women in particular, the necessity of improvising and operating on different registers and the capacity to negotiate multiple positions and identifications is vital to carving out personal spaces and fostering wayward intimacies and cosmopolitan desires under precarious postcolonial conditions.

A young self-identified lesbian in Accra once conveyed the following to me over a bottle of Coca Cola: "at first it was just civilized, but now you have it all over the world." We were sitting at a street joint during an annual Ga street festival in Accra, in the midst of an exuberant young crowd of people, making up their own "styles" and fashions. While suffused with dreams of travel and transnational connection, her statement pertained to her circle of friends and to the flamboyant young Ghanaians passing by whom she read as queer. It was too loud to launch into a discussion of the "civilized" world and its ongoing quest to construct itself as the sole hub of sexual modernity. Does her rightful claim to be part of this "civilized" gay and lesbian modernity include the queer, as in unruly, practices and desires of those "feeling backward" rather than gay (Love 2007)? And what is the loss inscribed in modernity's seamless absorption of intimate erotic friendships that do not speak their names, while walking the backstreets of queer globalization?

Inasmuch as the "backward" stories here - of "stealing" and "exchanging" lovers, or of the senseless joys and "spiritual" dangers of losing your mind by giving yourself fully to love - resist the positivist narrative of a liberated gay modernity, they speak to queer-feminist and postcolonial affect theories that reconsidered the gay "promise of happiness" (Ahmed 2010). By reclaiming negativities and re-centering 
uneasy and abject feelings - shame, obsession, or loss, but also the intense pleasures that inhabit the shadows of queer existence - they offer a point of coalition between those marked as Other through the cracks of gay globalization and "inferior by means of the allegation to backwardness" (Love 2007, 6). Bearing with the inconceivability of feeling "queer" as opposed to "gay," queer of color and postcolonial theorists further advocate the forging of provisional alliances and "affective communities" (Gandhi 2006) that are based not on a shared history or identity, but on different and multiple experiences of not fitting in (Anzaldúa 1981). Located at the periphery of the "civilized" with its normative categories of (sexual) difference, intersectional coalitions may have the capacity to undermine their own absorption into a universalizing narrative of a gay, capitalist modernity.

The question of cross-cultural coalition-building has been critical to queer activists on the African continent. They are faced with a conundrum: On the one hand, they are confronted with local and nationalist discourses that condemn LGBTI groups, subcultures, and activism as a foreign import. On the other hand, they are compelled to interrupt the "single story of 'African homophobia'" emanating from generic narratives about African nationalist leaders and homophobic policies. While this story often serves the homonormative, selfcongratulatory rhetorics of North Atlantic nation-states, it is also summoned by African LGBTI activists in need of donor moneys. As Okech and Sika argue, the exigencies of donor funding and "the watchdog' role of international LGBT networks" $(2019,21)$ have contributed to generic portrayals of African homophobia among activists in Africa. Increasingly, however, these transnational dynamics are resisted by African-based organizations such as the Coalition of African Lesbians (CAL). In 2012 CAL rejected the creation of a special United Nations mandate that was geared toward granting specific rights to LGBTI Africans.

CAL's main concern was that various African governments that cosigned the resolution for the special rapporteur tended to perceive this commitment as a something separate from their obligations to the social and economic, but also sexual, reproductive and political rights of all people. If human rights defined in relation to sexual orientation and gender identity are thus isolated it makes it easier for states to regress back towards affirmations that queer activists and feminists are un-African alien bodies, otherwise why would they need 'special' institutions and rights? (Sika and Okech 2019, 26) 
Queer and feminist African activists have been hesitant toward the imposition of policies that separate sexuality from other human rights, such as the right to mobility. Thus, Tamale critically compared the political economy of homophobia in African contexts to the rising tides of xenophobia in Europe and draws out parallels between the ways in which queer Africans are scapegoated and barred from cultural citizenship at home and the exclusion and inhumane treatment African migrants face in the global North $(2013,227)$. In Europe, these racialized exclusions happen in a setting where testifying to one's acceptance of gay culture has become a yardstick of a person's progressiveness that makes them fit for European citizenship (Mesquita and Purtschert 2016).

Both, North Atlantic representations of African queers in need of salvation and of African homophobes that should be educated and/or deported pose a challenge to queer postcolonial activism and scholarship. Inadvertently, a certain paternalism that racializes and others African bodies and intimacies is resurfacing in the field of Queer African studies. Keguro Macharia scrutinizes the well-meaning "western" desires to explore African queers or safe them from African homophobes (2018). As Macharia warns in the renowned Journal for Lesbian and Gay Studies GLQ, "queer African voices and experiences will be absorbed as 'data' or 'evidence' not as modes of theory or challenges to the conceptual assumptions that drive queer studies" $(2018,185)$. As in every field, research on queer Africa is not immune to the mistakes previous generations made when descending upon Africa. While refusing to be "area-studied," Macharia celebrates the "African genius of waywardness" that "accumulates odd stories, little moments, folksy wisdom and seemingly disconnected anecdotes." Rather than following the aesthetics of theory it is marked by a "stubborn refusal to come to the point" (Macharia 2018, 188). This stubborn refusal is nowhere more poignant than in my respondents' passive resistance to labeling themselves, in their creation of new terms, and their creativity in confronting hostilities and adverse living conditions.

Waywardness is also embedded in newly created words and phrases that take on a life of their own in the circles around "knowing women" like Okaile in Accra. This way with words, which includes the twisting and bending of words appropriated from or inspired by the global LGBT lexicon, is not unique to working-class women in Ghana. Slips and mispronunciations have been deployed by queer activists and writers throughout the continent. At a conference in Nairobi in 
March 2014, Binyavanga Wainaina, for instance, spoke about how he first came across the acronym LGBT. In doing so, he continually pronounced LGBT as "ligibit"(Matebeni and Msibi 2015, 1). For some queers in the audience this conscious slip momentarily opened up a new language that was detached from the rights-discourse, as Zethu Matebeni and Thabo Msibi observed: His vocabulary offered "a different way of naming oneself" and of making "identity categorization pronounceable" and impossibilities possible $(2015,1)$.

The peripheral role of African women within queer and academic discourses compelled me to search for women's own language. What I found was a rich repertoire of metaphors and indirect and poetic ways of invoking love and friendship, self, and society. In conclusion, I would like to use yet another metaphor, one which was imparted to me by a "knowing woman" in Suakrom, Ma'Abena Oppong. Though Ma'Abena is not a regular churchgoer, she identifies as a Christian. When we first met, she was looking for a suitable church congregation and followed the "preachings" of popular charismatic men on the radio. However, she did not buy into the devilishness attributed to "lesbianism" by many pastors in the aftermath of the imagined "homoconference." It is simply the pastor's job to preach, she argued. Interviewing Ma'Abena together with Josephine, I asked her how she has the strength to believe that it is a "normal" thing to kiss a woman, as she says. Ma'Abena replied by telling us the story of how she consulted a pastor about the legitimacy of female same-sex passion. The analogy the pastor made, speaks to the Ghanaian fabrics displayed on the title page of this book:

When they started talking about it on the FM [radio], I went to ask a certain pastor. [...] And I asked, 'Oh Pastor' - the church is Roman, near our place, the man is a young guy [and I asked] "so this thing, is it in the Bible?" And he said it was in, but it was something which happened in Sodom and Gomolia or something, something. [J.A. Gomorrah.] Exactly, long time. So for him, he felt that whatever happens, when it's time is past, it comes back again. So that's how the world is. And he said - even, first, our mothers, in the past, they wore something like "kimplin" clothing. That passed away. Later they wore something called "shada" that also came and went. So (.) it's one of those things of the world that goes and comes [...] So it all depends upon your heart. ${ }^{1}$

In Ma'Abena's rendering of the young pastor's voice, same-sex intimacies are considered a historical practice, fashionable since biblical

1 Interview with Ma'Abena Oppong at Suakrom, April 25, 2008. 
times. He compared it to an old Ghanaian fabric and a dress pattern that keeps returning in different shapes and with different names. Ultimately, these patterns are classics and will never disappear. Ma'Abena denied the pastor's nosy questions as to whether she herself was "doing it." Instead she seemed to find solace in the image of the fabric and the certainty that her heart alone is in charge of deciding how the fabric becomes her. Without knowing what exactly inspires Ma'Abena to think against homophobia, the heart appears to be the seat of her personal strength and certainty.

While the intimate discourse and practices of "hustling" women who love women in Ghana are not nearly as silent as they might seem to be, the question remains whether they can make themselves heard and under what conditions. Spivak controversially argued that although the subaltern woman does have agency on her own terms, she is not in the position to publicly articulate herself (1988). Since subalternity is undermined in the very moment it is articulated and taken up as such, the subaltern experience is by definition never fully accessible. Rather than providing political solutions or theoretical formulas for the emancipation of subaltern women and thereby usurping or assimilating their experience, Spivak insists on maintaining it as an "inaccessible blankness" and thereby pointing at the limits of western knowledge (Castro Varela and Dhawan 2015, 199). Conversely, approaching the subaltern experiences of "knowing women" in Ghana, requires not only the freeing of "our imaginations" (Wainaina 2014) in and about Africa, but the decolonization of the disciplines and epistemologies that systematically prevent certain forms of knowledge along the established lines of power. If decolonization starts with the process of "un-learning our privilege as our loss" (Spivak 1990, 9), we must constantly grapple with the inherent limitations of our privileged positions.

Privilege is not unlearnt by mystifying "knowing women" or appropriating their intimate knowledge. This implies critical reflection of our own institutional being and resistance to the internal dynamics of disciplined, academic knowledge production. While there is no ready-made formula to decolonize the established categories of knowledge and their inherent power relations, the project of transforming the knowledge we (dis)identify with and reducing the privileged distance to those whom we seek to study and know, requires creative, counter-intuitive, and unprecedented methodologies and practices - their results must remain radically open-ended. 


\section{Bibliography}

Abu-Lughod, Lila. 1991. "Writing against Culture." In Recapturing Anthroplogy, edited by R. G. Fox, 137-62. Santa Fe, NM: School of American Research Press.

1993. Writing Women's Worlds: Bedouin Stories. Berkeley: University of California Press.

Achebe, Nwando. 2011. The Female King of Colonial Nigeria: Ahebi Ugbabe. Bloomington: Indiana University Press.

Adam, Barry D. 1986. "Age, Structure, and Sexuality: Reflections on the Anthropological Evidence on Homosexual Relations." In The Many Faces of Homosexuality: Anthropological Approaches to Homosexual Behavior, edited by E. Blackwood, 19-33. New York: Harrington Park Press.

Adjabeng, Joshua. 1996. Teenage Sex and Love. Accra: Olive Publications Pentecost Press Ltd.

Adomako Ampofo, Akosua. 1997. "Costs and Rewards - Exchange in Relationships: Experiences of Some Ghanaian Women." In Transforming Female Identities: Women's Organizational Forms in West Africa, edited by E. E. Rosander, 177-94. Uppsala: The Nordic Africa Institute.

2007. “'My Cocoa Is between My Legs': Sex as Work among Ghanaian Women." In Women's Labor in the Global Economy, edited by S. Harley, 182-205. New Jersey: Rutgers University Press.

2011. "Lectures: William Ofori-Atta, a man of our times." In 12th in the series of the William Ofori-Atta Centeray Lectures. British Council, Accra (unpublished material).

Adomako Ampofo, Akosua, and John Boateng. 2007. "Multiple Meanings of Manhood among Boys in Ghana." In From Boys to Men: Social Constructions of Masculinity in Contemporary Society, edited by T. Shefer, K. Ratele, A. Strebel, N. Shabalala and R. Buikema, 53-75. Cape Town: University of Cape Town Press.

Ahmed, Sara. 2000. "Who Knows? Knowing Strangers and Strangerness." Australian Feminist Studies 15 (31): 49-68.

2010. The Promise of Happiness. Durham, NC: Duke University Press. 
Aidoo, Ama Ata, ed. 2006. African Love Stories. Banbury, Oxfordshire: Ayebia Clarke Publishing Ltd.

Akagbor, Sena. 2007. Same-Sex Attraction: Choice or Genetic? Edited by C. Diako. Tema: Seal.

Akyeampong, Emmanuel K. 1996. Drink, Power, and Cultural Change: A History of Alcohol in Ghana c. 1800 to Recent Times. Social History of Africa. Edited by J. Allman and A. Isaacman. Oxford: James Currey/Heinemann.

1997. "Sexuality and Prostitution among the Akan of the Gold Coast c. 1650-1950." Past and Present no. 156, 144-73.

2000. "Wo pe ntam won pe ba' ('You like cloth but you don't want children') Urbanization, Individualism \& Gender Relations in Colonial Ghana, c. 1900-39." In Africa's Urban Past, edited by D. M. Anderson and R. Rathbone, 222-34. Oxford: James Currey.

Akyeampong, Emmanuel K., and Pashington Obeng. 1995. "Spirituality, Gender, and Power in Asante History." International Journal of African Historical Studies 28 (3): 481-508.

Allen, Jafari S. 2011. Venceremos? The Erotics of Black Self-Making in Cuba. Edited by J. Halberstam and L. Lowe. Perverse Modernities Series. Durham: Duke University Press.

2012. "Introduction: Black/Queer/Diaspora at the Current Conjuncture." GLQ: A Journal of Lesbian and Gay Studies 18 (2-3): 212-48.

Allman, Jean, and Victoria Tashjian. 2000. "I Will Not Eat Stone": A Women's History of Colonial Asante. Portsmouth: Heinemann.

Altman, Dennis.1997. "Global Gaze/Global Gays." GLQ: A Journal of Lesbian and Gay Studies, 3 (4): 417-36.

2001. Global Sex. Chicago: University of Chicago Press.

Amadiume, Ifi. 1987. Male Daughters, Female Husbands: Gender and Sex in an African Society. London: Zed Books.

1997. Re-Inventing Africa: Matriarchy, Religion and Culture. London: Zed Books.

Amoah, Elizabeth. 1991. "Femaleness: Akan Concepts and Practices." In Women, Religion and Sexuality, edited by J. Beecher, 129-53. Philadelphia, PA: Trinity Press International.

Anzaldúa, Gloria. 1981. "La Prieta.” In This Bridge Called My Back, edited by C. Moraga and G. Anzaldúa, 198-209. New York: Kitchen Table: Woman of Color Press.

Appadurai, Arjun. 1990. "Disjuncture and Difference in the Global Cultural Economy.” Public Culture 2 (2): 1-24.

Appiah, Kwame Anthony. 2008. "Lyle's Images.” In Blow Up, edited by C. Coblentz and G. R. C. Miller. New York: Scottsdale Museum of Contemporary Art. 
Arnfred, Signe. 2004. “African Sexuality'/Sexuality in Africa: Tales and Silences." In Re-Thinking Sexualities in Africa, edited by S. Arnfred, 59-78. Uppsala: The Nordic Africa Institute.

2004a. "Introduction." In Re-Thinking Sexualities in Africa. Edited by S. Arnfred. Uppsala: Nordiska Afrikainstitutet.

2011. Sexuality and Gender Politics in Mozambique: Rethinking Gender in Africa. Woodbridge: The Nordic Africa Institute.

Arondekar, Anjali R. 2009. For the Record: On Sexuality and the Colonial Archive in India. Durham: Duke University Press.

Asamoah-Gyadu, Kwabena J. 2005. African Charismatics: Current Developments within Independent Indigenous Pentecostalism in Ghana. Leiden: Brill.

Awondo, Patrick. 2010. "The Politicisation of Sexuality and Rise of Homosexual Movements in Postcolonial Cameroon." Review of African Political Economy 37 (125): 315-28.

Awondo, Patrick, Peter Geschiere, and Graeme Reid. 2012. "Homophobic Africa? Toward a More Nuanced View." African Studies Review 55 (3): $145-68$.

Azuah, Unoma, ed. 2016. Blessed Body: Prose by LGBT writers from Nigeria. Jackson: Cooking Pot Publishing.

Bakare-Yusuf, Bibi. 2004. "Yorubas Don't Do Gender: A Critical Review of Oyéwùmí, Oyèrónkẹ́s the Invention of Women: Making an African Sense of Western Gender Discourses.” In African Gender Scholarship: Concepts, Methodologies, and Paradigms, edited by S. Arnfred 61-81. Dakar: CODESRIA.

Banks, William. 2011. “This Thing Is Sweet': Nteter and the Reconfiguration of Sexual Subjectivity in Post-Colonial Ghana." Ghana Studies no. 14, 265-90.

Baumgardner, Jennifer and Amy Richards. 2004. "Young Feminists Take on the Family: A Panel Discussion." The Scholar \& Feminist Online 2 (3). http://sfonline.barnard.edu/family/panel2_03.htm

Bell, Sandra, and Simon Coleman, eds. 1999. The Anthropology of Friendship. Oxford: Berg.

Bennett, Jane and Charmaine Pereira, eds. 2013. Jacketed Women: Qualitative Research Methodologies on Sexualities and Gender in Africa. Tokyo: United Nations University Press.

Berlant, Lauren. 1998. "Intimacy: A Special Issue.” Critical Inquiry 24 (2): 281-88.

Binnie, Jon. 2004. The Globalization of Sexuality. London: SAGE Publications.

Blacking, John. 1978. "Uses of the Kinship Idiom in Friendships at some Venda and Zulu Schools.” In Social Systems and Tradition in Southern 
Africa: Essays in Honour of Eileen Krige, edited by J. Argyle and E. P. Whyte, 101-17. Cape Town: Oxford University Press.

Blackwood, Evelyn, ed. 1986. The Many Faces of Homosexuality: Anthropological Approaches to Homosexual Behavior. New York: Park Press.

Blackwood, Evelyn. 2010. Falling into the Lesbi World: Desire and Difference in Indonesia. Honolulu: University of Hawai'i Press.

Blackwood, Evelyn and Saskia E. Wieringa, eds. 1999. Female Desires: Same-Sex Relations and Transgender Practices across Cultures. New York: Columbia University Press.

Bleek, Wolf. 1976. Sexual Relationships and Birthcontrol in Ghana: A Case Study of a Rural Town. Amsterdam: Center for Social Anthropology.

Bochow, Astrid. 2008. "Valentine's Day in Ghana: Youth, Sex and Secrets." In Generations in Africa: Connections and Conflicts, edited by E. Alber, S. v. d. Geest and S. R. Whyte, 333-56. Berlin: LIT Verlag.

Boellstorff, Tom. 2005. The Gay Archipelago: Sexuality and Nation in Indonesia. Princeton, NJ: Princeton University Press.

2007. "Queer Studies in the House of Anthropology." Annual Review of Anthropology no. 36, 17-35.

Bourdieu, Pierre. 1985. Sozialer Raum und "Klassen"; Leçon sur la leçon. Zwei Vorlesungen. Frankfurt: Suhrkamp.

Broqua, Christophe. 2009. "Sur les rétributions des pratiques homosexuelles à Bamako." Canadian Journal of African Studies 43 (1): 60-82.

2012. L'émergence des minorités sexuelles dans l'espace public en Afrique. Politique Africaine 126: 5-25.

Brubaker, Rogers. 2004. Ethnicity without Groups. Cambridge, MA: Harvard University Press.

Burch, Rebecca. 2013. "Du foot et des femmes ou comment mentir et vivre vraie." In Homosexualités en Afrique, edited by A. Crémieux, 62-65. Paris: L'Harmattan.

Burton, Richard F. 1885. "Terminal Essay." In A Plain and Literal Translation of the Arabian Nights' Entertainments, Now Entitled The Book of the Thousand Nights and a Night with Introduction[,] Explanatory Notes on the Manners and Customs of Moslem Men and a Terminal Essay upon the History of the Nights, vol. X, 63-302. Benares [London]: Kamashastra Society.

Butler, Judith P. 1990. Gender Trouble: Feminism and the Subversion of Identity. New York: Routledge.

1991. "Imitation and Gender Insubordination." In Inside/Out: Lesbian Theories, Gay Theories, edited by D. Fuss, 13-31. New York: Routledge. 
Caldwell, John C., Pat Caldwell, and Pat Quiggin. 1989. "The Social Context of AIDS in Sub-Saharan Africa." Population and Development Review 26 (1): 117-35.

Cameron, Deborah, and Don Kulick. 2003. Language and Sexuality. Cambridge: Cambridge University Press.

Cape Coast Metropolitan Assembly. 2006. Traditional Administration.

Cape Coast, http://capecoast.ghanadistricts.gov.gh/?arrow=atd\&_= 50\&sa=2655, accessed February 14, 2014.

Carrier, Joseph M., and Stephen O. Murray. 1998. "Woman-Woman Marriage in Africa." In Boy-Wives and Female Husbands: Studies in African Homosexualities, edited by S. O. Murray and W. Roscoe, 255-66. New York: St. Martin's Press.

Carsten, Janet. 1995. "The Substance of Kinship and the Heat of the Hearth: Feeding, Personhood, and Relatedness among Malays in Pulau Langkawi." American Ethnologist 22 (2): 223-41.

2000. Cultures of Relatedness: New Approaches to the Study of Kinship.

Cambridge: Cambridge University Press.

2004. After Kinship. Cambridge: Cambridge University Press.

Castro Varela, Maria do Mar, and Nikita Dhawan. 2009. Feministische Postkoloniale Theorie: Gender und (De-)Kolonialisierungsprozesse. Femina Politica (2): 9-18.

2015. Postkoloniale Theorie: Eine kritische Einführung (2nd ed.). Bielefeld: transcript.

Chauncey, George. 1994. Gay New York: Gender, Urban Culture, and the Making of the Gay Male World 1890-1940. New York: Basic Books.

Chitando, Ezra, and van Klinken, Adriaan, eds. 2016. Public Religion and the Politics of Homosexuality in Africa Religion in Modern Africa Series. London and New York: Routledge.

Christensen, J. B. 1954. Double Descent among the Fanti. New Haven, CT: Human Relations File Area.

Chuchu, Jim. 2014. Stories of Our Lives - an anthology film. Nairobi: The Nest Collective.

Clark, Gracia. 1994. Onions Are My Husband: Survival and Accumulation by West African Market Women. Chicago: University of Chicago Press. 1999. "Mothering, Work, and Gender in Urban Asante Ideology and Practice." American Anthropologist 101 (4): 717-29.

2001. "Gender and Profiteering: Ghana's Market Women as Devoted Mothers and 'Human Vampire Bats'." In "Wicked" Women and the Reconfiguration of Gender in Africa, edited by D. L. Hodgson and S. A. McCurdy, 293-311. Oxford: James Currey.

2010. African Market Women: Seven Life Stories from Ghana. Bloomington: Indiana University Press. 
Clifford, James, and George E. Marcus, eds. 1986. Writing Culture: The Poetics and Politics of Ethnography. Berkeley: University of California Press.

Cohen, Lawrence. 2005. "The Kothi Wars: AIDS Cosmopolitanism and the Morality of Classification." In Sex in Development, edited by V. Adams and S. L. Pigg. Durham, NC: Duke University Press.

Cole, Jennifer, and Lynn M. Thomas, eds. 2009. Love in Africa. Chicago: The University of Chicago Press.

Cole, Jennifer. 2010. Sex and Salvation: Imagining the Future in Madagascar. Chicago: University of Chicago Press.

Collins, John. 1996. Highlife Time (2nd ed. Accra: Anansesem Publications Ghana.

Crémieux, Anne. 2013. "Quelques images du foot fémin en Afrique.” In Homosexualités en Afrique, edited by A. Crémieux, 66-69. Paris: L'Harmattan.

Crenshaw, Kimberlé William. 1989. “Demarginalizing the Intersection of Race and Sex: A Black Feminist Critique of Antidiscrimination Doctrine, Feminist Theory and Antiracist Politics." University of Chicago Legal Forum 1989 (1):139-67.

Currier, Ashley. 2019. Politicizing Sex in Contemporary Africa: Homophobia in Malawi. New York: Cambridge University Press.

Cvetkovich, Ann. 1998. "Untouchability and Vulnerability: Stone Butchness as Emotional Style.” In Butch/Femme: Inside Lesbian Gender, edited by S. R. Munt, 159-69. London: Cassell.

2003. An Archive of Feelings: Trauma, Sexuality and Lesbian Public Cultures. Durham: Harvard University Press.

Dankwa, Serena Owusua. 2009. “'It's a Silent Trade': Female Same-Sex Intimacies in Post-Colonial Ghana." NORA - Nordic Journal of Feminist and Gender Research 17 (3): 192-205.

Datta, Ansu K., and R. Porter. 1971. "The Asafo System in Historical Perspective." The Journal of African History 12 (2): 279-97.

Dausien, Bettina. 1994. “Biographieforschung als 'Königinnenweg': Überlegungen zur Relevanz biographischer Ansätze in der Frauenforschung." In Erfahrung mit Methode: Wege sozialwissenschaftlicher Frauenforschung, edited by A. Diezinger, H. Kitzer, I. Anker, I. Bingel, E. Haas and S. Odierna, 129-53. Freiburg i. Br.: Kore.

Dearham, Kaitlin. 2013. "NGOs and Queer Women's Activism in Nairobi." In Queer African Reader, edited by S. Ekine and H. Abbas, 186-202. Nairobi: Pambazuka Press.

De Bruijn, Esther. 2008. "Reconfiguring Intimacy, Mediating Sexuality in Ghanaian Pamphlet Literature.” Paper presented at the Annual Meeting of the African Studies Association (ASA), New York. 
D'Emilio, John. 1983. "Capitalism and Gay Identity." In Powers of Desire: The Politics of Sexuality, edited by A. Snitow, C. Staeheli and S. Thompson. New York: Monthly Review Press.

De Graft Johnson, J. C. 1932. “The Fanti Asafu.” Africa 5 (3): 307.

Desai, Amit, and Evan Killick, eds. 2010. The Ways of Friendship: Anthropological Perspectives. New York: Berghahn Books.

Dover, KJ. 1988. "Greek Homosexuality and Initiation." In The Greeks and Their Legacy. New York: Blackwell.

Drewal, Henry John, ed. 2008. Mami Wata: Arts for Water Spirit in Africa and Its Diasporas. Los Angeles: Fowler Museum at UCLA.

Drucker, Peter. 1996. “'In the Tropics There Is No Sin': Sexuality and GayLesbian Movements in the Third World." New Left Review (218): 75-101.

Dynes, Wayne R., and Stephen Donaldson, eds. 1992. Ethnographic Studies of Homosexuality. Vol. 2, Studies in Homosexuality. New York: Garland Publishing.

Ebron, Paulla A. 2002. Performing Africa. Princeton, NJ: Princeton University Press.

2007. "Constituting Subjects through Performative Acts." In Africa After Gender? edited by C. M. Cole, T. Manuh, and S. F. Miescher, 171-90. Bloomington: Indiana University Press.

Ekine, Sokari, and Hakima Abbas, eds. 2013. Queer African Reader. Nairobi: Pambazuka Press.

El-Tayeb, Fatima. 2015. Anders europäisch. Rassismus, Identität und Widerstand im vereinten Europa. Münster: Unrast.

Eng, David L., Jack/Judith Halberstam, and José Esteban Muñoz. 2005. “Introduction: What's Queer about Queer Studies Now?” Social Text 84-85 23 (3-4): 1-17.

Epprecht, Marc. 2004. Hungochani: The History of Dissident Sexuality in SouthernAfrica: Montréal and Kingston: McGill-Queen's Press.

2008. Heterosexual Africa? The History of an Idea from the Age of Exploration to the Age of AIDS. New African Histories. Athens: Ohio University Press.

Epstein, Rachel. 2005. "Queer Parenting in the New Millennium: Resisting Normal." Canadian Woman Studies 24 (2/3): 6-14.

Essien, Kwame, and Saheed Aderinta. 2009. "'Cutting the Head of the Roaring Monster': Homosexuality and Repression in Africa." African Study Monographs 30 (3): 121-35.

Etaghene, Yvonne Fly Onakeme. 2015. For Sizakele. Washington: Redbone Press.

Evans-Pritchard, Edward E. 1951. Kinship and Marriage among the Nuer. Oxford: Oxford University Press. 
Faderman, Lilliane. 1981. Surpassing the Love of Men: Romantic Friendships and Love between Women from the Renaissance to the Present. New York: Morrow.

Fortes, Meyer. 1969. Kinship and the Social Order. London: Routledge and Kegan Paul.

1975. "Kinship and Marriage among the Ashanti." In African Systems of Kinship and Marriage, edited by A. R. Radcliffe-Brown and D. Forde, 1950, 278-83. London: Oxford University Press.

Foucault, Michel. 1975. Surveiller et punir. Paris: Gallimard. 1980. The History of Sexuality. New York: Vintage Books.

1989. "Friendship as a Way of Life." In Foucault Live: Interviews, 1961-1984, edited by S. Lotringer, 308-12. New York: Semiotext(e). 1998. "Technologies of the Self." In Technologies of the Self, edited by L. Martin, H. Gutman and P. H. Hutton, 16-49. Amherst: University of Massachusetts Press.

Franklin, Sarah and Susan McKinnon, eds. 2001. Relative Values: Reconfiguring Kinship Studies. Durham, NC: Duke University Press.

Gandhi, Leela. 2006. Affective Communities: Anti-Colonial Thought, Fin-de -Siècle Radicalism, and the Politics of Friendship. Durham, NC: Duke University Press.

Gaudio, Rudolf P. 1998. "Male Lesbians and Other Queer Notions.” In BoyWives and Female Husbands: Studies in African Homosexualities, edited by S. O. Murray and W. Roscoe, 115-28. New York: St. Martin's Press.

2009. Allah Made Us: Sexual Outlaws in an Islamic African City. Chichester: Wiley-Blackwell.

Gay, Judith. 1986. “'Mummies and Babies' and Friends and Lovers in Lesotho." In The Many Faces of Homosexuality: Anthropological Approaches to Homosexual Behaviour, edited by E. Blackwood, 97-116. New York: Harrington Park Press.

Geoffrion, Karine. 2012. "Ghanaian Youth and Festive Transvestism." Culture, Health \& Sexuality: An International Journal for Research, Intervention and Care 15 (sup.1): 48-61.

Gevisser, Mark, and Edwin Cameron. 1994. Defiant Desire: Gay and Lesbian Lives in South Africa. New York: Routledge.

Giddens, Anthony. 1993. The Transformation of Intimacy: Sexuality, Love and Eroticism in Modern Societies. Cambridge: Polity Press.

Gifford, Paul. 2004. Ghana's New Christianity: Pentecostalism in a Globalising African Economy. London: Hurst \& Company.

Gilbert, Michelle. 1993. "The Cimmerian Darkness of Intrigue: Queen Mothers, Christianity and Truth in Akuapem History." Journal of Religion in Africa 23 (1): 2-43. 
Gilroy, Paul. 1993. Black Atlantic: Modernity and Double Consciousness. Cambridge, MA: Harvard University Press.

Göpfert, Mirco and Andrea Noll. 2013. Disziplin und Kreativität an ghanaischen Internatsschulen. Frankfurt: Brandes \& Apsel.

Graham, C. K. 1976. The History of Education in Ghana. Tema: Ghana Publishing Corporation.

Greenberg, David F. 1988. The Construction of Homosexuality. Chicago: University of Chicago Press.

Green-Simms, Lindsey. 2012. "Occult Melodramas: Spectral Affect and West African Video-Film." Camera Obscura: Feminism, Culture, and Media Studies 80, 27 (2): 25-59.

Green-Simms, Lindsey, and Unoma Azuah. 2012. “The Video Closet: Nollywood's Gay Themed Movies.” Transition no. 107, 32-49.

Grotanelli, Vingi L. 1988. The Python Killer: Stories of Nzema Life. Chicago: University of Chicago Press.

Gqola, Pumla Dineo, ed. 2005. Agenda: Sexuality and Body Image. Special issue, 19 (63).

Gueboguo, Charles. 2006. La question homosexuelle en Afrique: Le cas du Cameroun. Paris: L'Harmattan.

Gunkel, Henriette. 2010. The Cultural Politics of Female Sexuality in South Africa. London: Routledge.

Gyamerah, Akua. 2015. "Print and digital news media discourses on samesex sexualities in Ghana." Unpublished article.

Gyekye, Kwame. 1995. An Essay on African Philosophical Thought: The Akan Conceptual Scheme. Philadelphia, PA: Temple University.

Halberstam, Judith/Jack. 1998. Female Masculinity. Durham, NC: Duke University Press.

2002. "An Introduction to Female Masculinity: Masculinity without Men." In The Masculinity Studies Reader, edited by R. Adams and D. Savran, 355-74. Oxford: Blackwell.

2005. In a Queer Time and Space: Transgender Bodies, Subcultural Lives. Sexual Cultures: New Directions from the Center for Lesbian and Gay Studies, edited by J. E. Muñoz and A. Pellegrini. New York: New York University Press.

2008. "Introduction to the Spanish Edition of Female Masculinity." In Masculinidad Feminina. Barcelona: egales editorial. (Unpublished English version.)

Hall, Stuart. 2004. “Das Spektakel des ‘Anderen'.” In Ideologie, Identität, Repräsentation. Ausgewählte Schriften 4, edited by J. Koivisto and A. Merkens, 108-66. Hamburg: Argument.

Halperin, David M. 1998. "Forgetting Foucault: Acts, Identities, and the History of Sexuality.” Representations no. 63: 93-120. 
2003. "The Normalization of Queer Theory." Journal of Homosexuality 45 (2): 339-43.

Hansen, Karen V. 1995. “No Kisses Is Like Youres’: An Erotic Friendship between Two African-American Women during the Mid-Nineteenth Century." Gender \& History 7: 153-82.

Haraway, Donna J. 1991. "Situated Knowledges: The Science Question in Feminism and the Privilege of Partial Perspective." In Simians, Cyborgs, and Women: The Reinvention of Nature, edited by D. J. Haraway, 183-202. New York: Routledge.

Harries, Patrick. 1990. "Symbols and Sexuality: Culture and Identity on the Early Witwatersrand Gold Mines.” Gender \& History 2: 318-36.

Harrington, Maxwell. 2005. “Adabraka: Ghana's Gay Neighbourhoood?” Dissertation, University of Ghana, Legon, Accra.

Hasty, Jennifer. 2005. The Press and Political Culture in Ghana. Bloomington: Indiana University Press.

Hayes, Jarrod. 2000. Queer Nations: Marginal Sexualities in the Maghreb. Chicago: University of Chicago Press.

Heinemann, Alisha M. B. 2019. "Gayatri Chakravorty Spivak and Adult Education - Rearranging Desires at Both Ends of the Spectrum." Postcolonial Directions in Education 8 (1): 36-60.

Herdt, Gilbert H., ed. 1984. Ritualized Homosexuality in Melanesia. Berkeley: University of California Press.

Héritier, Françoise. 2002. Two Sisters and Their Mother: The Anthropology of Incest. New York: Zone Books.

Herskovits, Melville J., and Frances S. Herskovits. 1936. Suriname FolkLore. New York: Columbia University Press.

Herskovits, Melville J. 1937. “A Note on 'Woman Marriage' in Dahomey.” Africa 10 (3): 335-41.

Hirsch, Jennifer S., and Holly Wardlow. 2006. Modern Loves: The Anthropology of Romantic Courtship and Companionate Marriage. Ann Arbor: University of Michigan Press.

Hoad, Neville. 2007. African Intimacies: Race, Homosexuality, and Globalization. Minneapolis: University of Minnesota Press.

Hodgson, Dorothy L., and Sheryl A. McCurdy. 2001. "'Wicked' Women and the Reconfiguration of Gender in Africa. Social History of Africa Series. Oxford: James Currey.

Hollibaugh, Amber and Cherrie Moraga. 1983. "What We're Rollin' Around in Bed With: Sexual Silences in Feminism." In Powers of Desire: The Politics of Sexuality, edited by A. Snitow, Ch. Stansell and Sh. Thompson, 395-405. New York: Monthly Review Press.

Hunter, Mark. 2010. Love in the Time of AIDS: Inequality, Gender, and Rights in South Africa. Bloomington: Indiana University Press. 
Illouz, Eva. 1997. Consuming the Romantic Utopia: Love and the Cultural Contradictions of Capitalism. Berkeley: University of California Press.

Jackson, Peter A. 2000. "An Explosion of Thai Identities: Global Queering and Re-Imagining Queer Theory." Culture, Health and Sexuality, 2(4): 405-24.

Janssen, Diederick F. 2002. Growing Up Sexually. Volume II: The Sexual Curriculum: The Manufacture and Performance of Pre-Adult Sexualities, Appendix III. Amsterdam: Interim Report.

Kahiu, Wanuri. 2018. Rafiki (drama film). Nairobi.

Karsch-Haack, Ferdinand. 1911. Das gleichgeschlechtliche Leben der Naturvölker. New York: Arno Press.

Kendall, Limakatso Kathryn. 1999. "Women in Lesotho and the (Western) Construction of Homophobia." In Female Desires: Transgender Practices across Cultures, edited by S. Wieringa and E. Blackwood, 157-81. New York: Columbia University Press.

Kennedy, Elizabeth Lapovsky and Madeline D. Davis. 1993. Boots of Leather, Slippers of Gold: The History of a Lesbian Community. New York: Routledge.

Khor, Lena. 2009. "Mama Benz and the Taste of Money." In On the Edges of Development: Cultural Interventions, edited by K.-K. Bhavnani, 167-87. New York: Routledge.

Kilson, Marion. 1974. African Urban Kinsmen: The Ga of Central Accra. London: C. Hurst and Company.

Kim, Lisa Sunghee. 2005. "One Foot In, One Foot Out: Gay, Lesbian, Bisexual Ghanaians Share Their Experiences.” Dissertation, University of Ghana, Legon.

Kirschke, Amy, and Helene Kirschke-Schwartz. 2013. “Questions-réponses: homosexualité, sida et pratiques culturelles au Ghana.” In Homosexualités en Afrique, edited by A. Crémieux 72-87. Paris: L'Harmattan.

Kisseado, Samuel V. A. 2002. Why Do We Marry and Who Is the Head of the Home? Accra: Asempa Publishers.

Konadu, Yaa, and Ronald Mensah. ca. 1970 (exact year unknown). The Young Woman and the Corridor of Life. Accra: Romans Publishing and Gospel Communications.

Kouassiaman, Caroline, and Mariam Armisen. 2012. Struggling Alone: The Lived Realities of Women Who Have Sex with Women in Burkina Faso, Ghana and Nigeria. Ouagadougou: Queer African Youth Network (QAYN).

Krige, Eileen Jensen. 1974. "Woman-Marriage, with Special Reference to the Lovedu - Its Significance for the Definition of Marriage." Africa no. 44: $11-37$. 
Kuate-Defo, Barthelemy. 2004. "Young People's Relationships with Sugar Daddies and Sugar Mummies: What Do We Know and What Do We Need to Know?" African Journal of Reproductive Health 8 (2): 13-37.

Kulick, Don. 1995. “The Sexual Life of Anthropologists: Erotic Subjectivity and Ethnographic Work." In Taboo: Sex, Identity and Erotic Subjectivity in Anthropological Fieldwork, edited by D. Kulick and M. Willson, 1-28. London: Routledge.

Kulick, Don, and Margaret Willson, eds. 1995. Taboo: Sex, Identity and Erotic Subjectivity in Anthropological Fieldwork. London: Routledge.

Kunzel, Regina G. 2002. "Situating Sex: Prison Sexual Culture in the Mid-Twentieth-Century." GLQ: A Journal of Lesbian and Gay Studies 8 (3): 253-70.

Lévi-Strauss, Claude. 1969. The Elementary Structures of Kinship. Boston: Beacon Press.

Lewin, Ellen, and William L. Leap, eds. 1996. Out in the Field: Reflection of Lesbian and Gay Anthropologists. Urbana: University of Illinois Press.

Lewin, Ellen, and William L. Leap. 2009. "Editors' Introduction.” In Out in Public: Reinventing Lesbian/Gay Anthropology in a Globalizing World, edited by E. Lewin and W. L. Leap, 1-24. Malden: WileyBlackwell.

Lorde, Audre. 1978. "Scratching the Surface: Some Notes on Barriers to Women and Loving." The Black Scholar 9 (7): 31-35.

1984. Sister Outsider: Essays and Speeches. Trumansburg: Crossing Press. 2007. Sister Outsider: Essays and Speeches. Trumansburg: Crossing Press, reprint of 1984 edition.

Lowy, Michael J. 1977. "Establishing Paternity and Demanding Child Support in a Ghanaian Town." In Law and the Family in Africa, edited by S. Roberts, 15-37. The Hague: Mouton.

Lorway, Robert. 2008. "Defiant Desire in Namibia: Female Sexual-Gender Transgression and the Making of Political Being." American Ethnologist 35 (1): 20-33.

Love, Heather. 2007. Feeling Backward: Loss and the Politics of Queer History. Cambridge, MA: Harvard University Press.

Lugones, Maria. 2007. "Heterosexualism and the Colonial/Modern Gender System.” Hypatia 22 (1): 186-209.

Macharia, Keguro. 2009. Unpublished Panel Abstract: Queer African Studies. New Orleans: African Studies Association.

2018. "On Being Area-Studied." GLQ: a Journal of Lesbian and Gay Studies 22 (2): 183-90.

Malinowski, Bronislaw. 1967. A Diary in the Strict Sense of the Word. New York: Harcourt, Brace \& World. 
Mama, Amina, Charmaine Pereira and Takyiwaa Manuh, eds. 2005. Feminist Africa: Sexual Cultures, no. 5. Cape Town: African Gender Institute.

Martin, Biddy. 1994. "Sexualities without Genders and Other Queer Utopias." Diacritics 2/3 (4): 104-21.

1996. Femininity Played Straight: The Significance of Being Lesbian. New York: Routledge.

Martin, Karen, and Makhosazana Xaba, eds. 2013. Queer Africa. Braamfontein: MaThoko's Books.

Masquelier, Adeline. 2009. "Lessons from Rubi: Love, Poverty, and the Educational Value of Televised Dramas in Niger." In Love in Africa, edited by J. Cole and L. M. Thomas, 204-28. Chicago: Chicago University Press.

Massad, Joseph. 2002. "Re-Orienting Desire: The Gay International and the Arab World.” Public Culture 14 (2): 361-85.

2007. Desiring Arabs. Chicago: University of Chicago Press.

Matebeni, Zethu. 2012. Black Lesbian Sexualities and Identity in South Africa: An Ethnography of Black Lesbian Urban Life. Saarbrücken: Lambert Academic Publishing.

ed. 2014. Reclaiming Afrikan. Queer Perspectives on Sexual and Gender Identities. Athlone: Modjaji Books.

Matebeni, Zethu and Thabo Msibi. 2015. "Vocabularies of the Non-Normative." Agenda (29) 1: 1-7.

Mauss, Marcel, Mary Douglas, and W. D. Halls. 2002. The Gift: The Form and Reason for Exchange in Archaic Societies. London: Routledge. Essai sur le don, first published in L'Année Sociologique in 1925; first English edition published 1954 by Cohen \& West; this translation first published by Routledge 1990.

Mbembe, Achille. 2001. On the Postcolony. Berkeley: University of California Press.

2010. Sortir de la Grande Nuit: Essai sur l'Afrique Décolonisée. Paris: Editions La Decouverte.

McCaskie, Tom C. 1981. "State and Society, Marriage and Adultery: Some Considerations towards a Social History of Pre-Colonial Asante." The Journal of African History 22 (4): 477-94.

McClintock, Ann. 1997. Imperial Leather: Race, Gender, and Sexuality in Colonial Context. New York: Routledge.

McFadden, Patricia. 2003. "Sexual Pleasure as Feminist Choice." Feminist Africa Changing Cultures (2).

McHardy, Cécile. 1968. "Love in Africa.” Présence Africaine no. 68: 52-60.

McKinley, Catherine E. 2011. Indigo: In Search of the Color that Seduced the World. New York: Bloomsbury. 
Meiu, Paul. 2009. “'Mombasa Morans': Embodiment, Sexual Morality, and Samburu Men in Kenya." Canadian Journal of African Studies 43 (1): $106-28$.

Menon, Nivedita. 2007. "Outing Heteronormativity: Nation, Citizen, Feminist Disruptions." In Sexualities: Issues in Contemporary Indian Feminism, edited by N. Menon, 3-49. New Delhi: Women Unlimited.

Mensah, Matthew. n.d. ca. 2005. Love in the Girl's Dormitory: 'Supi' Palava. Accra-New Town: Mensco.

Mensah, Ronald. n.d. earliest 1970. The Qualities of a Healthy Young Woman. Accra: Romans Publishing and Gospel Communications.

Mesquita, Sushila. 2011. Ban marriage! Ambivalenzen der Normalisierung aus queer-feministischer Perspektive. Vienna: Zaglossus.

Mesquita, Sushila, and Eveline Y. Nay. 2013. "We Are Family!? Eine queerfeministische Analyse affektiver und diskursiver Praxen in der Familienformenpolitik." In Keine Zeit für Utopien? Perspektiven der Lebensformenpolitik im Recht, edited by B. Bannwart, M. Cottier, C. Durrer, A. Kühler, Z. Küng and A. Vogler, 193-218. Zurich: Dike.

Mesquita, Sushila, and Patricia Purtschert. 2016. "Gay Governance: Challenges to Coalition Building against Homophobia in Postcolonial Switzerland." In Politics of Coalition: Thinking Collective Action with Judith Butler, edited by D. Gardey and C. Kraus. Zurich/Geneva: Editions Seismo.

Meyer, Birgit. 1999. Translating the Devil: Religion and Modernity among the Ewe in Ghana. Edited by J. D. Y. Peel, D. Parkin and C. Murray, International African Library. Edinburgh: Edinburgh University Press.

2003. "Visions of Blood, Sex and Money. Fantasy Spaces in Popular Ghanaian Cinema." Visual Anthropology 16 (1): 15-41.

Miescher, Stephan F. 2005. Making Men in Ghana. Bloomington: Indiana University Press.

2007. "Becoming an Opanyin: Elders, Gender, and Masculinities in Ghana since the Nineteenth Century." In Africa After Gender, edited by S. F. Miescher, C. M. Cole and T. Manuh, 253-69. Bloomington: Indiana University Press.

Miescher, Stephan F., Catherine M. Cole, and Takyiwaa Manuh. 2007 "Introduction: When Was Gender?" In Africa After Gender, edited by C. M. Cole, T. Manuh, and S. F. Miescher, 1-16. Bloomington: Indiana University Press.

Miescher, Stephan F., and Lisa A. Lindsay. 2003. "Introduction: Men and Masculinities in Modern African History." In Men and Masculinities in Modern Africa, edited by L. A. Lindsay and S. F. Miescher, 1-28. Portsmouth: Heinemann. 
Moodie, D., and V. Ndatshe. 1994. Going for Gold: Men, Mines, and Migration. Berkeley: University of California Press.

Mohammed, Azeenarh, Chitra Nagarajan, and Rafeeat Aliyu, eds. 2018. She Called Me Woman: Nigeria's Queer Women Speak. Abuja: Cassava Republic Press.

Moore, Mignon. 2006. "Lipstick or Timberlands? Meanings of Gender Presentation in Black, Lesbian-Headed Households." SIGNS: Journal of Women in Culture and Society 32 (1): 113-39.

2011. Invisible Families: Gay Identities, Relationships, and Motherhood among Black Women. Berkeley: University of California Press.

Morgan, Ruth, and Saskia E. Wieringa, eds. 2005. Tommy Boys, Lesbian Men and Ancestral Wives: Female Same-Sex Practices in Africa. Johannesburg: Jacana.

Muholi, Zanele. 2010. "Faces and Phases." Safundi: The Journal of South African and American Studies 11 (4): 407-20.

Muñoz, José Esteban. 1999. Disidentifications: Queers of Color and the Performance of Politics. Minneapolis: University of Minnesotta Press.

Murray, Stephen O. 1979. The Institutional Elaboration of a Quasi-Ethnic Community. International Review of Modern Sociology 9 (2): 165-77. 2000. Homosexualities. Chicago: University of Chicago Press.

Murray, Stephen O., and Will Roscoe, eds. 1998. Boy-Wives and Female Husbands: Studies in African Homosexualities. New York: St. Martin's Press.

Mutongi, Kenda. 2009. “'Dear Dolly's’ Advice: Representations of Youth, Courtship, and Sexualities in Africa." In Love in Africa, edited by J. Cole and L. M. Thomas, 83-108. Chicago: University of Chicago Press.

Mwachiro, Kevin. 2014. Invisible: Stories from Kenya's Queer Community. Nairobi: Goethe-Institut Kenya, Native Intelligence.

Nay, Yv E. 2017. Feeling Family: Affektive Paradoxien der Normalisierung von "Regenbogenfamilien.” Vienna: Zaglossus.

Ndashe, Sibongile. 2013. "The Single Story of 'African homophobia' Is Dangerous for LGBTI Activism." In Queer African Reader, edited by S. Ekine and H. Abbas, 155-64. Nairobi: Pambazuka Press.

Nestle, Joan. 1987. A Restricted Country. Ithaca: Firebrand Books.

ed. 1992. The Persistent Desire: A Femme-Butch Reader. Boston: Alyson.

Newton, Esther. 1993. "My Best Informant's Dress: The Erotic Equation in Fieldwork." Cultural Anthropology 8 (1): 3-23.

Nguyen, Vinh-Kim. 2010. The Republic of Therapy: Triage and Sovereignty in West Africa's Time of AIDS. Durham, NC: Duke University Press. 
Njambi, Wairimu Ngaruiya, and William E. O’Brien. 2000. "Revisiting "Woman-Woman Marriage"": Notes on Gikuyu Women." NWSA 12 (1): 1-23.

Nyamnjoh, Francis B. 2005. "Fishing in Troubled Waters: Disquettes and Thiofs in Dakar." Africa 75 (3): 295-324.

Nyarko, Philomena. 2012. 2010 Population \& Housing Census. Census report. Edited by G. S. Service. Accra: Ghana Statistical Service.

Nyanzi, Stella. 2013. "Rhetorical Analysis of President Jammeh's Threats to Behead Homosexuals in Gambia." In Sexual Diversity in Africa: Politics Theory, Citizenship, edited by S. N. Nyeck and M. Epprecht, 67-87. Montréal and Kingston: McGill-Queen's University Press.

Nyeck, S. N. 2013. "Mobilizing against the Invisible: Erotic Nationalism, Mass Media, and the 'Paranoid Style' in Cameroon." In Sexual Diversity in Africa: Politics, Theory, Citizenship, edited by S. N. Nyeck and M. Epprecht, 151-69. Montréal and Kingston: McGillQueen's University Press.

Nzegwu, Nkiru. 2005. "The Epistemological Challenge of Motherhood to Patriliny." JENda: A Journal of Culture and African Women Studies no. 5.

Obeng, Pashington. 2003. "Gendered Nationalism: Forms of Masculinity in Modern Asante of Ghana." In Men and Masculinities in Modern Africa, edited by S. F. Miescher and L. A. Lindsay, 192-209. Portsmouth: Heinemann.

Okparanta, Chinelo. 2013. Happiness, like Water. Boston: Houghton Mifflin Harcourt.

2015. Under the Udala Trees. Boston: Houghton Mifflin Harcourt.

O’Mara, Kathleen. 2007. "Homophobia and Building Queer Community in Urban Ghana." Phoebe: An Interdisciplinary Journal of Feminist Scholarship, Theory, and Aesthetics 19 (1): 35-46.

Osam, E. Kwaku, Charles Marfo, and Kofi Agyekum. 2013. “The Morphophonology of the Akan Reduplicated Verb-Form." Journal of Language and Linguistic Studies 9 (2): 45-56.

Osei, George M. 2009. Educational Reform in Post-Colonial Ghana: Teachers, Schools and Bureaucracy. New York: Nova Science Publishers.

Ottosson, Daniel. 2007. State-sponsored Homophobia: A world survey of laws prohibiting same sex activity between consenting adults. International Lesbian and Gay Association (ILGA) report. http://ilga .org/historic/Statehomophobia/State_sponsored_homophobia_ILG A_07.pdf, accessed September 9, 2019.

Otu, Kwame Edwin. 2018. "Listen: Anthropologist Kwame Edwin Otu on Normative Collusions and Amphibious Evasions.” www.swarthmore.edu 
/news-events/listen-anthropologist-kwame-edwin-otu-normative-collu sions-and-amphibious-evasions, accessed September 9, 2019.

Oyéwùmí, Oyèrónké. 1997. The Invention of Women: Making an African Sense of Western Gender Discourses. Minneapolis: University of Minnesota Press.

2004. "Conceptualising Gender: Eurocentric Foundations of Feminist Concepts and the Challenge of African Epistemologies." In African Gender Scholarship: Concepts, Methodologies, and Paradigms, edited by S. Arnfred, 1-8. Dakar: CODESRIA.

Perbi, Anyele, and Yaw Perbi. 2007. X-Sense: The "Sixth Sense" Missing from Today's Sex "Miseducation.” Accra: The HuD Group.

Pereira, Charmaine. 2003. "Where Angels Fear to Tread?” Some Thoughts on Patricia' McFadden's 'Sexual Pleasure as Feminist Choice'." Feminist Africa: Changing Cultures (2).

Pierce, Steven. 2007. "Identity, Performance, and Secrecy: Gendered Life and the 'Modern' in Northern Nigeria." Feminist Studies 33 (3): 539-65.

2008. "The Power of a Name: Talking about Same-Sex Intimacy in West Africa." Paper presented at the Annual Meeting of the African Studies Association (ASA), Chicago.

Pinechon, Bill Standford. 2000. "An Ethnography of Silences: Race, (Homo) Sexualities, and a Discourse of Africa.” African Studies Review 43 (3): 39-58.

Popoola, Olumide. 1999. "african princess.” In Talking Home: Heimat aus unserer eigenen Feder, Frauen of Color in Deutschland, edited by O. Popoola and B. Sezen. Amsterdam: Blue Moon Press.

2017. When We Speak of Nothing. Abuja: Cassava Republic Press.

Potgieter, Cheryl-Ann, ed. 2006. Agenda: Homosexuality. Special issue, 67. Puar, Jasbir K. 2007. Terrorist Assemblages: Homonationalism in Queer Times. Durham, NC: Duke University Press.

Purtschert, Patricia. 2006. Grenzfiguren: Kultur, Geschlecht und Subjekt bei Hegel und Nietzsche. Frankfurt: Campus.

Purtschert, Patricia, Barbara Lüthi, and Francesca Falk. 2012. Postkoloniale Schweiz: Formen und Folgen eines Kolonialisums obne Kolonien. Bielefeld: transcript.

2019. Kolonialität und Geschlecht im 20. Jahrhundert: Eine Geschichte der weissen Schweiz. Bielefeld: transcript.

Quartey, Kwei J. 2009. Wife of the Gods. New York: Random House.

Rao, Rahul. 2010. Third World Protest: Between Home and the Third World. Oxford: Oxford University Press.

Rattray, Robert S. 1929. Ashanti Law and Constitution. Oxford: Oxford University Press. 
Rehnstrom, Jeannette B. 2001. "Voices that Do Not Exist: The Relationship between Homosexuality and Religion in Ghana." Independent Study Project BA, Department of Study of Religions, SOAS, London.

Reid, Graeme. 2007. "How to Be a 'Real Gay': Emerging Gay Spaces in Small-town South Africa.” Ph.D. diss., University of Amsterdam.

Robertson, Claire, C. 1984. Sharing the Same Bowl: A Socioeconomic History of Women and Class in Accra, Ghana. Bloomington: Indiana University Press.

Rosenthal, Gabriele. 1993. Erlebte und erzählte Lebensgeschichte: Gestalt und Struktur bio-graphischer Selbstbeschreibungen. Frankfurt: Campus.

Rosenthal, Gabriele, and Wolfram Fischer-Rosenthal. 1997. "Warum Biographieanalyse und wie man sie macht. Why Biographical Analysis and how to Do It." ZSE no. 17.

Ruschak, Silvia. 2006. "Hosen mit Bedeutung: Weibliche Bekleidungsformen in Südghana im 20. Jahrhundert." Feministische Studien: Zeitschrift für interdisziplinäre Geschlechterforschung 24 (2): 303-13.

Sackey, Brigid M. 1998. "Asafo and Christianity: Conflicts and Prospects." Transactions of the Historical Society of Ghana New Series no. 2: 71-86.

2006. "The Vanishing Sexual Organ Phenomenon." In Sex and Gender in an Era of AIDS: Ghana at the Turn of the Millennium, edited by C. Oppong, M. Y. P. A. Oppong and I. K. Odotei, 287-302. Accra: SubSaharan Publishers.

Salo, Elaine, and Pumla Dineo Gqola, eds. 2006. Feminist Africa 6: Subaltern Sexualities. Special issue, 6: www.FeministAfrica.org.

Sarpong, Peter. 1971. The Sacred Stools of the Akan. Tema: Ghana Publishing Corporation.

1991. Girls' Nubility Rites in Ashanti. Ulm: Süddeutsche Verlagsgesellschaft. First published 1977. Tema: Ghana Publishing Corporation.

Schirmer, Uta. 2007. “Wollt ihr alle Männer sein?' Drag Kinging, geschlechtliche Verortungen und Strategien der 'disidentification'." Freiburger Geschlechterstudien 13 (21): 191-206.

Schneider, David. M. 1968. American Kinship: A Cultural Account. Englewood Cliffs: Prentice-Hall.

1984. A Critique of the Study of Kinship. Ann Arbor: University of Michigan Press.

Sedgwick, Kosofsky Eve. 1990. Epistemology of the Closet. 6th pr. ed. Berkeley: University of California Press.

Shipley, Jesse Weaver. 2009. "Comedians, Pastory, and the Miraculous Agency of Charisma in Ghana.” Cultural Anthropology 24 (3): 523-52. 
2013. Living the Hiplife: Celebrity and Entrepreneurship in Ghanaian Popular Music. Durham, NC: Duke University Press.

Shouse, E. 2005. "Feeling, Emotion, Affect." M/C Journal 8 (6). http://jour nal.media-culture.org.au/0512/03-shouse.php, accessed May 28, 2014.

Signorini, Italo. 1971. Agonwole agyale: Il matrimonio tra individui dello stesso sesso negli Nzema del ghana sud-occidentale. Rassegna italiana di sociologica no. 12, 539-45.

Sika, Varyanne, and Awino Okech. 2019. "African Sexual Politics: A PanAfrican Lesbian Perspective." In Sex Politics: Trends \& Tensions in the 21st Century - Volume 2, edited by Sonia Corrêa and Richard Parker. Rio de Janeiro: Sexuality Policy Watch.

Sill, Ulrike. 2007. "Encounters in Quest of Christian Womanhood. The Basel Mission in Pre- and Early Colonial Ghana.” Ph.D. diss., University of Basel.

Sinnott, Megan J. 2004. Toms and Dees: Transgender Identity and Female Same-Sex Relationships in Thailand. Honolulu: University of Hawai'i Press.

Smith Oboler, Regina. 1980. "Is the Female Husband a Man? Woman/Woman Marriage among the Nandi of Kenya." Ethnology 19 (1): 69-88.

Smith-Rosenberg, Carroll. 1975. "The Female World of Love and Ritual: Relations between Women in Nineteenth-Century America." SIGNS: Journal of Women in Culture and Society 1 (1): 1-29.

Søgaard, Mathias. 2013. Consequences of Imposing the Homo/Hetero Binary and the Prospect For Decriminalisation of MSM in Contemporary Ghana. MA thesis, University of Copenhagen.

Spittler, Gerd. 2001. "Teilnehmende Beobachtung als Dichte Teilnahme." Zeitschrift für Ethnologie 126 (1): 1-25.

Spivak, Gayatri Chakravorty. 1988. "Can the Subaltern Speak?" In Marxism and the Interpretation of Culture, edited by C. Nelson and L. Grossberg, 271-316. Chicago: Illinois University Press.

1990. The Post-Colonial Critic. Interviews, Strategies, Dialogues, edited by S. Harasym. New York: Routledge.

2012. "Scattered Speculations on the Subaltern and the Popular." In An Aesthetic Education in the Era of Globalization, edited by G. C. Spivak. Cambridge, MA: Harvard University Press.

Spradley, James P. 1979. The Ethnographic Interview. New York: Holt, Rinehart and Winston.

Spronk, Rachel. 2006. "Ambiguous Pleasures: Sexuality and New SelfDefinitions in Nairobi." Ph.D. diss., University of Amsterdam.

2018. "Invisible Desires in Ghana and Kenya: Same-Sex Erotic Experiences in Cross-Sex Oriented Lives." Sexualities 21 (5-6): 883-98. 
Stack, Carol B. 1974. All Our Kin: Strategies of Survival in a Black Community. New York: Harper \& Row Publishers.

Steegstra, Marijke. 2004. Resilient Rituals: Krobo Initiation and the Politics of Culture in Ghana. Münster: LIT.

2006. "A 'License to Indulge in Premarital Sexual Activities'? Dipo and the Image of Krobo Women." In Sex and Gender in an Era of AIDS: Ghana at the Turn of the Millennium, edited by C. Oppong, M. Y. P. A. Oppong and I. K. Odotei, 271-316. Accra: Sub-Saharan Publishers.

Stoler, Ann Laura. 1995. Race and the Education of Desire: Foucault's History of Sexuality and the Colonial Order of Things. Durham, NC: Duke University Press.

2002. "Foucault's 'Geschichte der Sexualität' und die koloniale Ordnung der Dinge." In Jenseits des Eurozentrismus: Postkoloniale Perspektiven in den Geschichts- und Kulturwisenschaften, edited by S. Conrad and S. Randeria, 313-34. Frankfurt: Campus.

Strathern, Marilyn. 1988. The Gender of the Gift: Problems with Women and Problems with Society in Melanesia. Berkeley: University of California Press.

1992. Reproducing the Future: Essays on Anthropology, Kinship and the New Reproductive Technologies. Manchester: Manchester University Press.

Tamale, Sylvia. 2003. "Out of the Closet: Unveiling Sexuality Discourses in Uganda." Feminist Africa: Changing Cultures (2). www .feministafrica.org/index.php/out-of-the-closet (unpaginated).

2011. Researching and Theorising Sexualities in Africa. In African Sexualities: A Reader, edited by S. Tamale, 11-36. Cape Town: Pambazuka Press.

2013. "The Politics of Sexual Diversity: An Afterword." In Sexual Diversity in Africa: Politics, Theory, Citizenship, edited by S. N. Nyeck and M. Epprecht, 225-28. Montréal and Kingston: McGillQueen's University Press.

ed. 2011. African Sexualities: A Reader. Cape Town: Pambazuka Press.

Tessmann, Günther. 1921. "Die Homosexualität bei den Negern Kameruns.” Jabrbuch für sexuelle Zwischenstufen 21: 121-38.

Tetteh, Merci Naa K. 2004. "A Sociological Study of Lesbianism in AccraTema Metropolis.” Dissertation, University of Ghana, Legon.

Tettey, Wisdom J. 2010. "Sexual Citizenship, Heteronormativity, and the Discourse of Homosexual Rights in Ghana." In The Public Sphere and the Politics of Survival: Voice, Sustainability and Public Policy in Ghana, edited by W. J. Tettey and K. P. Puplampu, 38-66. Accra: Woeli Publishing Services. 
Teunis, Niels. 1996. "Homosexuality in Dakar: Is the Bed the Heart of the Sexual Subculture?" Journal of Gay, Lesbian, and Bisexual Identity no. 1: 153-69.

Tietmeyer, Elisabeth. 1985. Frauen heiraten Frauen: Eine vergleichende Studie zur Gynaegamie in Afrika. Münster: LIT.

Tinsley, Omise'eke Natasha. 2008. "Black Atlantic, Queer Atlantic: Queer Imaginings of the Middle Passage." GLQ: A Journal of Lesbian and Gay Studies 14 (2-3): 191-215.

2010. Thiefing Sugar: Eroticism between Women in Caribbean Literature. Durham, NC: Duke University Press.

Tocco, Jack. 2008. "Watching Will and Grace in Niger: Negotiating Gay Discourse in Urban West Africa." Paper presented at the Annual Meeting of the African Studies Association, Chicago.

Tsikata, Dzodzi. 2009. "Women's Organizing in Ghana since the 1990s: From Individual Organizations to Three Coalitions." Development 52 (2): 185-92.

Van der Geest, Sjaak. 1998. "Participant Observation in Demographic Research: Fieldwork Experiences in a Ghanaian Community." In The Methods and Uses of Anthropological Demography, edited by A. M. Basu and P. Aaby, 39-56. Oxford: Clarendon Press.

2006. "It Is a Tiresome Work': Love and Sex in the Life of an Elderly Kwahu Woman." In Sex and Gendering in an Era of AIDS: Ghana at the Turn of the Millennium, edited by C. Oppong, M. Y. P. A. Oppong, and I. K. Odotei, 211-32. Accra: Sub-Saharan Publishers.

2012. "Kinship as Friendship: Brothers and Sisters in Kwahu, Ghana." In The Anthropology of Sibling Relations: Shared Parentage, Experience, and Exchange, edited by E. Alber, C. Coe and T. Thelen. London: Palgrave.

Vicinus, Martha. 1984. "Distance and Desire: English Boarding-School Friendships." SIGNS: Journal of Women in Culture and Society 9 (4): 600-22.

Wa Baile, Mohamed, Serena O. Dankwa, Tarek Naguib, Patricia Purtschert, and Sarah Schilliger, eds. 2019. Racial Profiling: Struktureller Rassismus und antirassistischer Widerstand. Bielefeld: transcript.

Wainaina, Binyavanga. 2014. "We Must Free Our Imaginations." www.you tube.com/channel/UC_TNgy8CzdmFdhfA5irWeIQ, YouTube, accessed July 13, 2020.

Warren, Dennis M. 1975. The Techiman-Bono of Ghana: An Ethnography of an Akan Society. Dubuque: KendaII/Hunt Publishing Co. 
Weeks, Jeffrey. 1977. Coming Out: Homosexual Politics in Britain from the Nineteenth Century to the Present. London: Quartet Books.

1984. "The Invention of Sexuality." In Sexuality, edited by J. Weeks, 19-44. London: Travistock.

Weiss, Margot. 2011. "The Epistemology of Ethnography." GLQ: A Journal of Lesbian and Gay Studies 17 (4): 650-64.

Wekker, Gloria. 2006. The Politics of Passion: Women's Sexual Culture in the Afro-Surinamese Diaspora. New York: Columbia University Press.

Westermarck, Edward. 1906-1908. The Origin and Development of the Moral Ideas. London, New York: Macmillan.

Weston, Kath. 1991. Families We Choose: Lesbians, Gays, Kinship. In the series Between Men - Between Women, edited by R. D. Mohr. New York: Columbia University Press.

1993. "Lesbian/Gay Studies in the House of Anthropology." Annual Review of Anthropology no. 22: 339-67.

White, Luise. 2000. Speaking with Vampires: Rumor and History in East and Colonial Africa, Studies on the History of Society and Culture. Berkeley: University of California Press.

Wieringa, Saskia. 2005. "Women Marriages and Other Same-Sex Practices: Historical Reflections on African Women's Same-Sex Relations." In Tommy Boys, Lesbian Men and Ancestral Wives: Female Same-Sex Practices in Africa, edited by R. Morgan and S. Wieringa, 281-307. Johannesburg: Jacana.

Wilson, Ara. 2004. The Intimate Economies of Bangkok: Tomboys, Tycoons, and Avon Ladies in the Global City. Berkeley: University of California Press.

Woodford-Berger, Prudence. 1997. “Associating Women: Female Linkages, Collective Identities, and Political Ideology in Ghana.” In Transforming Female Identities: Women's Organizational Forms in West Africa, edited by E. E. Rosander, 37-51. Uppsala: The Nordic Africa Institute.

Yahaya, Hanifatu. 2003. "The Reality of Homosexuality in Ghana: A Case Study of Homosexuality in Accra.” Dissertation, University of Ghana, Legon.

Yankah, Kwesi. 1983. “The Akan Trickster Cycle: Myth or Folktale.” Graduate Student Paper, African Studies Program, Indiana University. 1995. Speaking for the Chief: Okyeame and the Politics of Akan Royal Oratory. Bloomington: Indiana University Press.

Yarrow, Thomas. 2011. Development Beyond Politics: Aid, Activism and NGOs in Ghana. Basingstoke: Palgrave Macmillan. 
Zelizer, Viviana A. Rotman. 2005. The Purchase of Intimacy. Princeton, NJ: Princeton University Press.

Znoj, Heinzpeter. 1995. Tausch und Geld in Zentralsumatra: Zur Kritik des Schuldbegriffs in der Wirtschaftsethnologie. Berner SumatraForschungen, edited by M. Wolfgang. Berlin: Reimer. 


\section{Index}

Aba Adama (pseudonym), 18

Abotsi, Ernest Kofi, 65-66

abstinence, 56

Abu-Lughod, Lila, 7

abusive dynamics

age difference and, 217

concealment of, 173

emotional, 188

feeling “used," 199, 202

jealousy and, 203

kinship terminology and, 268

sex workers and, 199

abusua (family, matrilineal family), 85, 129, 136, 141, 169, 227

Accra Central, 190

Accra Girls Senior Secondary School, 192

Accra, Ghana, 14-17, 174

activism. see LGBT (lesbian, gay, bisexual, and transgender) activist politics

activist-ing, 76

Adizah (Adi) Cortey (pseudonym), 174, 184-89, 199, 215

Adjabeng, Joshua, 84

Teenage Sex and Love, 79

Adomako Ampofo, Akosua, 66, 172, 199

Adwoa Boateng (pseudonym), 80, 84, 97-106, 119, 154, 161-68, 169-70, 172, 176, 213, 220-22, 225-26, 228-40, 250, 263

affect, 107, 117, 119, 271

affect theory, 275

African bodies, as sexualized and racialized Others, 28-32, 277

African migrants, 277

African Women's World Cup, 178

African-American English, 273

African-American hip-hop artists, 143
African-American women, 42, 119, 144,259

Afro-Surinamese Creole, 273

Agbenozan, Josephine Enyonam, 9, 10-11, 16, 63, 109, 152, 165, 185, 186,213

age. see also erotic age, social age as relational category, $128,176-78$ gender and, 45, 129-31, 271

seniority and, 151, see also seniority status and, 147

age gaps in relationships, 40, 172-75, 187-89, see also senior-junior hierarchies, sugar motherhood anthropological terms for, 176-78 sibling terminology and, 226 agency, 155, 204, 206, 222, 264, 273 Agenda, 24

agonwsle agyale (friendship marriage), 39-41

agonwolcyele kpale ("good" friendship), 39

Ahinful, Kwamena, 93

Ahmed, Sara, 10, 117

Aisha (pseudonym), 18, 267

Akagbor, Sena, 241

Akan ethno-linguistic group, 15, 52 anthropological studies of, 32-34 female beauty ideal, 131 matrilineality, 85, 129-31, 141, 169, $176,228,245$

narrative traditions, 11-12

social and political organization, 224

Akan language

gender and, 40

indirection and, 52-53

terms for same-sex practices, 71

akomofor (diveners), 144

Akwetey-Kanyi, Ashiagbar, 94

Akyeampong, Emmanuel K., 86, 235 
Allen, Jafari, 22, 150

Allman, Jean, 141

allusion, 73, 122, see also indirection, verbal discretion, speech norms

Amadiume, Ifi, 31, 127

Male Daughters, Female Husbands, 128-29

ambiguity, 53, 220

in ethnographic research, 8-11

siblinghood and, 241

Ameley Norkor (pseudonym), 57, 72-73, 109-10, 154-58, 169-71, 238

Amoah, Elizabeth, 130

Anarfi, Mrs. (pseudonym), 201-7, 214

anti-gay discourse, 6, 24, 47-49, 61-63, see also homophobic discourse

law and, 63-68

nature and nurture debates, 66-68

anti-imperialism, 42, 62

Appiah, Kwame Anthony, 53-54, 67-68

Arnfred, Signe, Re-thinking Sexualities in Africa, 51

arrival stories, $2-3,12$

Asafo companies, 80, 95-97, 120

Asante, 53

incest bans, 242

king-queen terminology, 163

speech norms, 133

Asantewa, 146

asexual relationships, 263

atwebenefie, 243-44

autonomy. see also economic

independence

erotic, 142,151

financial, 139, 161

of market women, 181

sugar motherhood and, 189, 209

urban women and, 146

baa banyin, 132, see also sbaa barima (manly/brave woman)

Badu, Mr. (pseudonym), 59-60, 67

Banks, William, 71

barima (man, manly), 131

barrenness. see infertility

bars. see drinking spots

Bartels, Kwamena, 49-50, 53
Basel Mission, 2, 4, 40-41

bathhouse intimacies, 101, 106, 107-11

privacy and, 108

sharing substance and, 234, 263-64

sisters and, 228

Baule language, 52

Bayo, Adjoa, 179

Becky McCarthy (pseudonym), 208, 244

Berlant, Lauren, 21

Beyoncé, 95

"big men," 131, 161, 216, 257

“big women," 131, 146, 162, 216

discretion and, 199

Mami Wata and, 191, 198

sexualized rumors of selfishness, 174 small girls and, 178

binary gender roles, $271-72$, see also gender

bi-national families, 2-3

biological determinism, 128

biological kinship, 223

birth order, 112, 225, see also siblinghood

bisexuals, 74

black Atlantic world, 143

queer relationships and, 38, 120, 273-74

black feminism, 144

black lesbians, 119, 144, 166

black masculinity, 143

Black Queens (national football team), 134, 179

Blacking, John, 88-89, 113

blackmail, 212

Blackwood, Evelyn, 25, 136-37, 169

Bleek, Wolf, 130, 138

blood, 235-36, 243, 249, 269-70

kinship and, 228-29

blood friendship, 198, 270

boarding schools

as homosocial bonding space, 270

Asafo companies and, 97

comparisons of, 86-91

dormitory "partner" setup, 90

in Victorian England, 87, 98

kinship terminology, 87-91, 113, 121

lack of privacy at, 116 
mother-child terms used in, 80 pre-marital pregnancies and, 40 reports, 4 senior-junior hierarchies, 111-16, 120-21, 173 supi girlfriendships, 80, 81-91, see also supi girlfriendships supi-supi lesbianism, 91-94

Bochow, Astrid, 56

bodily fluids. see sexual fluids, blood body ideals, 146

Boellstorff, Tom, 252

Bourdieu, Pierre, 112

bragoro nubility rites, $113-15$

break-ups and heartbreaks, 179, 208, 211-13, 233, 244, 246, 257

breasts, 100, 201

holding of, 231

"British Accra," 190

British colonial administration, 81 , see also colonialism educational system, 87, 122 laws, 41

British Common Law, 64

British Council, 68

British sodomy laws, 77

Brubaker, Roger, 150

Burton, Richard, 28

butch-femme discourse. see also masculine gender presentation clothing and, 144 emotional butchness, 207 erotic subjectivities and, 149 , 152-54, 166-67, 168-71, 207 female footballers and, 132 gender and, 125-27, 271-72 giving and receiving, 211

Butler, Judith, 126, 127, 148, 153, 241

\section{Cameroon, 27, 77}

Cape Coast, 81-82, 95, 97

caring, 239-41

cars, gender and, 134-37

Carsten, Janet, 223, 228-29, 235-36, 265

Cultures of Relatedness, 41

Castle School, 83

Castro Varela, María do Mar, 23

casual relationships, 210-12
Catholic boarding schools, 192, see also boarding schools

Catholics, 58

Central Market Kumasi, 16

charismatic Christianity, 48, 54-58, 278-79, see also Christianity

anti-gay initiatives, 68

condemnation of homosexuality, 50

sexualization of public sphere and, 77

Chauncey, George, 67

childhood. see also motherhood, youth gender and, 134-37

chop bars, 193-94

chop money, 104, 158, 181, 195, 200, 207

chosen families, 253-54, 265

Christensen, James, 132-33

Christian educational booklets, 204

Christian women's groups, 270

Christianity, 278, see also Pentecostalism, charismatic Christianity

discourse on homosexuality, 66-67, 77

fatherhood and, 141

CitiFM (radio station), 65

Clark, Gracia, 11, 16, 130, 131-33, 139, 141, 178, 194

Clarkson, Kelly, 95

Clifford, James, 7

closeness, 268

ambiguous, 226-28

forms of address and, 222

status and, 234

closet metaphor, 38-39

clothing, 144-45, 162, 275

Coalition of African Lesbians (CAL), 276

Cole, Jennifer, 121

Coleman, Khadija (pseudonym), 5

collectivization of love, 174-75, 216-19

colonial records, 4

colonial violence, 44

colonialism, 181, see also British colonial administration

homosexual theories and, 77

imperialist "rescue narratives," 35

sexual relationships and, 33

colonizing keyhole gaze

male same-sex relationships, 28 
colonizing keyhole gaze (cont.) sexualized and racialized African bodies, 28-32

women marriages, 30-32

Comfort Otu (pseudonym), 103

coming out, 15, 68

feelings and, 117-19

men and, 77

metropolitan emphasis on, 37-38, 44

community-based organizations, 14, 61

companionate marriage, 121, 139, 237, 271

Confederation of African Football, 178 conflicts, 231-33, see also jealousies, fights (between lovers)

confusion, 117-18

conjugal households, 169, 192, 194, 208

duo-local, 268

conjugal intimacy, 230

connectedness, 267

Connie Ofosu (pseudonym), 233-34

consensual relationships, 188

consumerism, 188, 237, 240

Convention People's Party (CPP), 51

cooking, 194-95

cornrows, 143

cousins, 46, see also parallel-cousins, cross-cousin marriage

fear of incest and, 222, 265

incest and, 241-42

terminology for, 222

Crenshaw, Kimberlé, 36

Criminal Code (1960), sodomy law, 64-68

cross-cousin marriage, 242, 244, 247

culture, discourse on homosexuality and, 62

customary court cases, 4-5

customary marriage, 138, 237

Cvetkovich, Ann, 153, 166, 171

Dakar, 188

Dankwa, E. Akurang, 82

darling bonds, 89

Dearham, Kaitlin, 76

decolonization, 279

Dede Kpobi (pseudonym), 139, 163

dees, 271
Defiant Desire (Gevisser and Cameron), 25

democratization, 59, 76

denial, 106, 193

desire, 20-23

desire for knowledge, 9, 10

deviance, 10

Dhawan, Nikita, 23

Dina Yiborku (pseudonym), 164, 166,

174, 184, 208-15, 216, 232, 235

discretion. see verbal discretion

disgrace, 117-18

“doing everything together," 213, 269

erotic intimacies, 220-21

sharing and, 261-64

siblinghood and, 229-41, 265-66

Dokua Hewlett (pseudonym), 92

domestic helpers, 173, 193-95, 202-3

dramas, 18

dreadlocks, 143-44

drinking spots, 5, 186

masculinity and, 124

Ebron, Paulla, 145, 169

economic independence, 156-68, 231, 245 , see also autonomy

Economic Recovery Program, 172

economic support, 245

Edna (pseudonym), 18, 267

Efua Aikins (pseudonym), 107-19

egalitarian relationships, 34-35, 176-77, 200, 213, 218, 271

eggs, symbolism of, 239-40

elite women, 4

emotional butchness, 207

emotional intimacy, 160

emotions, 106-20

employment, 193-94, 229-30, 260

enjoyment. see pleasure

erotic

as power, 21-22, 150

in ethnographic research, 8-11

erotic age. see also age

gender and, 155

seniority and, 157-58, 170

erotic capital, 187

erotic hierarchies, 203, see also

hierarchies

erotic intimacies, 42

erotic subjectivity, 21 
adulthood and, 250

gender and, 147-54

Esther Gyamerah (pseudonym), 164, 259-64

ethical questions, 6

ethnocartographies, 34

ethnographic fieldwork locations, 14-17

ethnopornographic gaze, 29, see also colonizing keyhole gaze

Europe. see also global North

civilizing mission, 28, 87, 121

racialized exclusions, 277

Evans-Pritchard, Edward, 30

Ewe, 53

ex-gay Christians, 67

exploitation, 45, 203

extended family model, 254-58

extra-large beds, 32-33

Faderman, Lillian, 43

family ties

importance of, 138

marriage and, 169

situational, 254-58

Fante, 53, 71, 191

Asafo and, 95

gender and, 132-33

Fante-Asante wars, 95

fathers

authority of, 136

disapproval of same-sex desire, 102, 105, 106

Felicia Clottey (pseudonym), 254-58

female agency, 22-23

female egalitarianism, 34-35

female elderhood, 129, 131, 157-58, 170

female footballers, 16, 260-61, 270

casual relationships and, 210

friendships among, 19, 118-20

masculine gender expression, 132, 134-36, 152, 179

police interventions and, 63-64

senior-junior hierarchies in, 90, 181

sugar mummies and, 4, 16, 45, 174, 179-81

female masculinity, 125-27, 146, 168, see also masculine gender presentation female traders, 16, 230, 234, 247, see also market women

helpers and, 178

supi, 81

femininity

age and, 177, 218

autonomous, 126

butch-femme theory and, 153, 272

motherhood and, 130, 175

passivity and, 153

Feminist Africa, 24

feminist anthropology, 7, 30-32

feminist fiction writers, 27

femme. see butch-femme discourse

fertility, 40-41, see also motherhood

fictive kinship, 221, 228, see also kinship terminology

fights (between lovers), 231-33, 236, 237

visibility and, 261

fluids

bathwater, 21, 112, 228, 234-35, 263, 265

bodily, 235-36, 243, 249, 269-70

sexual, 235, 243, 249, 265

football, 178-79, see also female footballers

Fortes, Meyer, 101, 112, 175-76, 226, 228

Kinship and the Social Order, 224-25

Foucault, Michel, 110, 150

"ars erotica," 122

friendship as a way of life, 42

History of Sexuality, 33

repressive hypothesis, 56

repressive thesis, 77

France, 77

free marriage, 138

Freundin (German), 273

friendship, 18-20, see also networks as a way of life, 42

as ambiguous term, 12, 264, 273

distinction between kinship and, 222, 223

erotic intimacies and, 3, 21

exchange of gifts and, 156-57

in nineteenth-century Britain and

North America, 42-43

language of, 34 
friendship (cont.)

love and, 103-6, 237-39

love triangles and, 208-16

same-sex desire and, 116-22

subversive potential of, 42-43

use of term, 267

friendship marriage (agonwsle agyale), 39-41

Fulani, 248, 249

funding, international, 14, 69, 70, 74, $76,78,276$

funerals, 13, 85-86, 255, 257

Ga ethno-linguistic group, 71, 169, 191-92, 194, 249

matrifocality, 176, 223

patrilineality, 176, 245, 247-48

same-sex desires and, 94, 133

Ga language, 10, 53

Ga-Dangme ethno-linguistic group, 15, 53

Gambia, 27

Gandhi, Leela, Affective Communities, 42

Gaudio, Rudolf, 34-35

Allah Made Us, 22

gay and lesbian (sub)cultures emergence of, 20

Gay and Lesbian Association of Ghana (GALAG), 49, 70-71

gay bars, 187, see also drinking spots

gay kinship, 252-53, see also queer kinship

Gay, Judith, 30, 88

gay, use of term, 76

gay/lesbian anthropology, 33

"gayism," 48, 50

gender

age and, 129-31, 177-78, 271

as relational category, 45, 154-60, 168-71

colonial violence and, 44

flexibility of, 131-33

incest and, 242

performativity of, 171

power relations and, 37

situational, 127-29

gender expression, $143-47$, see also masculine gender presentation

gender roles binary, 271-72

homosexuality and, 34, 67, 147

transferability of, 40

gender studies, 36-37

gender-neutral pronouns, 40, 128-29, 164

genealogical kinship, 223, 228, 252

Germany, Ghanaian migrants in, 17

Ghallywood (Ghanaian cinema), 27, $94,120,183$

Ghana

economic growth, 61

educational system, 86-87

postcolonial precariousness in, 21

research on same-sex intimacy in, 26-27

urban same-sex subcultures, 61

Ghana News Agency, 49

Ghana Telecom, 178-79

Ghanaian English, 93, 107, 201

Ghanaian highlife music, 236, 238

Ghanaian languages. see also Ga

language, Akan language,

Twi language, speech norms

reduplication in, 93

Giddens, Anthony, 217

gift economy, 218

gift exchanges, 39, 260, 267, see also sharing, materiality of love, sugar motherhood

between boarding school girls, 173, 266, 272, see also supi girlfriendships

caring and, 239-41

erotic intimacies and, 44

gift theory, 81, 98, 100, 120, 215

Gifty (pseudonym), 168

Gikuyu women marriages, 31

girlfriend, 273

girlfriend, use of term, 271

girlfriendships

at secondary schools, 80 , see also supi girlfriendships

pregnancy and, 104

use of term, 80

givers and receivers, 208-16

Gladys Agyeman (pseudonym), 211-13, 216, 232

global North

female egalitarianism and, 34 
queer studies, 38

same-sex marriage rights, 41

go-betweens, 208

gossip, 18-19, 133, see also visibility of same-sex desiring women

among female relatives, 226-28

consequences of, 58

denial and, 193

love triangles and, 215

media attention and, 102-3

police interventions and, 196

social networks and, 174

supi, 251

Grace Tagoe (pseudonym), 238, 245-46

Greece, ancient, 177

Greenberg, David, 32-34

Green-Simms, Lindsey, 94

Grotanelli, Vingi L., 39-40

Gunkel, Henriette, 88

Gyamerah, Akua, 62

Gyekye, Kwame, 117, 132

hairstyles, 57, 143-44, 161, 164

Halberstam, Jack, Female Masculinity, 125,126

half-caste, 9, 17, 50

Halperin, David M., 150

Hamda Ibrahima (pseudonym), 246-52

Hanses, Karen, 42

Hasty, Jennifer, 13

Hausa, 52, 273

heartbreaks. see break-ups and heartbreaks

Helena Asamoah (pseudonym), 243-46

Héritier, Françoise, 242-43, 249, 251-52

Herskovits, Frances, 205

Herskovits, Melville, 30-31, 128, 205, 219

heteronormativity, 36, 58

heterosexual matrix, 126

hierarchies. see also erotic hierarchies, senior-junior hierarchies

gift exchange and, 98

in friendships, 268

in giving and receiving, 174

in sibling relations, $224-26$

social, 191

Hirschfeld, Magnus, 29
HIV/AIDS programs, 49

MSM peer educators, 16, 60, 69, 197

queer globalization and, 60-61

sexualization of African bodies and, 29

WSW peer educators, 69

HIV/AIDS risk, 189

homo/heterosexual binarism, 30, 31, $38,76,125$

"homoconference" debate, 44, 47-51, $58-60,76,278$

homonormativity, 253, 276

homophobia, 199

Euro-American discourse on, 48

imperialist "rescue narratives" and, 36

in Africa, 47-49, 77, 276-77

internalized, 118

homophobic discourse, 20, 25, 76, 200, 204-5, see also anti-gay discourse countering, 71

incest and, 243, 251

homophobic exclusions, 103

"homosexualism," 47, 204

homosexuality. see also same-sex desiring women

age-differentiation and, 176-78

as concept in precolonial Ghana, 53

as modern and Euro-American, 47

concept of, 20-21

in Sub-Saharan Africa, 24-27

non-natural world and, 102-3

revolutionary potential of, 42

situational, 73

taboo on public discourse about, 3

"unafricanness" of, 80

homosocial spaces, 85-86, 270

in precolonial Ghana, 39

in USA, 87

male, 177

puberty rites, $113-15$

human rights, 14, 65, 68-69, 277

Hunter, Mark, 195-96, 217

husbands. see also marriage

shared housing and, 254-58

"husband-wife game," 88

"hustling” women, 162-68, 170, 273, 275, 279, see also "tricksters";

tricksters

hypersexuality, 51 
I will not eat stone (Allman and Tashjian), 22

identity, 20, 77, 150, 274, see also sexual identity, self-identity

resistance to labels, 277

identity politics, 39

Igbo

motherhood paradigm, 175

woman marriages, 31, 128-29

Illouz, Eva, 237

immoral practices, 51

imperialist "rescue narratives," 35, 36, see also colonialism

incest, 46

fears of, 222, 265-66

gender and, 242, 244

incest bans, 241-43

social networks and, 251

India, 73, 228

indirection, 51-54, 270, see also verbal discretion, speech norms

charismatic movement and, 55

culture of, 48

gossip and, 133

identities and, 78

labels and, 73

police interventions and, 64

research methodology and, 6, 8-11, 15

supi and, 122

Indonesia, 136-37, 169, 271

infertility, 134, 183

initiation, 29, 39, 81, 97, 112, 121, 177

Krobo, 231

Ma'Abena, 111

International Monetary Fund (IMF), 55,172

intersectionality, 36

intimacy, 21, see also same-sex desiring women

as socializing process, 46

conjugal, 230

emotional, 160

Irene Bonsu (pseudonym), 82

Islamic groups, 54

Ivory Coast, 52

Janet Aidoo (pseudonym), 8-9, 14, 123-25, 134-54, 169-71, 207, 274 jealousies, 18, 179, 200, 205-6, 218

abusive dynamics, 203

between siblings, 227, 236

love triangles, 198, 218, 240, see also love triangles

witchcraft accusations, 57, 240

Jezebel (2007), 94

Johnson, Graft, 96

Joy FM (radio station), 49, 60

Junior Secondary School (JSS), 86, 246

Karsch-Haack, Ferdinand, 29

kawa, 273

Kenya, 24

Kilson, Marion, 247-48

king-queen terminology, 161-68

kinship. see also queer kinship, motherhood, siblinghood

gender roles and, 40

Ghanaian principles, 46

in Africa, 41

in global North, 41

normative ideas of, 222

social construction of, 223

kinship terminology, 34, 212, 255, 267-68

kinship theories

on substance, 228-29

"knowing women," 74, 81, 120-22

"doing everything together," 220, 230

masculinity and, 127

meaning of term, 274

knowledge production, 279

research methodology and, 8

kodjo besia (feminine man), 6, 71

Korkoi Okudzeto (pseudonym), 220-21, 226, 229-39, 263

Krobo Girls School, 83

Krobo girls' initiation rites, 231

Kufuor, John, 59

Kulick, Don, 9

kunya (shame or modesty), 52

Kunzel, Regina, 150

Kwaku Ananse (trickster figure), 162

labels. see sexual identity

Langkawi (Malaysia), 228-29

language, 34, see also indirection, verbal discretion, speech norms 
gendered, 45, see also gender-neutral pronouns

in female friendship networks, 44

performativity of, 52

Latasha Ray (pseudonym), 75

law

discourse on homosexuality and, 48

on sexual practices, 63-68

"lesbian bed death," 263

lesbian groups, 3

lesbian invisibility, 72

lesbian visual language, 148

lesbian, use of term, 24, 43, 73-75, 76, $147,198,274$

lesbian/gay studies, 36

lesbian-feminist historians, 42, 125-26

lesbianism. see also same-sex desiring women

as identity, 14-15, 163

as invisible, 47

laws on, 65

Lesotho, 30, 88, 273

Lévi-Strauss, Claude, 251

LGBT (lesbian, gay, bisexual, and transgender) activist politics, 20, see also sexual rights politics

chosen families and, 253

cultural imperialism of, 68

family arrangements and, 257

gender and sexual categorization, 151, 274

global, 48

HIV/AIDS initiatives and, 27

in Accra, 14

in Africa, 276-77

international, 38, 44, 72, 74

male-dominated, 27

names and naming, 71-76

women's voices in, 44, 68-71, 76-78

LGBTIQA+, use of term, 37

life history genre, 11-14

lifestyles ("liking life"), 143-47

Lithur, Nana Oye, 66

Lorde, Audre, 21-22, 31, 150

love, 236-40

affective work of, 271

as mode of sociality, 216-19, 267

declarations of, 154, 159-60

siblinghood and, 239-41

working for, 207
Love in the Girl's Dormitory: 'Supi'

Palava (2005), 95

love letters, writing of, 87, 89, 121

love triangles, 174, 186-87, 189-200

banning of, 243

friends and, 208, 215, 267

in same-sex bonding networks, 265

incest and, 249

jealousies in, 198, 218, 240, see also jealousies

shared housing and, 254-58

supi, 272

Love, Heather, 117

Feeling Backward, 117

"loveless Africa," 47, 196, 267

lover's marriage, 138

lovership, 233, 236-37, 268

Lydia Sackey (pseudonym), 144, 152, 174, 183, 185-200, 208, 215, 216, 217

Ma'Abena Oppong (pseudonym), 80, 90-91, 106-19, 154, 164, 259-64, 278-79

Maa'Evelyn (pseudonym), 167, 172-73, 176, 203, 218

Macharia, Keguro, 277

Mahmood (pseudonym), 67

Makola Market, 182, 192

Malaysia, 228

male same-sex intimacies. see also Men who have Sex with Men (MSM)

colonizing keyhole gaze and, 28

in Nigeria, 61

masculinity and, 71

patriarchal bonding and, 35

political focus on, 50

research on, 22, 24-25, 27

sugar daddies and, 185, 187

Malinowski, Bronislaw, Diary, 9

“Mama Benz," 178

Mami Wata, 57, 94, 120, 183, 216

Marcus, George E., 7

market literature, 94-95

market women. see also female traders as sugar mummies, 4, 45, 174, $181-83$

gender and, 131

military attacks on, 54, 182 
market women (cont.) sexualized rumors of greediness,

181-83, 216

supi and, 122

marriage. see also same-sex marriage

autonomy and, 214

cooking in, 194-95

heteronormative script on, 15

in working-class context, 1

monogamous, 55, 58

motherhood and, 138-43

Martin, Biddy, 43, 153

Marxist scholars, 20

Mary Awoonor (pseudonym), 235

masculine gender presentation, 16, 158, $170,214,254,258$, see also female masculinity

masculinity, 45

activity and, 153

in women, 16, 123-27, 133-71, 201-2, 203-4

relational, 169-71

Massad, Joseph, 38

masturbation, 41

matchmakers, 208

material circumstances, 13, 16-17, 257, see also poverty

materiality of love, 45, 172-75, 195, 268-69, see also sharing, gift exchanges

collectivized, 216-19

sugar motherhood and, 184-208

maternal support, 269

matrilineality, 169

Akan, 85, 129-31, 141, 169, 176, 228,245

authority of relatives, 136

Mauss, Marcel, 98, 100, 215

Mavis Marfo (pseudonym), 100

Mbembe, Achille, 25, 275

McKinley, Catherine, 96

media

discourses on homosexuality, 48, $58-63,102$

liberalization, 55, 59, 76

state-owned, 59

Melanesia, 177

men. see also husbands, "big men"; sugar daddies

cis-gendered, 125, 134 fear of female closeness, 227

Men who have Sex with Men (MSM), 16,49 , see also male same-sex intimacies

HIV/AIDS programs, 60, 69, 197

Menon, Nivedita, 73

Mensah, Ronald, 92

menstrual blood, 235

metaphorical kinship, 223

Meyer, Birgit, 57

Meyerowitz, Eva, 33

mi mati, 273

Middle Passage, 38, see also black Atlantic world

middle-class aspirations, 146, see also upward mobility

Miescher, Stephan, 131

mission churches, 54, 58

mission reports, 4

mixed ethnic background, 191, 245

mixed parentage, 7, 244

mixed-race, 2, 7

mockery, 62

modernity, 47, 121, 275-76

mogya (blood/line), 140

Monica Ankrah (pseudonym), 213-15

monogamy, 213, 215, 219, 222

Moore, Mignon, 119, 144

moral corruption, 188, 204

moral decay, 50, 61

motherhood, 130, 169, see also pregnancy, motherhood paradigm, sugar motherhood

as metaphor for intimate relationships, 45-46

barrenness and, 134

gender and, 147

marital sex and, 207

marriage and, 138-43, 211

mother-daughter relations, 88-91, 175

same-sex relationships and, 200

motherhood paradigm, 173, 175-76, 216

motsoalle, 273

mpena (lover)

mpena awadec (lover's marriage), 138

mpena twee (lovership), 236-37, 268

Murray, Stephen O., 34, 177, 218, 253 
Muslim religious authorities, 77 my girl, 273

Naa (pseudonym), 18, 267

names and naming, 71-76, see also sexual identity

Nana Mansa (pseudonym), 6

National Archives of Ghana, 4

National Coalition for Proper Human Sexual Rights and Family Values, 68

National Democratic Congress (NDC), 50

"natural law of compensation," 212

nature, 64-68

non-natural world and, 102-3

neoliberalism, 60-61

Nestle, Joan, 126

Netherlands, 85

networks. see also queer family networks, personal kindreds, networks of

collectivized love and, 218-19

friendship marriage and, 40

of female friends, 19-20, 174-75, $216,267,271$

of same-sex desiring women, 19

New Patriotic Party (NPP), 51

newspapers, 59

Nguyen, Vinh-Kim, The Republic of Therapy, 69

Niger, 61

Nigeria, 22, 27, 35, 52, 273, see also Nollywood (Nigerian cinema) criminal code, 65 gender in, 128, 168 male same-sex subcultures in, 61 repatriation from, 55

Nkrumah, Kwame, 54, 59

Noll, Andrea, 89

Nollywood (Nigerian cinema), 26, 94, 97, 120, 183

non-normative practices, research on, 6

North America. see also United States (USA)

boarding school crushes, 80

North Atlantic queers, 117

ntoro (spiritual aspect of paternity), 140-41

nubility rites bragoro nubility rites, 113-15

nuclear family ideal, 41, 56, 58, 71, $121,128,130,254,264,271$

Nuer women marriages, 30

nurture argument, 67-68

Nyamnjoh, Francis, 188

Nzema friendship marriage, 39-40

sbaa (woman), 131

sbaa barima (manly/brave woman), 45, 131-33, 168-71, 271

sbaapanyin, 82

sbaatan (nursing mother), 96

sbarima (man, valiant man), 131

occult forces, 57,102

occult same-sex bonding practices, 198

occult sexual crimes, 64

occupational work, 134-37, 143, 193-94, 229-30, 260, see also vocational identity

sexuality and, 148

ods (love), 237, 239

shemaa (queen-mother), 82, 163

shene (chief), 82, 163

Okaile Allotey (pseudonym), 73-74, 174, 200-8, 217, 223, 246-52

Okech, Awino, 77, 276

skyeame (spokesperson), 53

Onions are my husband (Clark), 22

open narrative interviews, 11-14

opposite-sex desire, 166-67, see also marriage

material exchanges and, 195

oral sex, 235

Orientalist discourse of sexuality, 28, 38

Others, 3, 7-8, 10, 23, 28-32, 33, 276

Otu, Kwame E., 71

outdooring (abadinto) (name giving ceremony), 141-42, 144, 169, 187, 197

Oyéwùmí, Oyèrónké, 154, 170, 175

The Invention of Woman, 127-28 smanhene (king), 163

pamphlet literature, 94-95

parallel-cousins, 242, 244

Paramaribo, 205

participant observation, 6-8 
passion, 151, 222, 237, see also pleasure, sexual activity gifts and, 240 lack of, 234 loss of urgency in, 263-64

paternalism, 277

Patricia Opoku (pseudonym), 1

patrilineality, 169

in Ga ethno-linguistic group, 176, 245, 247-48

motherhood and, 216

patronage, 170

Penal Codes, 64

penis, 139, 179, 211

Pentecostalism, 54, 56

performativity, 159

permanence, 264

personal kindreds, networks of, 228, $245,252-64,265,267$, see also networks

personhood, 40, 136, 236

Pierce, Steven, 61

pleasure, 151, 154, 198, 222, 236, 237, see also passion, sexual activity

police interventions, 63-65, 101-2, 196

politeness, 51, 52, see also speech norms

Popoola, Olumide, 3

popular entertainment, 55

popular fiction, 94-95

postcolonial feminists, 23, 35

postcolonial subject, 275

postcolonial theory, 23, 38

postmenopausal women, 173, see also sugar motherhood

post-structuralist theory, 3

poverty, 156, 160, 270, see also material circumstances, precariousness

exploitation and, 203, see also abusive dynamics

family arrangements and, 254, 259

power relations. see also abusive dynamics

decolonization and, 279

gendered, 37, 154-68

queer globalization and, 38

practice, 34

precariousness, 16-17, 270, 275, see also poverty

queer family arrangements and, 254-58 social identities and, 61

pregnancy, 103-6, 116, see also motherhood

fear of, 190

football careers and, 179

premarital sex, 56

Presbyterians, 58

Prince Kweku MacDonald (pseudonym), 49-50, 58-60, 68-75

privacy

access to, 270

in bathhouses, 108

lack of, 18-19, 38-39, 116, 247

loss of, 71

right to, 66

privilege, 279

pro-natalist culture, 40

pronouns, gender-neutral, 40, 128-29, 164

provider love, 156, 170, 217, 269

puberty rites, 113-15, 231

public display of affection, 52

public spaces, 275 , see also sexualization of public sphere

queen-mother, 82-83, 113, 114, 115, $131,146,163$

Queer African Studies, 25

Queer African Youth Networking Centre (QAYN), 27

queer family networks, 219, 252-64, see also networks

queer globalization, 60-63, 275-77

queer kinship, 41-42, 46, see also

kinship

queer postcolonial scholars, 42

queer theory, 43, 253

queer, use of term, 24, 37

queer-feminist theory, 31, 36-39, 275

Q-zine, 24

racialized bodies, 28-32, 33, 277

radical participation, 6

radio stations, 65,93

private, 55, 59-60, 103

Rao, Rahul, 36

Rattray, Robert S., 140, 242, 243

Rawlings, Jerry J., 50, 54-55, 59, 182 
reciprocity, 113, 122, 168, 207, 218, 269, 271

conjugal, 206

lack of, 199

siblinghood and, 240

relatedness

forms of, 230, 251, 264-66

gender and, 272-73

queer forms of, 216

relational manhood, 154-60

religion, 54, 181, 184, 247, see also charismatic Christianity

reproductive practices, 40-41, 200, 258 , see also motherhood

research methodology, 1-17

resistance, 42

respectability, 143, 200, 245, 250

Rita (pseudonym), 223

rivalries, 18, see also jealousies, love triangles

Robertson, Claire, 176, 192, 202-3

Roman Catholic Girls Schools, 82

romance, 46, 89, 105, 160, 221, 230, 231, 236, 237, 238, 240, 267

romantic courtship, 237

romantic friendships, 43

romantic love, 121, 160, 267

Rose Asuku (pseudonym), 84-85, 249

Rosenthal, Gabriele, 11

Ruby (pseudonym), 186-99, 208, 215

rumors, 183

Sackey, Brigid, 96

sadness, 117-18

Safo, Socrates, 94, 183

sameness, 252

same-sex desiring women. see also sexual identity, lesbianism, homosexuality, erotic subjectivity, siblinghood, "doing everything together"; doing, indirection, gender, sugar motherhood, butch-femme discourse, supi girlfriendships, friendship, sexual activity, "knowing women"; knowing research on, 1-17, 23-27, 28-32, 267-79

visibility of, 72, 232, 261 same-sex marriage, 236-37, 253, 266, see also marriage

Sandra (pseudonym), 165

Sarpong, Peter, 106, 114, 239

saso (same-sex desiring men), 27, 71

Schneider, David, 228

Scottish Mission Sisters, 83

secondary schools. see Senior Secondary School (SSS), Junior Secondary School (JSS), boarding schools

secrecy, 51, 80, 198, 217

Sedgwick, Eve, Epistemology of the Closet, 38

seduction, 147, 163

self-identity, 20-21, 33, 76, see also identity

semen, 140, 177, 235

Senegal, 77

Senior Secondary School (SSS), 83, 86, 107

seniority, 168-69

erotic age and, 157-58, 170

gender and, 45, 131, 272-73

language and, 128-29

social age and, 112, 157-58, 168, 271

senior-junior hierarchies, 90-91, 97, 107, 111-16, 120-21, 268, see also hierarchies, sugar motherhood

female footballers and, 90, 181

in girls' boarding schools, 111-16, 120-21, 173

in social networks, 218

sugar motherhood, 186, 213-14, 271

sensationalism, 58-60, 76

Serwa Asiedu (pseudonym), 225-26

sex work, 5, 27, 195, 199

sexual activity. see also pleasure

attitudes toward, 40-41, 67-68

expressions of interest in, 8-10, see also romance

friendship and, 39

oral sex, 235

pleasure and, 197-98

power dynamics in, 206-7, 231

sexual identity and, 37,274 , see also sexual identity

sexual appetite, 67

sexual deviants, 48 , see also homophobic discourse 
sexual difference, 251, see also gender roles

sexual experience. see also erotic age seniority and, 151

sexual fluids, 235, 243, 249, 265

sexual health, 197

sexual identity, 8, 14, 19-21, 25, 270, see also identity

as category, 3, 32, 36, 37

as distinct from sexual practice, 33 , 47

community and, 253

gender and, 125, 147-54, 201-2

global media and, 61-62

labels and, 71-76

verbal discretion and, 52

visibility and, 110, 117-19

sexual modernity, 275-76

sexual rights politics, 19, 26, 198, see also LGBT (lesbian, gay, bisexual, and transgender) activist politics

in Ghana, 48, 50, 61

in North Atlantic, 117

sexualization of public sphere, 51,56 , 68,77

sexualized African bodies. see African bodies, as sexualized and racialized Others

sharing, 266, see also substance, materiality of love, siblinghood, gift exchanges

siblinghood and, 260-64

Sharing the same bowl (Robertson), 22

Shipley, Jesse, 55

Living the Hiplife, 162

siblinghood, 46

"doing everything together" and, 220-22

equality in, 226

hostilities in, 226-28

in Euro-American contexts, 253

love and, 239-41

metaphorical, 252

seniority and, 112, 225, see also seniority

sharing and, 260-64, 269

sharing substance and, 234-36

terminology, 222-23

Signorini, Italo, 39

Sika, Varyanne, 77, 276 silence, 49, 51

similitude, 252

sin, 92

sisterhood, 221-22, see also siblinghood

situational homosexuality, 73

“small girls," 187, 232

as domestic helpers, 208

"big men" and, 189

masculinity and, 214

schoolteachers and, 202-3

Smith-Rosenberg, Carrol, 87-88

social age. see also age, seniority

seniority and, 112, 157-58, 168, 271

social kinship, 223, see also kinship terminology

social networks. see networks

social status, 162, 261

socio-economic status, 271

sodomy, 77, 205

sotadism, 28

South Africa, 24, 26, 77, 88

boarding school crushes, 80

migrant workers in, 213

Southern Africa, 25-26

romantic love in, 121

sovereignty, 62

speech norms, 49, 51, 270, see also language, allusion, indirection, verbal discretion

spirits, 57-58, 94, 101-3, 118, see also occult forces, Mami Wata

blood friendship and, 198

spiritual, 55, 56, 77, 87, 102-3, 117, 140-41, 198, 275

Spivak, Gayatri, 23, 35, 279

Stack, Carol, All Our Kin, 259

Stella Odamten (pseudonym), 14, 68-78, 200

Stoler, Ann Laura, 33

Stone Addai (pseudonym), 164-65, 181, 212-13

stone butch, 153

Strathern, Marilyn, 100, 120, 271

structural adjustment programs, 55, 172,182

style, 275

(liking) life or lifestyles, 143-47

gender expression and, 143-47 
Suakrom (pseudonym for research location), 14-17

subalternity, 10, 23, 35-36, 279

subjectivity, 34

subjugation, 22, 44, 218, see also abusive dynamics

subordination, 34, 35, 177, 178, 206

substance, 234-36

transfer of, 242, 243, 263, 265

success, 55

sugar daddies, 185, 187, 269

sugar motherhood, 45-46, 167, 269

autonomy and, 189

collectivized love and, 216-19

discretion and, 4

gifts and givers, $208-16$

junior-senior dynamics and, 186, 271

materiality of love and, 184-208

overview of, 172-75

power dynamics in, 206-7, see also

abusive dynamics

sunsum (spirit), 132

supi. see also same-sex desiring women

supi girlfriendships, 44-45

affective challenges of, 106-20

as initiation into sexuality, 81 , 97-106, 109-11

Asafo companies, 95-97

cousins and, 243

exchange of gifts and, 80-81, 82-83,

$85,91,98-101,112-13,120$

girlfriendships, 80, 81-91, 193, 197

gossip, 251

in video-film industries, 94

meanings of, 5 , 43, 48, 79-81, 272-74

negative stereotypes, 198

origin of term, 72

pranks on junior girls, 115

public discourse on lesbianism and,

80, 81, 91-95, 149-50, 209, 246

secrecy and, 98, 105, 116-20

senior-junior hierarchies, 111-16

timing and, 110-11

Supi: The Real Woman to Woman

(1996), 94

supi-supi, 93-94

Swiss-Ghanaian families, 2-3

Switzerland, 4

symbolic capital, 112 taboos. see also incest bans

on pre-nubile pregnancies, 41

research on, 6

same-sex desire as, 3

Takoradi-Sekondi metropolitan area, 61

Tamale, Sylvia, 22, 24, 29-30, 277

Tashjian, Victoria, 141

teacher-pupil hierarchies, 201-7, 217

"team daughters," 45, 90, 174

"team mothers," 45, 90, 174

technologies of the self, 69, 76

Teley Kwao (pseudonym), 254-58

Tetteh, Merci Naa K., 26

Thailand, 271

Thomas, Lynn, 121

timing, 110-11

Tinsley, Omise'eke Natasha, 38, 44, 120, 205, 273

tombois, 136-37, 169, 271

Tommy Boys, Lesbian Men and Ancestral Wives (2005), 31

toms, 271

tradition, 62

transactional sex, 177, 190, 195-96, 217,269

transatlantic slave trade, legacy of, 44

tribadism, 29

“tricksters," 162, 167, 273, see also "hustling" women; hustling

Twi language, 10

gender and, 131

gender-neutral pronouns, 129, 164

indirection and, 52

sibling terminology, 221, 222

time and, 111

Twinglish, 111, 145

Uganda, 65, 77

United States (USA). see also global North

charismatic Christianity and, 54

"unnatural carnal knowledge," 64-68

upward mobility, 143, 237, 245, 251

urban same-sex subcultures, 61

vagina, 1, 105, 139, 200, 214, 242

van der Geest, Sjaak, 224, 226-27

Venda, 88, 113

venereal diseases, 61 
verbal discretion, 4, 51-54, 270, see also indirection, speech norms

"big women" and, 199

culture of, 48

gossip and, 133

identities and, 78

in locating respondents, 8,15

visibility politics and, 118

Vicinus, Martha, 87, 98

Victorian England, boarding school crushes in, 80

Vida, 159-60

video-film industries. see Nollywood (Nigerian cinema), Ghallywood (Ghanaian cinema)

visibility of same-sex desiring women, $72,110,232,261$, see also gossip visibility politics, 118,253

visual knowledge, 154, 170

vocational identity, 134-37, 143, see also occupational work

Wainaina, Binyavanga, 19

Warren, Dennis, 92

Wekker, Gloria, 211

The Politics of Passion, 22, 205

Wesley Girls High School, 82

Weston, Kath, 258-59

Families We Choose, 252-53

white bourgeois femininity, 29

white feminists, 31

white masculinities and femininities, 28

witchcraft accusations

among siblings, 226-27

jealousy and, 57, 240

woman marriages, 30-32, 128-29

women. see also elite women, working-class women, "big women"; gender

as category, 43

charismatic Christianity and, 55

in public space, 178

intersectional subject positions, 36

marginalization from public

discourse, 72, 77

social advancement, 129-31, 143

status of, 175
Women in Love (1996), 94, 183

women who desire women. see also friendship, "knowing women"; knowing, same-sex desiring women

use of term, 43

Women Who Have Sex With Women

(WSW) peer workers, 69-70

women's trading associations, 16

work. see also masculinity, provider love

occupational work, 134-37, 143, 148, 193-94, 229-30, 260

work of love, 148, 149, 218, 271

working-class women, 22-23, see also vocational identity, kinship, economic independence, material circumstances, family ties, employment, sharing, gift exchanges, "tricksters"; tricksters, friendship, precariousness, same-sex desiring women, "hustling" women; hustling

feminist research on, 22

identities of, 77

World Bank, 55

xenophobia, 277

'yan daudu, 35

Yankah, Kwesi, Speaking for the Chief, 52

Yinka Okafor (pseudonym), 185

Yorùbá, 128

youth

gender and, 130

informal networks, 273, see also female footballers

sugar daddies and, 187-89

sugar mummies and, 187-89, 211, see also sugar motherhood

Zelizer, Viviana A., The Purchase of Intimacy, 195

Znoj, Heinzpeter, 215

Zulu schools, 88 